Design

to

Degrade

Dynamic 3D/4D Printing of Bio-based Material towards Incoporation of Death and Decay into Digtial Creation.

ZARA FONG 


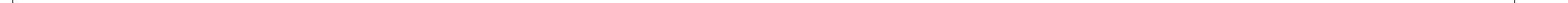




\section{Design to Degrade}

Dynamic 3D/4D Printing of Bio-based Material towards Incoporation of Death and Decay into Digtial Creation.

A 90-point thesis submitted to the Victoria University of Wellington in partial fulfillment of the requirements for the degree of Master of Design Innovation in Industrial Design

by

Zara Fong

MDI specialising in Industrial Design

Victoria University of Wellington

Victoria University of Wellington, 2017

School of Design

Image 1 - Mouldy orange macro shot (left)

This pattern and form in the photo

is enabled by degradation. 


\section{andwisy}

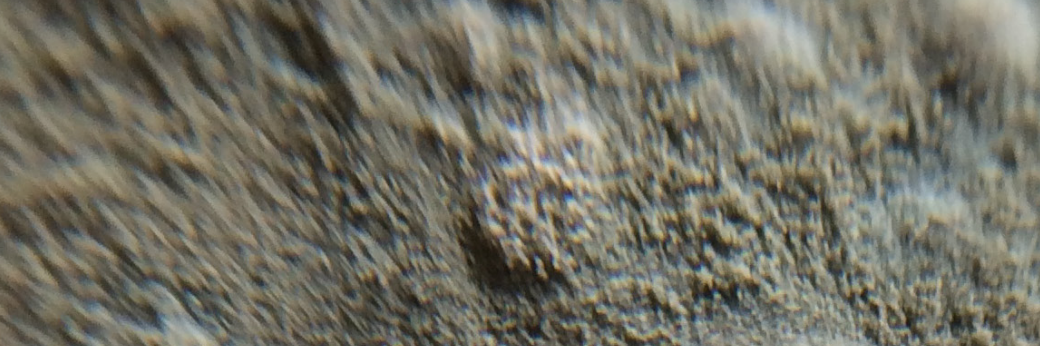

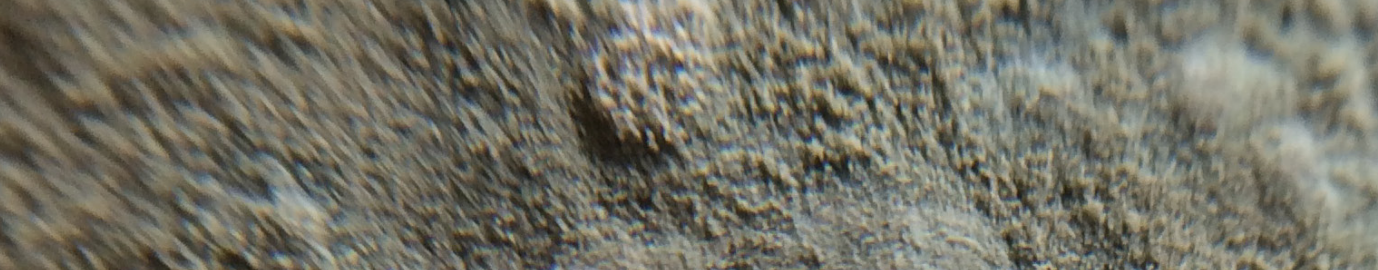

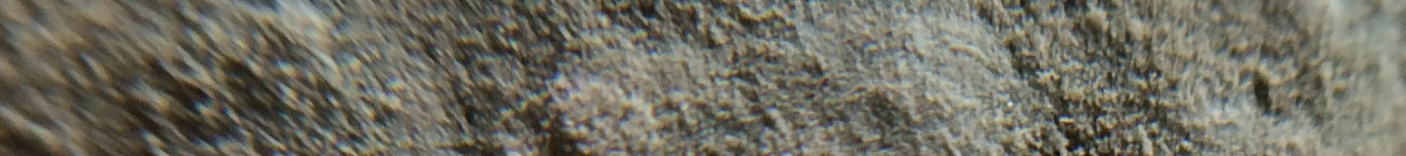

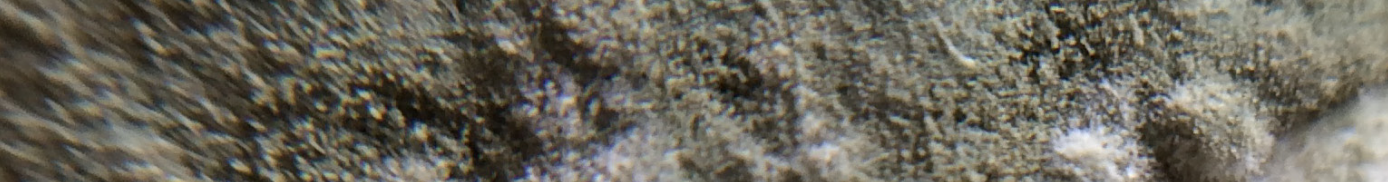

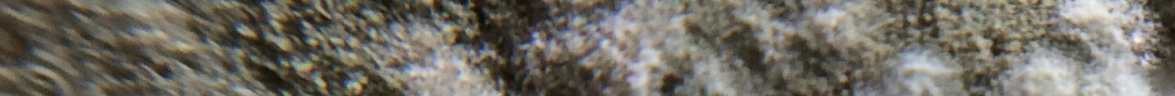

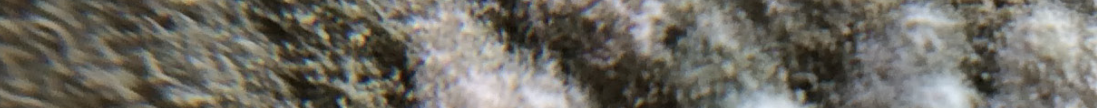

- S.

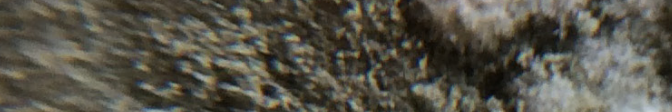

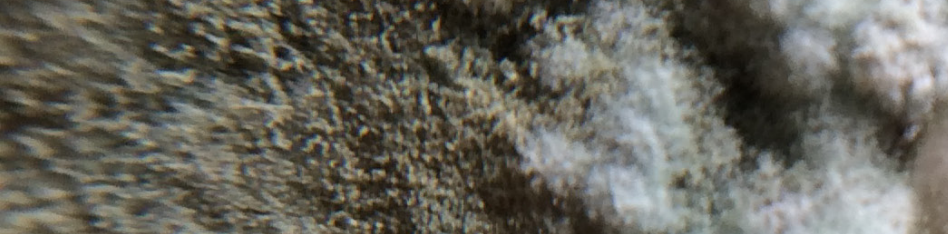

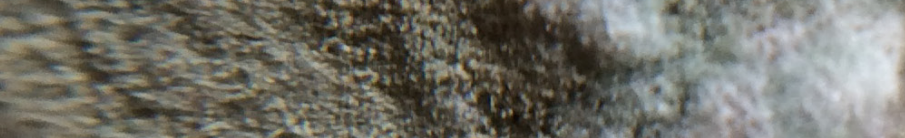

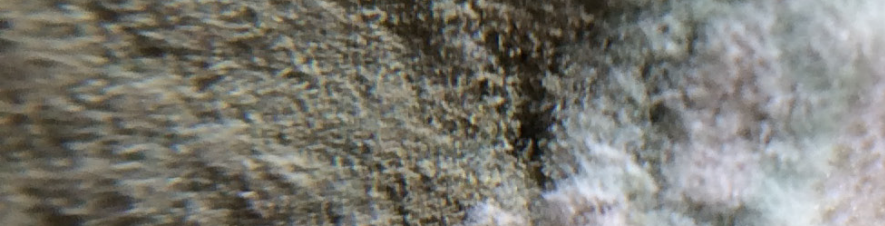

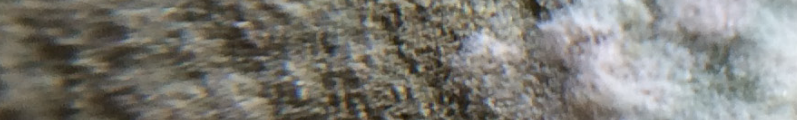

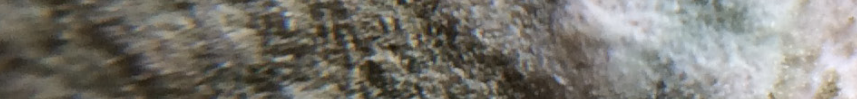

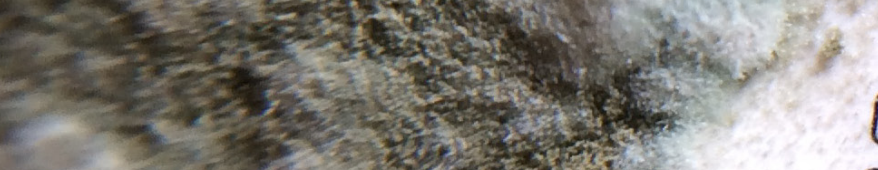

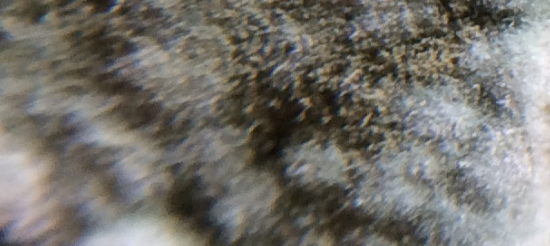

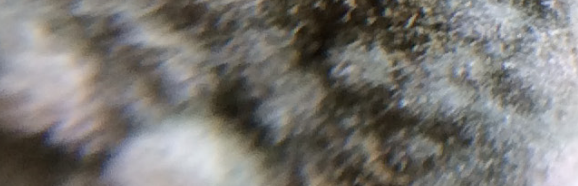
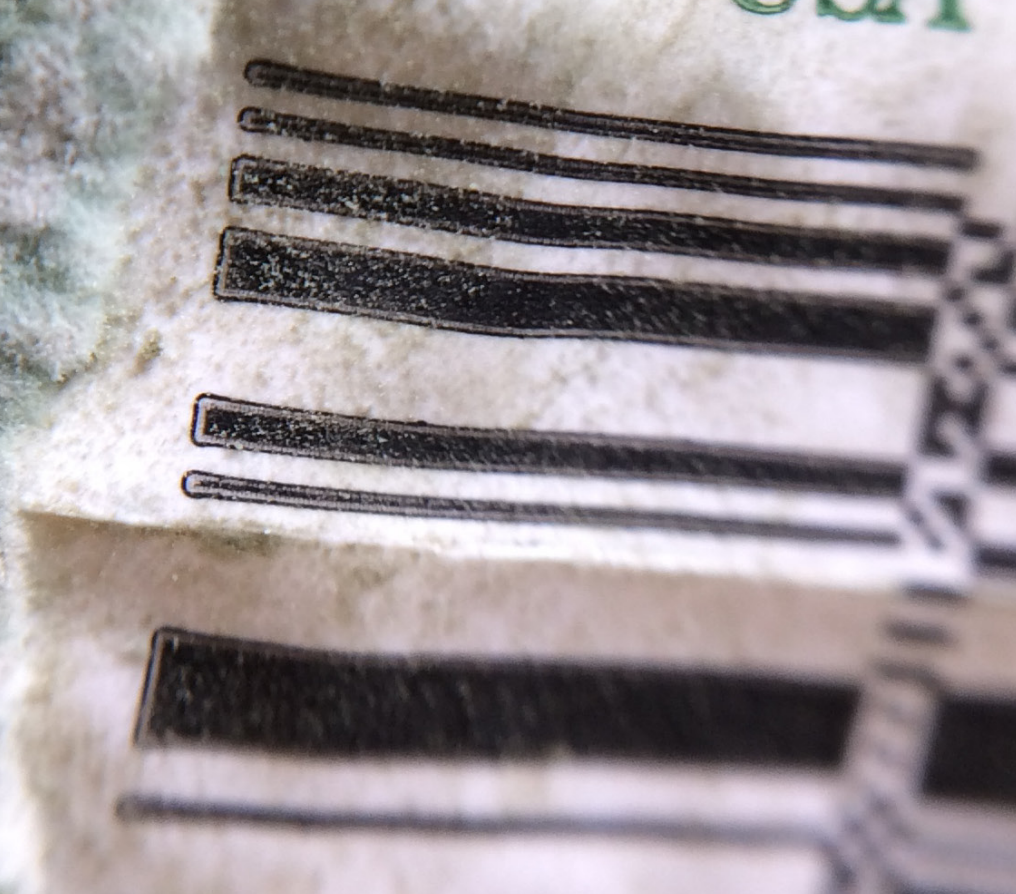
USA

emon
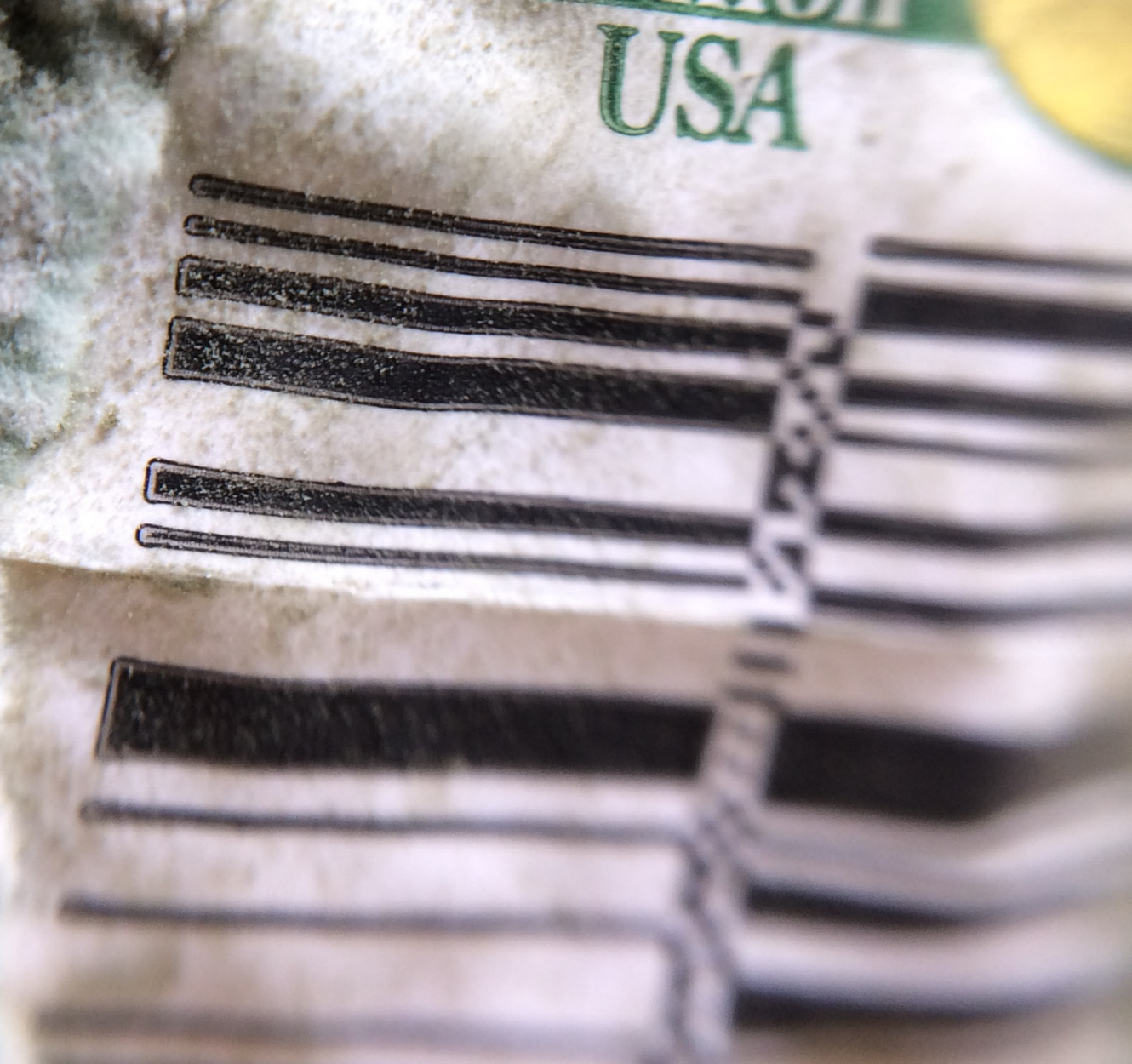


\section{ABSTRACT}

Image 2- Mouldy lemon (left) This image portrays the possible beauty of degradation as well as the contrast between nature and man-made. The sticker did not degrade at all while the lemon is going through the degradation process.
Birth, growth, death and decay constitute an inherent cycle in nature that maintains balance and enables ecosystems to adapt to external changes. Although death and decay are essential for birth and growth of the following generations, these disappearing stages are often ignored and unappreciated in manmade cultures and practices. Especially in design, in the era of mass production, the pursuit of quantity and uniformity inevitably link to many environmental issues. As a desperate response, bio-based materials have recently gained attention as alternatives to fossilderived materials or new resources for industry, and rapid advancement of additive manufacturing (AM) has revolutionised conventional methods of manufacturing, enabling low volume, quality-focused production. This research discusses the pioneering incorporation of the stages of death and decay into design practices, exploiting a novel opportunity provided by the two key innovations, AM technologies and bio-based materials. A series of digital plants which employ and undergo the two degenerative stages are designed and produced using digital and scientific processes, and their transformative degradation induced by environmental stimuli, including humidity and UV, is demonstrated. The programmed visual and physical deformations suggest that a purposeful and systematic introduction of the two stages to the current design and manufacturing practices could offer a more sustainable and responsible approach to creation and production. They also exhibit new possibilities for digital processes, including parametric modelling and 3D-printing, through an integrative combination with biobased materials. 


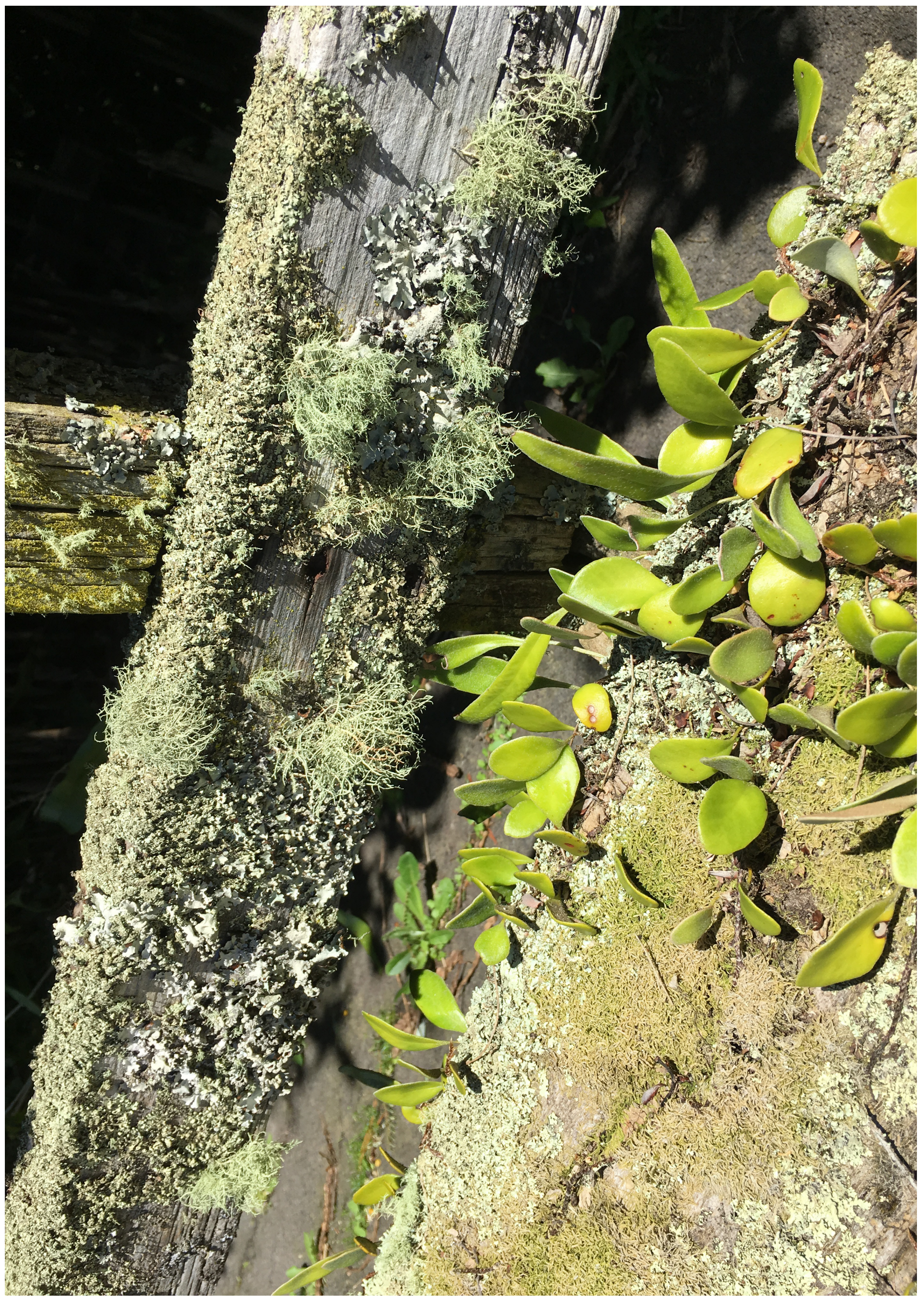




\section{DEDICATION}

To all my friends, family and teacher. 


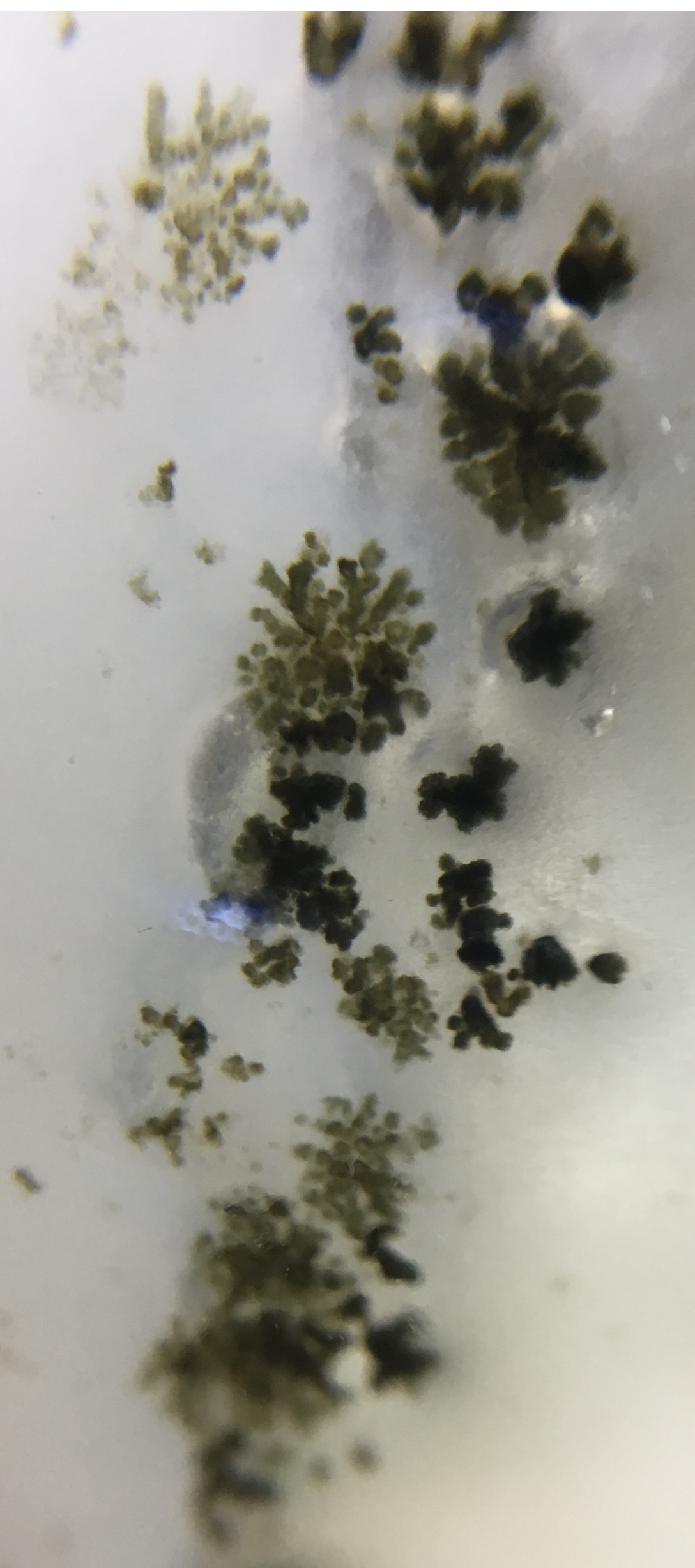




\section{Acknowledgements}

JeongBin OK

Alex Christensen, RuiFeng Yeo, Helen Andreae, Liam Giltberson, James Brundell and Candy Chen 


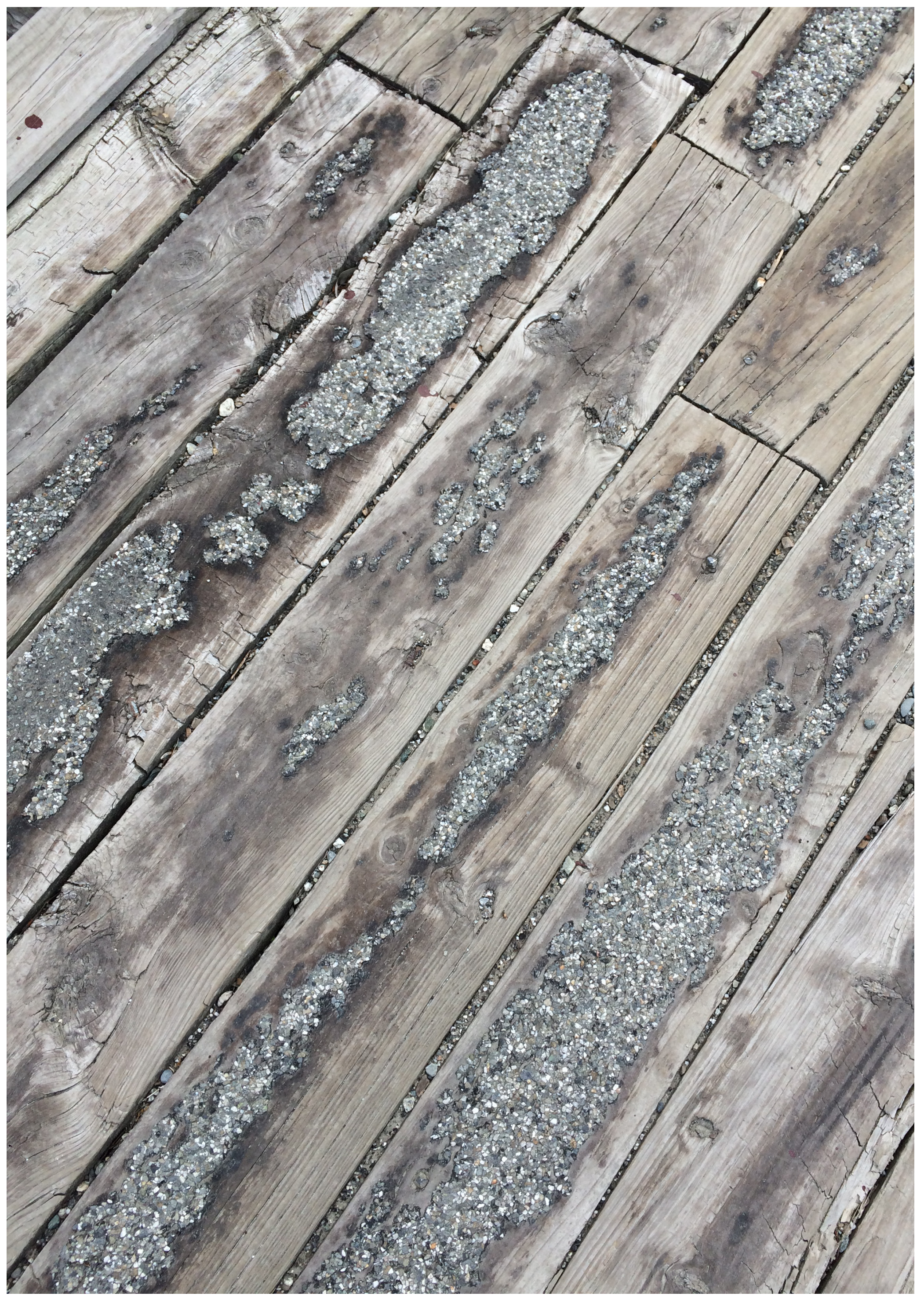




\section{Introduction}

Imagine a world with neither death nor degradation. Fruits and vegetable in your fridge will never go off; your pet fish won't die if you are away for the holidays, friends and family will never die of old age or sickness. There will be no time limit or due date to living things. Everything will only grow and increase. Wouldn't that be wonderful?

In this world, you would probably wake up feeling like you are on a train in Japan during peak hours not able to turn your body as you are packed with hundreds and thousands of others. This is because nothing nor anyone dies or disappears there will not be sufficient space for everyone and everything. This world is very similar to the world of artificial objects. There are only increase with no sense of decline.

3D printing and degradable materials have evidently evolved and influenced the traditional way of making. It is the wealth of research in these technologies and materials that permit novel possibilities that weren't achievable previously. This fast pace development is the optimum moment to evaluate and revise the current paradigm of making and prompt recognition of the afterlife of an object.

Consequently, this research utilised the contrasting degradative properties of PVA and cellulose acetate to create a series of digital plants via multimaterial aqueous 3D printing. Firstly, learning and exploring unique quality of material and aqueous 3D printing reveals that CA has a high shrinkage rate which was further investigated and controlled to use to its advantage. Secondly, via visual observation of degradation, five criteria was determined - interaction with the surrounding environment, change in role, colour, texture and form. The use of multi-material and CAD grant flexibility to design form and rate of degradation. Therefore each digital flower encompasses various degradation criteria to suggest natural degradation visually. The combination of PVA and CA with 3D printing established the different rate and initiate of degradation that resulted in a dynamic and transformative object, unlike traditional man-made objects. 


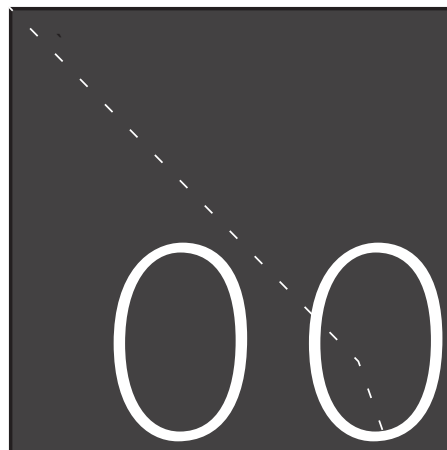

iV Abstract

Vi Dedication

v Acknowledgements

$X$ Introduction ,

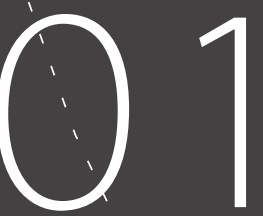

Backg'round

[03] Ugly, Disgust, Beauty

[06] Literature R'éview

[06] Death and Degradation

[11] Addative Manufacturing

[13] Materals

[19] Precedent review'

[27]Aims \& Objective

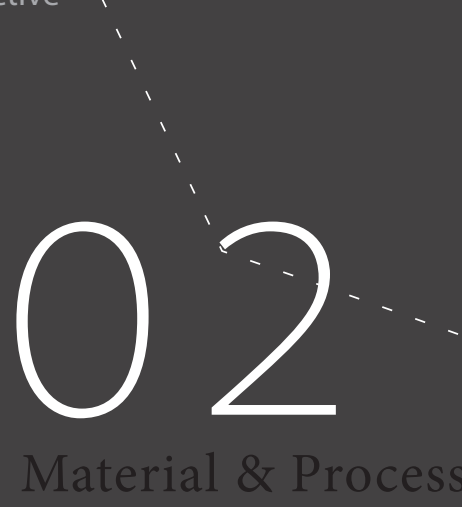

[31] Introduction

[35] Commercial Filaments

[39] Paste Exploration

[46] Material Exploration Results.

[48] 3D Printing Exploration

[63] 4D Properties

[73] Results and Discussion

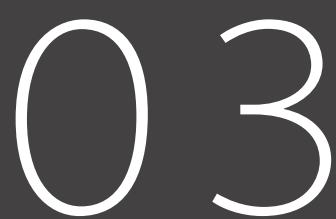

Degradation

[79] Introductión

[84] Degradation Results

[35] Commercial Filaments

[41] Material Exploration

[63] 3D Printing exploration

[77] 3D Print Evaluation

[70] Shrinkage Exploration

[91] Discussion 

CHAPTER

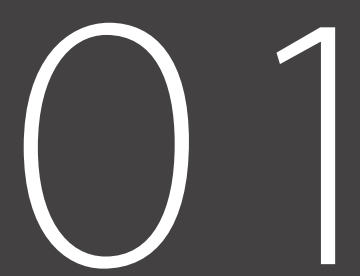

Background 
"Ask a toad what is beauty - the great beauty To Kalon; he will answer that it is the female with two great round eyes coming out of her little head, her large flat mouth, her yellow belly, and brown back. Ask a negro of Guinea; beauty is to him a black, oily skin, sunken eyes, and a flat nose. Ask the devil; he will tell you that the beautiful consists in a pair of horns, four claws, and a tail. Then consult the philosophers; they will answer you with jargon; they must have something conformable to the archetype of the essence of the beautiful".

(Voltaire, 1764) 


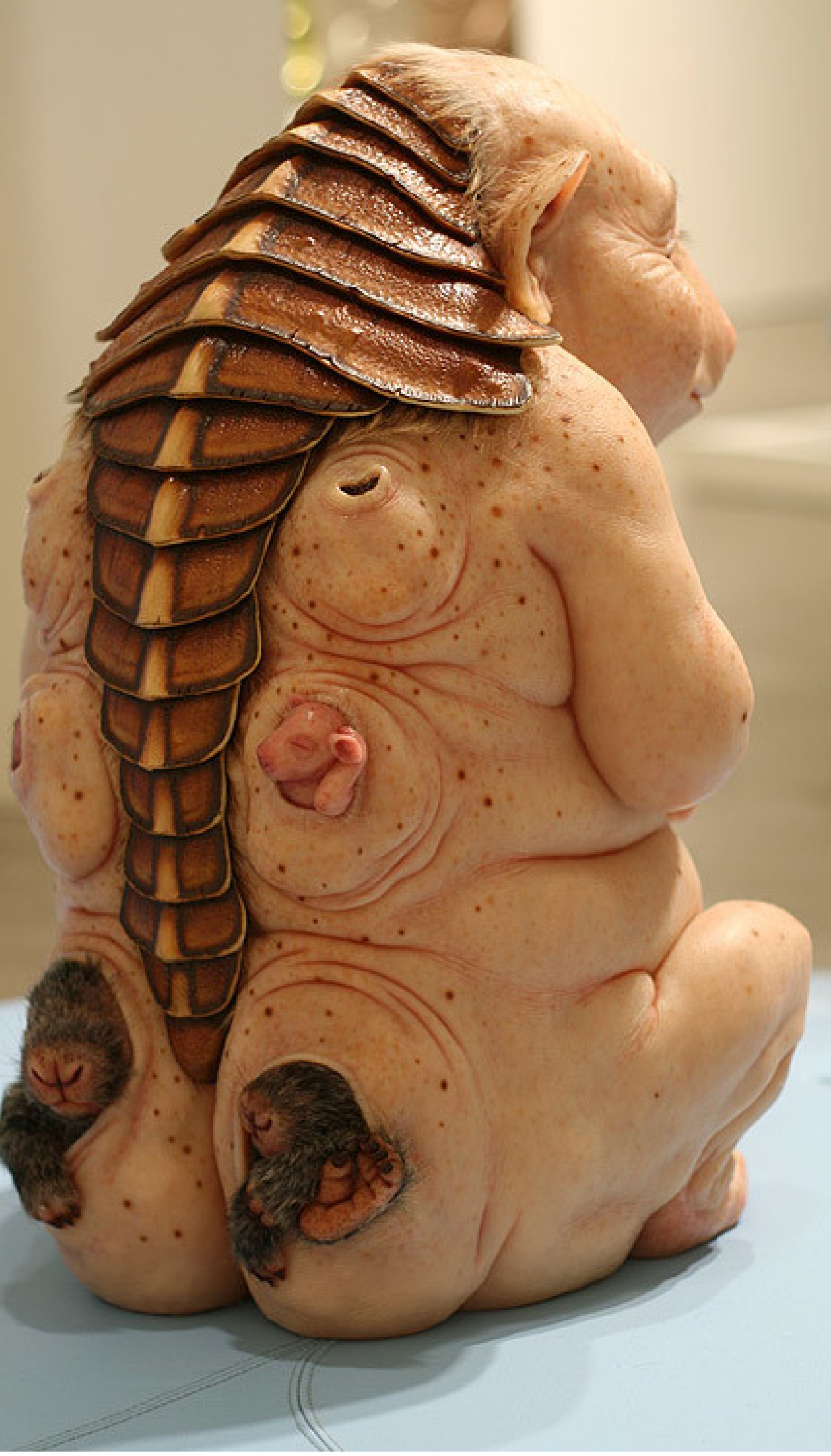


I identified possible opportunities and gaps in existing research and design. This research tackles the idea of finding beauty in the 'ugly', or things that we tend to avoid. Agreeable processes that are often dismissed are death and degradation. Death and degradation are processes that people should appreciate, yet designers often fail to consider them as part of a product's design. With today's digital tools and knowledge in material sciences, we can adapt such important processes of degradation into our daily objects to bring back the natural balance.

\section{Ugliness, Disgust, Beauty.}

What is beauty? Can beauty exist without ugliness? Why do we associate ugliness with disgust? Is disgust pure ugliness? Or do disgust inherit essence of beauty?

"The way to perfection, Leonardo believed, is "through a series of disgust" (Baley, 2012). Ugliness is often repulsive yet fascinating. Throughout history there was beauty, but there was also fascination towards ugly things. Examples like Patricia Piccinini (2005) and her series of human and animal hybrid sculptures reflects modern society's fears about lack of beauty, ageing and disease. Despite the uncomfortable feeling of such artworks, there is a sense of bizarre fascination.

Moreover, ugliness and disgust can be a form of inspiration. Greg Lynn, an architect, was inspired by the rule of William Bateson in his form design. Bateson was a teratologist as well as a geneticist. He studied abnormality of branched legs in animals. In his research, he found that the branched legs of an animal "always manifest new planes of mirror symmetry that obey what is now called the 'Bateson's rule'" (Lewis \& Held, 2009) (Figure 6). Lynn used this natural abnormality that may perceive as ugly as a source of inspiration. He was able to apply the concept to design and architectural forms. He successfully created odd yet beautiful forms using a calculusbased digital method. The concept of inverting a negatively connoted concept and extracting the essence of beauty is the core incentive that directed this research. From the above examples, it is apparent that negatively connotated concepts can bear beauty. 


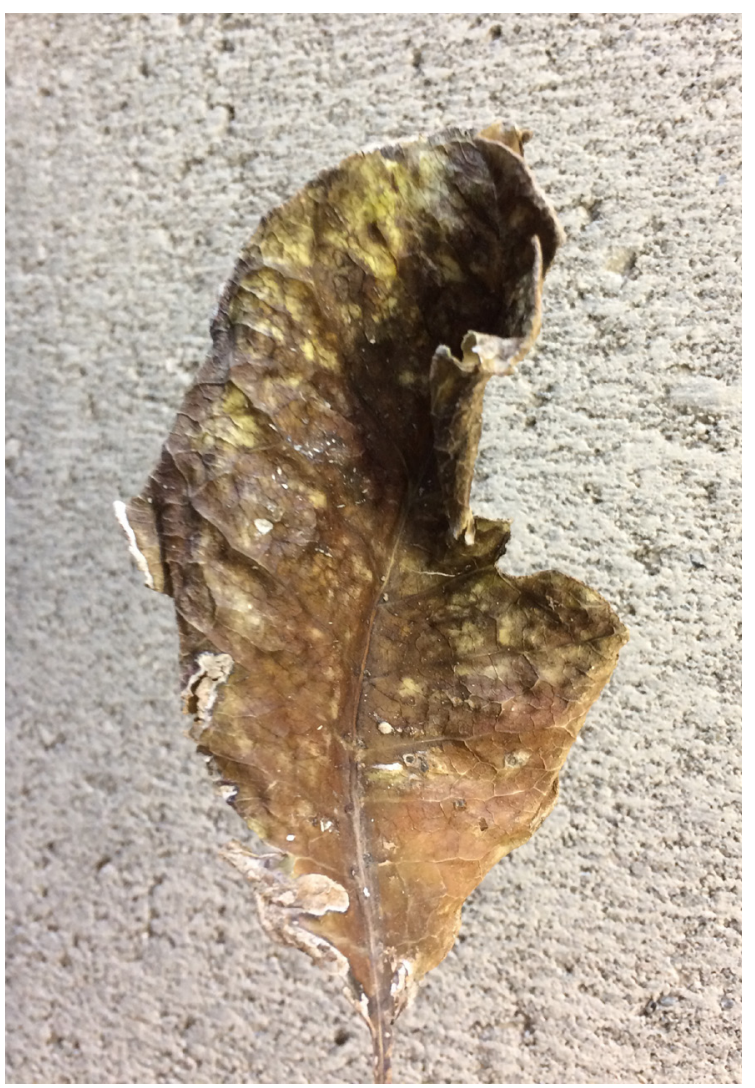

mage 1.4 (Below), Dry leaf, expressing

some interesting texture and curling. 


\section{Death and Degradation}

Degradation, a negatively connoted natural process that is also often associated with disgust but it can be beautiful. Humans strive to reverse or slow down degradation. However, death and degradation are crucial to nature's life cycle. Death and the consequential degradation are what give the space and nutrients for new things be born and grow. In fact, it is partly because of the current lack of degradation of our waste from overproduction of non-degradable products, that our waste disposal crisis is growing. To appreciate degradation, we must first understand the process and then learn to celebrate it through design.

\section{Death of Humans}

Degradation process begins at the point of death and ends when only the skeletons remain (Goff, 2009). After Death - "The cessation of all vital functions of the body including the heartbeat, brain activity (including the brain stem), and breathing." (Medical Dictionary, 2017), shortly the corpse and will undergo decay. The degradation process of a body can be generalised to five stages - fresh, bloated, decay, post decay and skeletal or remains (Goff, 2009).

Fresh - From the moment of death, fresh stage begins until bloating happens. Some notable visual changes include greenish discolouration, skin cracking and tache noir. At this stage insects such as Calliphoridae (blow flies) and Sarcophagidae (flesh flies) may enter through any openings. These insects will deposit larvae eggs or maggots. These then, later on, hatch and help further the process of decay.
Bloating - One of the main chemical decompositions, putrefaction, begins at the bloating stage. The bloating stage is when anaerobic bacteria in the body starts to digest the tissue and liquefy organs, producing gases that inflate the abdomen. This causes fluids to seep out from the body's natural openings. At the same time, it increases the Ph of the surrounding soil, which accelerates the decay process.

Decay - The decay stage begins when the body deflates as both maggots feeding and bacterial putrefaction break the outer skin layer and allow gases to escape. At this stage, there will be a strong odour and large feeding masses of Diptera larvae. At the end of this stage, most larvae would have fully grown and left only skin and cartilage.

Post decay - The post decay stage removes all of the remaining dried flesh and cartilage, all cleaned by Diptera.

Skeletal/ remains - The corpse then reaches the last stage, skeletal/remains. This is the stage where only bones and hair remains. There is no definite end point to this stage.

As established by the brief understanding of the five degradation stages in human corpses, it is evident that each stage is essential for the subsequent ones from death to degradation. Natural degradation uses not only the corpse to decompose itself, but also uses its relationship with the surrounding area (e.g. soil) and other living organisms (e.g. maggots). 


\section{Death in the Product Realm}

The definition of death in the product world bears a different meaning from death in nature. We often create things without considering the product's end life and consume with no consideration of the environment or sustainability of resources (Cooper, 2010). We dismiss the importance of degradability. This results in the buildup of waste and environmental problems. Both our capitalist culture and habit of careless consumption drive increased production of short lifecycle products. They even encourage manufacturers to use planned obsolescence (Cooper 2010). Shove (2003) suggests habit heavily influences consumption. We are no longer rewarded for creating things that are long-lasting and durable because style obsolescence arrives before a product's absolute obsolescence (Cooper, 2004).

How do we determine the death of a product? Although there is no agreedupon or universal definition of product death, perhaps that is because we seldom consider what would happen to objects after "death". The term "death" in the product realm often refers to failure or when a product reaches its end of life.

A product can be considered dead or failed when it is unable to make sales, explained by Chen (2015) as product death cycle. "Death" here refers mainly to newly introduced products that fail to sell.

A product can be considered "dead" when a product reaches its end of life (EOL). This is when the product reaches "retirement", where consumers will dispose of the product. (Lee, Lye, \& Khoo, 2001). The end of life of a product could be a result of absolute product obsolescence (Cooper, 2004, pp 423), where the product no longer functions the way it is supposed to function and required to be replaced. However, end of life could also be a consequence of style obsolescent (cooper, 2004, pp 423) where functioning items are replaced driven by fashion or trend.

These references to "death" of products show that designers and manufacturers have never deeply considered the afterlife of a product. They are often focused on creating new things mostly for financial profit. However, nature always has a balance of birth and death: death in nature 
always contributes back into nature unlike "death" in the product realm which only results in increased amount of waste and pile of junk. As the number of potential landfill sites decreases, it stresses the need for sustainable design and disposal solutions (Lee, Lye, \& Khoo, 2001). Some product end of life options includes disposal method, easier disassembly for disposal, reuse, recycle, landfill and incineration.

Some suggest planning for material recycling at the design stage (Ishii, Eubanks, \& Marco, 1994). Others suggest prolonging obsolescence and increase product lifespan (Cooper, 2010). However, to forestall obsolescence involves various elements including public policy, design and marketing, consumer attitudes and behaviour, and socio-cultural norms (Cooper, 2010).

Instead of prolonging obsolescence which can go into effect through systematic and orchestrated implementation around the world. By learning from natural ways of degradation, there is an opportunity to design not against but for the throwaway culture by pre-planning for the afterlife of a product with a predetermined control lifetime. "In recent years biodegradable polymers with controllable lifetimes are becoming increasingly important for application in the areas of waste management." (Abd El-Rehim, Hegazy, Ali, \& Rabie, 2004). Designers can't account for all the complex factors that are involved in forestalling obsolescence, but we can change the design process and materials used, and to be more conscious of the environment and its finite resources. Cooper (2010) highlights that designers are not as focused on waste reduction as they are for recycling or incineration. "The spotlight is usually pointed towards managing the end product, 'waste', rather than the processes by which it is generated" (Cooper, 2010)

This study explores the opportunity to exploit and integrate, visually and poetically, the idea of degradation in a design concept. It aims to critique current manufacturing practices and to suggest a new way of designing inspired by nature. 


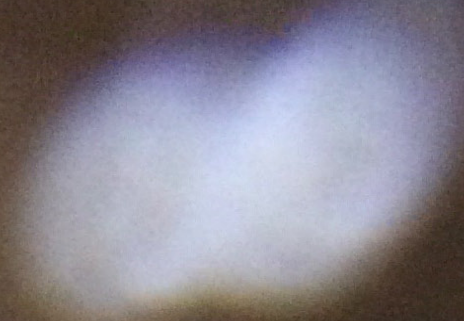

\section{nases}

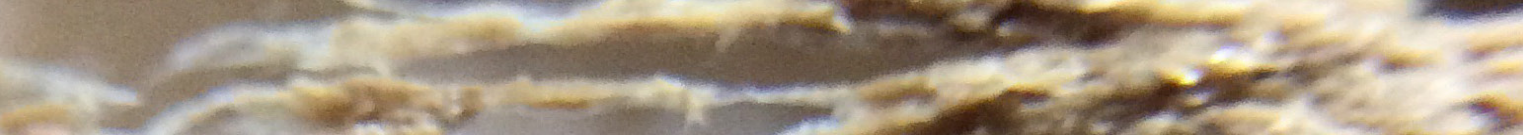

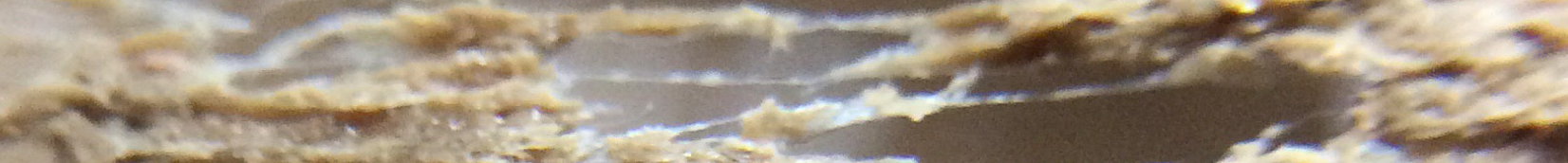

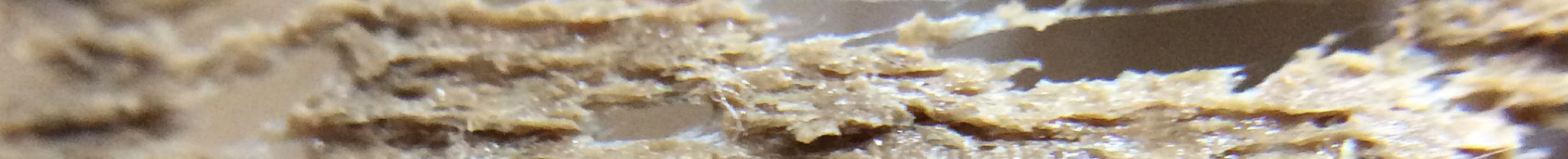

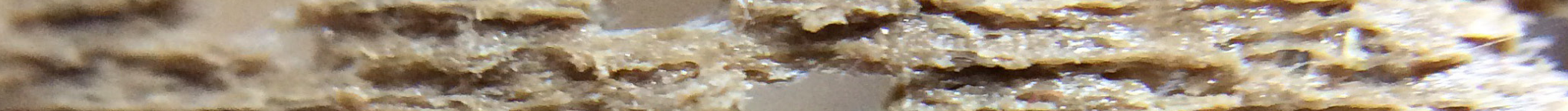

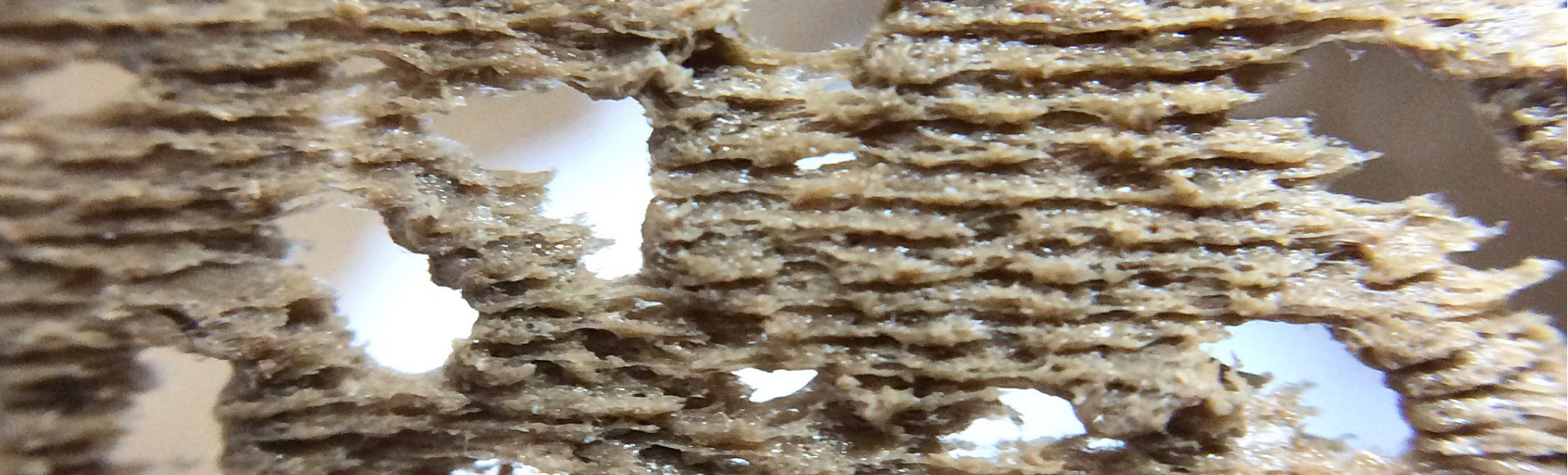

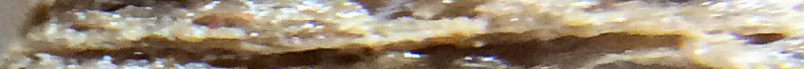

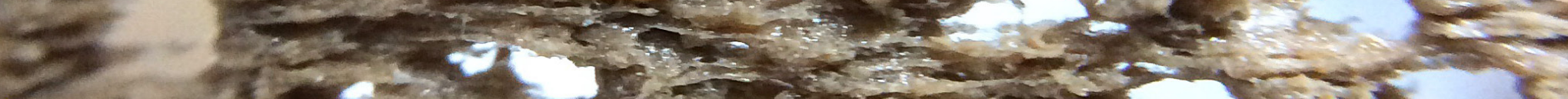

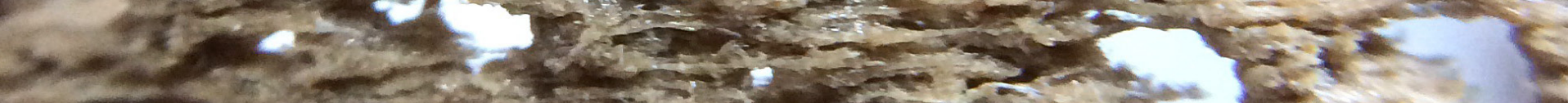

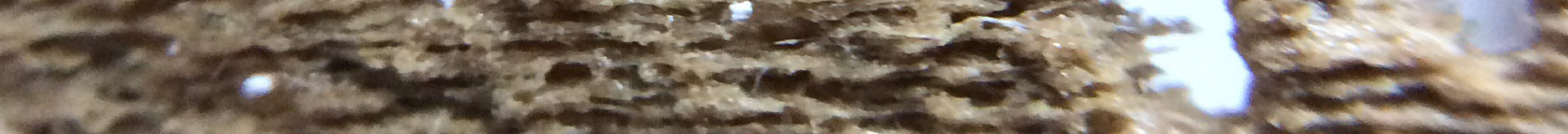

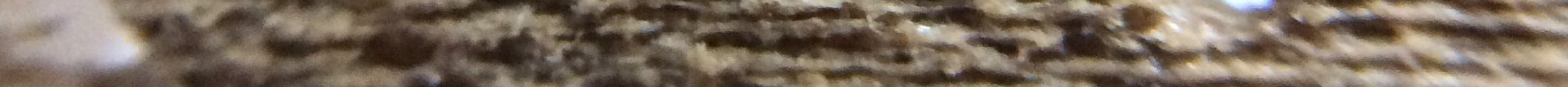

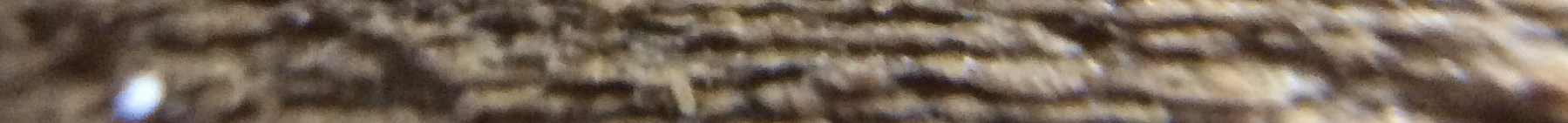

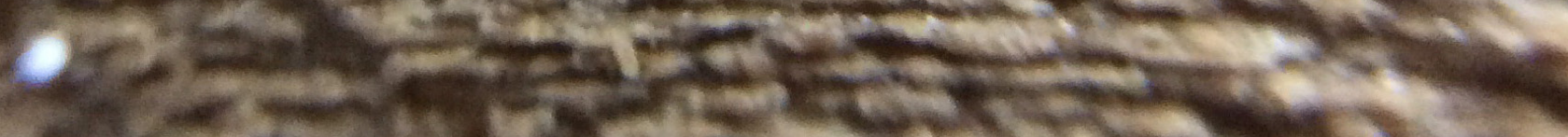

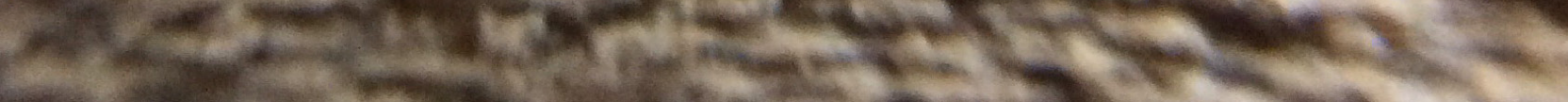

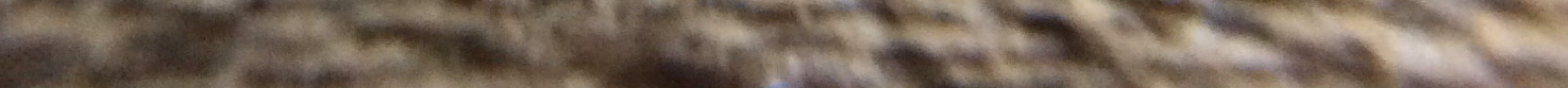




\section{Additive Manufacturing (AM)}

There are two emerging areas, AM and bio-based materials, that can provide design opportunities. Both areas are attracting lots of attention in recent years and are rapidly improving. "An understanding of materials and manufacturing is a core element of the design process." (Ashby \& Johnson, 2013)

\section{D - Printing}

AM usually refers to three dimensional (3D) printing. It has advanced expeditiously in recent years and has profoundly influenced the way we create things. AM is a subdivision of digital manufacturing along with subtractive manufacturing (Buechley \& Zoran, 2013).

AM was once merely a prototyping method (Gibson, Rosen, \& Stucker, 2015), now it can create complex models by depositing multi-materials layer by layer (Wijk \& Wijk, 2015). Some consider AM as part of the third industrial revolution as this manufacturing method broke through the limitations of traditional manufacturing and opened opportunities (Berman, 2012). The recent thriving of AM not only renewed our methods and views of manufacturing and prototyping products, but it also renewed product categories and businesses (Thilmany, 2009). As AM advances rapidly and gradually integrates into our manufacturing methods and design processes, there is an opportunity and need to modify current manufacturing and design practices. We now have the freedom realise new ideas with these new technologies, bearing in mind the consequences of previous manufacturing practices pollution and waste build up. Nonetheless, mass production is, and will still be, a big part of productive industries. AM is not a replacement for mass production but a tool to invent new production and design methods that consider the afterlife of a product. This is especially true at this early stage of AM's development before any methods become entrenched. Thus with the aid of AM, there is space to create novel ways of manufacturing and using new and old materials.

Different types of 3D printing include stereolithography (SLA), digital light processing (DLP), fused deposition modelling (FDM) selective laser sintering (SLS) and more (3D printing from scratch, 2017).

FDM printing usually refers to thermal extrusion as it is currently the most common type of FDM printing. Recently paste 3D-printing is a budding area. Two popular areas of material explored with paste 3D printing are clay printing and bio-compatible tissue printing, such as digitally manufacturing 3D nanostructures for medical use (Billiet, Vandenhaute, Schelfhout, Van Vlierberghe, \& Dubruel, 2012).

\section{D printing}

As 3D-printing matures, 4D-printing is the next step in development. The term 4D printing is not defined solidly yet but generally refers to 3D-printing with smart materials that have additional properties that allow shape alteration or change in properties over time due to external stimuli (Khoo et al., 2015). Tibbits (2013) suggests that time is the fourth dimension. I have chosen to define the fourth dimension of $4 \mathrm{D}$ printing as time-dependent changes that are driven by external stimuli. Tibbits, director of the self-assembly lab at MIT, argues that 4D printing involves self-assembling, programmable materials, and transformation over time. Most $4 \mathrm{D}$ printing is made possible due to polyjet technology. However, these are high cost and have limited access. This thesis uses FDM printing, focusing on materiality and structural form, to create low-cost 4D printing. 
"We live in a world of materials; it is materials that give substance to everything we see and touch. Our species-homo sapiens- differs from others most significantly, perhaps through the ability to design - to make things out of material - and the ability to see more in an object than merely its external form. Objects can have meaning, carry associations, or be symbols of more abstract ideas. Designed objects, symbolic as well as utilitaria, predate any recorded language - they provide the earliest evidence of a cultural society and a symbolic reasoning."

-Ashby, \& Johnson (2013) 


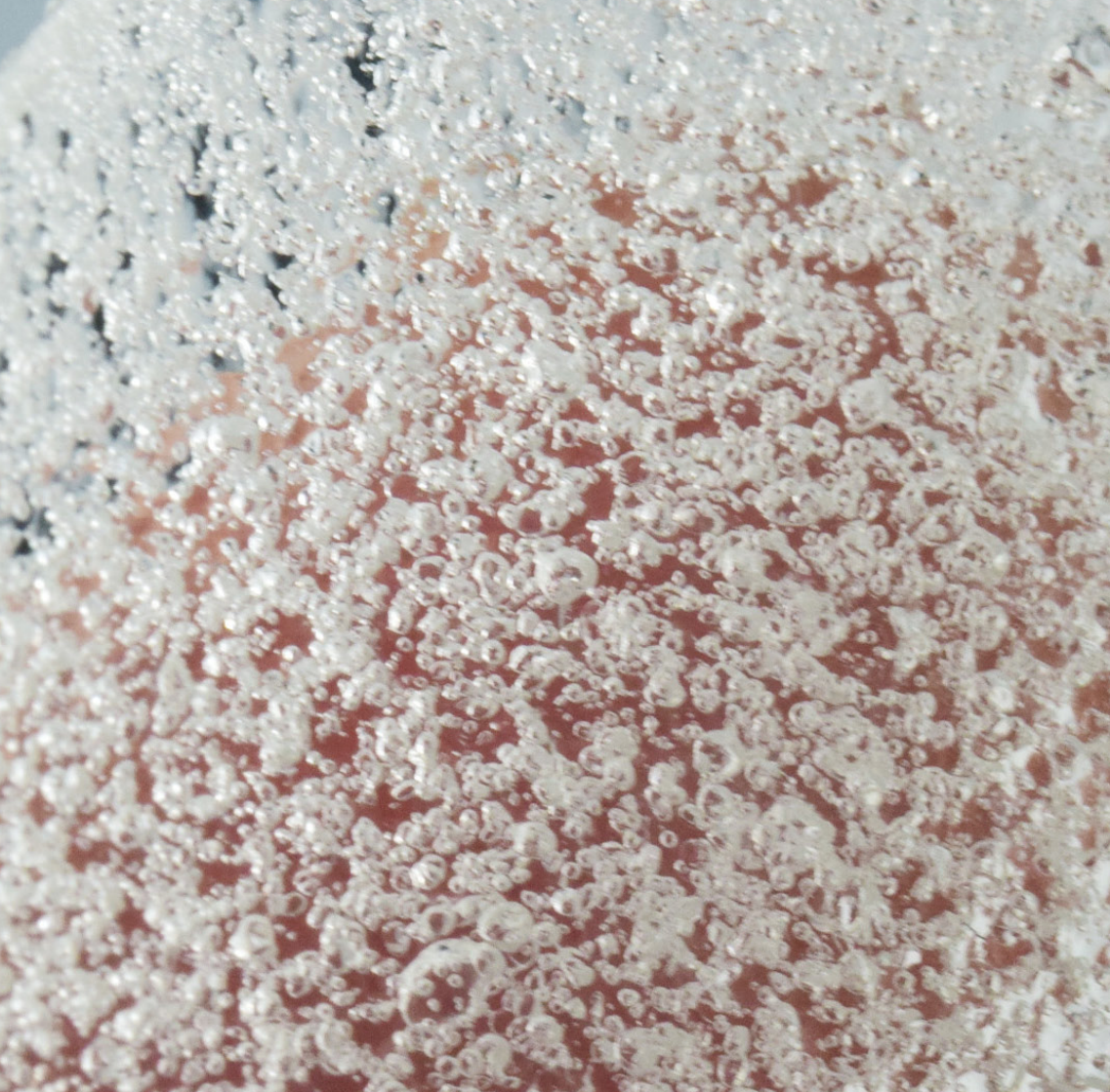

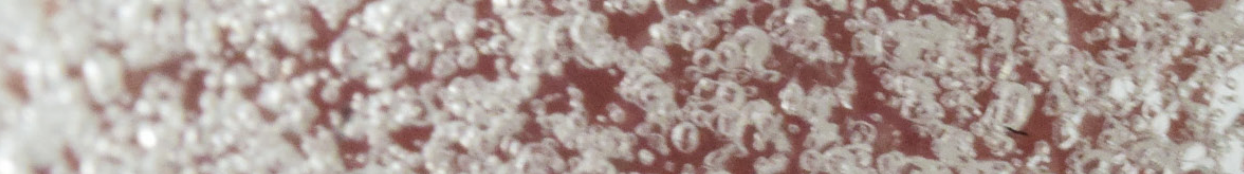

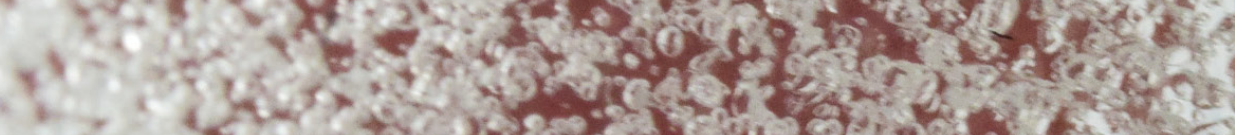

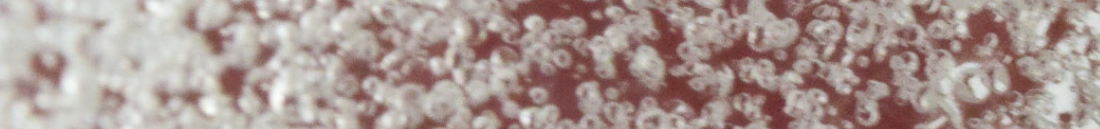

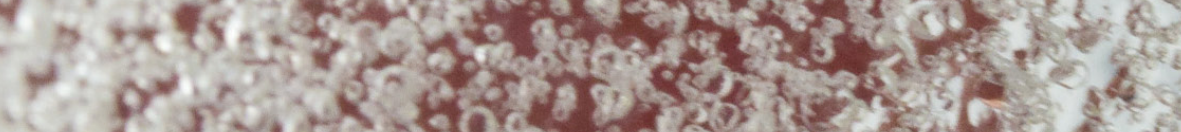

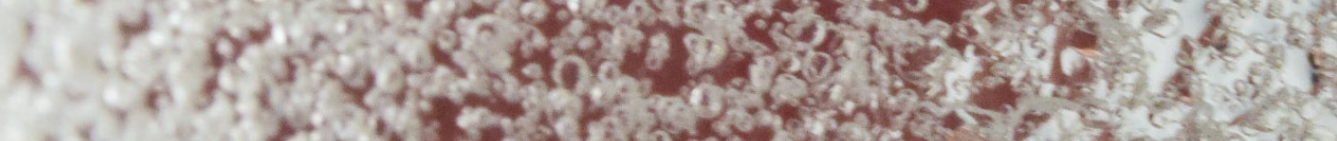

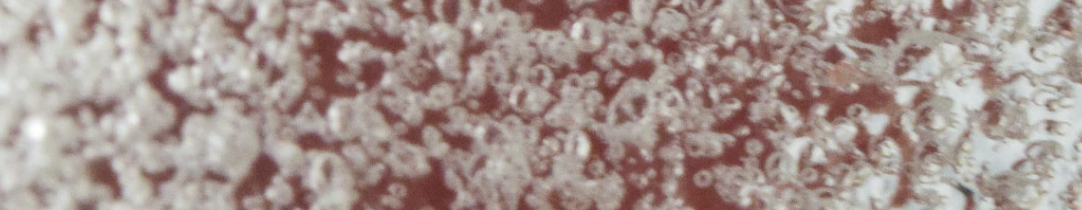

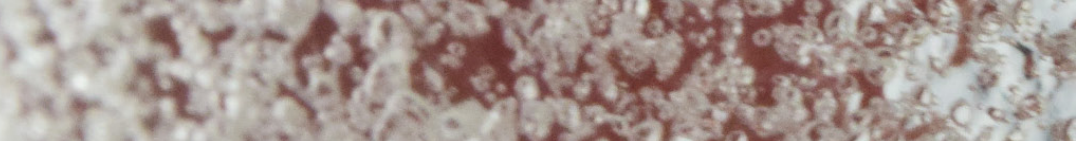

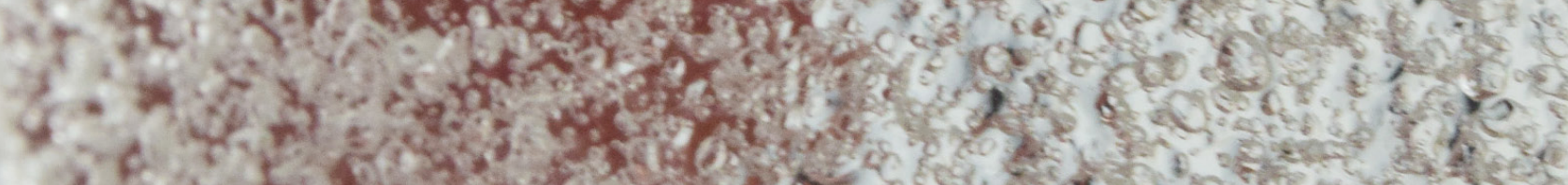

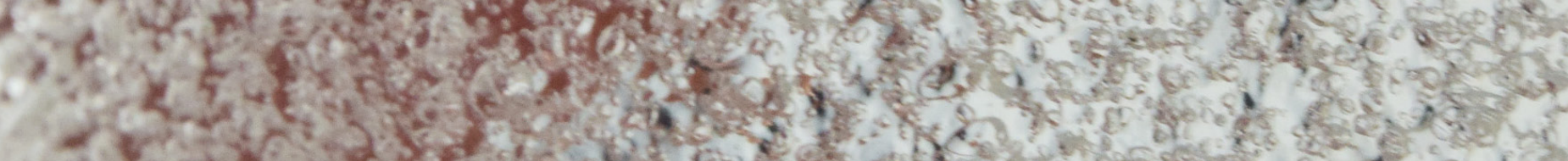

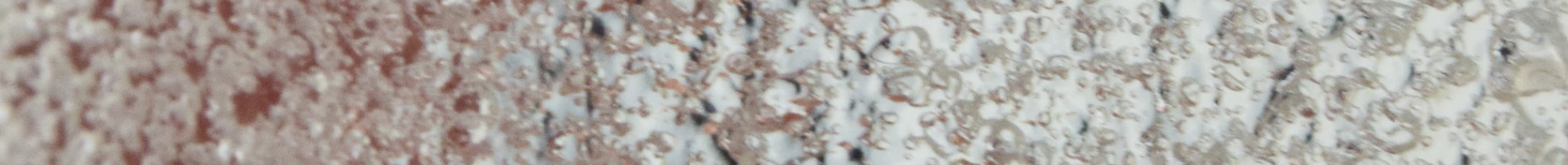

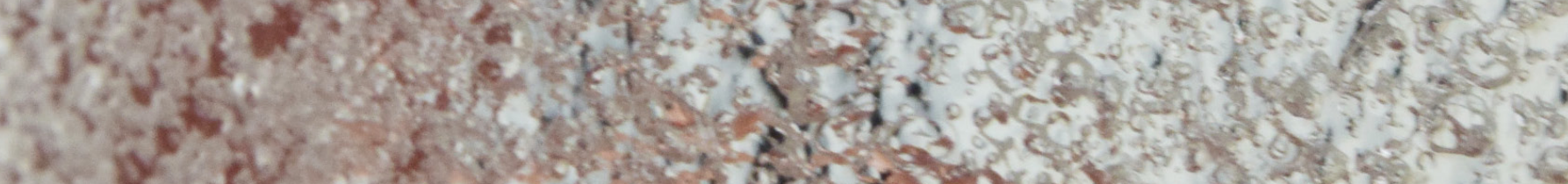

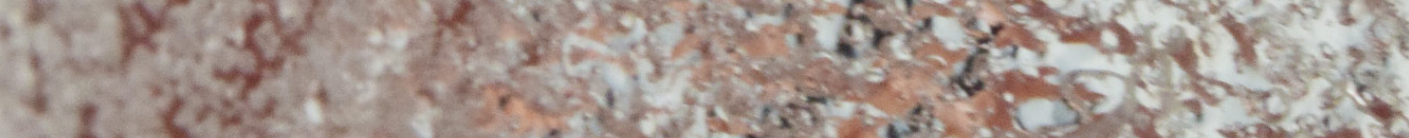

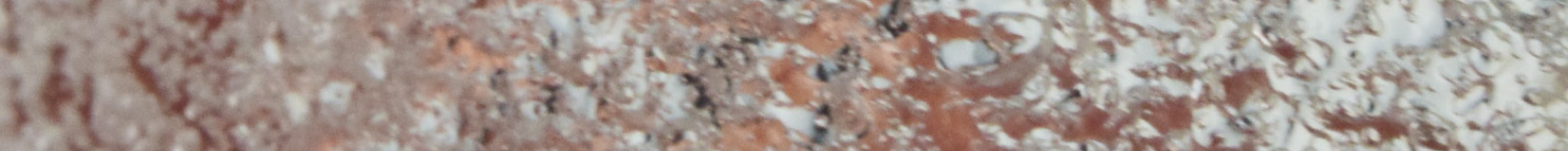

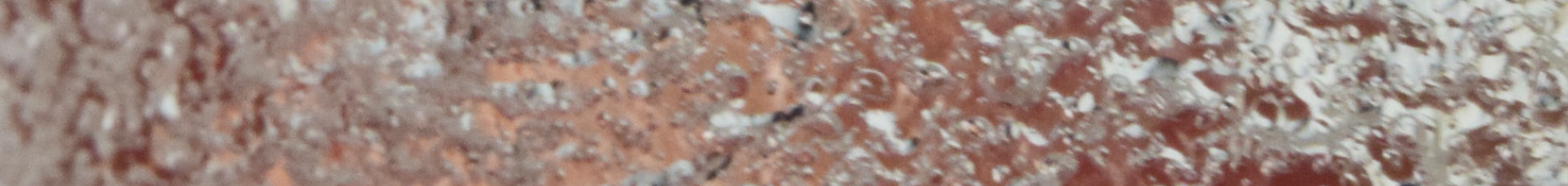

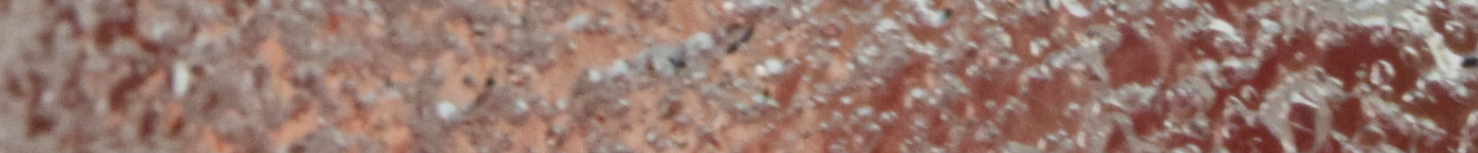

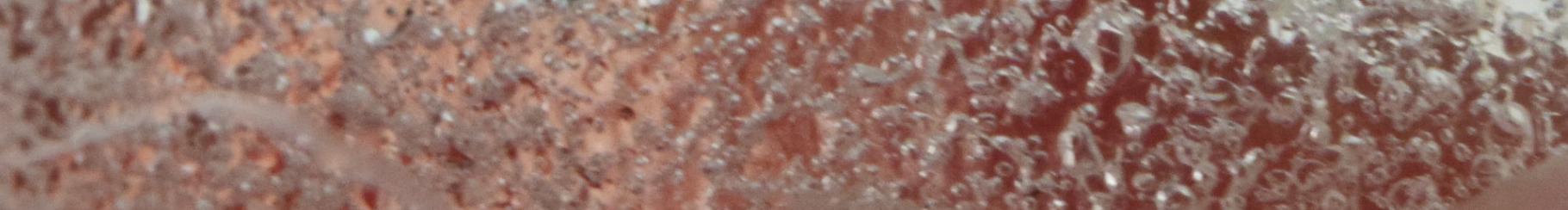




\section{Synthetic Materials}

The material has always played a significant part in the making of any products. Modern industrialised society is consuming not only more materials than ever, but also a more diverse range of materials (Karana, Hekkert, \& Kandachar, 2008). Materials determine not just a product's visual and tactile quality, cost, and physical and chemical properties, but also its environmental impact. Today, plastics enjoy its dominant position as a material for manufacturing processes, both in mass production and $\mathrm{AM}$, thanks to its unique properties and, more importantly, its outstanding inexpensiveness.

Plastics are synthetic long chains of polymers that are malleable and have continuously improved in durability, thermal and mechanical properties throughout the last 50 years (Shah, Hasan, Hameed, \& Ahmed, 2008). This has made plastics an ideal material for mass production. They have become an indispensable part of our lives. "Each year approximately 140 million tonnes of synthetic polymers are produced" (Shimao, 2001; Leja \& Lewandowicz, 2009) and "Synthetic plastics are traditionally made from inorganic and organic materials, with base materials that are derived from oil, coal and natural gases." (Shah, Hasan, Hameed, \& Ahmed, 2008).

Most products, especially disposable items, are dependent on synthetic polymers. Only limited synthetic plastics such as starch blended plastics or PVA (Leja \& Lewandowicz,2009) are considered biodegradable. The majority of synthetic plastics are not biodegradable or require a decade to degrade (Shah, Hasan, Hameed, \& Ahmed, 2008). Moreover, numerous synthetic polymers are resistant to chemical and physical degradation (Leja \& Lewandowicz,2009), making it extremely difficult to dispose of them. Such a huge quantity of non-biodegradable plastics has caused the current and concerning buildup of waste and its associated environmental pollution. This situation, in combination with the consistently rising price of petroleum (Gironi \& Piemonte, 2011), has led to the search for alternatives to plastics. 


\section{Bio-Based Materials}

In contrast to petroleum-based materials, bio-based materials are natural and renewable (Wijk \& Wijk, 2015) and include derivatives of living organisms (Sustainable Management, 2016). They were used as early as the first tool made by man. After years of research and experiments, it is now possible tailor bio-based materials with desired attributes. Common naturally occurring biopolymers include collagen and gelatin (from anima sources), chitin (from marine sources), micro biopolymer feedstock and agricultural feedstocks (e.g. starch) (Kolybaba et al., 2003).

Bio-based plastics are still in their infancy compared to their synthetic counterparts, and thus there is only a small market for them now. Bastioli (2005) suggests that there is "an average annual growth rate of over $35 \%$ over the five-year period from 1998 to 2003". In addition, he argues, regulation and legislation will drastically influence this market's growth (Bastioli, 2005).

Bio-based and petroleum-based materials are gradually levelling in price (Bastioli, 2005), reducing the price barrier of bio-based material. Moreover, bio-based materials are increasing in properties and suitability for mass production (Lu, Xiao \& Xu, 2009) and AM (Lam, Mo, Teoh, \& Hutmacher, 2002). There is a growing commercial interest in developing biodegradable materials for consumer products (Leja \& Lewandowicz, 2009). Bio-based materials are, therefore, a true rival to petroleum-based materials. Bio-based materials are increasing in demand. Mohanty, Misra, and Drzal argue that it will play a significant role in the future of manufacturing (Mohanty, Misra, \& Drzal, 2002). Designers have an opportunity to experiment with and blend materials to give them various new properties. These properties can offer a newer look and feel to products, especially for 3D printed ones (Wijk \& Wijk, 2015). 


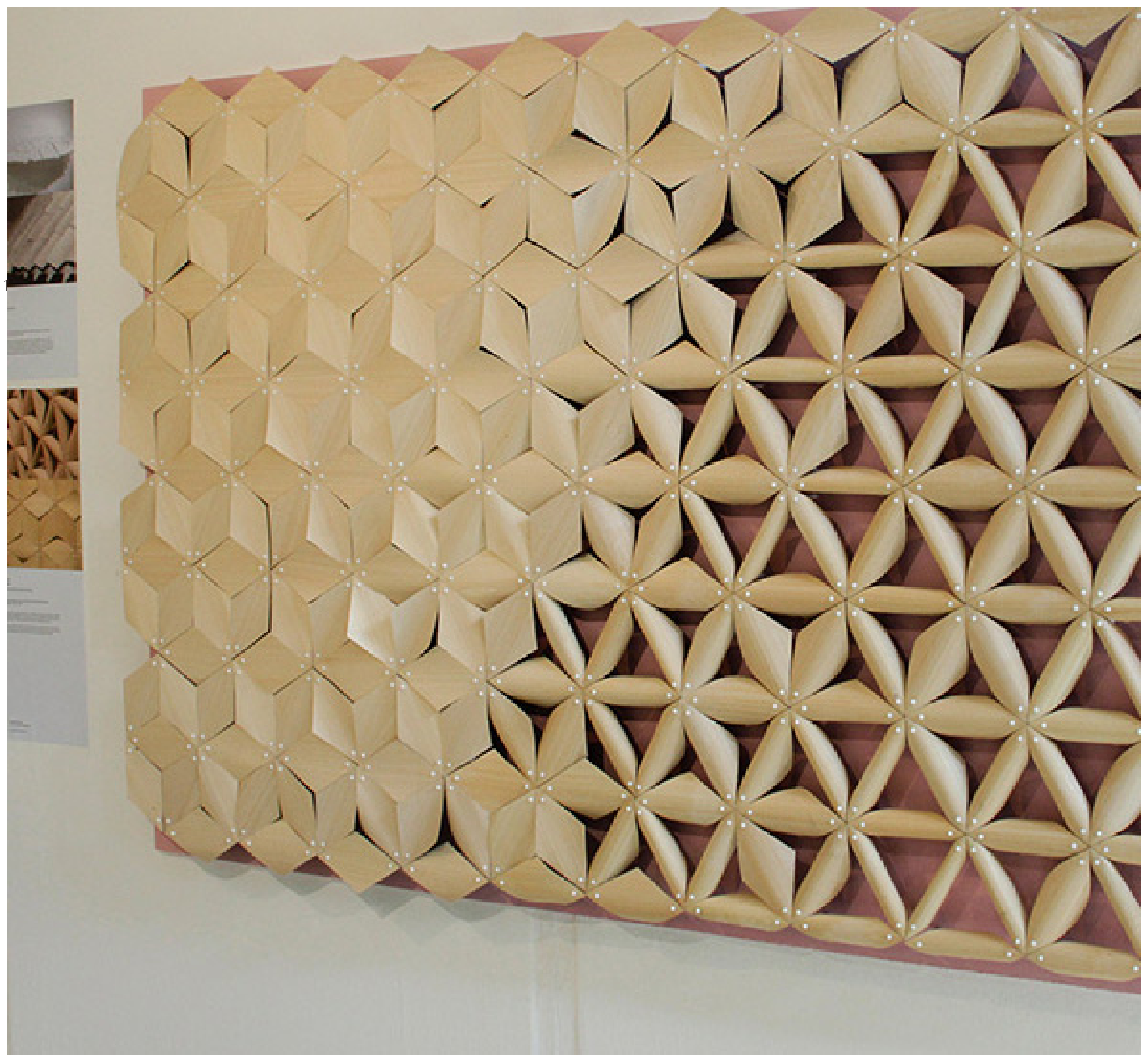




\section{Stimulus-sensitive materials}

This recent attention in bio-based material has encouraged designers, architects, engineers, and material scientists to integrate them into current product design and manufacturing. This has also encouraged innovative functions and the creation of smarter materials. Smart material is generally considered to have changeable properties (Addington \& Schodek, 2005), such as the ability to change shape or properties when influenced by external stimuli (Khoo et al., 2015). These changes are repeatable and reversible (BBC, 2014). Qiu and Hu (2013) suggest smart material's ability to be altered in a controlled manner is a crucial attribute. For example, photochromic materials are capable of changing colour when exposed to different light intensity (Addington \& Schodek, 2005). Water Reaction by Chao Chen (see figure $x x x$ ) is a water-reacting surface for architectural exteriors made of tiles that open and closes to conceal or reveal colours to brighten up spaces on rainy days (Aiello, 2014). It has multiple states. This is a characteristic of smart materials.

A pioneer in this field of research is the MIT self-assembly lab. In recent years MIT lab has been exploring contrasting reactive material to create self-assembly including projects that collaborate with Stratasys polyjet 3D-printing technique. Some may label these self-assembled 3D-prints as $4 \mathrm{D}$ printing. This emphasises that the combination of AM and material is a vast area for research.

Material plays a huge role in design and development. New materials are being created or altered continuously to reduce petroleum-based plastics. Materials are also being used in new ways, and smarter materials are emerging that are more responsive to their environment and have less environmental impact. Meaning material and AM are tools that can assist in ensuring more controlled product degradation. 


\section{Precedent Review}

I have conducted a precedent review to investigate and acknowledge existing design concepts that relate to degradation, bio-based material, and 3D printing. This review will explore and critique precedents in design and art that confesses a sense of beauty in what many might find disgusting and design examples that is dynamic and transformative. 


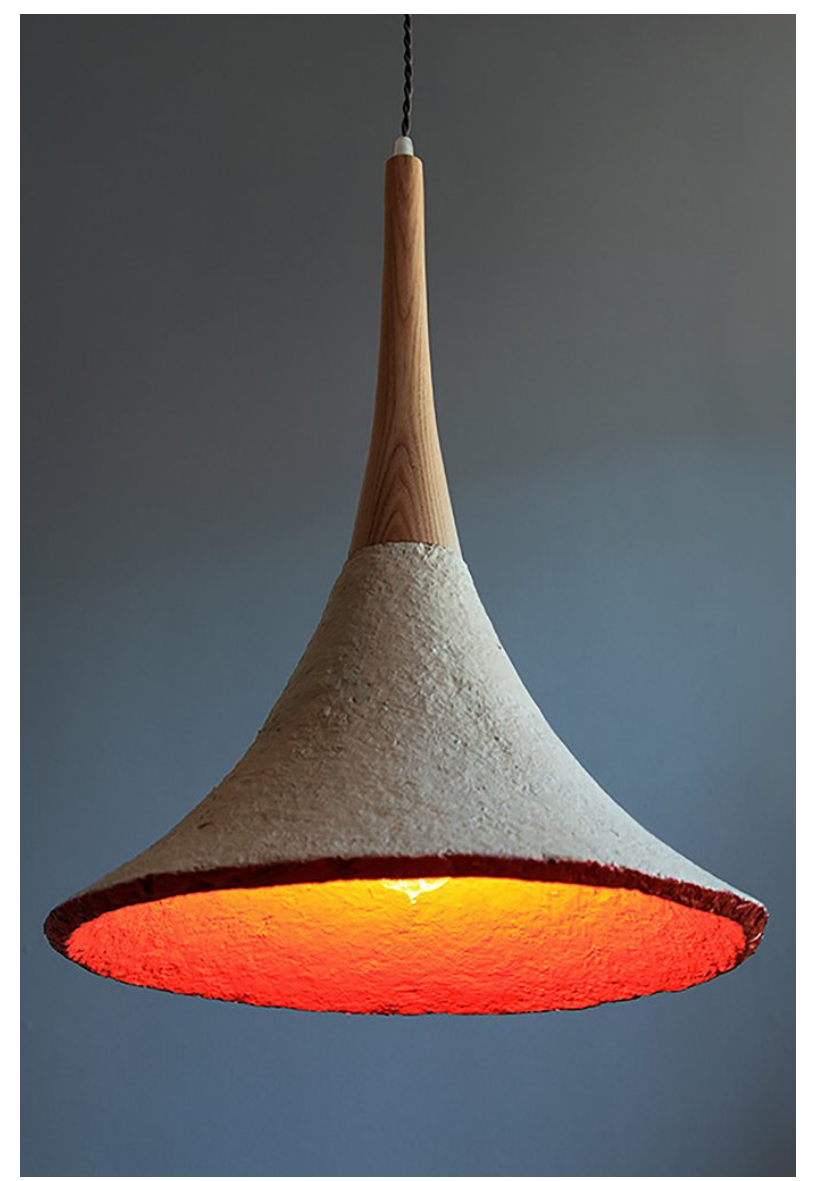

Image 1.8 (Above) MushLume

Trumpet Pendant

Danielle Trofe (2016)

Mushlume Trumpet Pendent (Danielle Trofe, 2016) is a table lamp grown out of mushroom mycelium. The lampshade is made out of agriculture byproduct combined with liquid mushroom mycelium; thus it is entirely biodegradable. Mycelium is grown naturally within a mould to achieve the desired shape, and to bind the two materials together. When the mycelium is fully grown, it is then heated and dried to end the growth cycle.

This emerging method of growing materials is very different to traditional manufacturing methods, yet nature has depended on it for billions of years. The MushLume Trumpet Pendent focused heavily on sustainability and material science, yet neglected design and style. Moreover, although these lamps are made with a natural material and method, they are still inanimate like conventional products and materials. The disposal method is not integrated into its product life cycle but only after disposal.

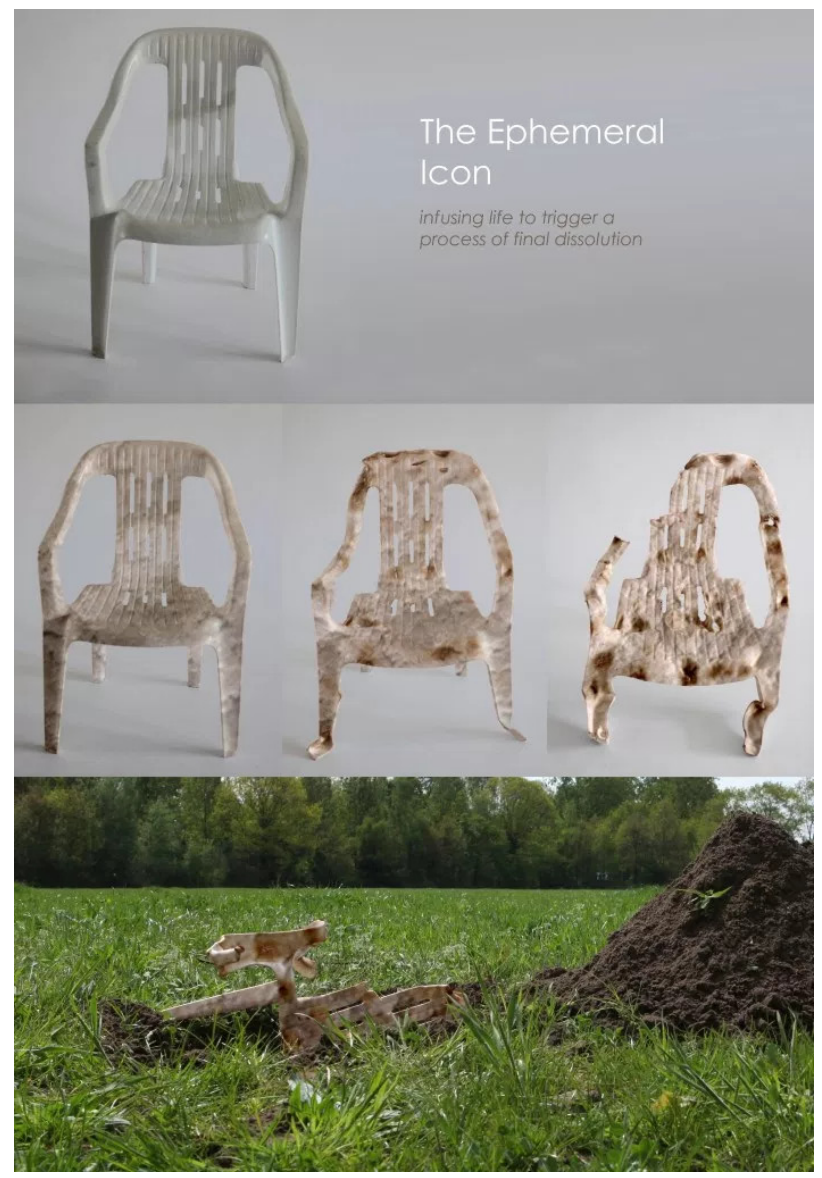

Image 1.9 (Above) The Ephemeral

con,

Maurizio Montalti (2010).

The Ephemeral Icon (Corpuscoli, 2010), researched the ability of fungus Phanerochaete chrysosporium to decompose synthetic materials naturally. The project aims to question the 'throw away' culture and to address designers' role and responsibility to the environment. The project is a bio-cover for the iconic Monobloc plastics chair. The bio-cover turns this inanimate object into a living thing and induces degradation.

This project took a different approach to using bio-materials. Instead of creating more objects, the project deals with an existing object, and with reducing the number of objects that exist. The use of a bio-cover to coat the chair conveys a strong visual image. It is powerful to see the inanimate plastic chair degrading like a living entity. However, as the chair degrades the functional and aesthetic qualities of the chair diminish, yet in nature degradation creates a new beginning and new roles. 
Image $1.10 \& 1.11$ (Right) One Third. Klaus Pichler (2014)

Image 1.12 (right last) Mestic Manure-Derived Bioplastic.

Jalila Essaidi. (N.D.)

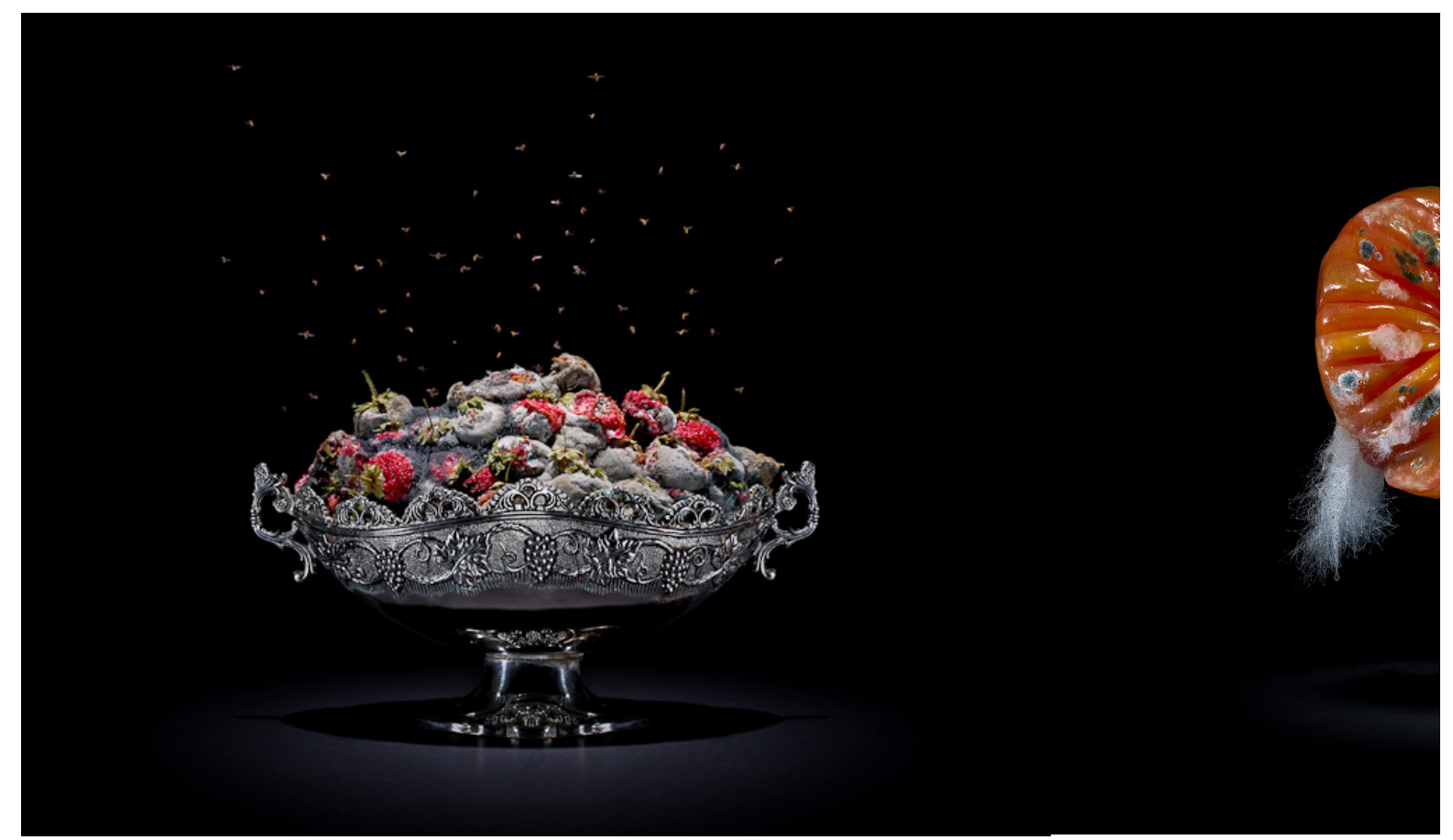

Klaus Pichler's project One Third (National Geographic, 2014), is a series of photographs of rotting food displaced elegantly. Each photo was captioned with the history and origin of the food, i.e., where was it produced. Pichler found that one-third of the produce made for humans goes to waste. This motivated Pichler to express this information with photography.

This is a fascinating and provocative set of photographs. Usually, rotten food, flies and maggots evoke a sense of disgust. However as the rotten foods are displayed and photographed with a sense of elegance, it overcomes the feeling of disgust and allows us to appreciate and celebrate the beauty in degradation. 


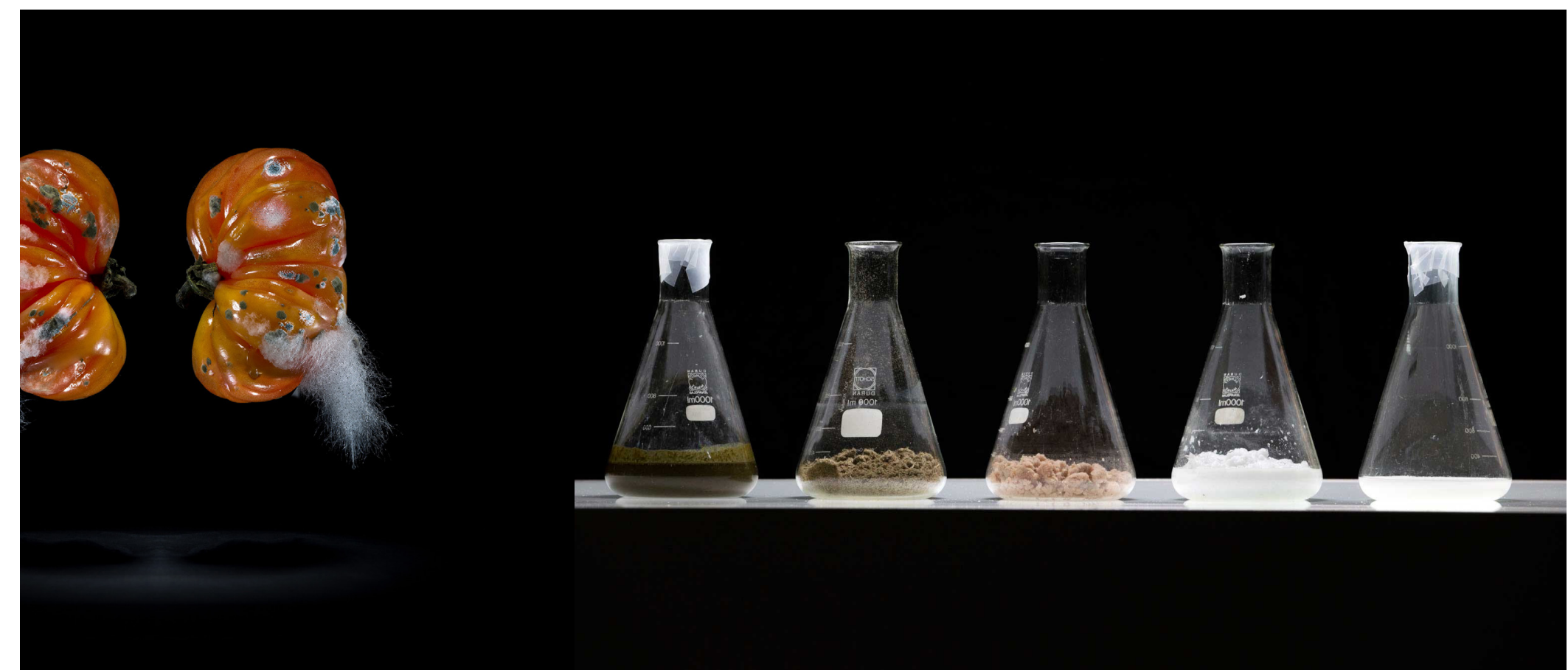

Mestic Manure-derived bioplastics (Essaidi, N.D.) aims to discover the beauty inherent in the most disgusting matter, manure. On the other hand, the project is trying to solve the pollution caused by manure disposal and run-off. By drying wet manure and extracting cellulose to create Cellulose Acetate, they were able to create textile and bio-plastics from something that many people will not normally consider a valuable resource.

This project is a particularly relatable precedent. They have incorporated disgust and bio-based material to create an end product that is perceived very differently in both its aesthetic and functionality from its raw form. This project makes us rethink manure from a different angle. 


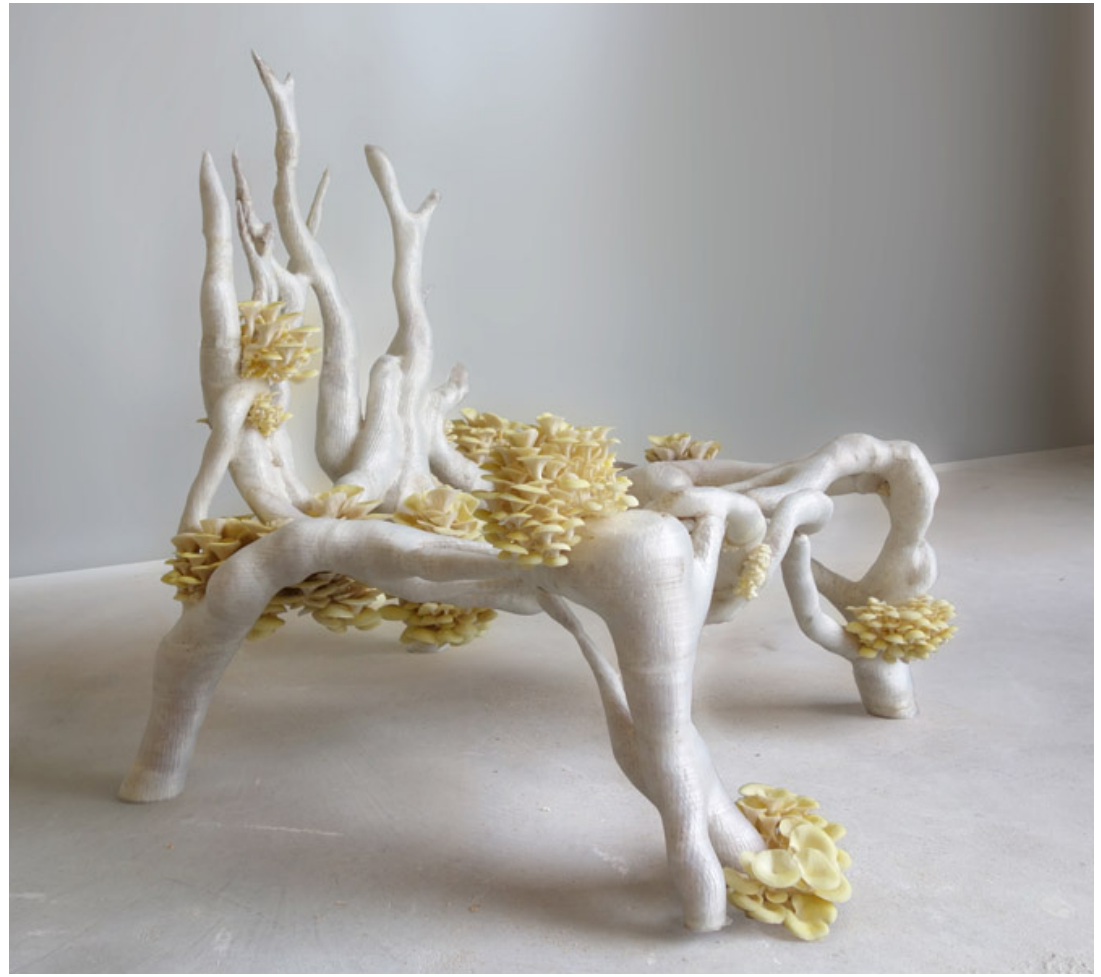

1.13 (Left) Mycelium Project.

Studio Eric Klarenbeek, Designers of the unusual (2013).

Mycelium Chair by Eric Klarenbeek (2013) is a chair 3D printed with live mycelium and local raw materials. Over time, the mycelium will mature and fully bloom into mushrooms that add to the chair as a decorative element. Through this process and choice of materials, Klarenbeek aims to encourage the audience to be more environmentally conscious and to reduce carbon footprint.

This is a unique project that deserves further development and elaboration as it has broken with the traditional way of thinking and manufacturing. However this bio-design again only focus on growth, and degradation is not suggested or acknowledged. This precedent inspires me to create through a similar process, but to focus on degradation.

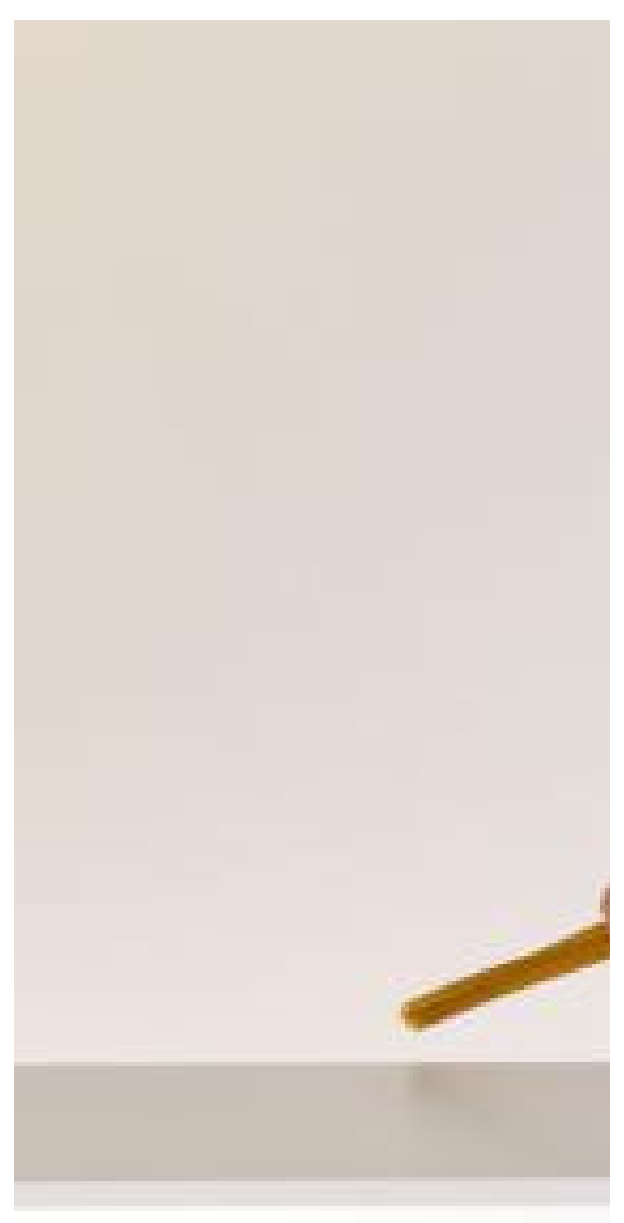


Water-based digital fabrication platform (MOGAS-SOLDEVILA, et al., 2015) investigated using robotics to dispose aqueous form of crustacean-derived biopolymer material for optical gradient and uses the shrinking of the material from water evaporation to create 3D form. The shrinkage is further controlled through a computerized evaporation control system.

This project has an exciting way of employing a simple digital manufacturing tool to create a novel structuring system and material property. It has also provoked a new way of using material and digital tools. 


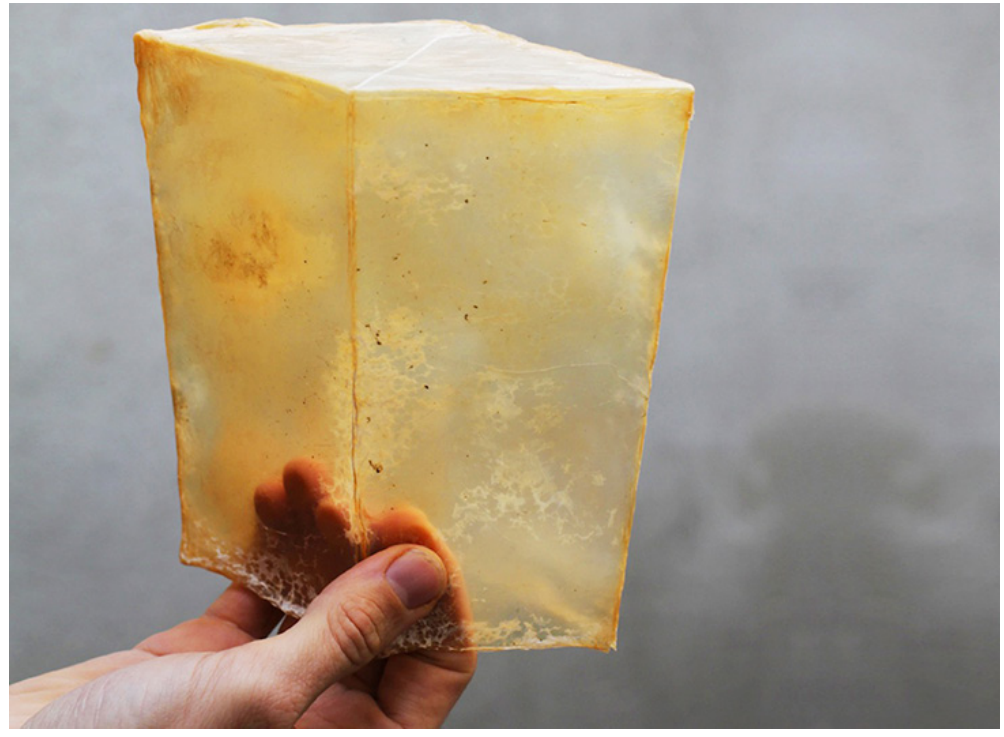

Xylinum cones (Inhabitate, 2015) is a made out of cellulose grown from bacteria. A particular kind of bacteria is used and incubated to grow in a mould. The bacteria will ripen in the mould for three weeks and then shape into the design. The properties of the material include high purity, strength, moldability, and increased water-holding ability.

This material is interesting in the way that it is made organically and it creates properties that are different with the conventional fossil-based material. This means the material is not only sustainable but also carries new function. This added function may provide reasons for manufacturers to shift from fossil-based material to organic bio-based materials.

Through precedent reviews, it is clear that bio-based material is an emerging area warranting more research and design applications. It is also clear that degradation is often an afterthought rather than part of the design's decisionmaking process. Some explored precedent acknowledge the disposal of the object can naturally biodegrade hence contribute to the environment.

However, I believe replacing the synthetic material with natural material does not fully utilising the benefit of bio-based materials. The Mycelium chair is pioneering the making of synthetic objects with natural growth process opening new opportunities for furniture design. Yet this method of making is still heavily focused on growth and increase of product.
Image 1.15 (Left) Xylinum Cones. Jannis Huelsen, (2015). 


\section{Situating the research}

Industrial revolution, allowed automatic simultaneous making of things. In this satisfaction of creating and financial gain, the importance of environmental consideration diminished. Because it is so easy and cheap to acquire product, they are not as cherished anymore. Consequently lead to careless disposal. Most mass produced items are made with synthetic plastic there is minimal attention to it's impact on the environment when disposed. This ever increasing disposal of non-degradable items is continuously impacting on our environmental condition.

Despite this alarming implication for sustainability, the prominent respond to this issue is concentrated at the disposal such as recycling or forestall obsolescence. There are minimal approach to solve the root of the problem, which is the process and material in designing and making of objects.

Recent years there is a growing attention on the merging of natural with artificial process and materials. It is an sprouting area as evident in both literature and precedent review. We now have the tools and technology to understand and alter bio-based material for taylor attribute. At the same time, AM provides a platform for quick and cheap adaptation of biobased material into the making process.

There is now an opportunity to revise the flaw of mass production and construction new strategies to combat the previous inconsideration of environment. 3D-paste printing and bio-based materials, provide to tools to focus on integration of degradation into our design process and material. In modification of the current design process and material, I want to celebrate the beauty and necessity of degradation to encourage others to appreciate and value it.

I see an opportunity to highlight bio-based material and to create a dynamic form that actively degrade while during the product life cycle. There is an alarming importance to actively consider degradation at the design stage to reduce severity of environmental issues and to critiquing the current manufacturing process. I will explore the metamorphic possibilities which could could chart a new design territory of time-dependent, environment-induced degradation and the transformation of man-made objects. Its findings could prove significant in design, science, and engineering.

I hypothesise that bio-based material and 3D-paste printing together can create objects that resemble degradation in nature, which could offer an entirely different concept to current mass-produced products.

Firstly, the design is prepared based on literature and visual observation of decay stages in nature and a deduced set of degradation criteria. Secondly, via CAD form and material distribution will be determine, Thirdly, 3D-printing gives form to the object by depositing materials layer by layer Lastly, materials used include CA and PVA, allowing the produced object to be sensitive to external stimuli and undergo transformative degradation, unlike conventional artificial materials and design. While precise control of the man-made degradation is an important part of my research, I also aim to offer aesthetic value and an opportunity for contemplation the revelation of a second identity through degradation and a different approach to demise. 


\section{Aims \& Objectives}

Research question: How can additive manufacturing and bio-based material together create artefacts with degradation qualities?

Multidisciplinary design has been adopted by university around the world including MIT (https://www.media.mit.edu/research/?filter=projects) and Stanford University (https://dschool.stanford.edu/about/). This thesis explore multidisciplinary design crossing between scientific and design research. The research is base on a Design Science Research (Johannesson and Perjons, 2014) approach. The method framework starts from an Explicate Problem, Define Requirements, Design and Develop Artefact, Demonstrate Artefact and lastly Evaluate Artefact. This method follows a similar structure of a scientific method: Ask a question, form a hypothesis, deduced predictions and check predictions. The two method shares commonality in its procedure to discover a challenge and formulate prediction and justify with testing and evaluation.

While literature and precedent Explicate Problem, the aims and objective are set to correspond to the remaining of the Design Science Research framework. 


\begin{tabular}{|c|c|c|}
\hline Aim & Objective & Approach \\
\hline \multirow[t]{2}{*}{$\begin{array}{l}\text { Phase } 1 \text { - Materials } \\
\text { To explore potential bio-based } \\
\text { materials for AM that have the } \\
\text { ability to degrade through natural } \\
\text { external stimulus. }\end{array}$} & $\begin{array}{l}\text { 1a) Identify appropriate materials } \\
\text { for 3D-printing. }\end{array}$ & $\begin{array}{l}\text { Define Requirement } \\
\text { Literature review } \\
\text { Experimental research } \\
\text { Research through making }\end{array}$ \\
\hline & $\begin{array}{l}\text { 1b) Test and identified materials } \\
\text { to evaluate degradability of each } \\
\text { material. }\end{array}$ & $\begin{array}{l}\text { Define Requirement } \\
\text { Empirical research }\end{array}$ \\
\hline \multirow{3}{*}{$\begin{array}{l}\text { Phase } 2 \text { - Design } \\
\text { To design and explore the quality } \\
\text { and relationship between the } \\
\text { 3D printing materials and the } \\
\text { process of degradation. }\end{array}$} & $\begin{array}{l}\text { 2a) Identify and evaluate } \\
\text { core visual criteria of natural } \\
\text { degradation process and } \\
\text { integrate into design concept. }\end{array}$ & $\begin{array}{l}\text { Design and Develop Artefact } \\
\text { Observation } \\
\text { Analysis }\end{array}$ \\
\hline & $\begin{array}{l}\text { 2b) Develop preliminary design } \\
\text { concept and Utilise an iterative } \\
\text { design process to develop a well } \\
\text { defined design concept. }\end{array}$ & $\begin{array}{l}\text { Demonstrate Artefact } \\
\text { Mind map } \\
\text { Case study } \\
\text { Iterative process } \\
\text { Prototyping }\end{array}$ \\
\hline & $\begin{array}{l}\text { 2c) Test and evaluate the } \\
\text { design's ability to degrade under } \\
\text { appropriate stimulus. }\end{array}$ & $\begin{array}{l}\text { Evaluate Artefact } \\
\text { Evaluation }\end{array}$ \\
\hline
\end{tabular}




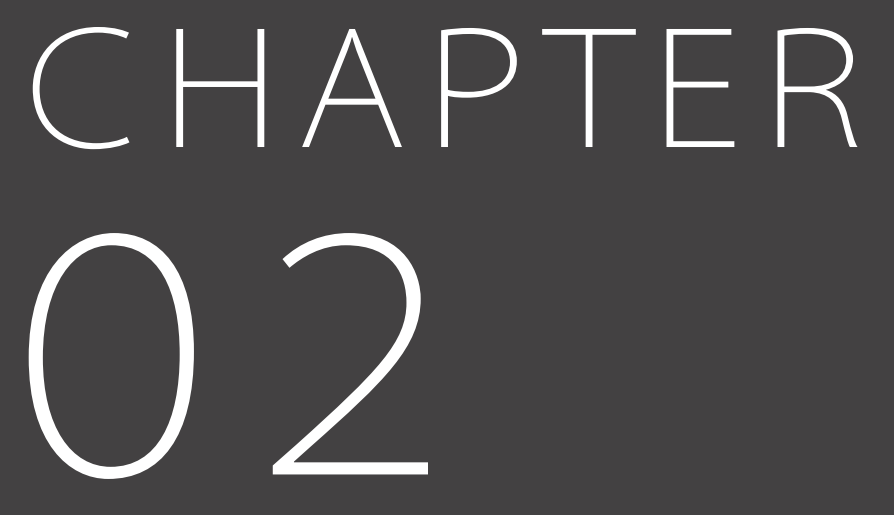

Materials and Processes 


\section{Materials}

\section{Introduction}

One of the fundamental influence on the ongoing environment build up of waste is material and production process. Hence I experimented with three common bio-based materials via 3D-paste printing,

3D-printing exists in various forms, as discussed earlier. This research focuses on the FDM printing process for a number of reasons including:

- It is affordable

- Tailoring the machine for different materials is easy.

- It is a quick process.

Paste 3D-printing bears a wealth of potential and is rarely explored in design, especially multi-material paste printing. This research will use two Discov3ry Paste extruder connected to an open source printer for all 3D-printing test.

Starch, PVA and cellulose are common materials used to make degradable bioplastic. Starch is the second most abundant material after cellulose (Bastioli, 2005), hence I investigated both. Despite PVA being a synthetic polymer, it is cheap and dissolves in water. Thus it is of interest to the research.

\section{Material Criteria and Deductive Method}

A list of material criteria is constructed based on literature and research focus. Each material is to be examined and assessed using the deduction criteria.

\begin{tabular}{|l|l|}
\hline Material Criteria & Key deduction criteria \\
\hline Degradable & $\begin{array}{l}\text { The material should physically and visually } \\
\text { degrade via external stimulus, within various } \\
\text { time frames. } \\
-\quad \text { Degrade at different rates. } \\
-\quad \begin{array}{l}\text { Degrade with specific stimulus (e.g. UV } \\
\text { or humidity) }\end{array}\end{array}$ \\
\hline Renewable & $\begin{array}{l}\text { The material should be renewable and } \\
\text { abundance. } \\
-\quad \text { Cheap } \\
-\quad \text { Abundance }\end{array}$ \\
\hline Adaptable with AM & $\begin{array}{l}\text { The material should be compatible with the } \\
\text { process of FDM paste printing. } \\
-\quad \begin{array}{l}\text { Short drying time } \\
\text { Easy to extrude and build layers }\end{array}\end{array}$ \\
\hline
\end{tabular}

Table 2.1 (Above) Material criteria and deduction criteria 


\section{Defining degradation}

Degradation of bio-based materials can be classified into four categories: bio-, photo-, oxidative and hydrolytic degradation.

\begin{tabular}{|l|l|}
\hline Types of degradation & Definition \\
\hline Biodegradable & $\begin{array}{l}\text { Plastics that degrade through the action } \\
\text { of microorganisms such as bacteria, fungi } \\
\text { and algae. }\end{array}$ \\
\hline Photodegradable & $\begin{array}{l}\text { Plastics that degrade when exposed to } \\
\text { natural light. }\end{array}$ \\
\hline $\begin{array}{l}\text { Oxidatively } \\
\text { Degradable }\end{array}$ & Plastics that degrade through oxidation. \\
\hline Hydrolytically Degradable & $\begin{array}{l}\text { Plastics that degrade when exposed to } \\
\text { water }\end{array}$ \\
\hline
\end{tabular}

Table 2.2 (Above) Types of degradation 


\section{Material research}

Starch, PVA and cellulose are common materials used in the making of degradable bioplastic as briefly mentioned in chapter 2 literature review on bio-based materials. This section will further review the related literature on each chosen materials.

\section{Starch}

Starch belongs to the carbohydrate family. It is used in food industry as well as paper textile and pharmaceutical industry (De Graaf \& Janssen, 2000). Starch derived from raw starch extracted particularly from potatoes, grain, corn and more (Tomka, 1994). To obtain the natural form of starch the raw starch is washed and dried (Tomka, 1994). Starch then need to be chemically modified for different applications (De Graaf \& Janssen, 2000). Starch has long been an interest to be used for injection moulding (Maye \& Elion, 1994). Starch is a popular candidate use as a degradable additive to the preparation of biodegradable polymer (Leja \& Lewandowicz, 2009). Starch is already involved with the making of synthetic plastic such as polyester polyurethane, polyethylene with starch. Not only is starch biodegradable, but it is also known to be UV degradable (Abd El-Rehim, Hegazy, Ali, \& Rabie, 2004).

\section{Cellulose}

Cellulose is found in green plants, and it acts as a structural support as well as a protection layer (O'sullivan, 1997). It is first discovered and isolated by Anselme Payen over 150 years ago (O'sullivan, 1997). Cellulose is a point of interest to sustainable and biodegradable research because it is the most abundant organic compound on earth (Puls, Wilson, \& Hölter, 2011) therefore it is considered a renewable resource (Kolybaba et al., 2003). Cellulose is biodegradable by the enzyme cellulase in organisms (Puls, Wilson, \& Hölter, 2011). Cellulose is low cost, biodegradable and contains strong mechanical properties. Therefore it is a popular choice for plastic filler materials. (Kolybaba et al., 2003). Cellulose has a very long molecular chain, which is infusible and insoluble in all but the most aggressive solvents (Chandra et al. 1998)

$P \vee A$

PVA is popular as a synthetic polymer because of its water solubility (Leja \& Lewandowicz,2009). Despite PVA being a synthetic polymer, it is one of the few synthetic polymers that are capable of biodegradation. PVA is a popular candidate as a base material to give structure for the making of bioplastic (Harmsen, Hackmann, \& Bos, 2014). Although PVA is a synthetic polymer, it has the capability to biodegrade, depending on the degree of polymerization (DP) and the degree of saponification (hydrolysis; DS), the totality of the main chain, ethylene content and 1,20 glycol content (Leja \& Lewandowicz,2009). This material is chosen because it meets all the material criteria this research is looking for except for being a synthetic polymer. However, Zeng, Liu, Cai, \& Zhang (2010), acknowledge that organic-inorganic hybrid materials combine organic and inorganic materials to achieve superior characters that attracted attention. For example, starch and PVA blends are a popular biodegradable plastic that is widely used for packaging and agriculture applications (Leja \& Lewandowicz, 2009). 


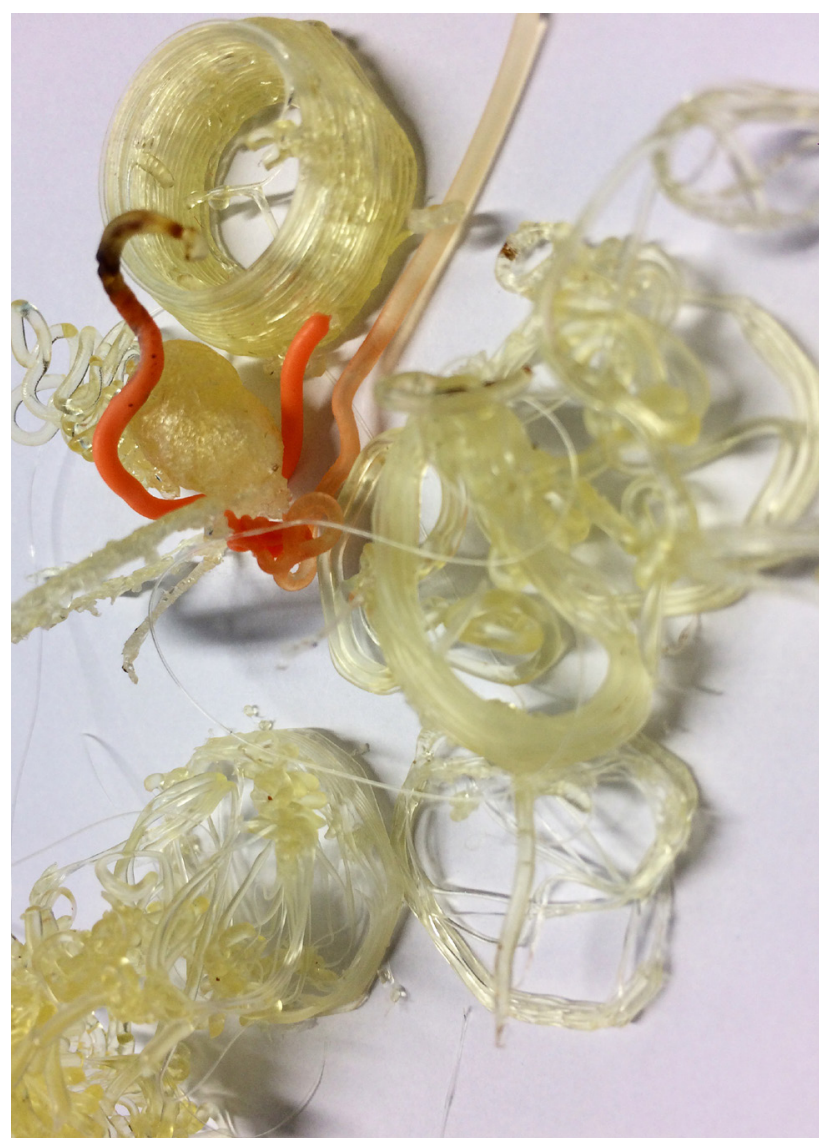




\section{commercial Filament}

Thermal extrusion is most used with FDM printing. In search of different 3D-printing filaments, there were multiple options for PVA. It is a popular support material for multi-material 3D-printing due to its solubility in water. However, there were not many commerically available starch filaments. Polylactic acid (PLA) is a starch-derived bioplastic, but it is not pure starch. BioMed3D also produces a starch-based filament, however it is only available in the US. There are a few cellulosebased or containing filaments, however, no high cellulose content filament was commercially available. This could be attributed to the fact that biopolymers tend to decompose upon heating, unlike synthetic polymers that have a defined melting point (Tharanathan, 2003).

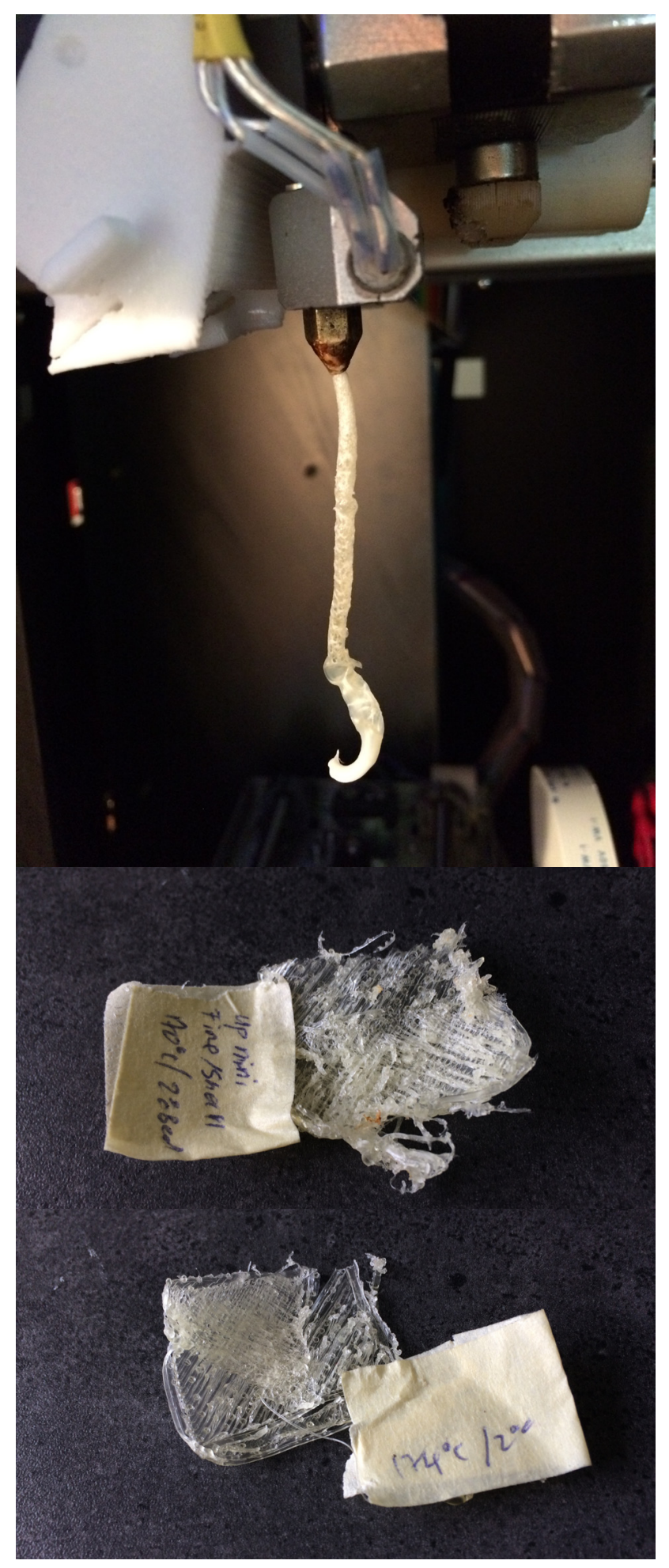

Image 2.2 (top) PVA extrusion overheated Image 2.3 (middle) PVA filled cube fail print at 170 degree.

Image 2.4 (bottom) PVA filled cube fail print at 174 degree. 
PVA filament made by Dutch Filament was purchased and experimented with a UP 3DPrinter.

Moisture - Related forums explains that PVA filament softens with moisture, resulting in problematic extrusion. Therefore, the filament is baked at 50-degrees Celsius overnight and printed instantly, with a bag concealing the filaments to retain dryness. The filament extrusion improved yet still was not consistent.

Temperature - The recommended extrusion temperature for this particular PVA filament is 180-205 degree Celsius, not exceeding 225-degree Celsius as the material will crystallise, along with a recommended print bed temperature of 35.6-degree celsius (Dutch Filaments, 2016). From experience, different FDM printers perform differently, therefore I tried different nozzle temperature ranging from 160-220-degree Celsius and bed temperature ranging from no heating to 80 -degree Celsius. Finally, the PVA filament printed (see figure $x x x$ ).

Form - The cylindrical print was very distorted from inconsistent extrusion. Next I printed solid cube. However, the material struggled to print after the second layer (see figure xxx).

Nozzle size and print setting - Shell setting was applied to the cube model and was printed with different nozzle size including $0.4 \mathrm{~mm}, 0.8 \mathrm{~mm}$ and $1.2 \mathrm{~mm}$ to experiment if the amount of material extruded influences extrusion quality. Additionally, one print was accidentally printed with ABS print setting (nozzle 270 degree celsius and bed temperature of $x x x$ ) and it resulted in a less distorted cube (see figure $x x x$ ). This accidental discovery was expanded on.

After numerous tests, I was still not able to create a full-shell PVA print. However, the quality of the inconsistent print created an interesting texture which I think convey a unique serendipitous quality (see figure $x x x$ ). 
Design to Degrade
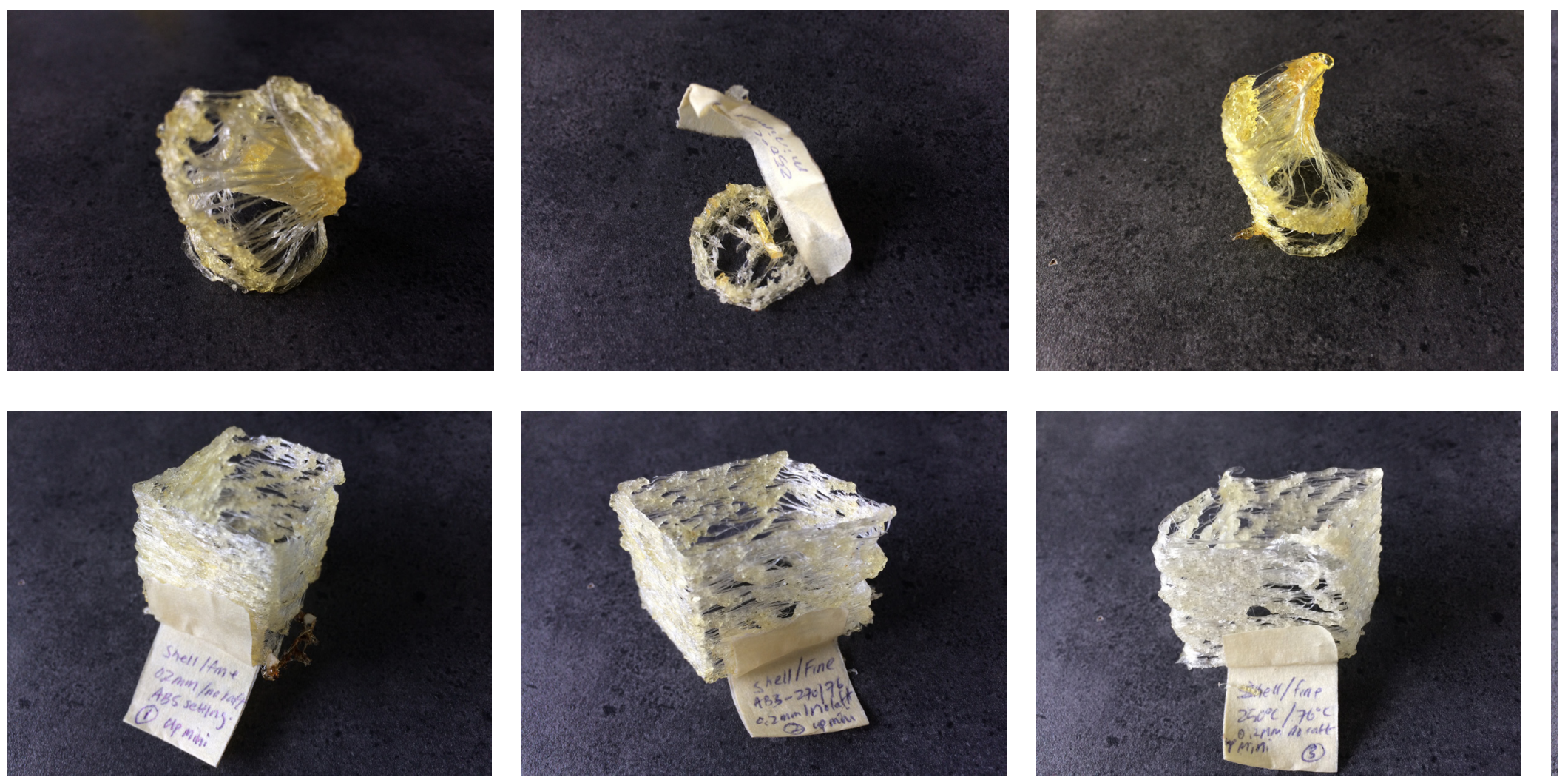

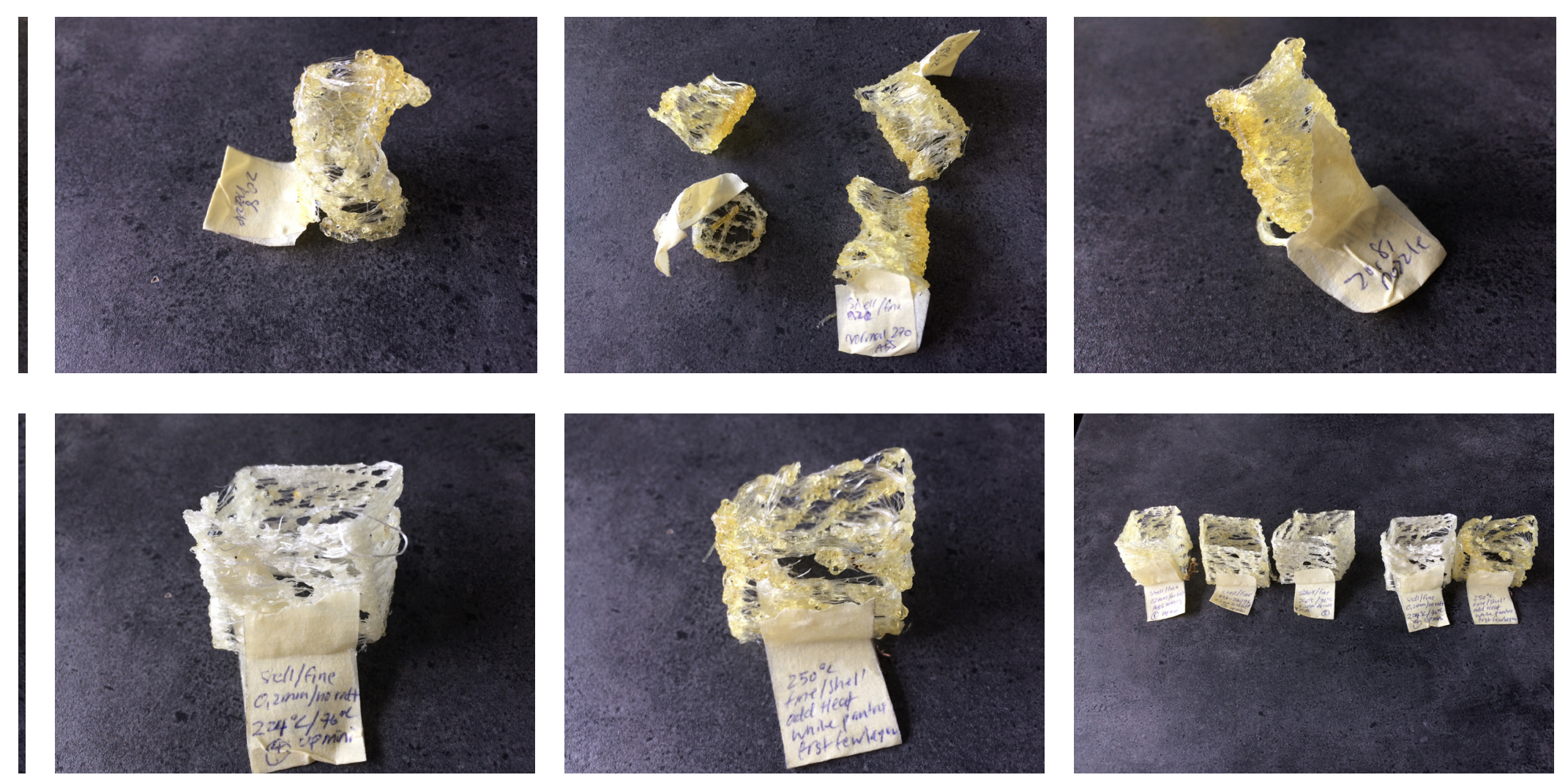

Figure 2.5 - 2.10 (top row) shell cylindrical PVA filament print test with various print temperature.

Figure 2.11-2. 16 (bottom row) shell cube PVA filament print test with various print temperature. 


\section{Paste Exploration}

The lack of desired materials in filaments led the research to shift its focus to paste $3 \mathrm{D}$ printing. A primary advantage of paste extrusion is the ability fully control material content, and the freedom to tailor material performance such as degradation rate and visual qualities. In addition, 3D paste printing is under-explored, hence there is the opportunity to produce novel findings.

Paste extrusion is relatively new, therefore there is limited research to guide my experiments. I examined the extrudability, drying time and layer retention of each material and $3 \mathrm{D}$ print with the material that performs the best.

Extrudability - materials were extruded using a syringe with a nozzle size of $0.7 \mathrm{~mm}$ to mimic a paste printing scenario.

Drying time - Observe and record the dry time of one layer thick material extrusion. In these experiments, dryness is defined as touchable.

Layer retention - Multiple layers of material were extruded on top of each other, repeatedly, to test each material's ability to retain layers.

3D print test - This test will use two Discov3ry Paste extruder connected to an open source printer.

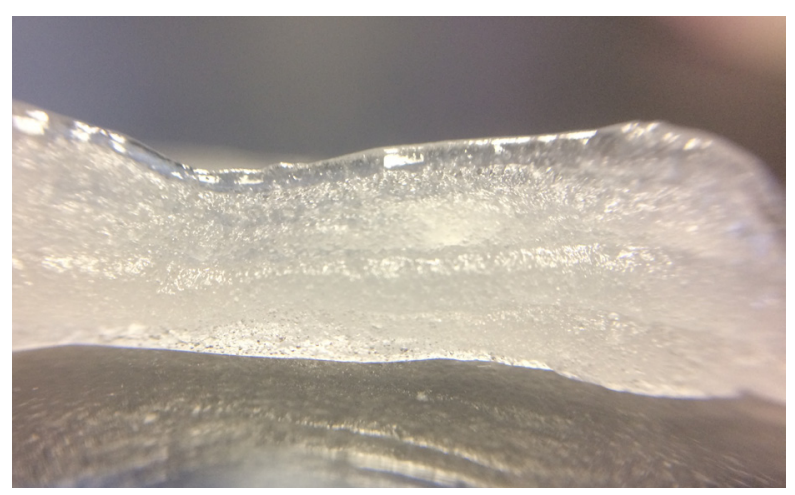

Image 2.17 (Top) PVA 117s extruded

in layers with heat inbetween each

layer.
Types of PVA

\begin{tabular}{|l|l|}
\hline PVA GRADE & hydyrolysis (\%) \\
\hline PVA 117S & $98-99$ \\
\hline PVA 205MB & $86.5-89$ \\
\hline PVA205s & $86.5-89$ \\
\hline PVA filament & N/A \\
\hline
\end{tabular}

\section{Methods}

Extrudability - Each type of PVA combined with a different Extrudability - Each type of PVA combined with a different amount of water to find suitable consistency. Three consistencies (low, medium and high viscosity) of each material were extruded.

Drying time - The dry time of each extrusion was observed and recorded.

Layer retention - To improve dry time and layer retention, heat was added in between each layer.

3D-Print test - One part fine powder PVA205 was mixed with two-part water for 3D print test. The initial test comprises of a volumetric cube and cylinder in both solid and shell setting. 


\section{Types of starch}

\section{- Potato starch}

- Tapioca starch

\section{Preparation}

Starches gelatinise with the presence of heat and water. Starches are highly branched, so heat and excess water break down their structure (Stepto, 2003). Therefore starch was boiled with water.

\section{Methods}

Extrudability - As the starch and water mixture was heated, both starch types presented an undesirable clumping effect. This inhibited extrusion with a small nozzle. Therefore starch powder was combined with cold water before adding heat.

Dry time - A thin film of starch was made and was left to dry. Alternative experiments endeavoured to decrease dry time. A DIY starch-based bioplastics recipe was tested. Vinegar and glycerin were added to starch accordingly. The vinegar breaks the hydrogen bonds, and glycerin acts as a plasticiser.

Layer retention - Multiple layers of cooled starch paste were extruded through a large nozzle.

Image 2.18-2.19 (right) Preparing starch

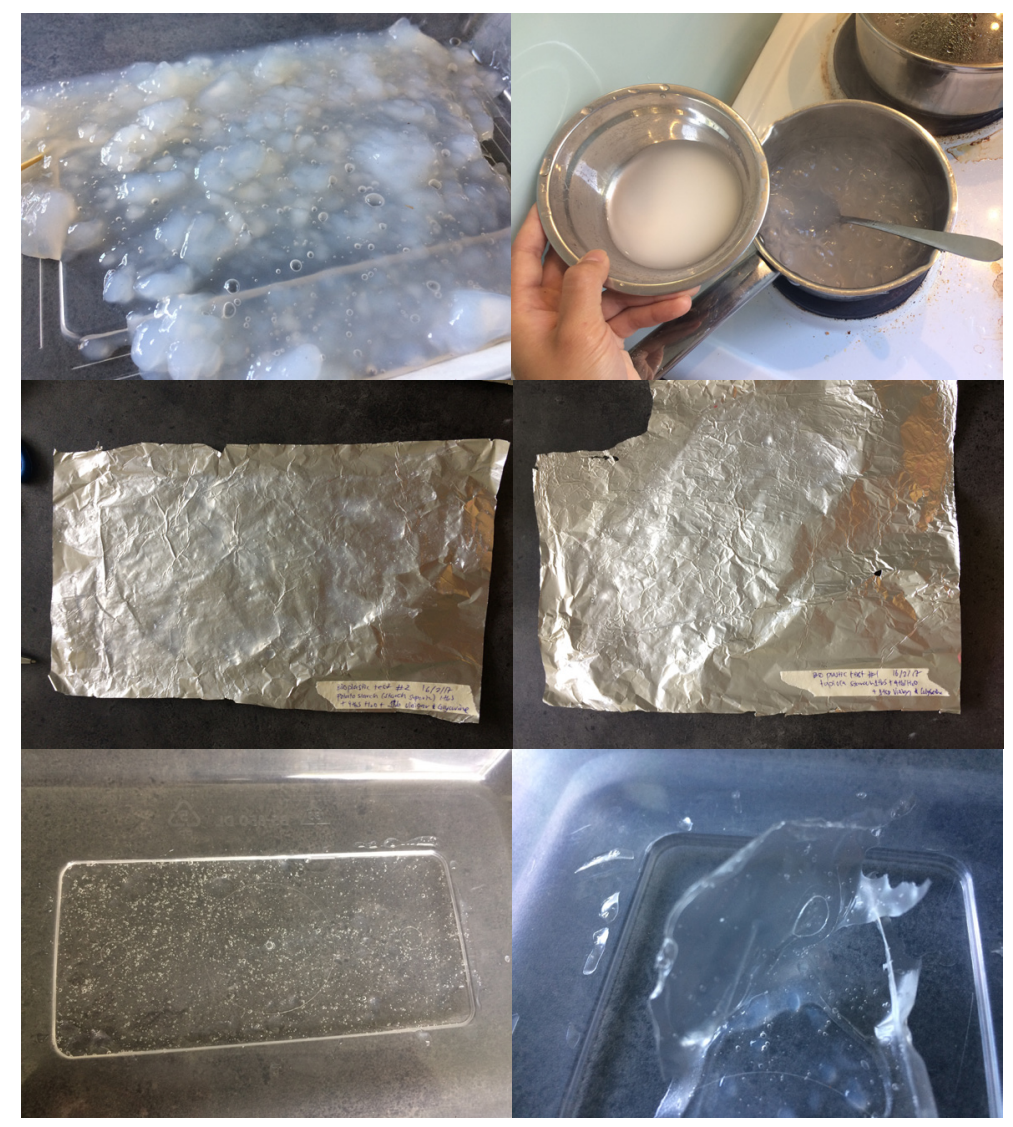

Image 2.20-2.21 (right) Preparing starch bio-plastic

Image 2.22-2.23 (right) Preparing starch bio-plastic 


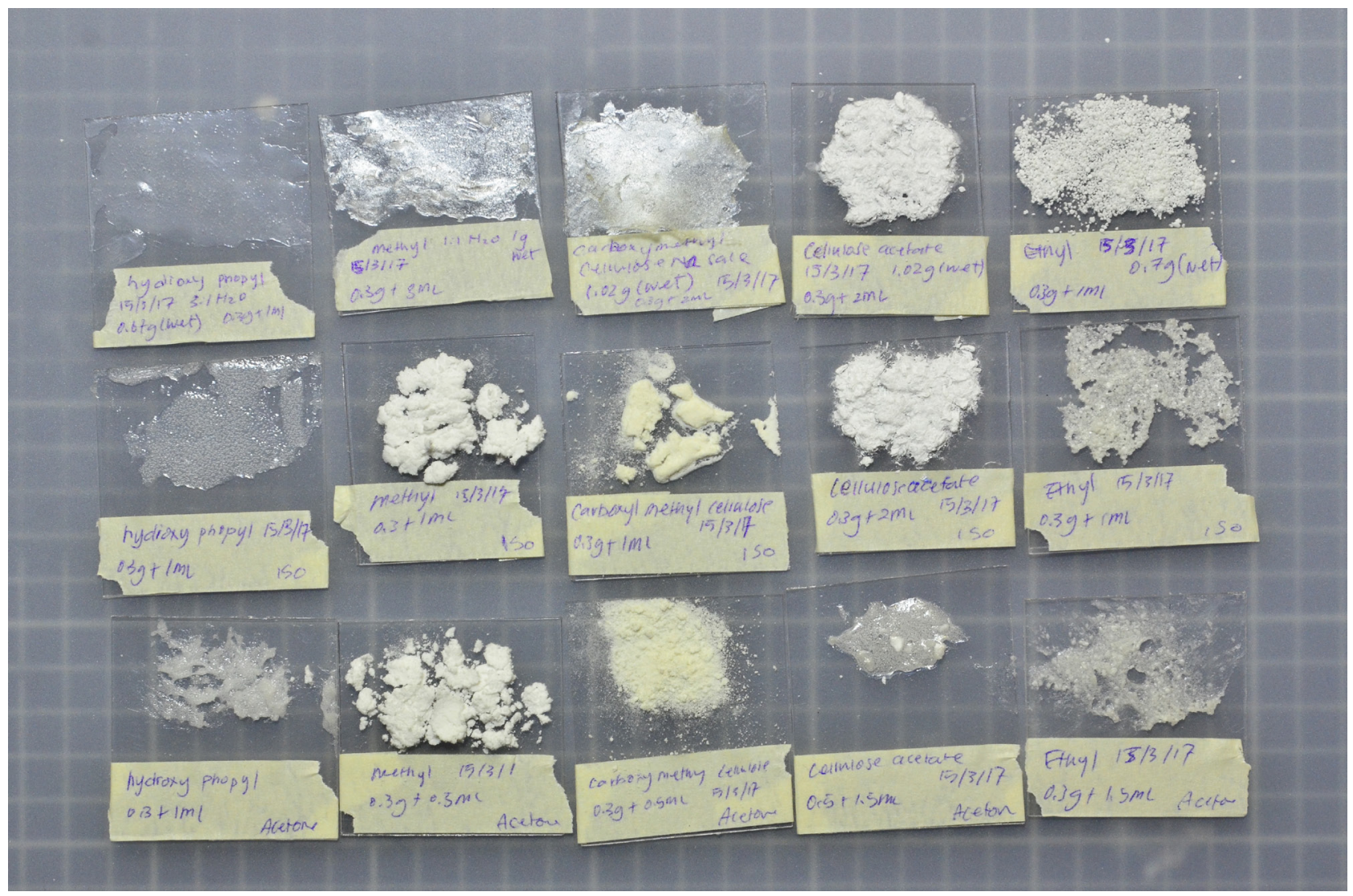

\section{Cellulose Exploration}

Types of cellulose

- Methyl cellulose (MC)

- $\quad$ Ethyl cellulose (EC)

- Cellulose acetate (CA)

- Carboxymethyl cellulose (CC)

- Hydroxypropyl cellulose (HC)

Types of solvent

- Water

- Isopropyle

- Acetone 


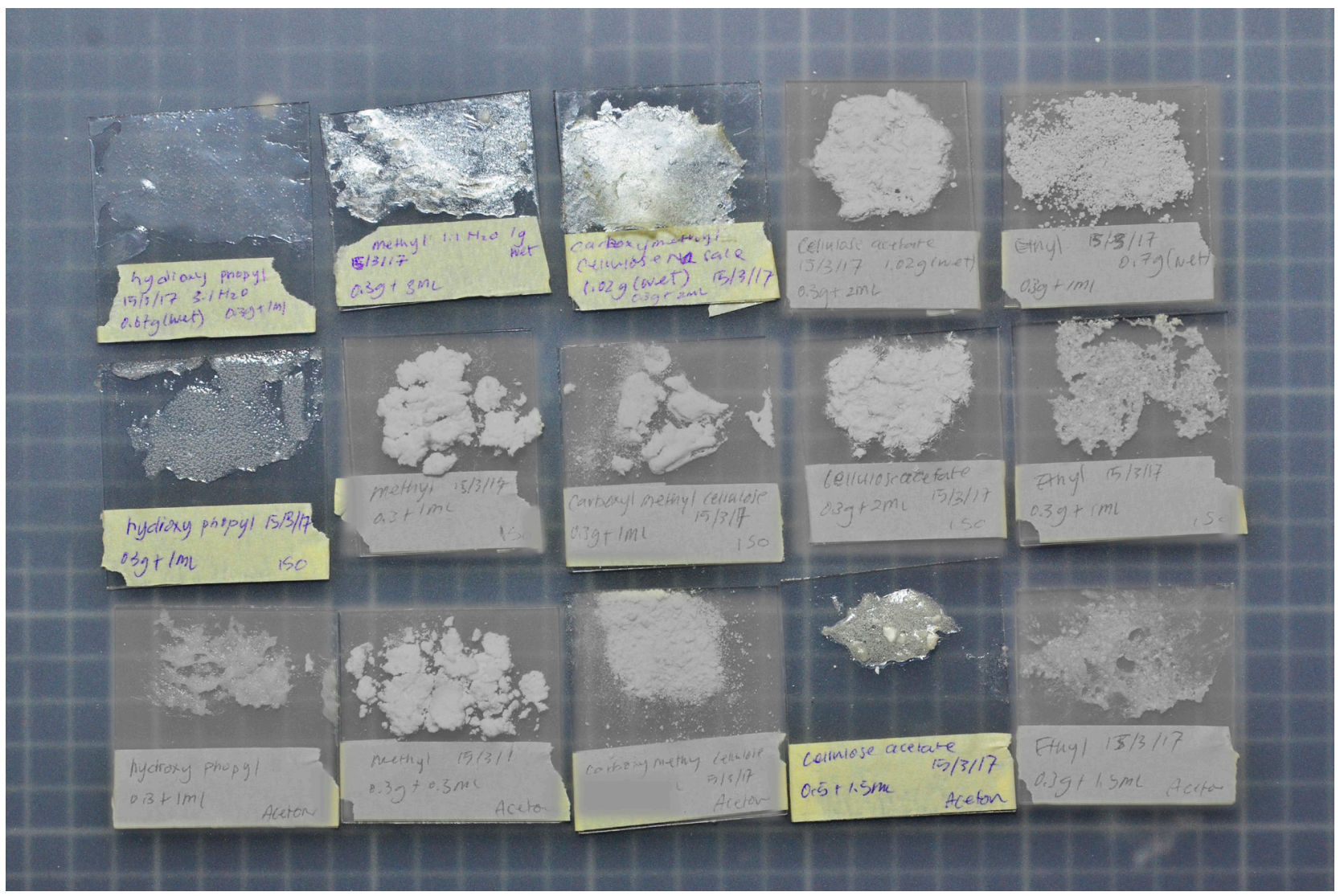

Image 2.25 (Top) Cellulose vs solvent test elimiation

Extrudability - Each type of cellulose was tested against each type of solvent. Among the cellulose-solvent combinations, those that showed a low dissolubility or excessive drying time were eliminated to identify four combinations with the shortest drying time and highest dissolvability for extrudability tests.

Chosen combinations

- $\mathrm{HC}$ with water

- $\mathrm{HC}$ with isopropyl

- CC with water

- CA with acetone

Drying time - All cellulose and solvent combination Completed the dry time test.

Layer retention - The four combinations were tested for layer retention. retention. 


\begin{tabular}{|l|l|}
\hline Samples with Water & Dissolvability \\
\hline Methyl $(0.30 \mathrm{~g})$ & \\
\hline Ethyl $(0.30 \mathrm{~g})$ & Not dissolved \\
\hline Hydroxypropyl $(0.30 \mathrm{~g})$ & \\
\hline Carboxy methyl cellulose $(0.30 \mathrm{~g})$ & \\
\hline Cellulose acetate $(0.30 \mathrm{~g})$ & Not dissolved \\
\hline
\end{tabular}

Table 2.3 (Top) Water and Cellulose

\begin{tabular}{|l|l|}
\hline Samples with Isopropyl & Dissolvability \\
\hline Methyl $(0.30 \mathrm{~g})$ & Not dissolved \\
\hline Ethyl $(0.30 \mathrm{~g})$ & Not dissolved \\
\hline Hydroxypropyl $(0.30 \mathrm{~g})$ & \\
\hline Carboxy methyl cellulose $(0.30 \mathrm{~g})$ & Not dissolved \\
\hline Cellulose acetate $(0.30 \mathrm{~g})$ & Not dissolved \\
\hline
\end{tabular}

Table 2.4 (Top) Isopropyl and Cellulose

\begin{tabular}{|l|l|}
\hline Samples with Acetone & Dissolvability \\
\hline Methyl $(0.30 \mathrm{~g})$ & Not dissolved \\
\hline Ethyl $(0.30 \mathrm{~g})$ & Half dissolved \\
\hline Hydroxypropyl $(0.30 \mathrm{~g})$ & \\
\hline Carboxy methyl cellulose $(0.30 \mathrm{~g})$ & \\
\hline Cellulose acetate $(0.30 \mathrm{~g})$ & Bigger peices not dissolved \\
\hline
\end{tabular}

Table 2.5 (Top) Acetone and Cellulose 
Image 2.26 (Right)

Hydropxypropyl

cellulose with water.

Image 2.27-2.29

(Right) Hydroxy propyl

with water extrusion exploration.

Image 2.30-2.35 (Right) Cellulose acetate with acetone extrusion exploration
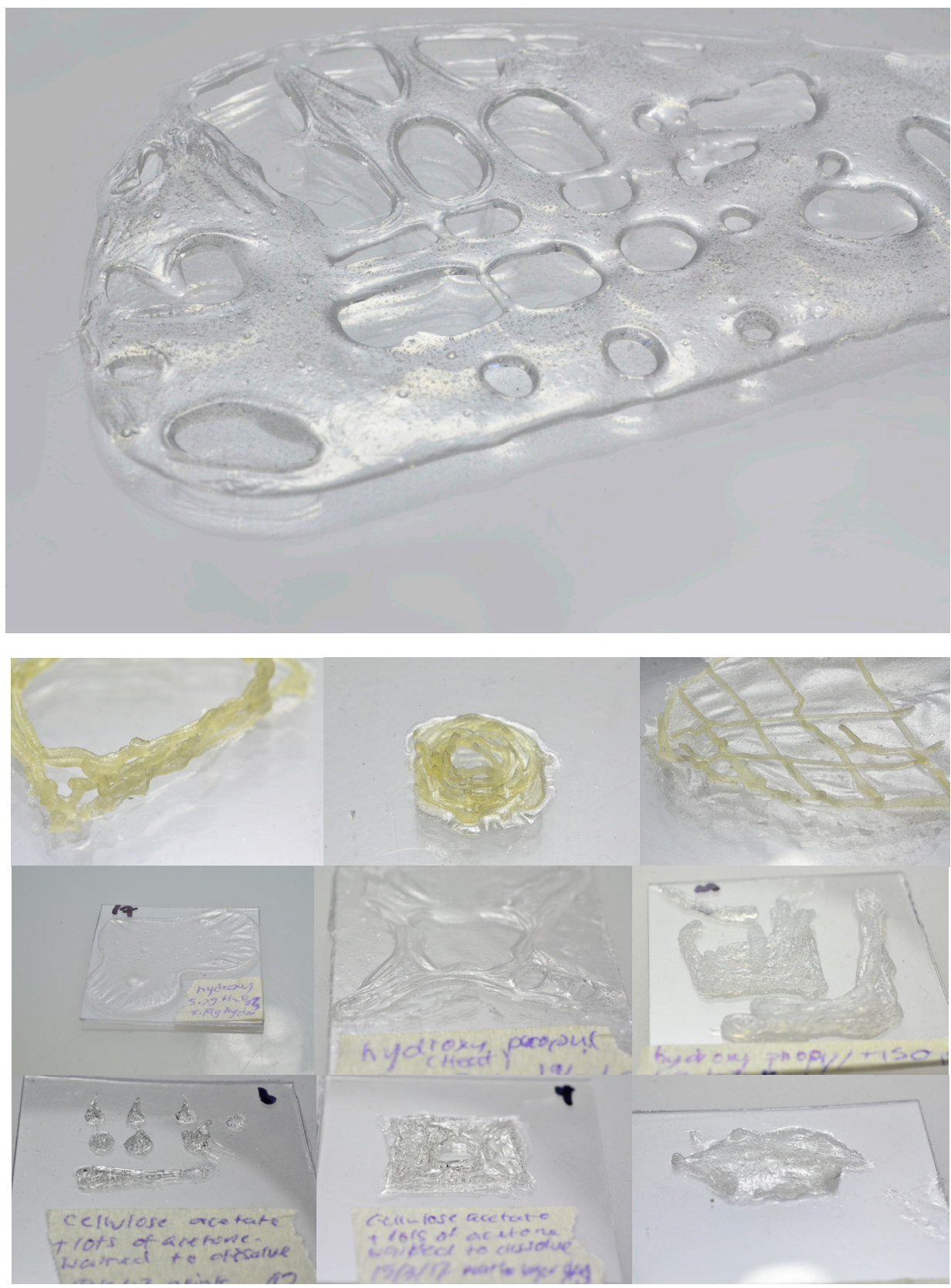


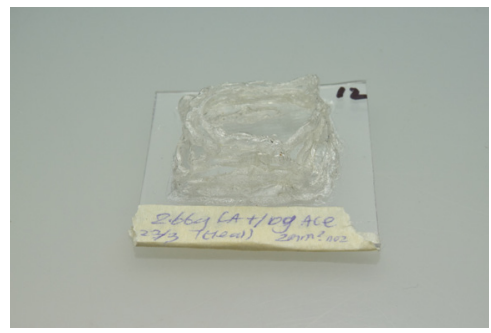

Image 2.36 (Top) Cevllulose acetate extrude with syringe. This test attempt to build height with this material.

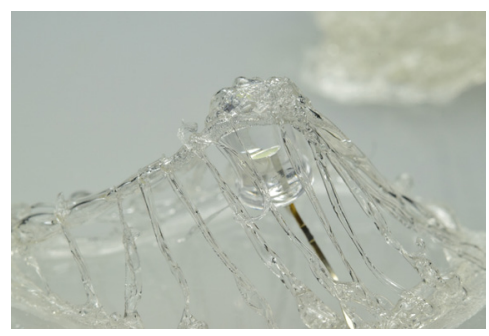

Image 2.39 (Top) Cellulose samples exploring various opportunity of cellulose acetate paste.

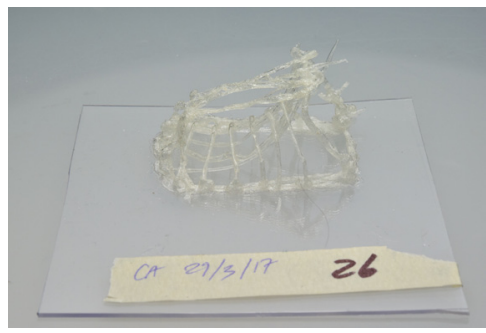

Image 2.37 (Top) Cellulose acetate syringe extrude with heat attempt to freeform.

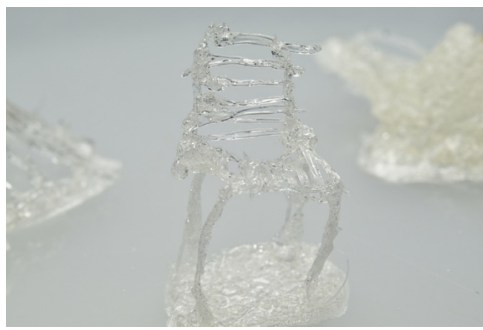

Image 2.40 (Top) Freeform CA with chair

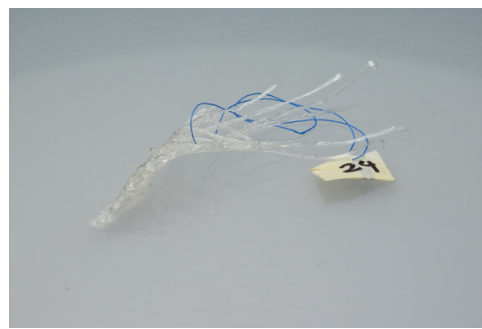

Image 2.38 (Top) Cellulose acetate syringe extrude with heat to create freeform without base.

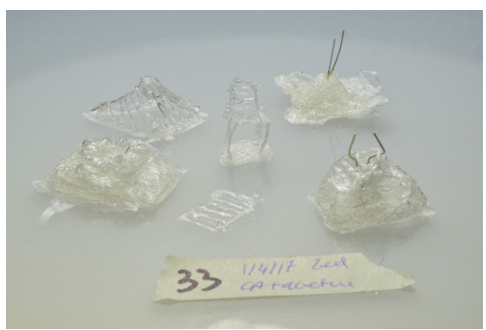

Image 2.41 (Top) Freeform CA with LED embedded.

This group of experimented (above) with freeform extrusion. The heat was added to reduce dry time for freeform. In addition, I attempt to high led embed led inside a print as I acknowledge that the materials are still malleable after extrusion.

I have also attempt to test the extent of CA's ability to create large form. The resulted objects is $120 \mathrm{~mm}$ in diameter.

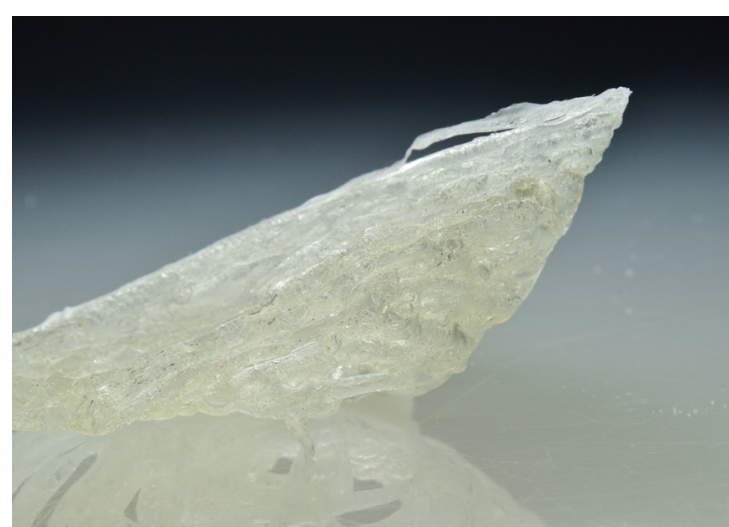

Image 2.42 (Top) Lampshade made out of cellulose acetate.

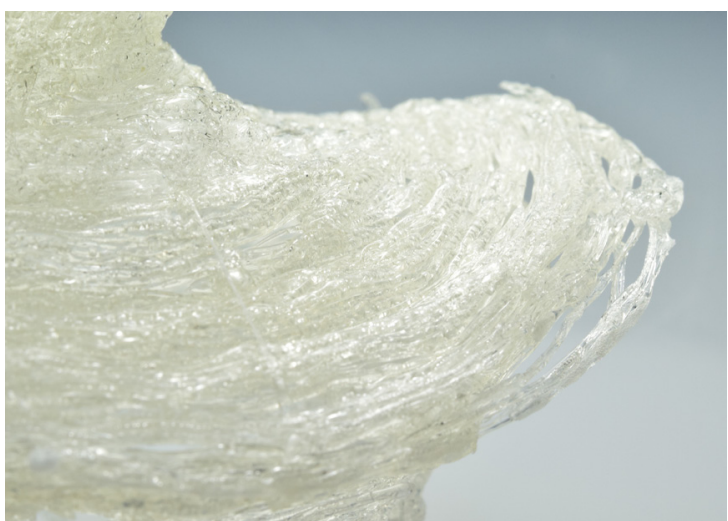

Figure 2.43 (Top) Bowl made out of cellulose acetate. 


\section{Material Results}

\section{PVA Material Exploration Results}

\begin{tabular}{|l|l|l|l|}
\hline & Extrudability & Dry time & Layer retension \\
\hline $\begin{array}{l}\text { PVA-117s } \\
\text { (fine powder) }\end{array}$ & $\begin{array}{l}\text { It has a smooth texture that is } \\
\text { ideal for extrusion. However } \\
\text { high pressure is required for } \\
\text { the high }\end{array}$ & $\begin{array}{l}\text { This material does not dry fast } \\
\text { enough to build layers. Heat } \\
\text { was required to reduce the dry } \\
\text { time. }\end{array}$ & $\begin{array}{l}\text { It can retain layer if 1-2 mins of } \\
\text { heat are applied in } \\
\text { between each layer which } \\
\text { decreases dry time. }\end{array}$ \\
\hline $\begin{array}{l}\text { PVA-205mb } \\
\text { (Granular) }\end{array}$ & $\begin{array}{l}\text { This material does not make a } \\
\text { smooth paste like PVA117s as } \\
\text { it is not in fine powder form. }\end{array}$ & $\begin{array}{l}\text { Similar dry time to PVA-117S. } \\
\text { Heat helps with drying. }\end{array}$ & $\begin{array}{l}\text { It can retain layer if 1-2 mins of } \\
\text { heat are applied in } \\
\text { between each layer which } \\
\text { decreases dry time. }\end{array}$ \\
\hline RS PVA filament & Easy to extrude. & Requires 1 day to fully dry. & $\begin{array}{l}\text { Does not retain layer even } \\
\text { when heat is applied. }\end{array}$ \\
\hline
\end{tabular}

Table 2.6 PVA Material exploration result

PVA generally extrude well, different grades of PVA perform similarly, The biggest influence is the finest of the material. The findings shows that finner materials improve extrdudability.

\section{Strach Material Exploration Results}

\begin{tabular}{|l|l|l|l|}
\hline & Extruability & Dry time & Layer retension \\
\hline Potato Starch & $\begin{array}{l}\text { Unsuccessful due to large } \\
\text { clumping }\end{array}$ & $\begin{array}{l}\text { A thin film required 2-3 days to } \\
\text { fully dry }\end{array}$ & Unable to retain one layer \\
\hline Tapioca Starch & $\begin{array}{l}\text { Unsuccessful due to large } \\
\text { clumping }\end{array}$ & $\begin{array}{l}\text { A thin film required 2-3 days to } \\
\text { fully dry }\end{array}$ & Unable to retain one layer \\
\hline
\end{tabular}

Due to starch in ability to retain layer and extrude, it will not conduct 3D-print test.

Table 2.7 Starch Material exploration result 


\section{Starch Exploration}

Cellulose Exploration Results

\begin{tabular}{|c|c|c|c|}
\hline & Extruability & Dry time & Layer retension \\
\hline $\begin{array}{l}\text { Hydroxypropyl cellulose with } \\
\text { water }\end{array}$ & Good texture & $\begin{array}{l}\text { Dry time was too long ( more } \\
\text { than } 24 \text { hours) }\end{array}$ & $\begin{array}{l}\text { Does not retain layer even } \\
\text { when heat is applied. Did not } \\
\text { retain itself when extruded }\end{array}$ \\
\hline $\begin{array}{l}\text { Hydroxypropyl cellulose with } \\
\text { isopropyl }\end{array}$ & Good texture & $\begin{array}{l}\text { Dry time was too long ( more } \\
\text { than } 24 \text { hours) }\end{array}$ & $\begin{array}{l}\text { Retains layer more than } \\
\text { Hydroxypropyl cellulose with } \\
\text { water.However, the structure } \\
\text { collapse during drying. }\end{array}$ \\
\hline $\begin{array}{l}\text { Carboxymethyl cellulose with } \\
\text { water }\end{array}$ & Moderate & $\begin{array}{l}\text { Few mins for surface to dry and } \\
\text { requires few hours to fully dry. }\end{array}$ & Layers does not stick together \\
\hline Cellulose acetate with acetone & Good texture & Aproxaminately one min. & $\begin{array}{l}\text { With heat, dry time and layer } \\
\text { retention improve. However, } \\
\text { this may improve if the cellulose } \\
\text { acetate was in fine powdered } \\
\text { form. }\end{array}$ \\
\hline
\end{tabular}

Table 2.8 Cellulose Material exploration result

Each type of cellulose perform differently in each test. Each material have it's own characteristic, unlike the variety of PVA exploded.

I explored different derivatives of some popular bio-based materials. After material elimination, PVA205s and CA dissolved in acetone is found to be best match with the material criteria. Therefore, they were used in the 3D-printing experiments. Research for both paste printing of PVA and CA is in it's infancy. There are only a few instance of paste 3D-printing with these materials. Therefore I want to explore and identify possible design application and 3D printed material quality. 


\title{
3D Printing Experiments
}

\author{
Objective 1c - Explore range of form and structure through $3 \mathrm{D}$ printing to find \\ opportunistic 3D print quality.
}

\section{Printer Modification}

CA with acetone was chosen for the 3D print test. As acetone is the solvent of the material, it was reacting with the tube of the Discov3ry. Therefore a Teflon tubing was used in replacement to prevent reaction during printing. 3:1 (acetone: CA) ratio was discovered to best suit the $3 \mathrm{D}$ print setup.

In addition, a nozzle holder was designed and made especially for this printer and dual extruder.

\section{Printer settings}

Firstly, single material CA with acetone 3D paste printing was explored. Here, Flow Rate, Feed rate, Layer height, Filament diameter and Print speed is focused.

\begin{tabular}{|l|l|}
\hline Settings & Influences / Adjustment \\
\hline Flow rate & $\begin{array}{l}\text { Flow rate relates to the speed of the print head movement. The } \\
\text { flow rate cannot be too high as the fluid nature of paste do not cure } \\
\text { instantly, therefore, require time for the layers to adhere to each other }\end{array}$ \\
\hline Feed rate & $\begin{array}{l}\text { Feed rate refers to the speed of extrusion. It influences the volume of } \\
\text { materials that will be extruded. If too much material is extruded, the } \\
\text { paste will clump up and not dry fast enough. }\end{array}$ \\
\hline Layer height & $\begin{array}{l}\text { The layer height influences the adhesion of the material to the print } \\
\text { bed and print layer. }\end{array}$ \\
\hline $\begin{array}{l}\text { Filament } \\
\text { diameter }\end{array}$ & \begin{tabular}{l} 
Filament diameter influence extrusion rate \\
\hline Print speed \\
Print speed needs to be coordinated with extrusion rate. This is usually \\
able to be calculated with thermal extrusion. However as different \\
this settings are required to find the optimal rate.
\end{tabular} \\
\hline
\end{tabular}




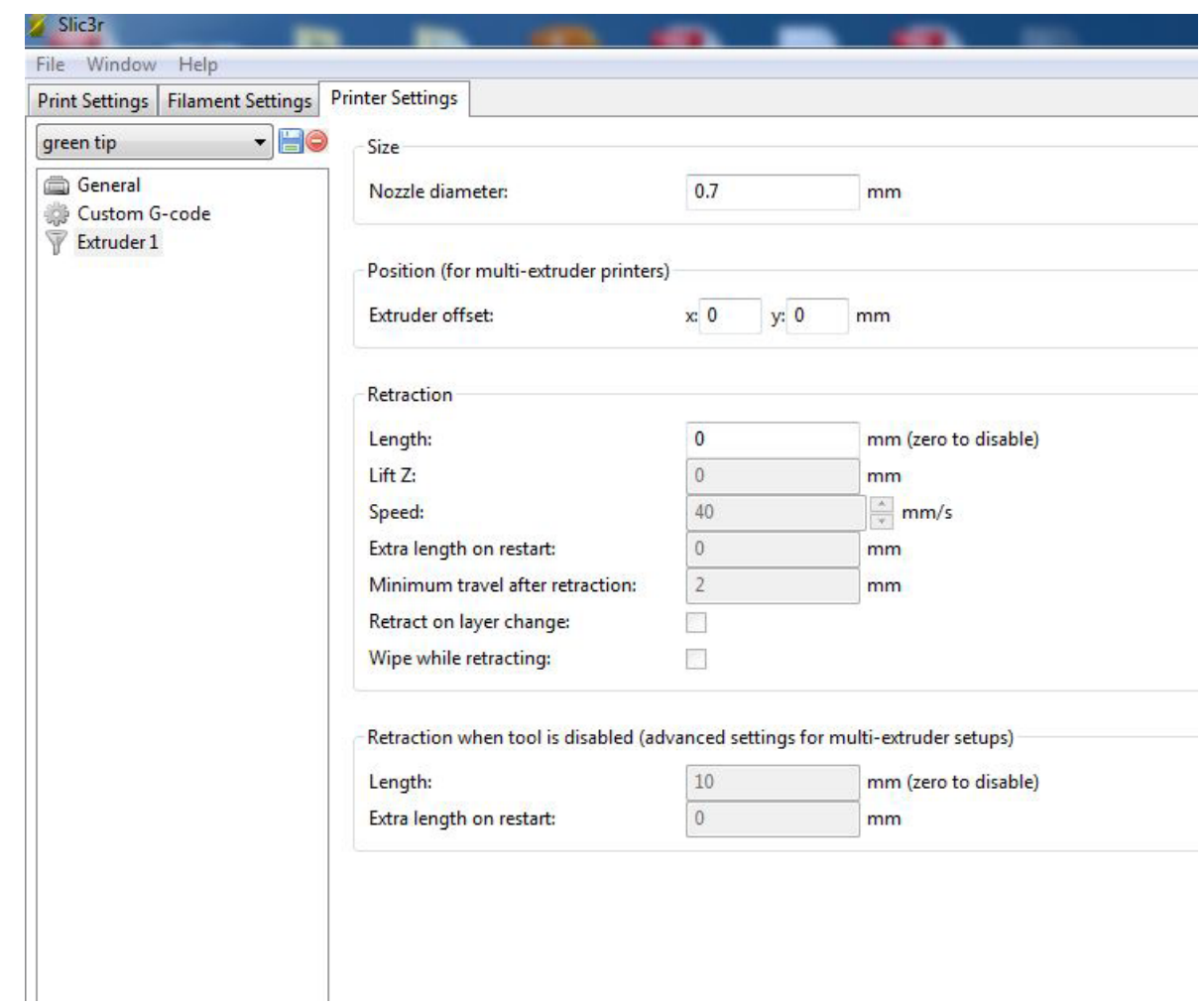

Image 2.44 (Top) Printer setting on Sli3er 


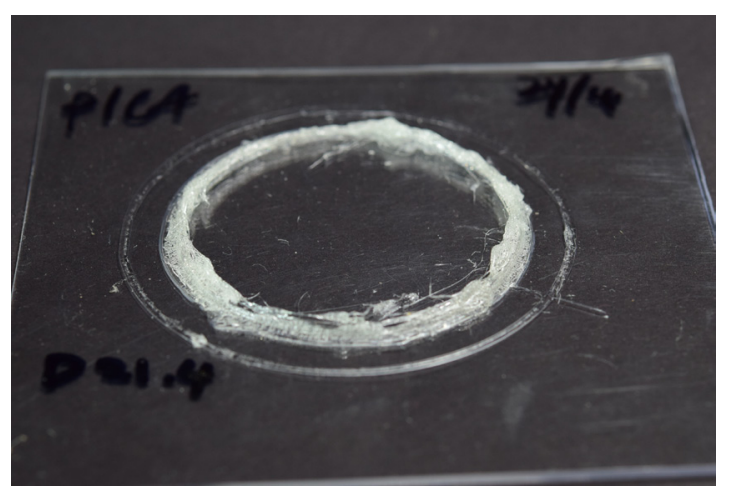

Image 2.45 (Left) - Cellulose

acetate $3 \mathrm{D}$ print test with

filament diameter set as

$21.4 \mathrm{~mm}$ which is the diameter of

the syringe

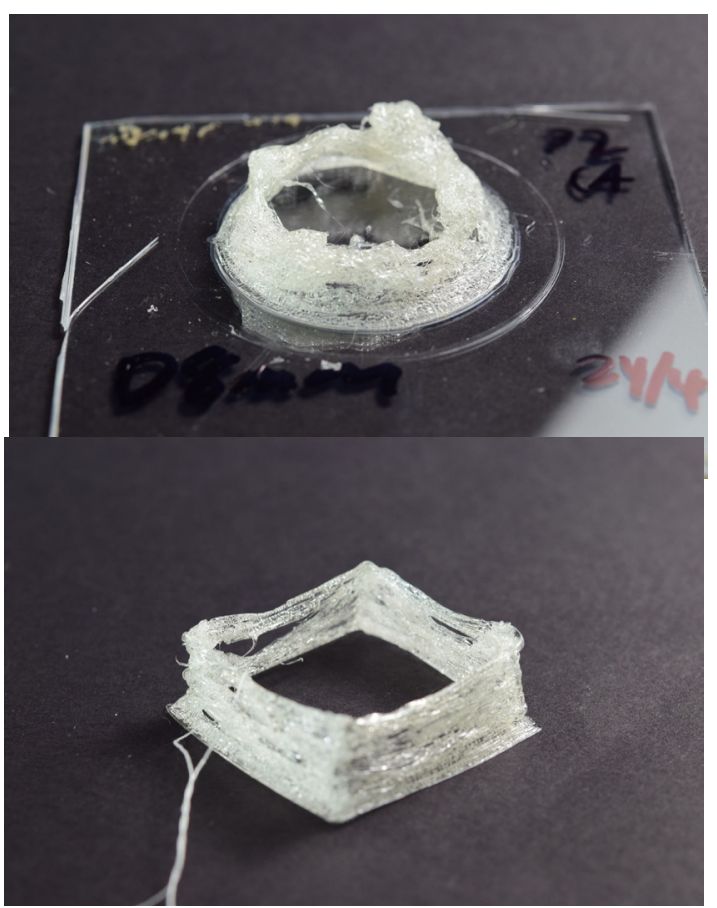

Image 2.46 (Left) - Cellulose

acetate 3D print test with

filament diameter set as $8 \mathrm{~mm}$.

Image 2.47 (Left) Cellulose

acetate $3 d$ print test cube shell. 
Design to Degrade

Image 2.48 (Full page) 3D paste printing multiple CA cube tappering

upwards.

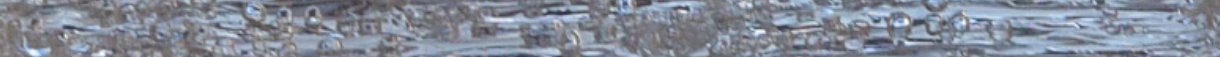

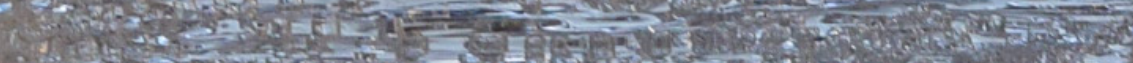

- 5 -

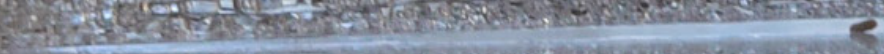

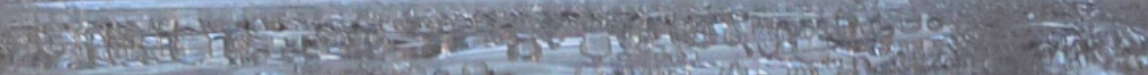

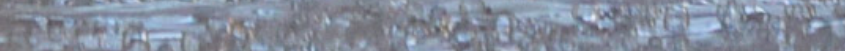

to

(5)

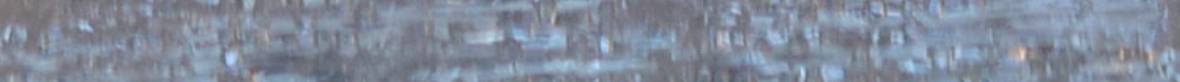

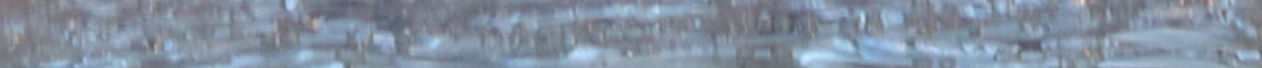

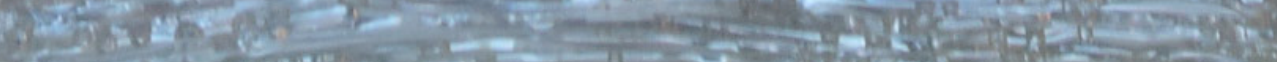





\section{Printing Settings}

A various print setting was explored to find optimal printer setting including:

- Seam alignment - random/ nearest/ aligned

- Printing multiple objects at once $-2 / 3 / 4$

- fan / no fan/ pause to dry

- Heat and no heat

- Nozzle size

- Layer height

- Solid vs shell

These factors influence the amount of material extruded and speed of printing. In thermal FDM printing with common materials such as ABS or PLA, these factors are provided or could be calculated. However for paste extrusion, these calculations are a guild and require alteration. Therefore this section will examine and determine the most suitable print setting with trial and error.
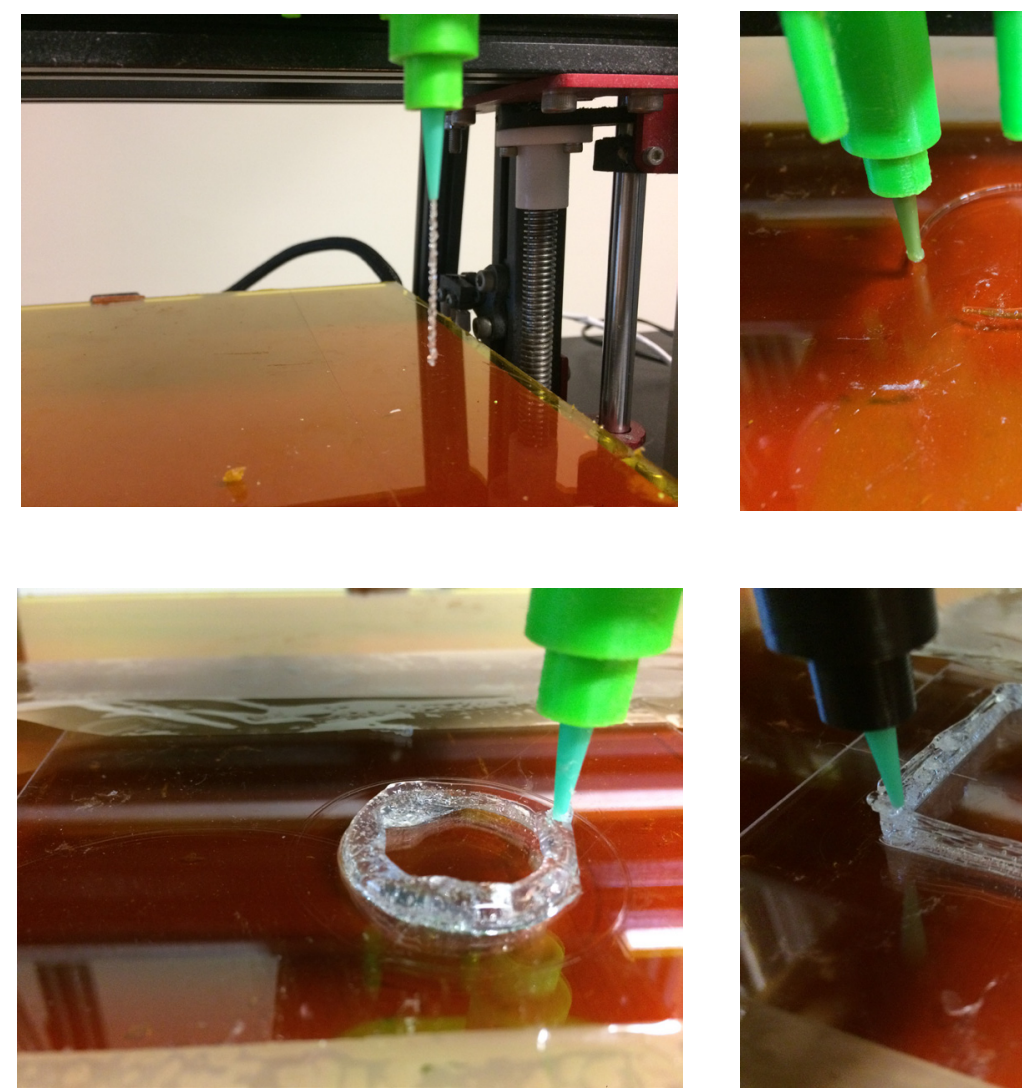

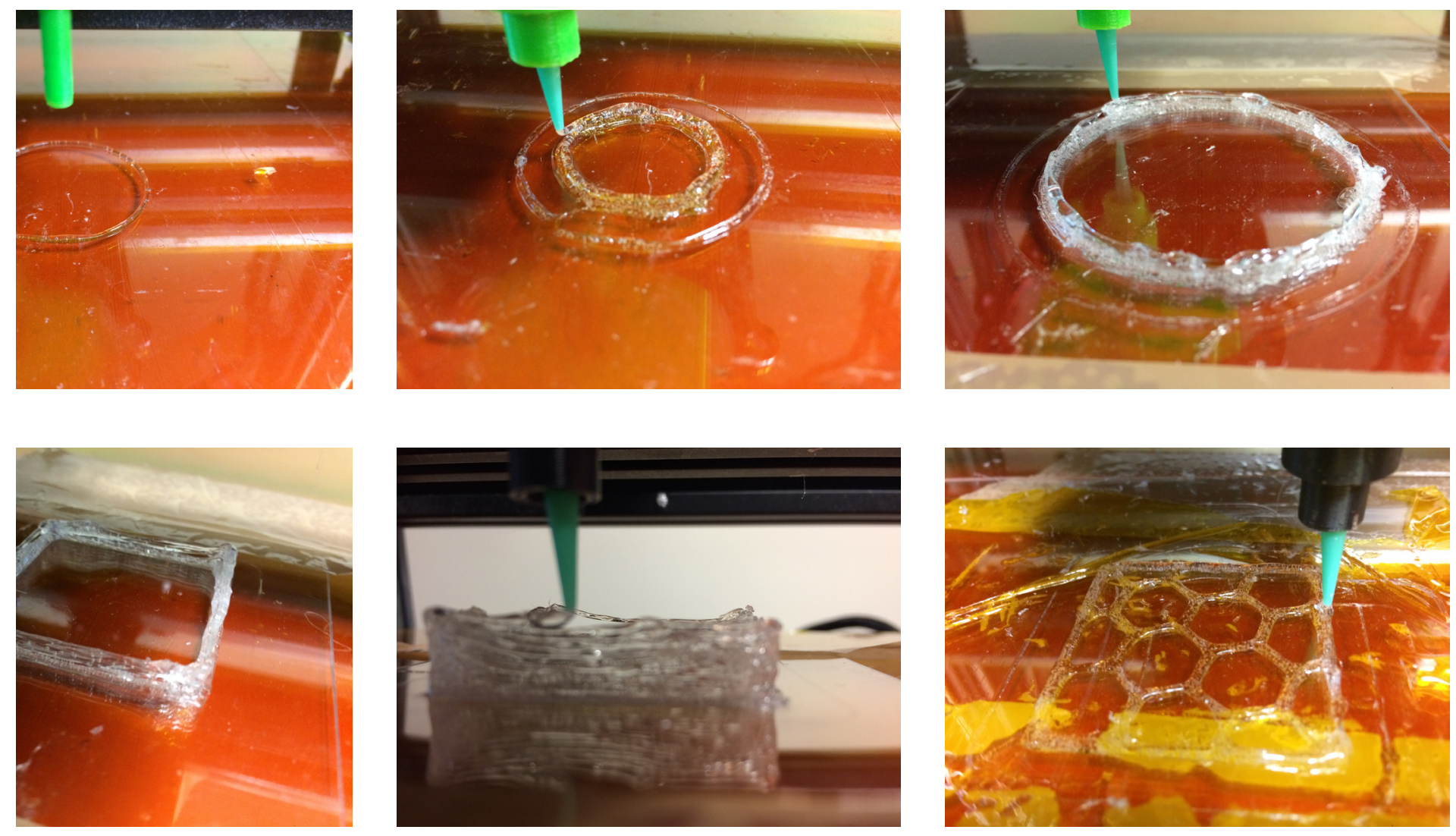

Image 2.49-2.56 (all above) Cellulose acetate initial print test. These initial printer test, experiments with various printer setting to find the optimal settings for aqueous cellulose acetae. 

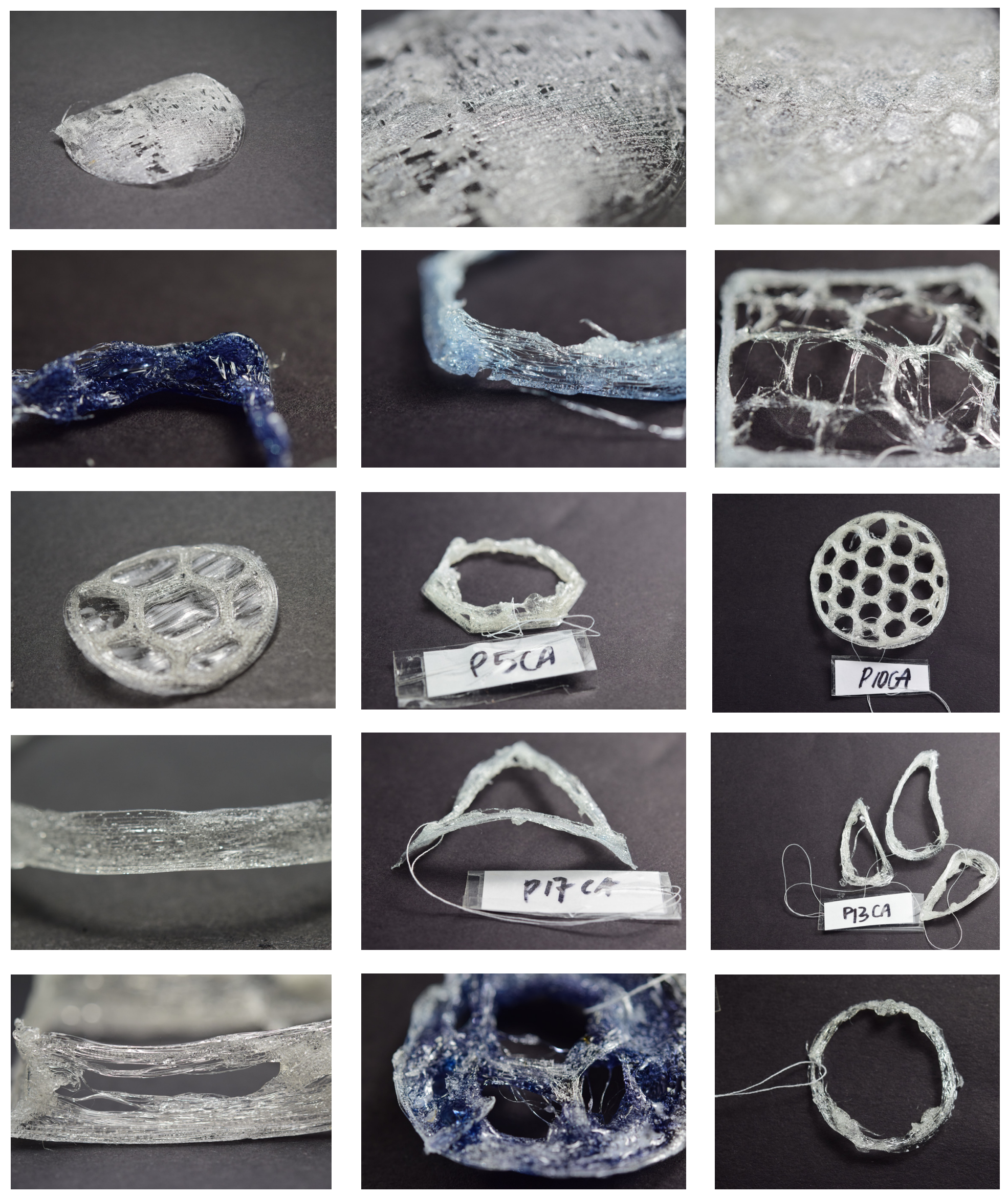

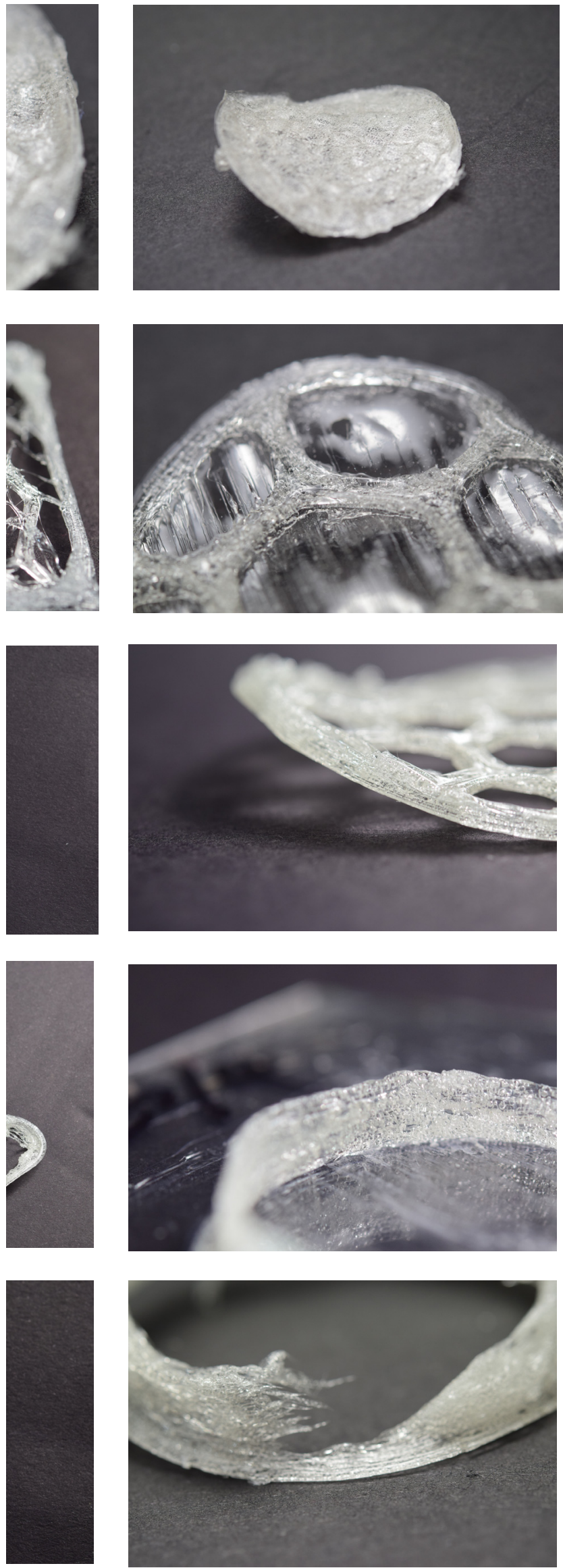

Image caption arrange from left to right, top to down.

Image 2.57-2.58 - Fail solid cylinder cellulose acetate print.

Image 2.59 - 2.60 - First successfull cellulose acetate 3D print test cube in shell setting. Image 2.61 - 2.62 - Cellulose acetate 3D printed hexagon in shell setting failed. Tinted with small amout of dye.

Image 2.63 - Cellulose acetate 3D printed cube in shell setting failed.

Image 2.64-65 - Cellulose acetate 3D printed cylinder with honeycome infill. Image 2.66 - Cellulose acetate 3d printed hexagon in shell setting.

Image 2.67 - Cellulose acetate 3D print cylinder with 50\% honeycomb infill.

Image 2.68 - Cellulose acetate 3D print cylinder with 50\% honeycomb infill shrink and lifted.

Image 2.69 - Print layer merged together.

Image 2.69 - Cellulose acetate 3D print pyrimid in shell, shrink and lifted.

Image 2.70 - Cellulose acetate 3D print of curved form.

Image 2.71 - 3D print curve objects failed after $7 \mathrm{~mm}$ height.

Image 2.72 - Small cellulose acetate cylinder with infill, tinted.

Image 2.73 - Failed cellulose acetate cube print.

Image 2.74 - Small cylinder hexagon fill with dye.

Image 2.75-2.76 - Cellulose acetate 3D printed cylinder failed. One section of a layer did not adhere therefore lead to layers after it to miss and created a void. 


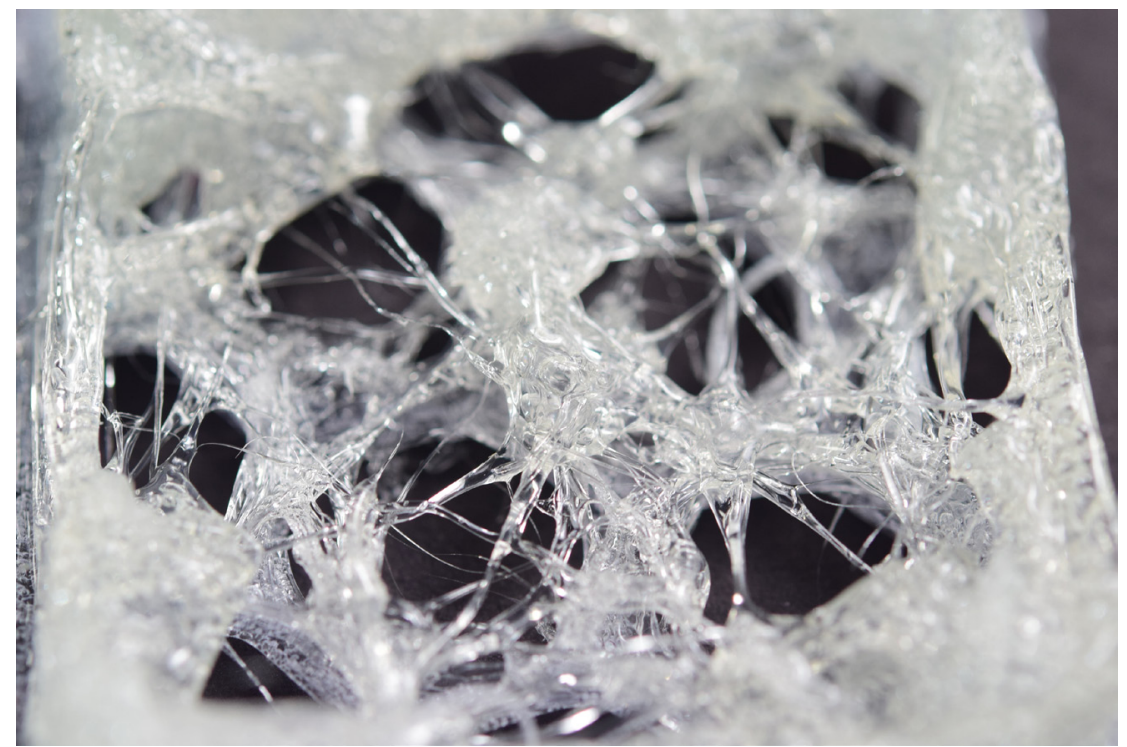

Image 2.77 (left) Cellulose acetate 3D

printing cube with infill. The infill print

speed was too fast therefore caused

interesting web-like structure.

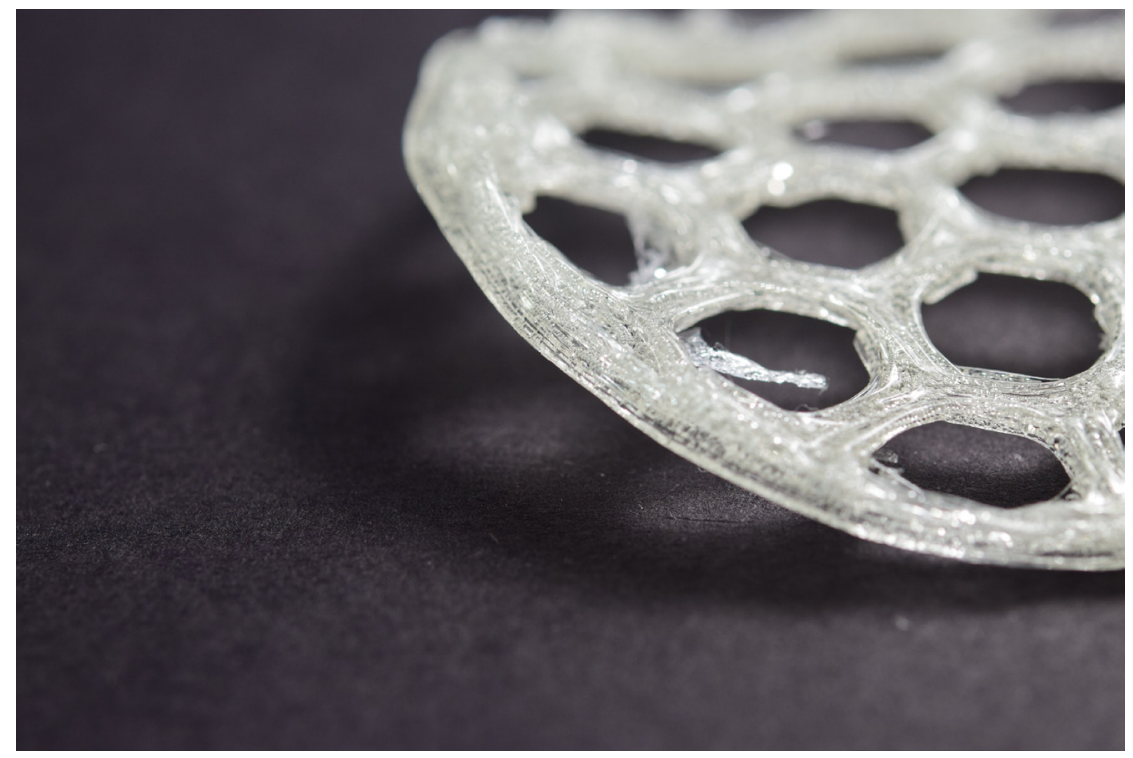

Image 2.78 (Left) Cellulose

acetate 3D print cylinder with 50\%

honeycomb infill shrink and lifted.

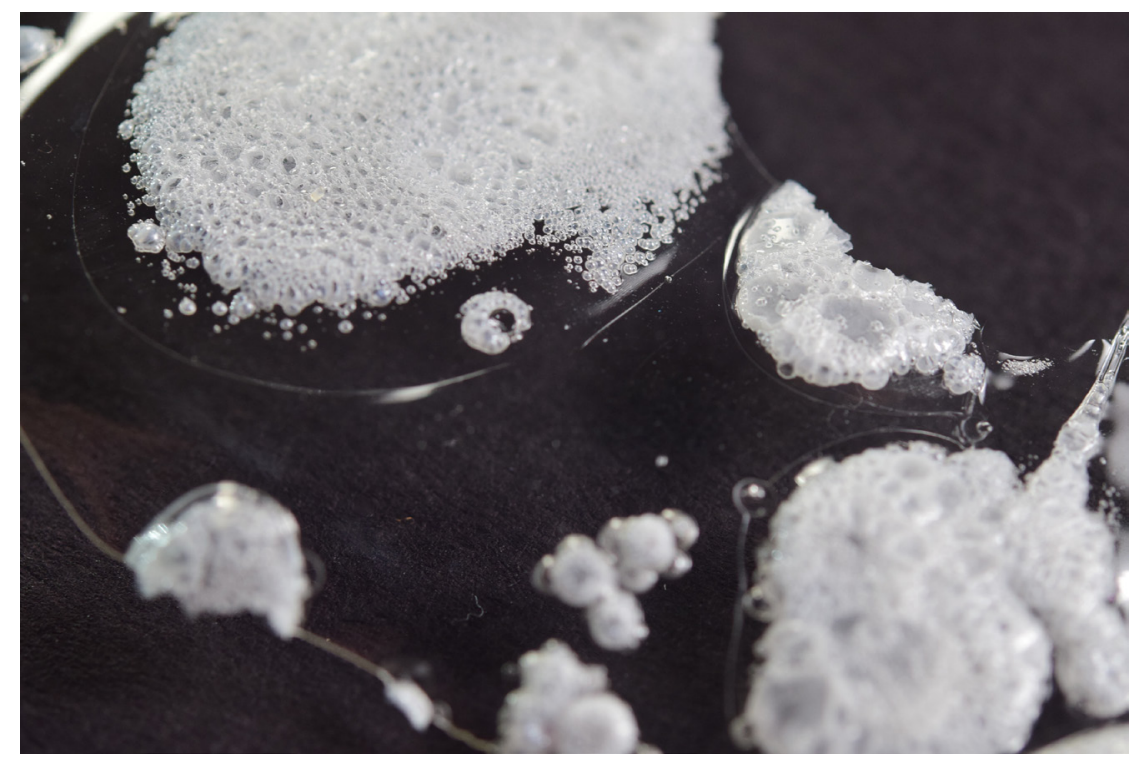

Image 2.79 (Left) Over heated

cellulose acetate, ubble and foam up. 
Image 2.80 (Right) Cellulose acetate $3 \mathrm{D}$ print cylinder with $50 \%$ honeycomb infill close up. The infills printed better when the size of the model was

bigger, as there is more time for each layer to dry.

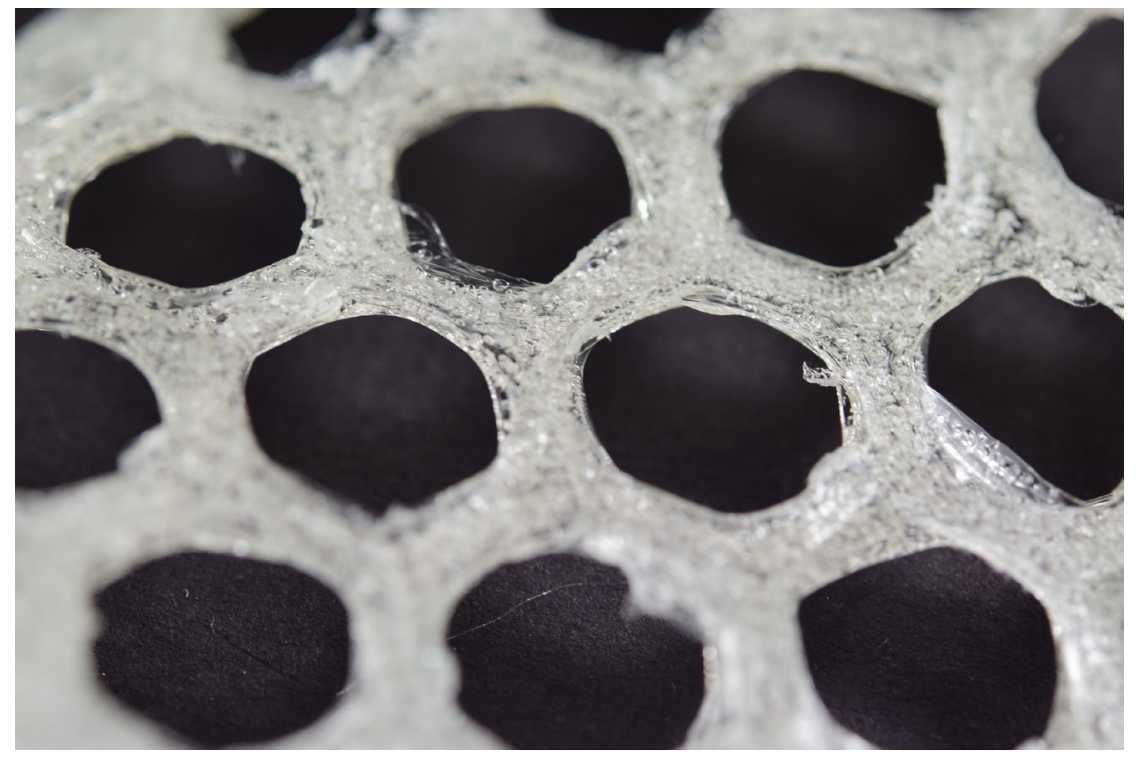

Image 2.81 (Right) Cellulose acetate 3D print cylinder with good layer adheasion

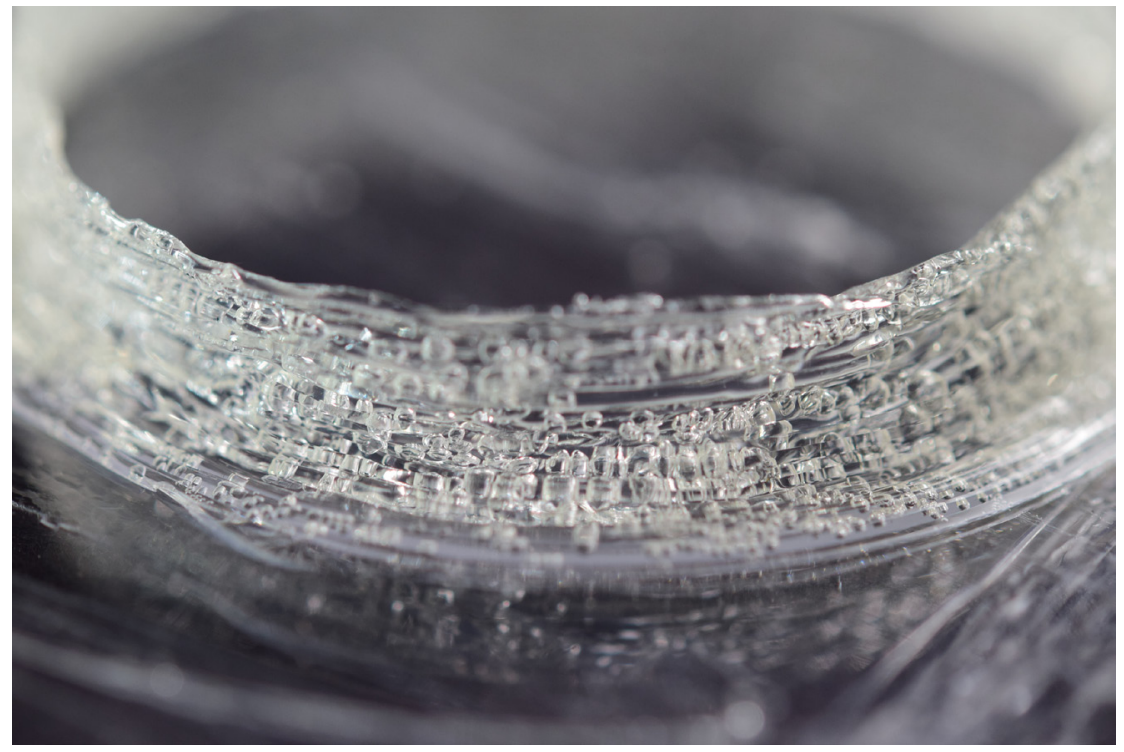

Image 2.82 Cellulose acetate 3D print hexagon corner close up. Corners are usually a challenge to print with cellulose acetate in aqueous form.

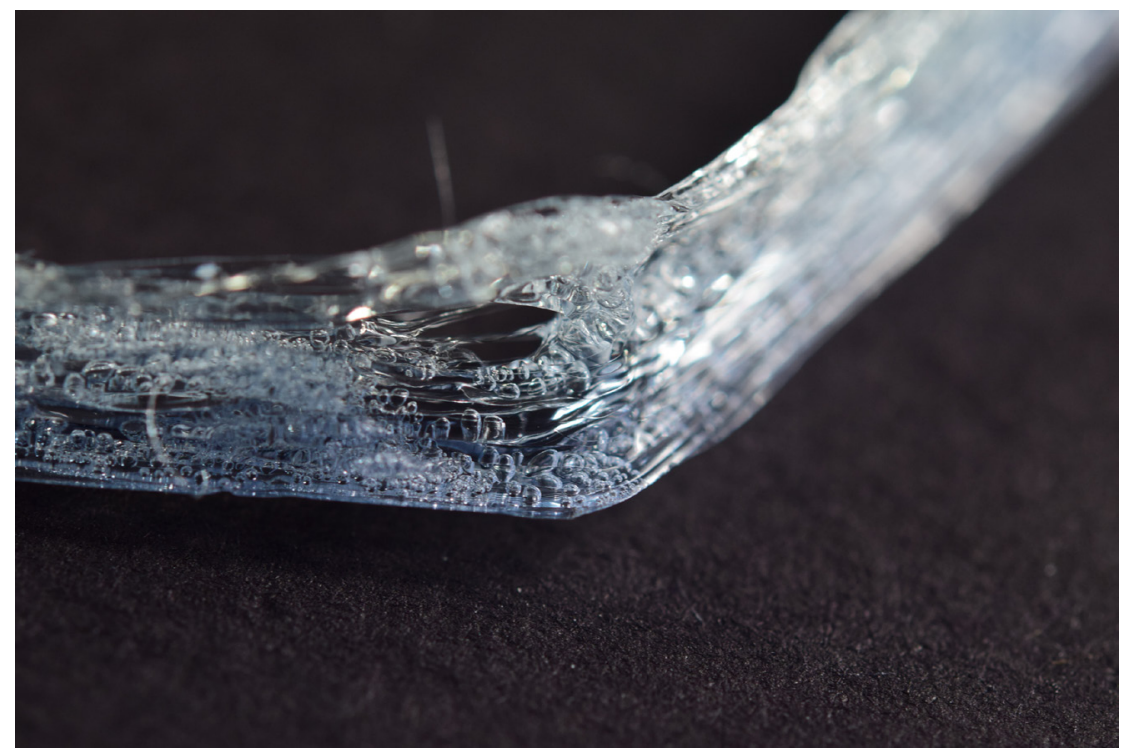




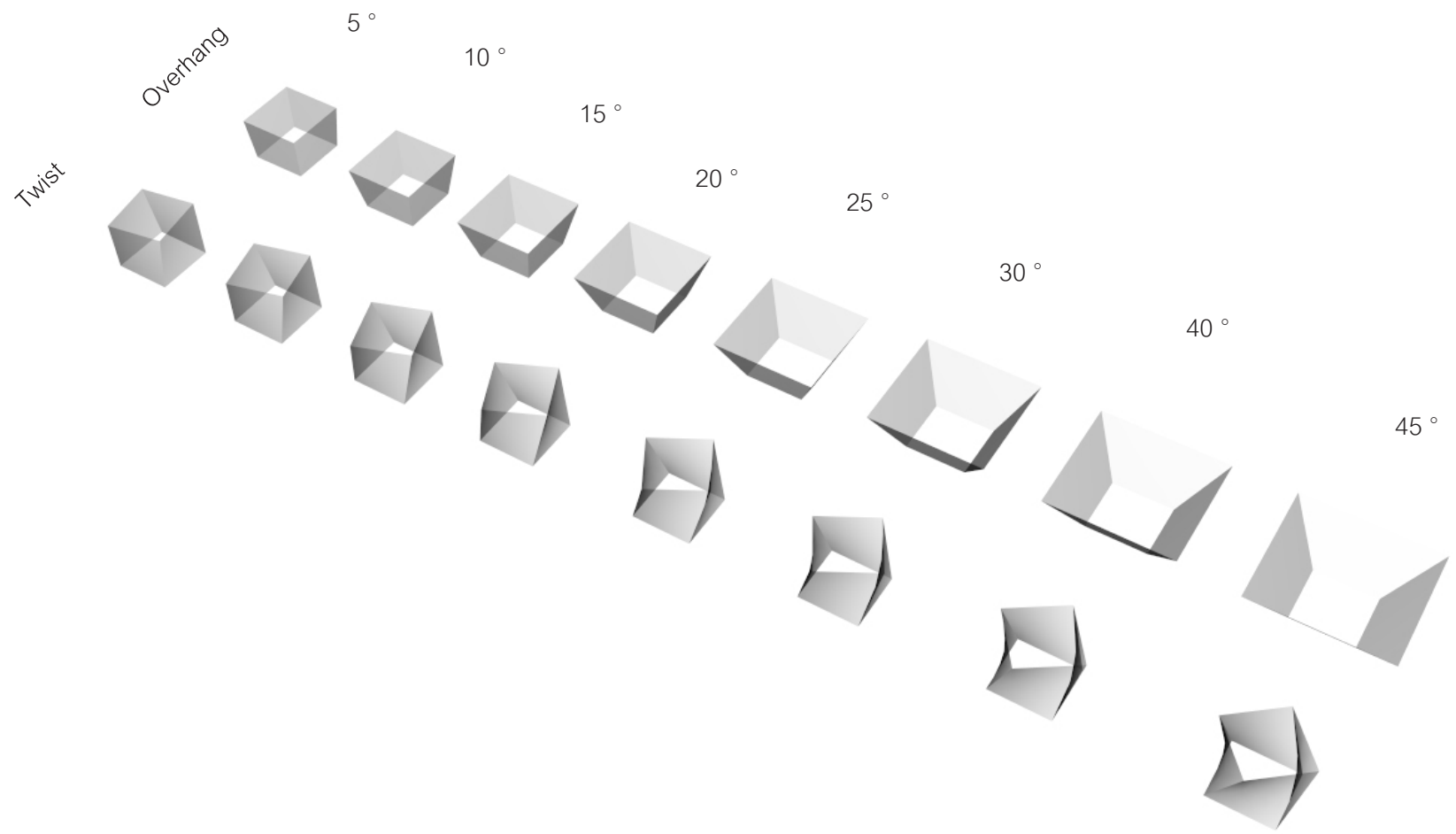

This series of test aims to test the ability of aqueous cellulose to perform overhanging/ selfsupporting structure via $3 \mathrm{D}$ printing.

The results show that cellulose is not a very good material to the $3 \mathrm{D}$ print self-supporting structure as the material does not dry instantly and do not perform high precision. 

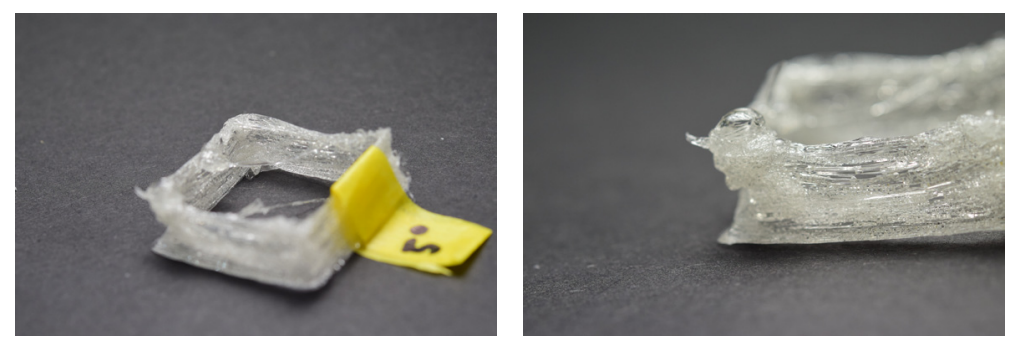

Image 2.83 - 2.84 (left) 5 degree tappered square.

The printer managed to

create 5 degree tappering however it wasn't too good

as the printer can't print in such high percision.
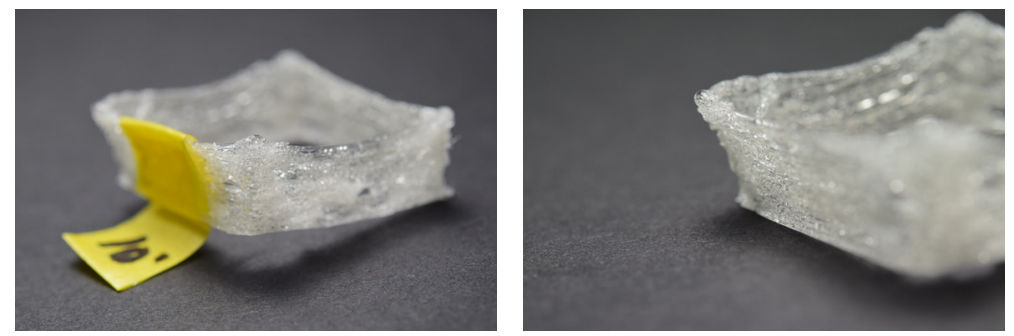

Image 2.85-2.86 (Left)10

degree tappered square.

10 degree tappered

worked the best. The

angle wasnt too big nor

too small for the printer to handle.
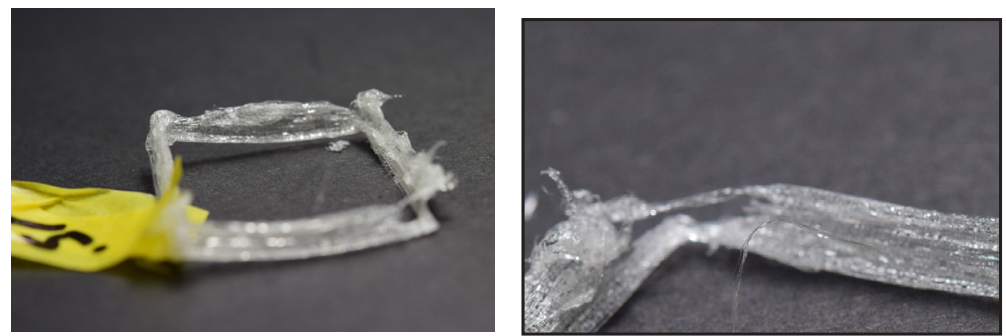

Image 2.87-2.88 (left) 15 degree tappered square. 15 degree tappered

didn't work out quite well. Possibily due to layer not able to sit on top of each other.
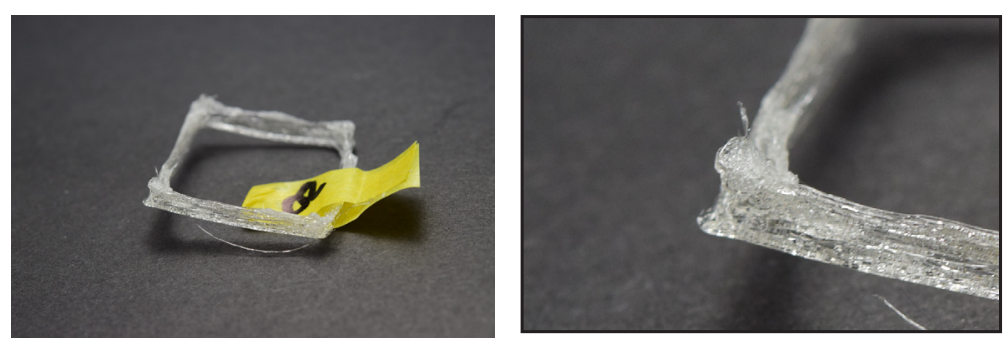

Image 2.89-2.90 (left)20 degree tappered square. Again building $Z$ height

was a problem for

tappering test.
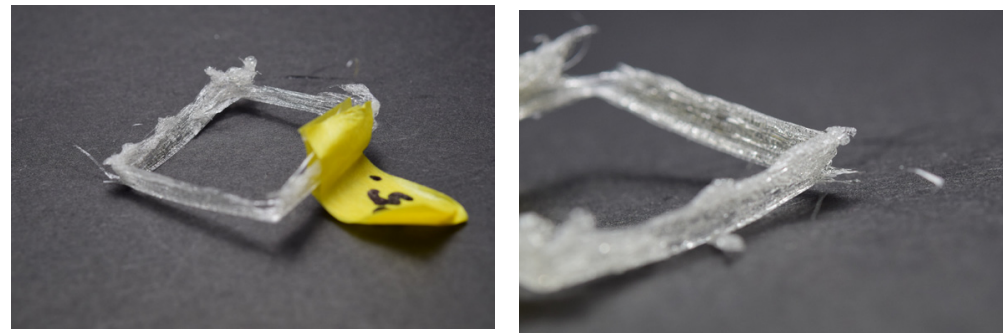

Image 2.91-2.92 (Left) 25 degree tappered square.

This degree seems to be worse and started to miss layers every early on. 


\section{Twisit}

This series of test aims to test the ability of aqueous cellulose to perform twisted overhanging structure via 3D printing.

As a smaller degree of twist didn't show any difference due to the imprecision of this material and printer. The twist test samples started at 20 degrees and continued with an increment of 10 degrees.

The results were surprisingly better than predicted. From the results of the tapered overhang test, it was predicted that cellulose would not perform well in the twisted test. However there was an obvious twist that can be seen from the top view. Yet $Z$ height was still a problem.
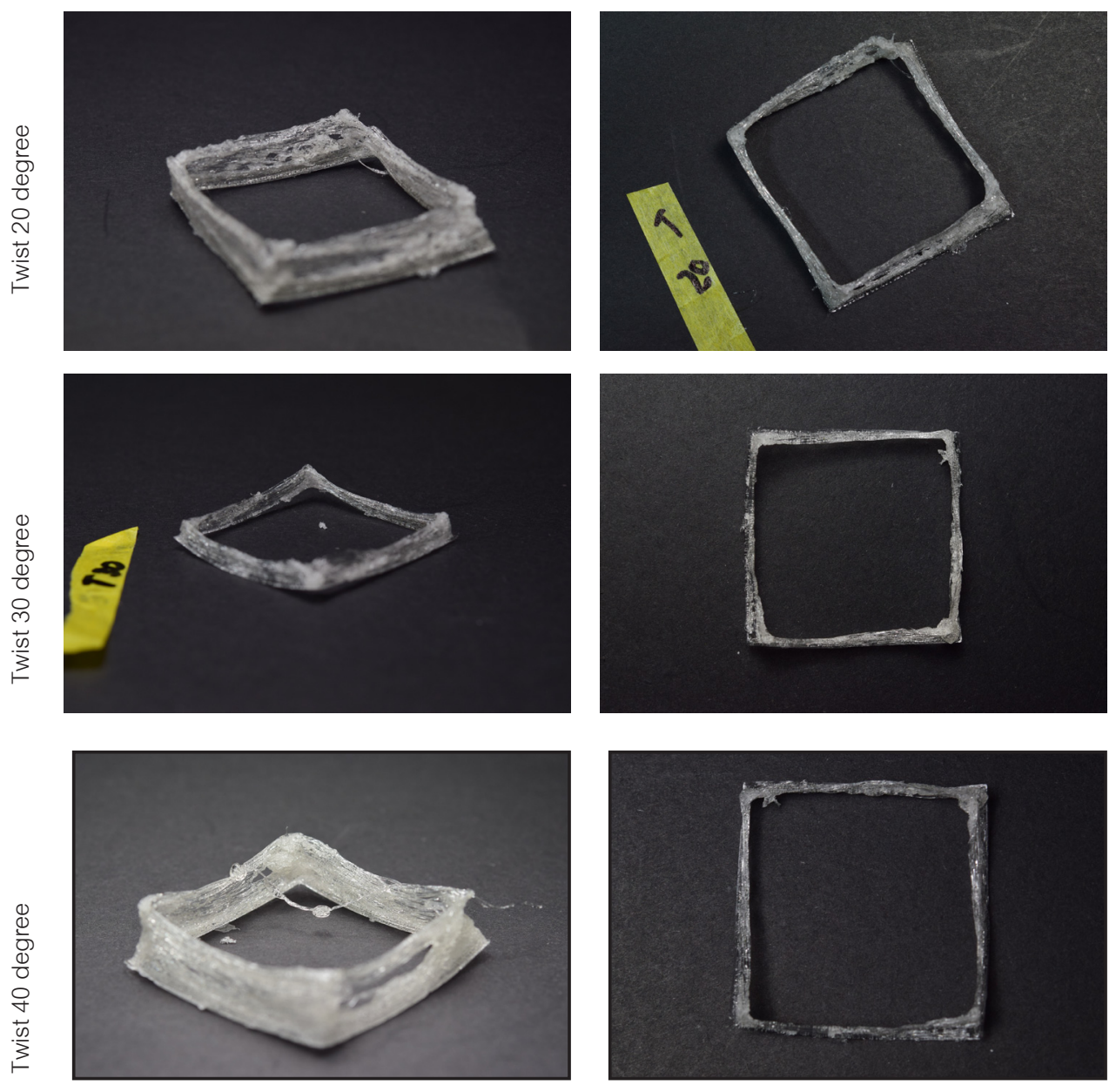

Image 2.93 - 2.98 (Top) 3D print CA test 


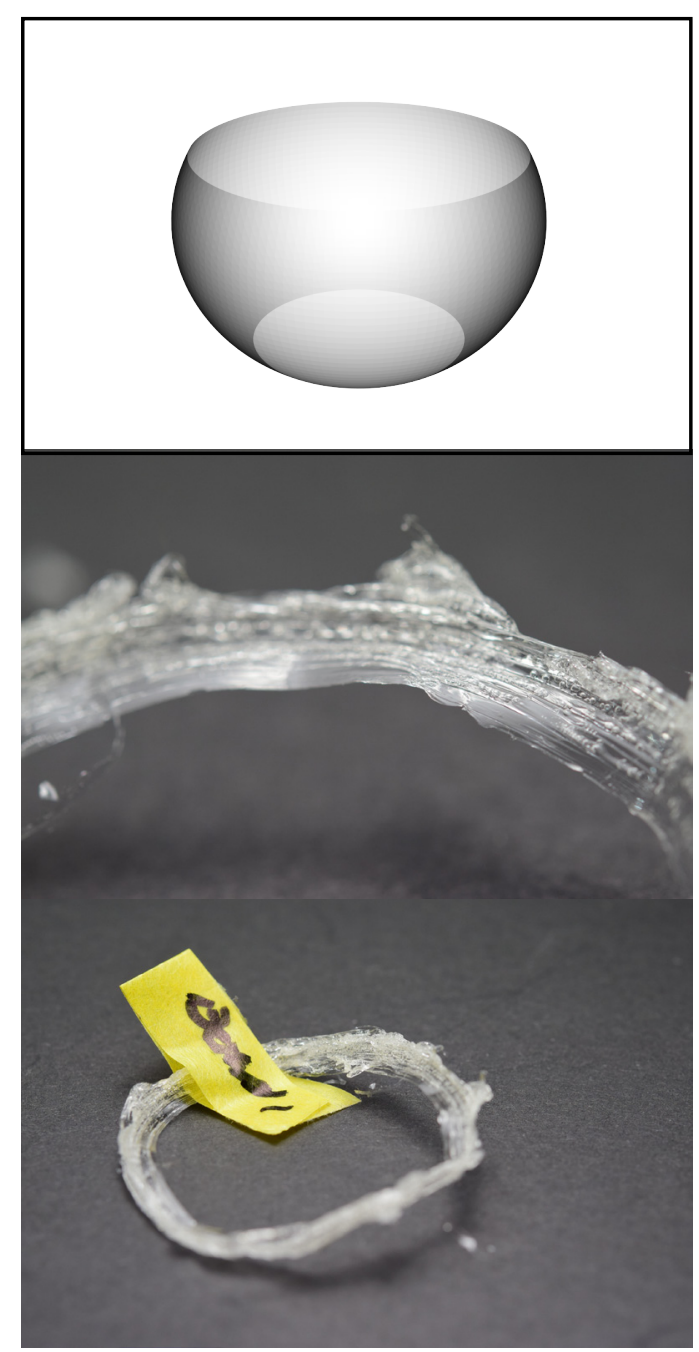

Image 2.99 (Top) attempt to 3D print a bowl shape, however due to the print material being a paste, the layers do not support overhanging layers as well as thermal FDM printing. 


\section{D Properties}

3D printing of CA accompanies a significant extent of shrinkage, and it is usually considered a disadvantage for precise production. Scientists have trialled various techniques to minimise shrinkage. However, here shrinkage is regarded as a unique quality, and an opportunity instead of a disadvantage. A high shrink rate aligns with the main theme of transforming people's perceptions about typically unwanted attributes. Therefore the next series of tests aims to investigate and control shrinkage for maximum benefit.

A series of basic tests were conducted, including:

Time before peeling - The previous test suggested the time before removing print influences the rate of shrinkage. Therefore this first test aims to determine the optimal time to remove print for the best shrinkage. Length versus curling - This test aims to determine whether the length of print will influence the way the material curls.

Amount of layers - This test aims to determine how a different number of layers can provide different curling strength and effects.

Shape test

(a) Basic shapes - to determine how different shapes will react to the shrinkage.

(b) Shapes with one line - to determine if an additional line can control the shrink direction

(c) Shapes with half-fill - to determine if a bigger area of thicker material can have a better control of the curling.

(d) Shapes with two lines - to determine if multiple lines can create different effects.

Advance exploration of possible interesting ways to use shrinkage. 

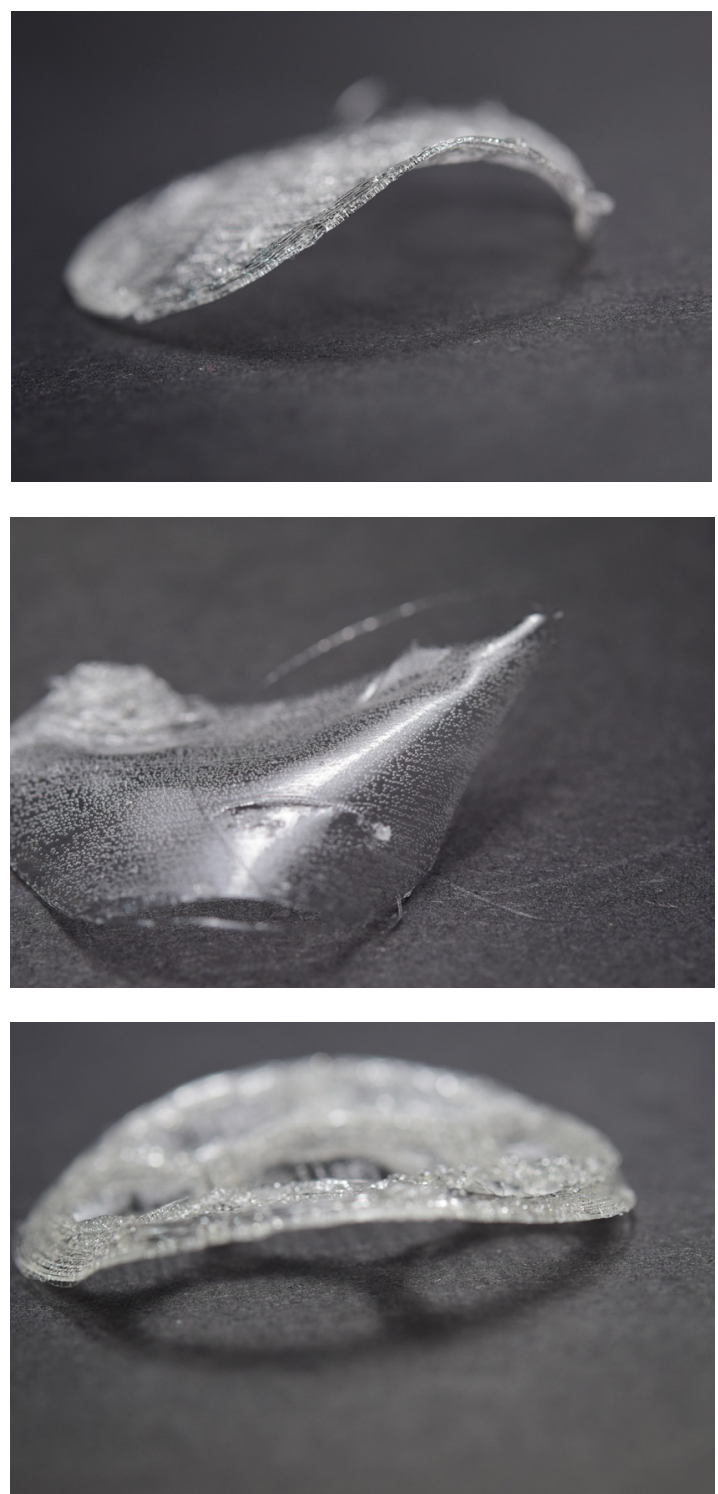

Image 2.99 - 2.101 (Above) Evidence of curling caused by shrinkage creating beautiful organic forms. 


\section{Basic Shrink test}

This series of tests is all one layer $0.3 \mathrm{~mm}$ thick unless stated. In addition, after the first series of tests (time before removal) it was found that 10 mins before removal provided the best results. Therefore the following test were all removed from the bed approximately 10 mins after print ended. This series of tests is all one layer $0.3 \mathrm{~mm}$ thick unless stated. In addition, after the first series of tests (time before removal) it was found that 10 mins before removal provided the best results. Therefore the following test were all removed from the bed approximately 10 mins after print ended.

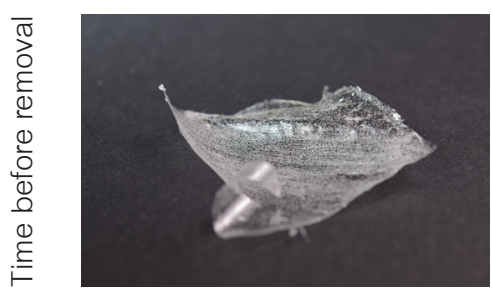

Test
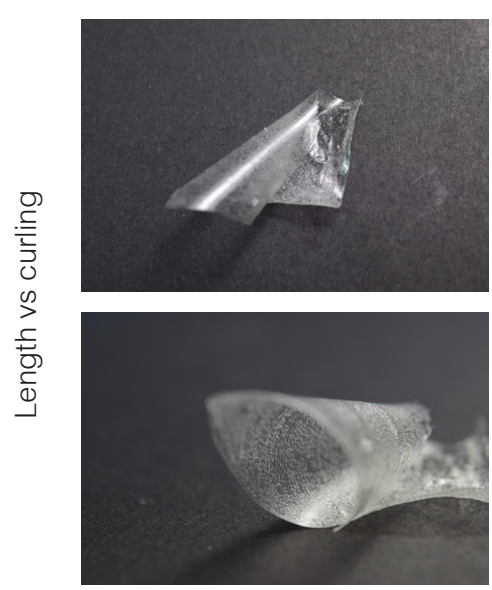

40 length

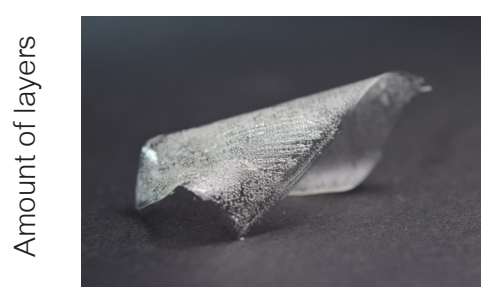

2layer

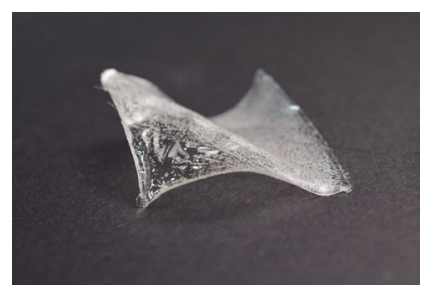

1 mins
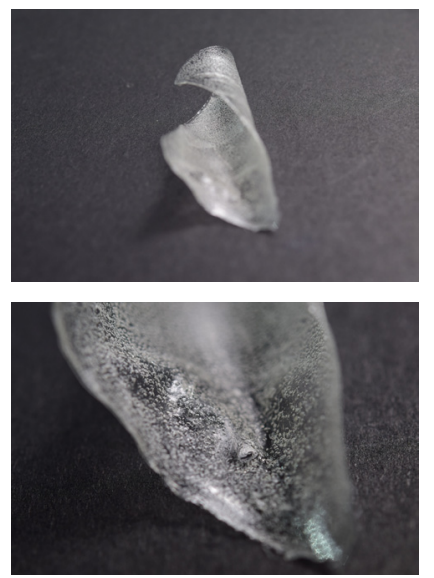

50 length

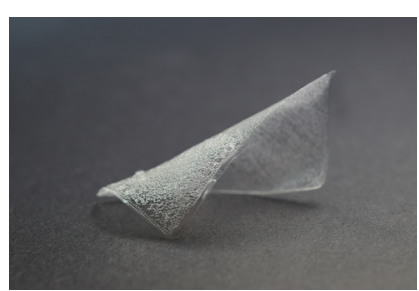

3 layer

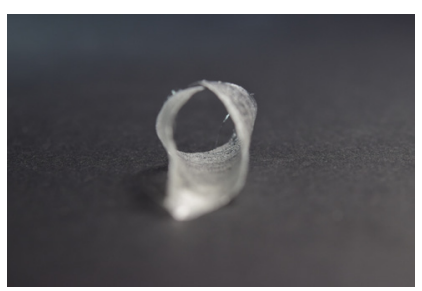

5 mins
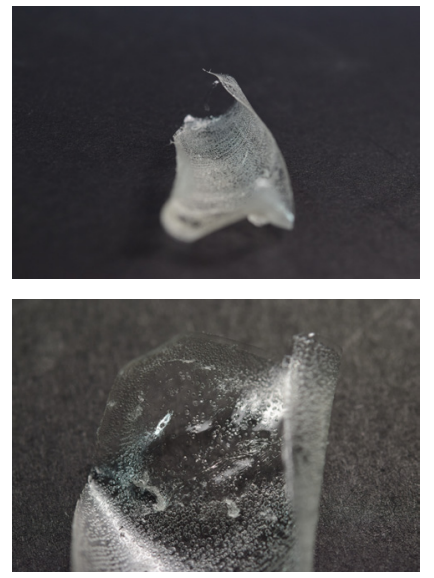

60 length

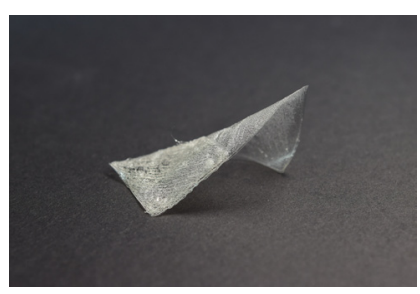

4 layer

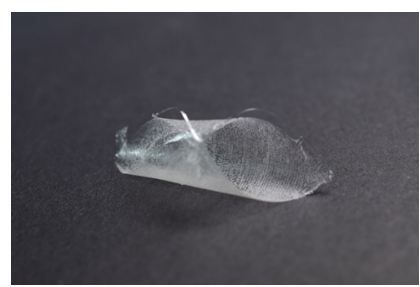

10 mins

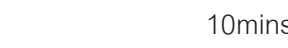

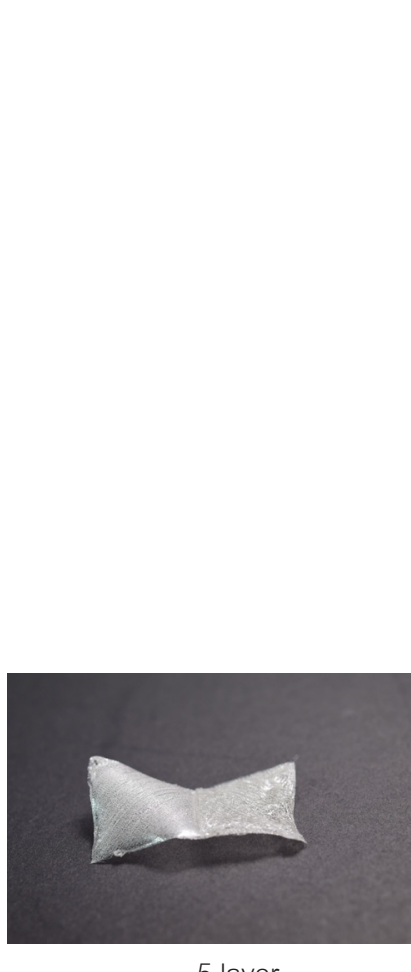

5 layer

Image 2.102 - 2.116 (Above group) Curling basic shrink test.

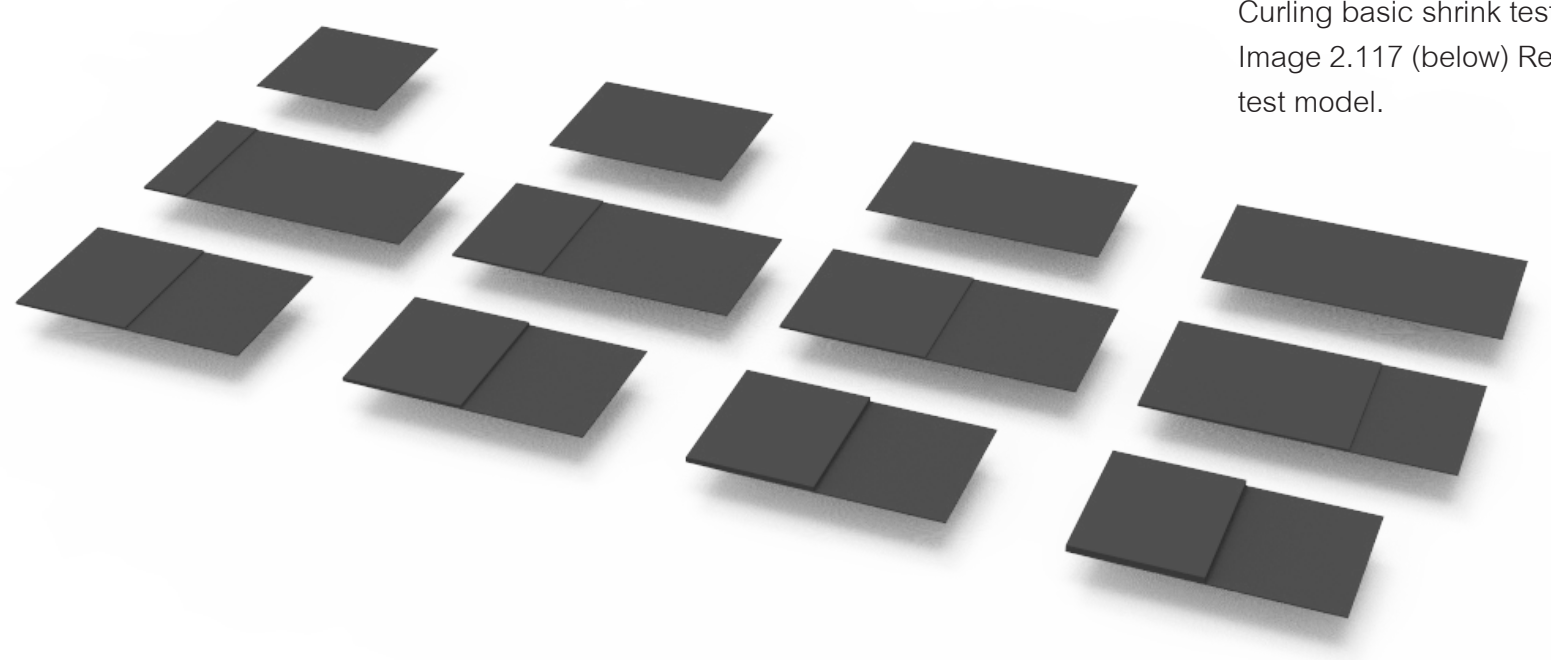




\section{Shape test}

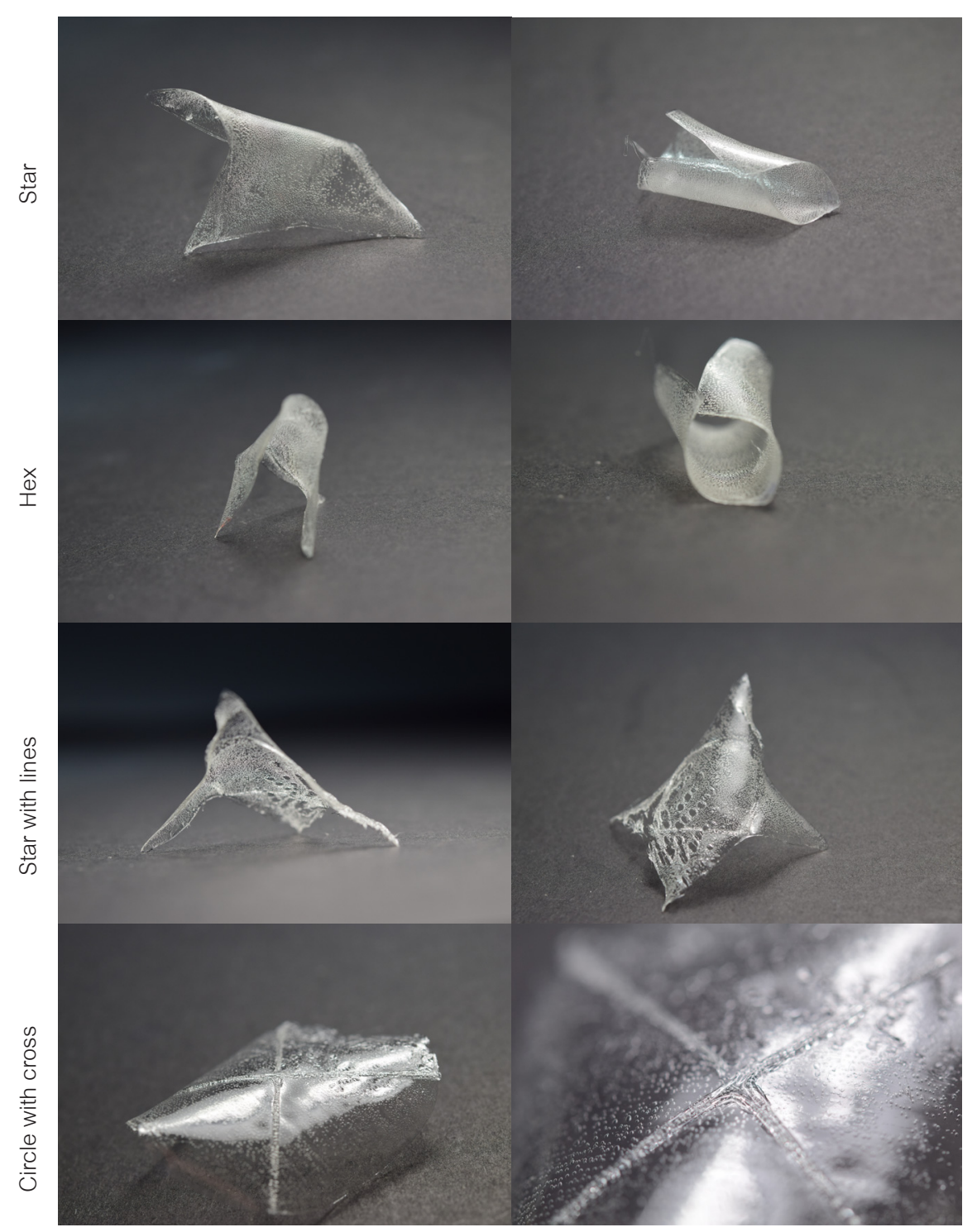

Image 2.102 - 2.116 (Above group) Shape shrink test. Image 2.117 (below) Render of shape test model.

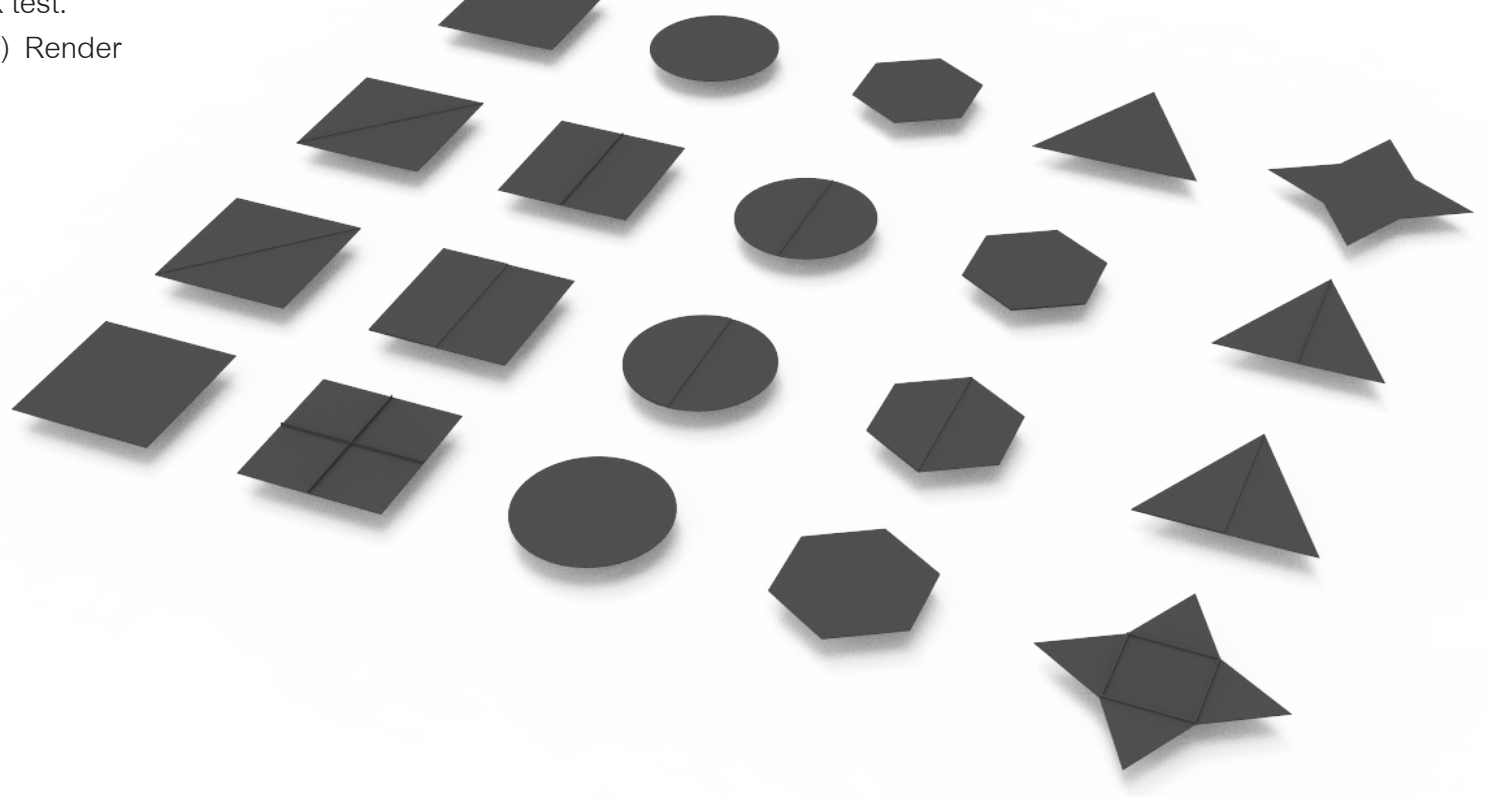


Advance exploration

The findings of the basic shape test and shape test are applied here to create a variety of complex forms and patterns for further testing.

A parametric software was used to obtain design G-code which determines the print path, providing further control of drying order. By controlling the drying order, I was able to control the curling a little more precisely.

Image 2.118 (Below) Render of advance exploration model

Image $2.119-2.135$ (Right from left to right, top to bottom ) 3D CA print

of shrink test advance exloration.
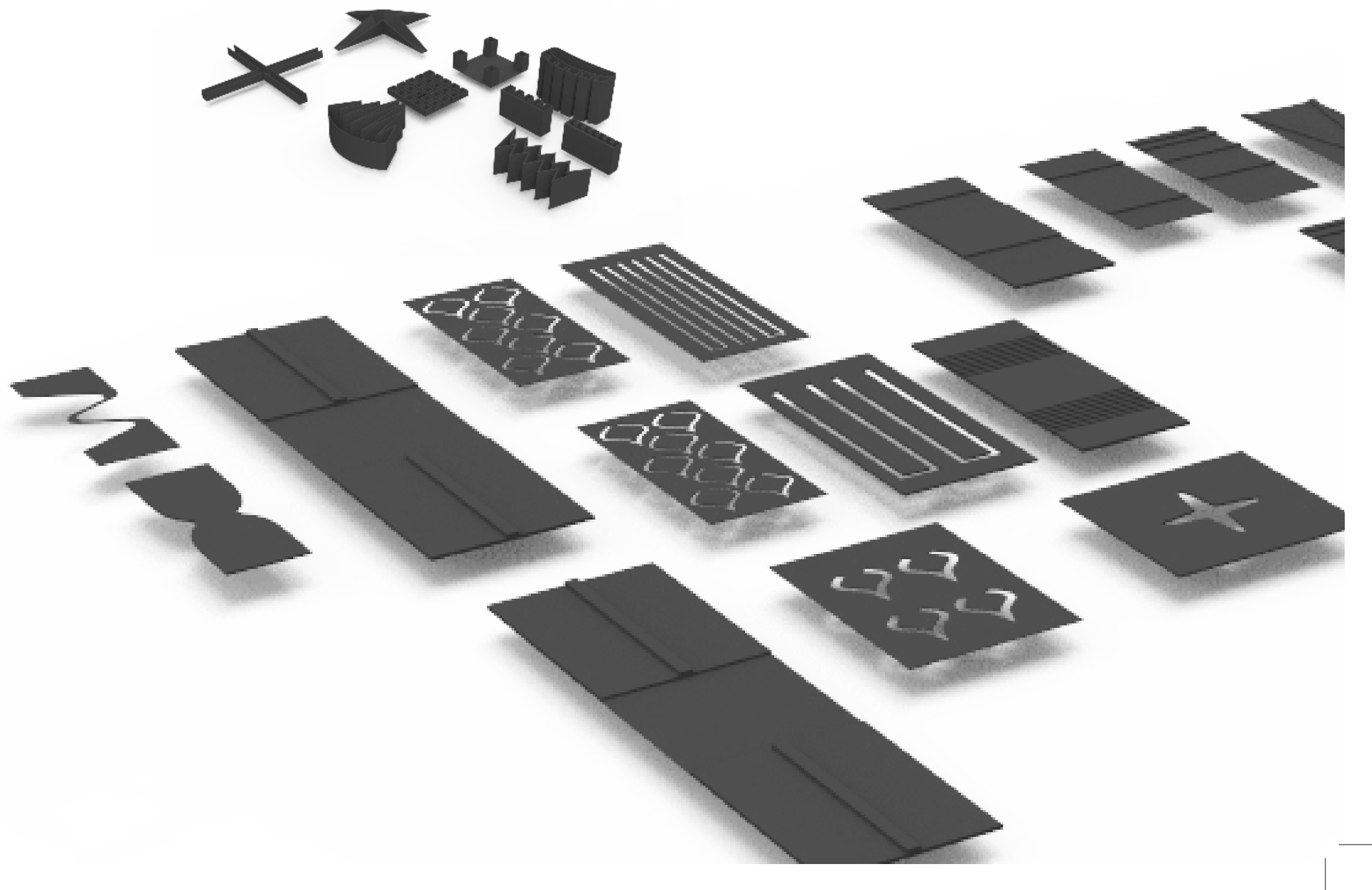

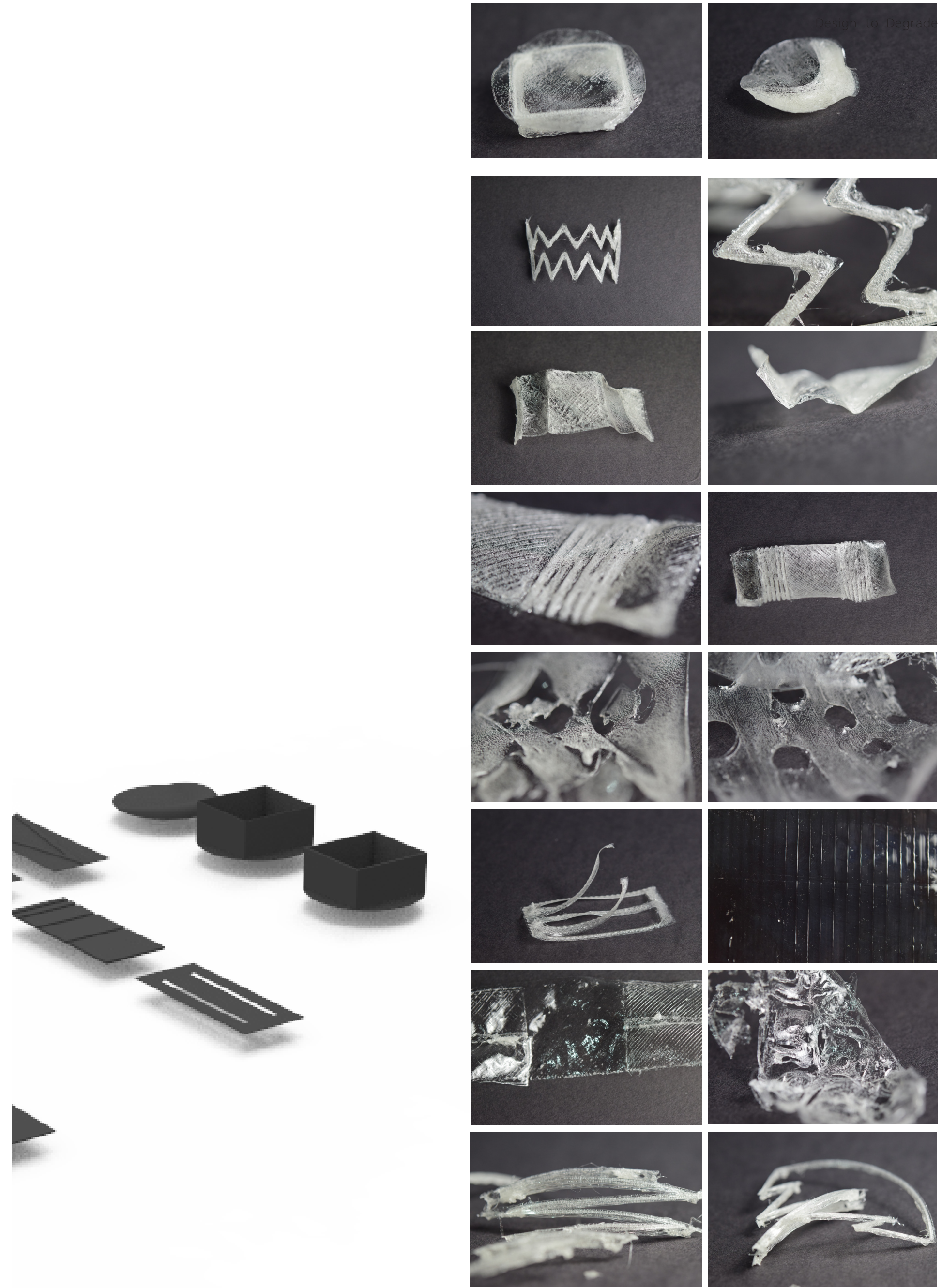
Design to Degrade

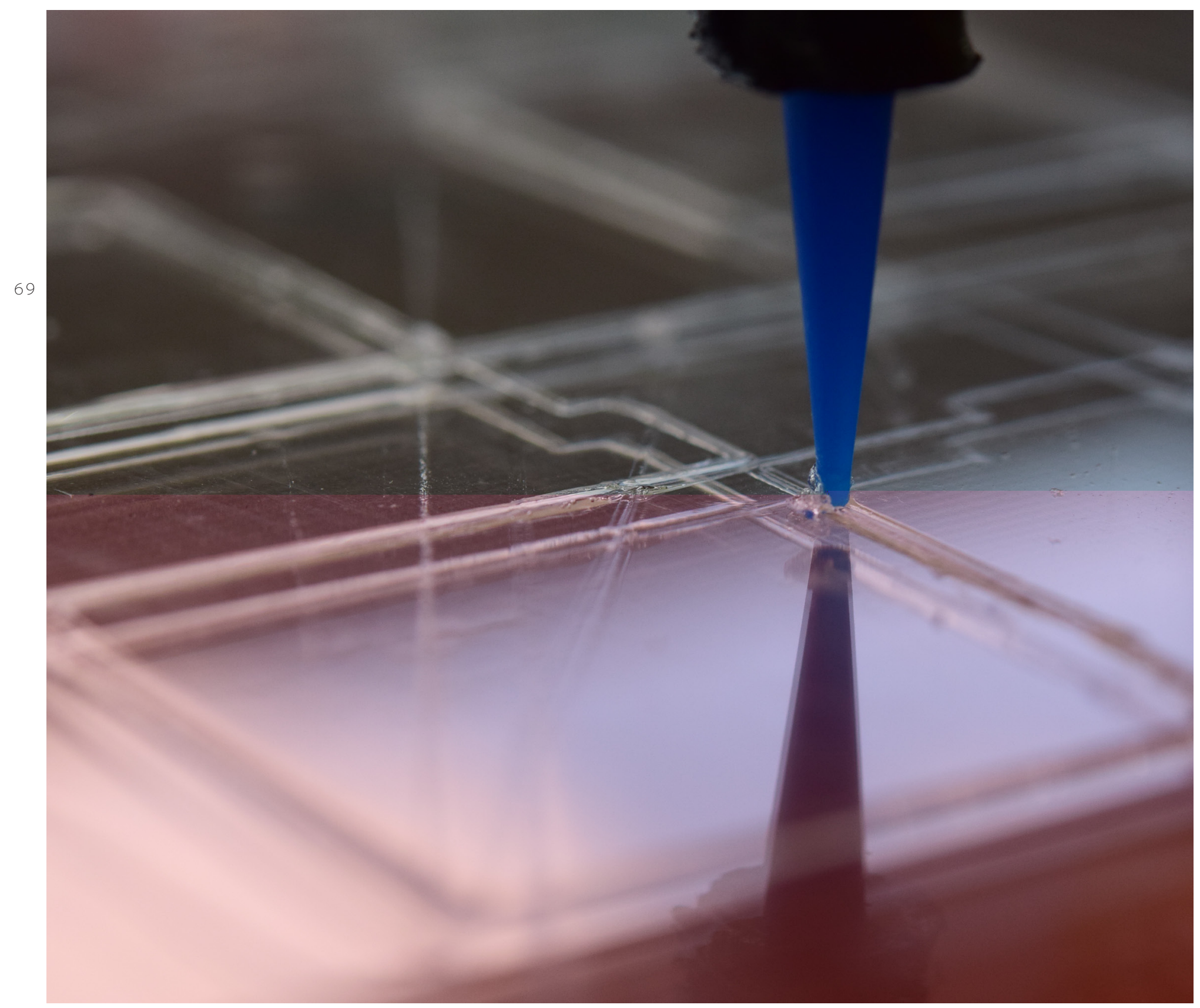




\section{Shrink test results}

From the series of test the results shows the following:

(1) Time before peeling - It was found that approximately 10 mins before removing a $40 \mathrm{~mm} \times 40 \mathrm{~mm} \times 0.3 \mathrm{~mm}$ (one layer thick) CA print provided the even curls.

(2) Length vs curling - The results proofs that the length influenced the way the material curl. It was also found that the curling tends to curl against the print lines, this is consistently found throughout the whole shrinkage test experiment. Therefore this could also be one factor that influences the curling as length increase as the print lines are in a different angle when the length of the print increases.

(3) Amount of layers - It was found that two to three layers of $0.3 \mathrm{~mm}$ layers were enough to direct the shrinkage. More than 3 layers cause the print to be very rigid. It was also found that the print tent to curls towards the print bed once removed. This is because the surface of the material touching the print bed was least exposed to the air therefore it was the moistest part of the print. Hence due to the difference in dryness the curling was directed to curl towards the least dry surface.

\section{(4) Shape test}

(a) Basic shapes - Star shapes made some interesting uniform curls, larger version of the star shape could be explored.

Shapes with one line - lines seem to only provide minimal directional control.

(b) Shapes with half-filled - having half have the shape filled with a second layer controlled the curling better than using lines.

Shapes with two lines - having two lines is quite interesting as it evens out the tension.

(d) Advance exploration - Some interesting curling were found heavily directed by form. E.g. zig zag.

Overall this exploration was fascinating and have suggested the possibility to integrate this technique of controlling shrinkage to create more intricate forms and pattern will minimal use of materials. This also diverges aqueous cellulose acetate 3D printing away from traditional thermal extrusion in FDM printing taking advantage of the unique opportunity of paste printing. Thus permitting it to perform in a way that is not possible with FDM printing. 


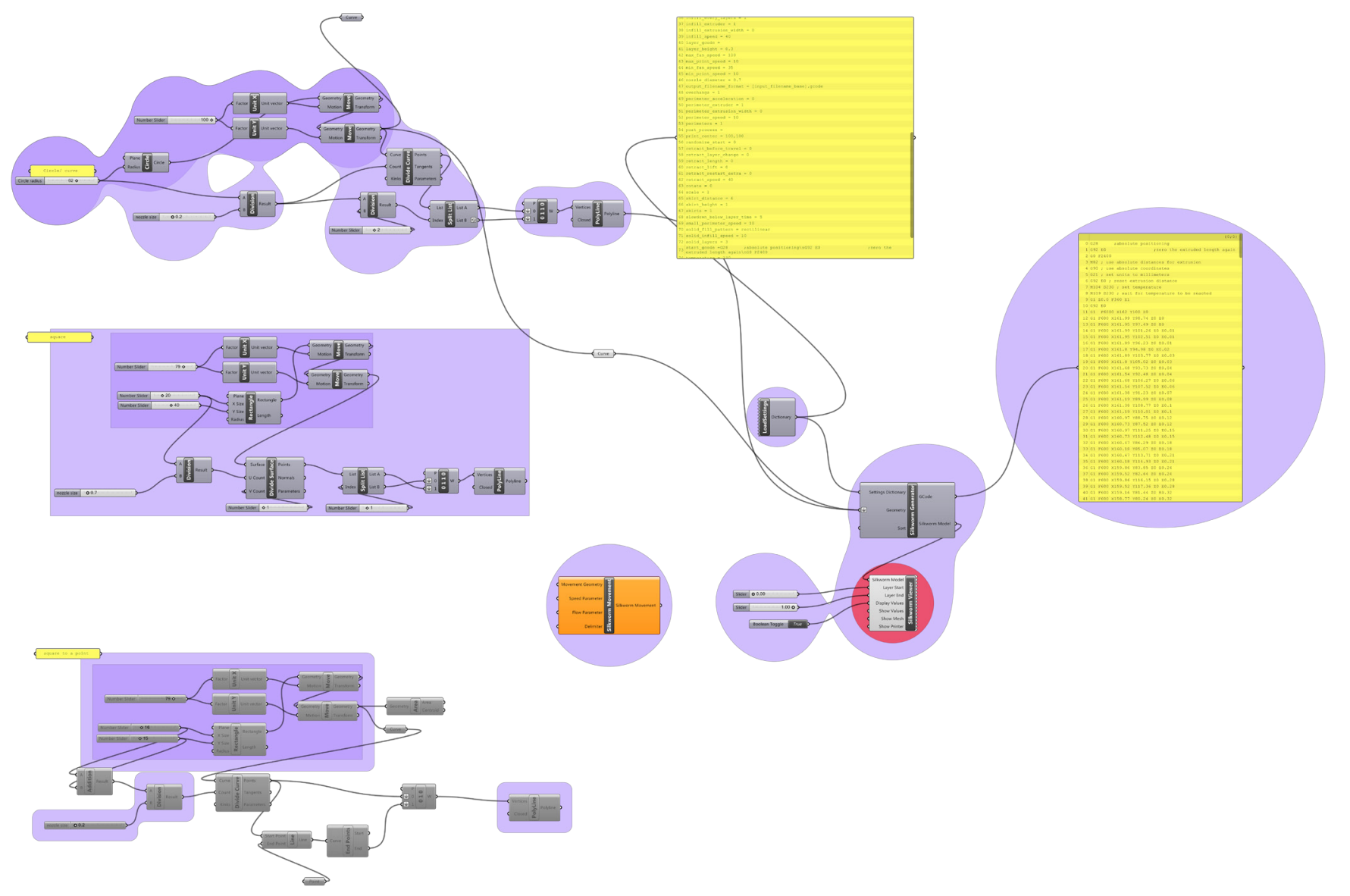

Image 2.137 (Top) Grasshopper definition to parametrically control print path using an obect or line as input. 


\section{Silk Worm}

As CA shrinkage is influenced by the direction of the print lines, this section employed parametric tools to control print lines to gain more control of curling.

Image 2.138 (Top) - Testing print path with pencil and paper. 


\section{D Printing Resutls}

\section{Printer setting findings}

The experimentation resulted in the following printThrough experimentation, the following printer setting is the optimal one for

Screenshot of settings.

\section{Printing setting findings}

The best print setting was found to be

Aligned seam - so the point of layer change is consistent and allows maximum length of material to continuously print without stopping, decreasing the chance of a misprint.

Printing multiple at the same time if objects are small. This allow materials layer to have more time to dry.

No fan - unless the fan is modified to spot cooling, the fan will dry material at nozzle increase chance of nozzle blockage.

0.3-0.7mm nozzle size

$0.3 \mathrm{~mm}$ layer height

Shell setting

Morphology findings

Overhang - The results shows that cellulose is not favorable for 3D printing selfsupporting structures as the material does not dry instantly and does not perform with high precision.

Twisted - From the results of the overhang test, it was predicted that cellulose will not perform well in the twisted test. However there was obvious twist that can be seen from top view. Yet $Z$ height was still a problem.

\section{Shrink test findings:}

From the series of tests the results show the following:

Time before peeling - Approximately 10 mins before removing CA print that is $40 \mathrm{~mm} \times$ $40 \mathrm{~mm} \times 0.3 \mathrm{~mm}$ (one layer thick) provided the best curl, as it curled evenly.

Length vs curling - There is a relationship between length and degree of curl. It was found that the curling tends to curl against the print lines. Therefore this could also be one factor that influences the curling as length increase as the print lines are in a different angle when the length of the print increases.

Amount of layers - It was found that two to three layers of $0.3 \mathrm{~mm}$ layers were enough to direct the shrinkage. More than three layers cause the print to be very rigid. It was found that the print tent to curl towards the print bed once removed, as the surface of the material touching the print bed was least exposed to the air. Therefore, it was the moistest part of 
the print, thus with a difference in dryness, the curling was directed to curl towards the least dried surface.

Shape test

Basic shapes - Star shapes made some interesting uniform curls, larger version of the star shape could be explored.

Shapes with one line - Lines seem to only provide minimal directional control.

Shapes with half-filled - Having half the shape filled with a second layer controlled the curling better than using lines.

Shapes with two lines - Having two lines is quite interesting as it evens out the tension.

Advance exploration - Some interesting curling were found heavily directed by form. E.g. zig zag.

\section{D Printing CA}

Overall the results for 3D printing aqueous cellulose acetate was found not very good at printing:

- small area

- Short lines

- Hard curves

- Height

The disadvantage of 3D printing aqueous cellulose acetate includes:

- Slow

- Wasteful of materials to print volumetric forms.

- When one layer/ one part of the layer misprint the whole print is influenced.

- Printing in shell is better than volume

- Overhang is challenging when it is more than 10 degree

- Not very good at printing small area objects as the material requires time to set and dry each layer to build well.

- However, cellulose acetate with acetone have a high degree of shrinkage causes higher z height more challenging to print as the layers and nozzle will grow further apart. Especially if the layer before was dried too much. When prints are not sufficiently dried, it also leads to issues.

- Cannot print high details.

The advantage of 3D printing aqueous cellulose acetate includes:

- Malleability - as the material is printing in aqueous form, the finished print is usually not fully harden yet. Thus I see this as an opportunity and a unique quality of this manufacturing process.

- No heat is required.

\section{Material properties}

- Shrinkage

- White when heated

- Transparent

- Ridget 


\section{Material and process discussion}

The material explorations have demonstrated diverse material properties.

PVA - The results of the PVA experiments show that PVA, in general, is suitable for extrusion. However, the long drying time hinders its 3D-printing ability. PVA behave differently to CA and therefore did not perform as efficiently as CA in 3D printing. PVA performs better with thermal extrusion as it is well studied. Thermal extrusion of PVA was still unable to print in high resolution as it is designed to be a support material.

Starch - Starch did not display many desirable attributes. All starch samples did not fulfil the material criteria. Starch is eliminated from further experimentation.

Cellulose - The results of cellulose experimentation shows that each type of cellulose performs differently, unlike the PVA experiments. All four combinations struggled with drying time and layer retention, except for CA and acetone because acetone volatilely evaporates at room temperature. CA 3D-printing test not only suggest that CA could be used in 3D-printing as a more sustainable choice, but it also demonstrated some unique material quality. The ability of CA to shrink and curl was particularly of interest as it advocates some 4D attributes of self-forming. This effect points out perhaps these material and process are not best suited to the conventional way of printing volumetric forms. They can do more than volumetric forms. 


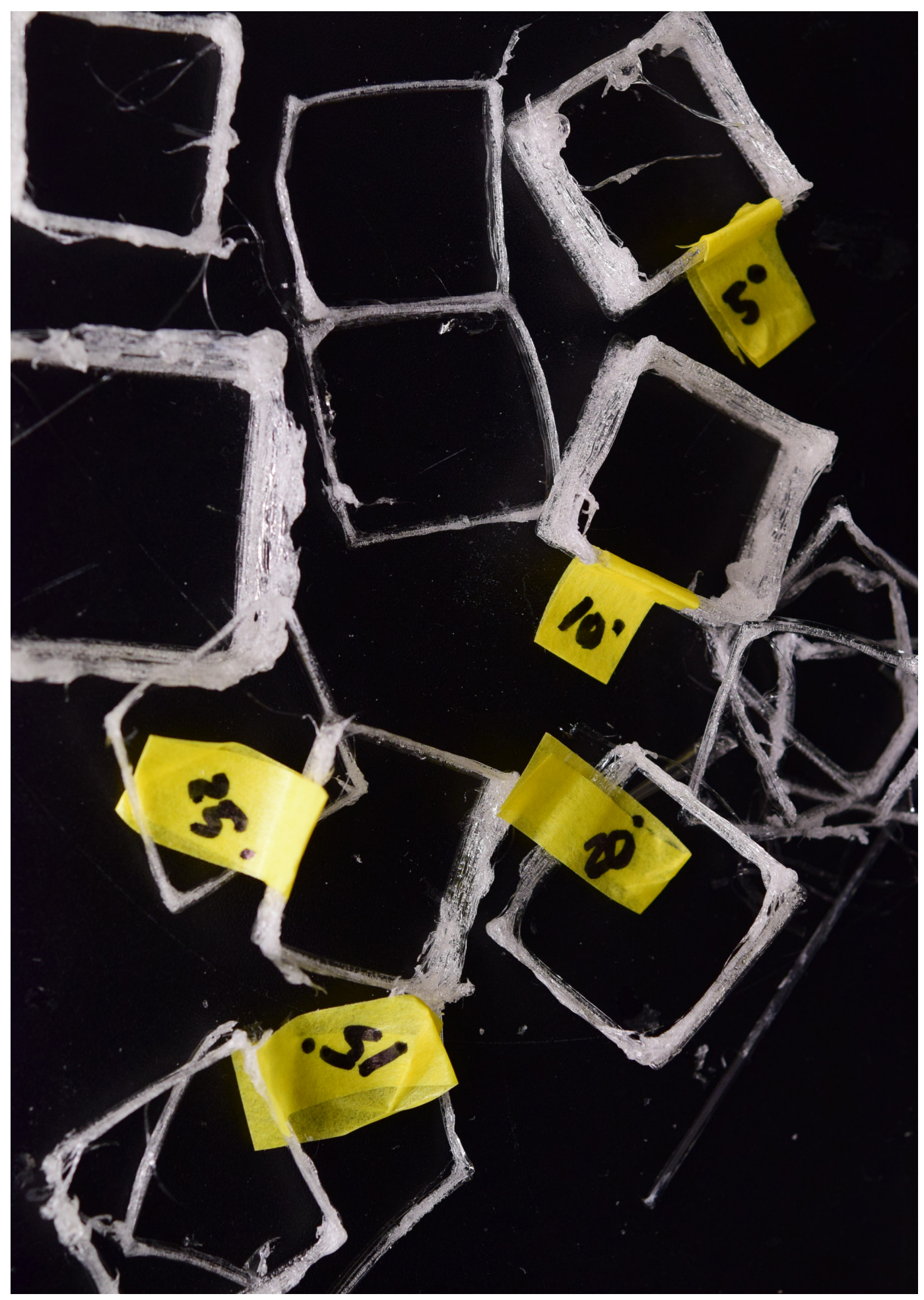

Image 2.139 (Top) 3D CA print, success and fail prints. 
CHAPTER

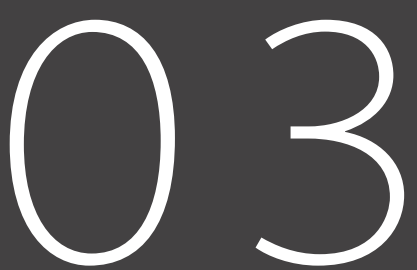

Degradation 
Objective 1b) Experiment identified materials to evaluate degradability of each material.

\subsection{Introduction}

UV degradation (UV-test) - Each sample was exposed to a 20W black light in a dark chamber. The light source is placed at the centre $200 \mathrm{~mm}$ above the samples. The weight loss assessment was adopted to quantify degradation (Copinet, Bertrand, Longieras, Coma, \& Couturier, 2003).

Hydrodegradation (Hydro-test) - Samples will be fully submerged in water to accelerate degradation. A time-lapse will be taken to record the visual changes. At the start of the test, every five minutes a photo of the sample will be taken. The time between each photo will be adjusted according to the visual degradation. The time between each photo is increased if the sample required a long time to display visible change vice versa. The time-lapse will end when the sample becomes stagnant. 

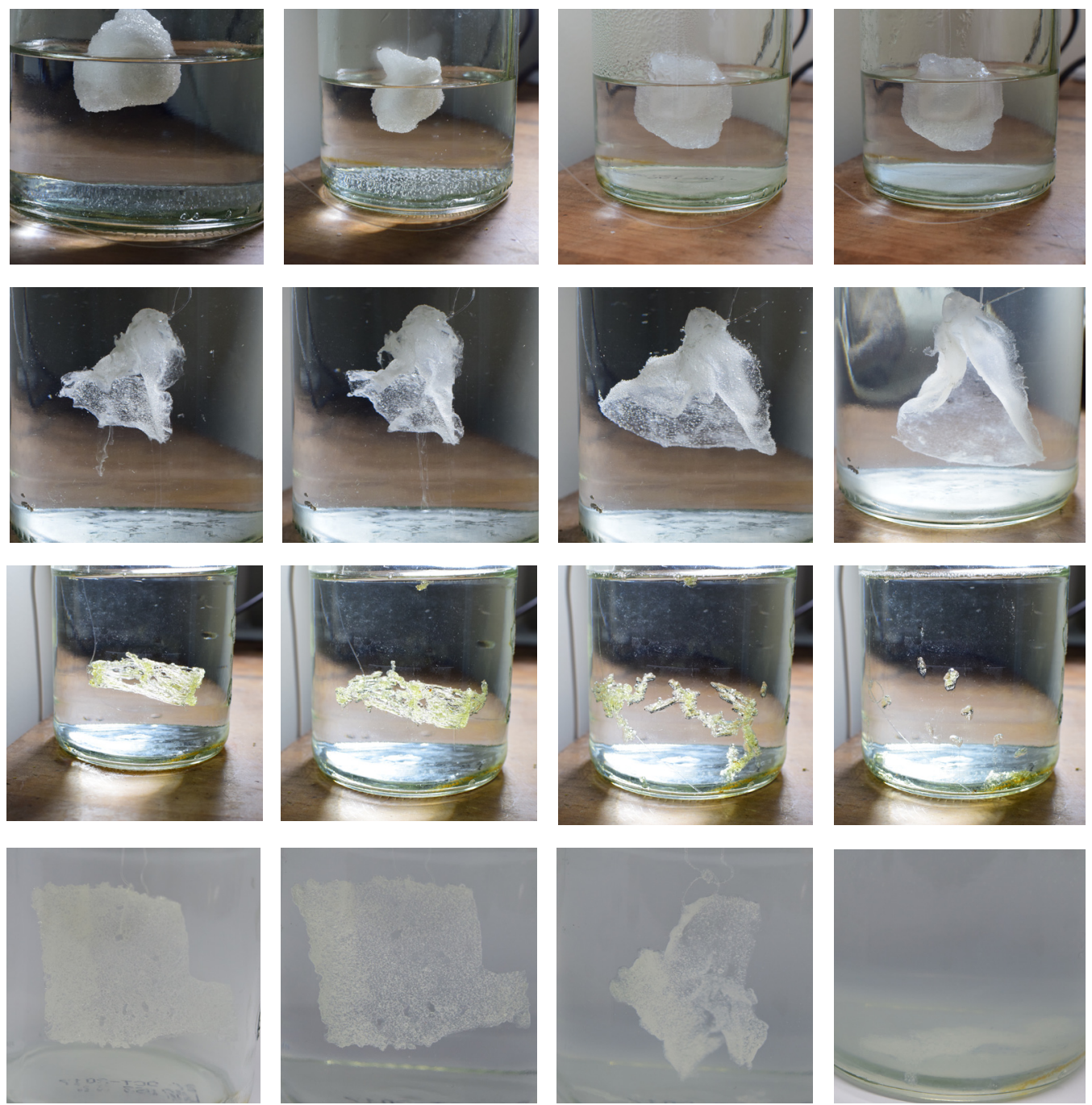

Image 3.1-3.4

Timelapse of PVA117k

over 1 week. Some

absorption of water and expansion can be observed.

Image 3.5 - 3.8

Timelapse of PVA117s over 1 week. Some absorption of water and expansion can be observed.

Image 3.9-3.12

Timelapse of PVA

filament over 2 hours.

There was a significant degradation.

Image 3.13-3.16

Timelapse of $205 \mathrm{mb}$

over 2 hours. There

was a significant

degradation.

\section{Starch degadation test Starch}

Each starch sample was made into film, dried and cut into a $50 \mathrm{~mm}$ by $50 \mathrm{~mm}$ square. Both samples was in the UV chamber for 15 continuous day. 


\section{Cellulose}

All cellulose combinations went through the UV test. However, the results showed no significant changes over the course of 11 days. Evaluating the results of the overall material exploration, within the cellulose group, CA with acetone best matched with the material criteria list, except for its inability to show significant data in the UV-test.

Pattinson and Hart (2017) proofed CA with acetone and were able to create 3D forms via paste extrusion. This is a promising combination that is worth further exploration.

In defence of CA degradability, Puls, Wilson, and Hölter (2011) suggest CA can be chemically degraded under UV wavelength shorter than $280 \mathrm{~nm}$. Additionally, titanium dioxide ( $\mathrm{TiO} 2)$ was proof to increases material surface area, thus enhance CA UV degradation (Puls, Wilson, \& Hölter, 2011). TiO2 is known to have photocatalytic properties (Pramauro, Bianco Prevot, Vincenti, \& Brizzolesi, 1997) Puls, Wilson, and Hölter (2011), demonstrated $0.05 \%$ of TiO2 could significantly increase photodegradation of CA.

Hosono, Kanazawa, Mori, \& Endo (2007), suggest benzophenone (BP) can successfully increase photo-degradability of CA with a wavelength of no shorter than $275 \mathrm{~nm}$. In the experiment, $160 \mathrm{mg} / \mathrm{g}$ of BP was used with CA.

Lastly, Quintana et al., (2013) experimented with UV-degradation of CA film. The samples were placed under a wavelength range of 295-800 $\mathrm{nm}$ with a daylight $\mathrm{Q}$ filter, which simulates noon summer sunlight. A particularly successful sample uses 20\% Tripropionin (TP) with CA and acetone. A visible breakage is shown at 225 hours (h) and further breakage at $425 \mathrm{~h}$. The visual breakage is particularly relevant for this research.

In sum, CA is capable of photodegradation given the right environment and additives to enhance the effect. Different additives might even be able to further enhance the degradation rate of $\mathrm{CA}$ for more intricate control and designing of degradation in an artificial artefact. Therefore, CA with TiO2, BP film was made and exposed to a UVB lamp consisting of a $150 \mathrm{~nm}$ wavelength, placed $20 \mathrm{~mm}$ from the light source for 240 hours (h) to simulate accelerated UV degradation. The TiO2, Bp and Ca (control) samples were evaluated via a scanning electron microscope (SEM) imaging as the results were predicted to be microscopic.

I hypothesised that the CA only (control) group will not show any significant difference, only Bp and TiO2 group will show a significant visual change under SEM. 


\section{Preparation}

\begin{tabular}{|l|l|l|l|}
\hline & Addatives & CA & Acetone \\
\hline Ca Only (Control) & Og & $2 \mathrm{~g}$ & $10 \mathrm{~g}$ \\
\hline $\mathrm{TiO} 2+\mathrm{CA}$ & $0.01 \mathrm{~g}$ & $2 \mathrm{~g}$ & $10 \mathrm{~g}$ \\
\hline $\mathrm{Bp}+\mathrm{CA}$ & $0,32 \mathrm{~g}$ & $2 \mathrm{~g}$ & $10 \mathrm{~g}$ \\
\hline
\end{tabular}

Table 3.1 (Top) Prepration recipe for CA and addative samples.

On the same day, I prepared three large films of CA with different additives. The additive ratio was added according to the literature's specification. Four samples of the same size were cut out from each of the three films, resulting in three groups of four samples. All samples except for the Oh samples were placed under UV. One sample from each group was taken out periodically up to $240 \mathrm{~h}$. All samples were then coated with a thin layer of platinum for conductance and placed in a vacuum for two days to reduce moisture.

\section{Samples}

$\mathrm{TiO} 2$

$\mathrm{Bp}$

CA

Oh

$80 \mathrm{~h}$

$160 h$

$240 h$

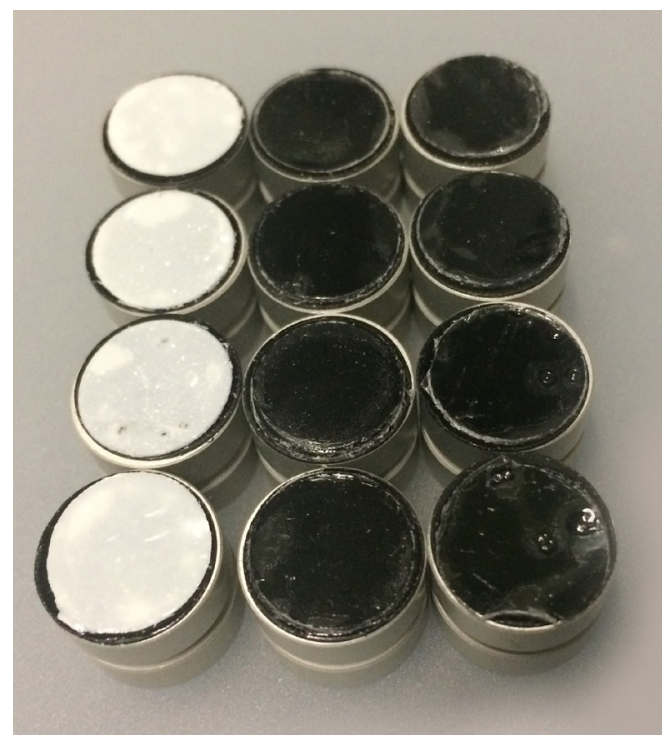

Image 3.17 (Top) CA and addative samples on studs, ready for SEM. 

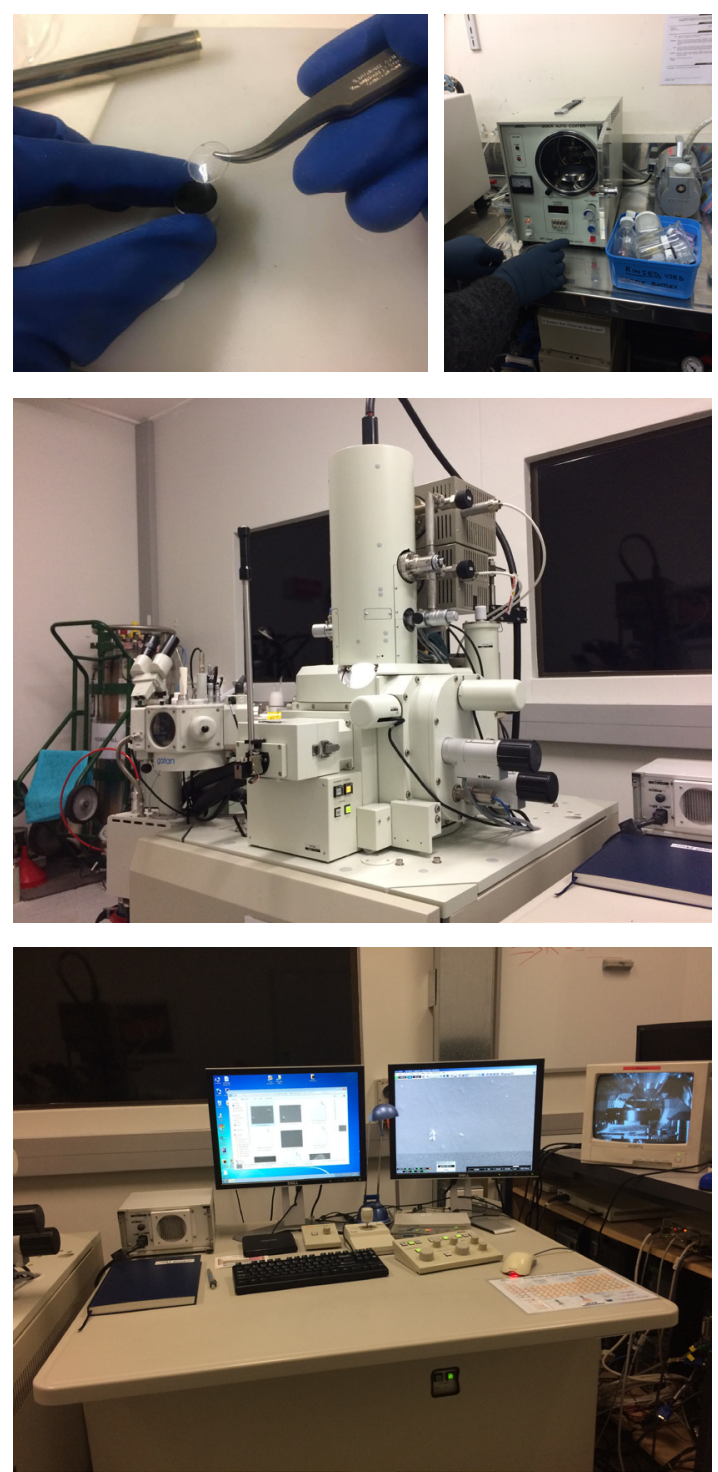

Image 3.18-3.21 (Top group) SEM process 


\section{Degradation Results}

\section{$P \vee A$}

The PVA filament sample started degradation as soon as it is submerged. Therefore a photo was taken every 3 mins, and the sample fully disappeared after approximately one hour.

PVA $117 \mathrm{k}$ started to swell after approximately 10 minutes in submerging water. After 1 hour, the swelling began to slow down, and there were only displayed slight gradual change. Therefore the time-lapse took a photo every 10 minutes for the first 3 hours and subsequently set for every 8 hours. After seven days, the samples did not disappear, and there was no further morphing.

PVA 117s performed similarly. This sample was made in a shell form, and the transformation was even more beautiful than pva117k as the shell form opens up.

Pva205mb almost immediately degrade when summered in the water. Therefore the time-lapse was set for every 3 minutes. After 40 minutes, the whole sample fully disappeared.

\section{Starch}

\section{UV degradation of Starch}

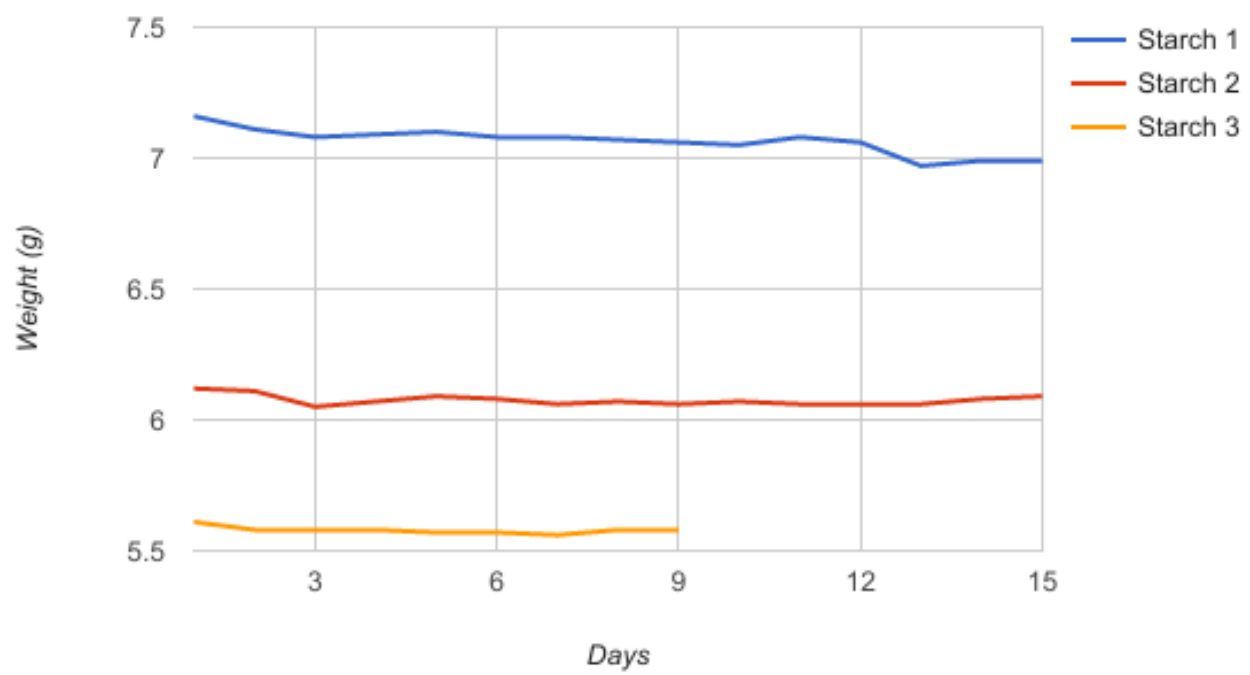

Image 3.18 (Top) Graph of UV degradation weight loss over 15 days

The graph show no significant change in either of the starch samples. 
Cellulose

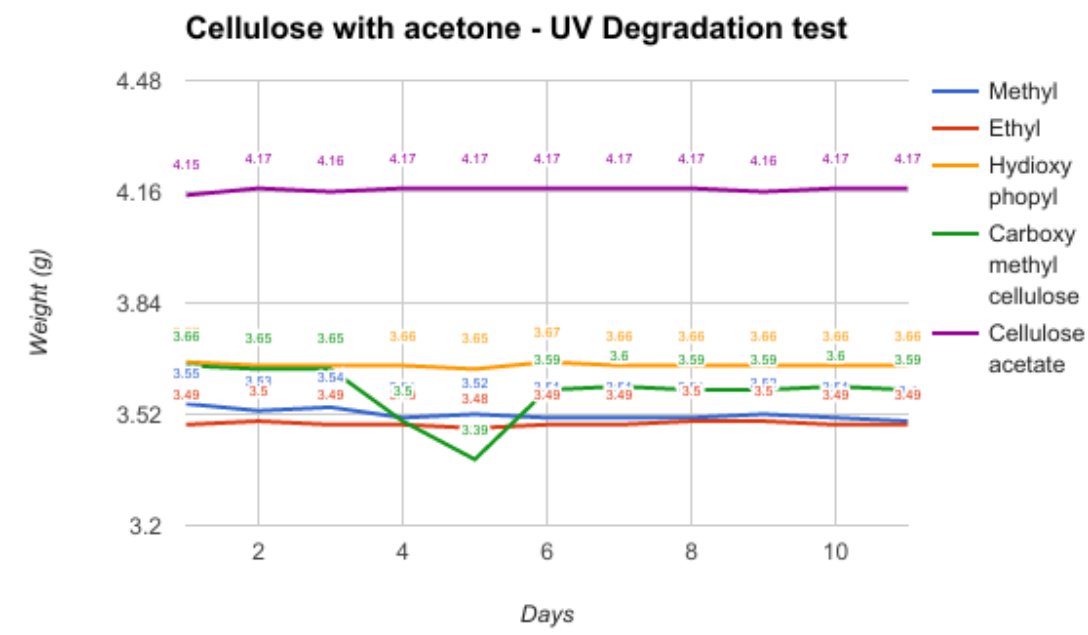

Cellulose with Isopropyl - UV Degradation test

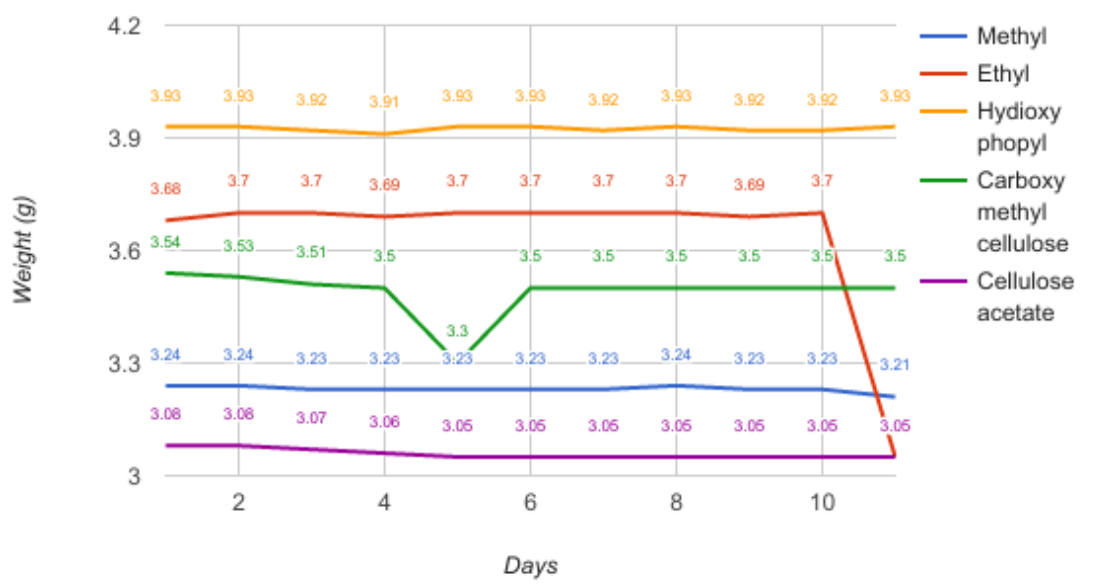

Image 3.19 (Top) Cellulose with acetone samples UV degradation, weight loss graph.

Image 3.20 (bottom) Cellulose with Isopropyl samples UV degradation, weight loss graph. 


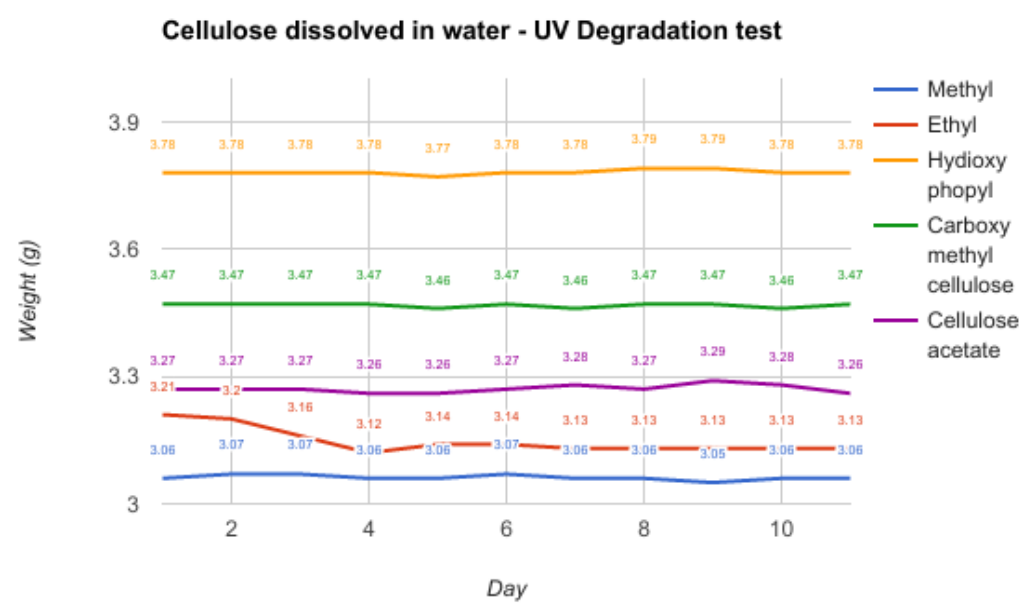

Image 3.21 (Top) Cellulose with water samples UV degradation, weight loss graph.

\section{TiO2 vs Cellulose acetate}

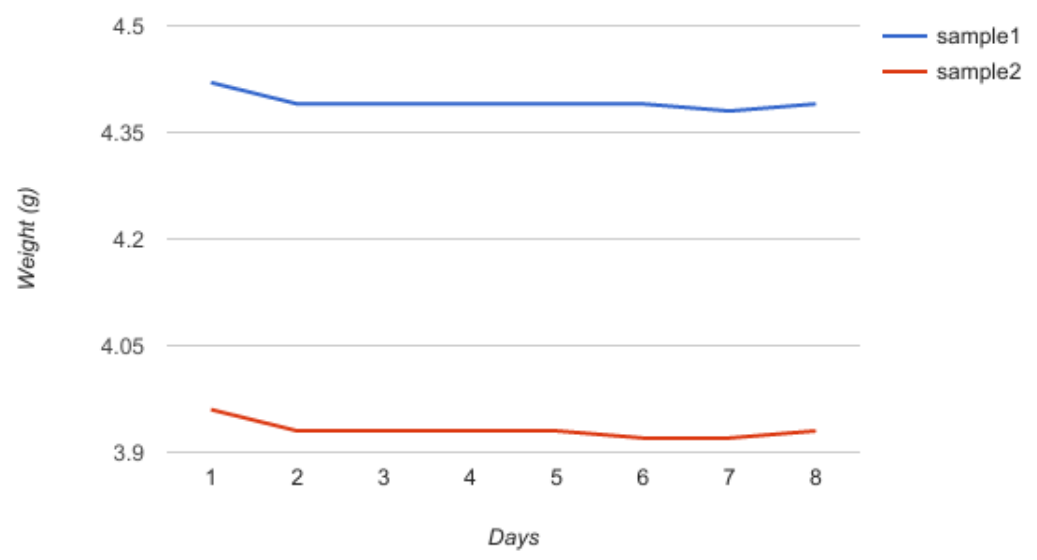

The graph shows no significant weight loss in all Cellulose samples. This is probably because the change was smaller than the hypothesis, therefore require a different method to quantify the degradation. 
$x 1000$
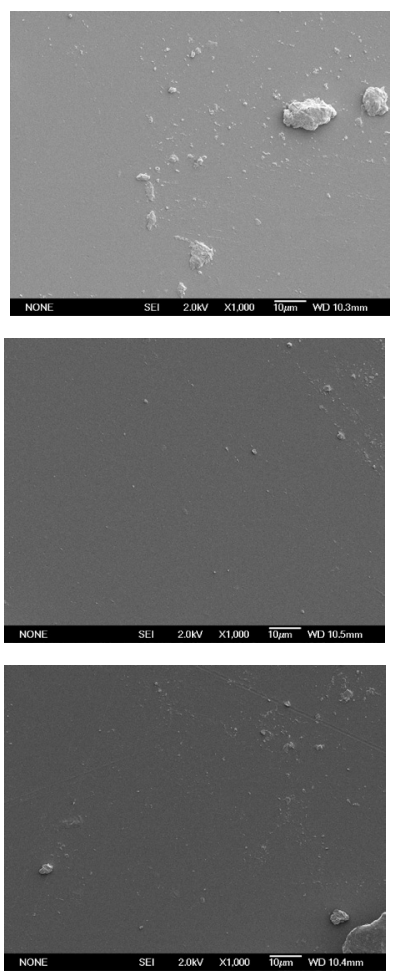

$240 \mathrm{~h}$

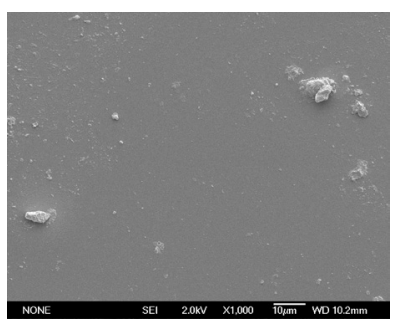

$\times 5000$
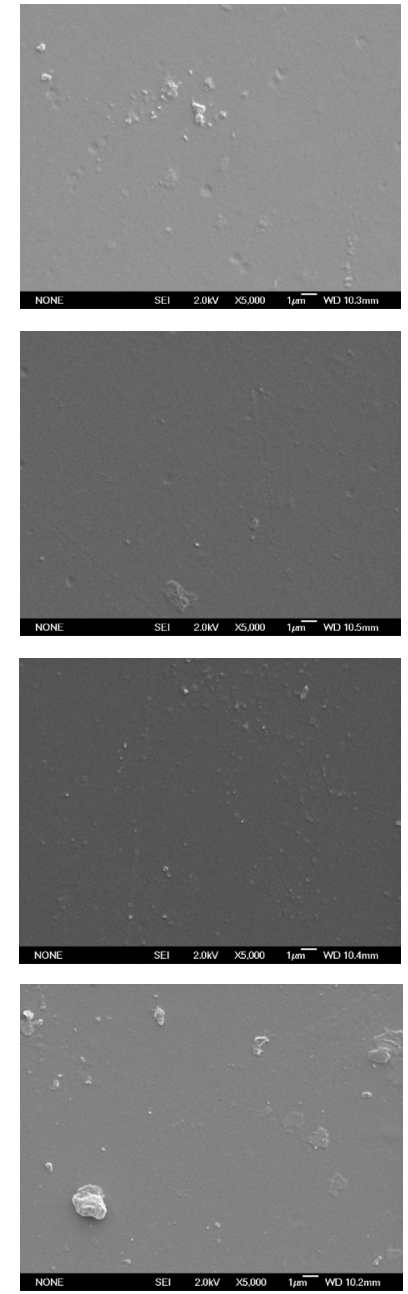

$x 20,000$
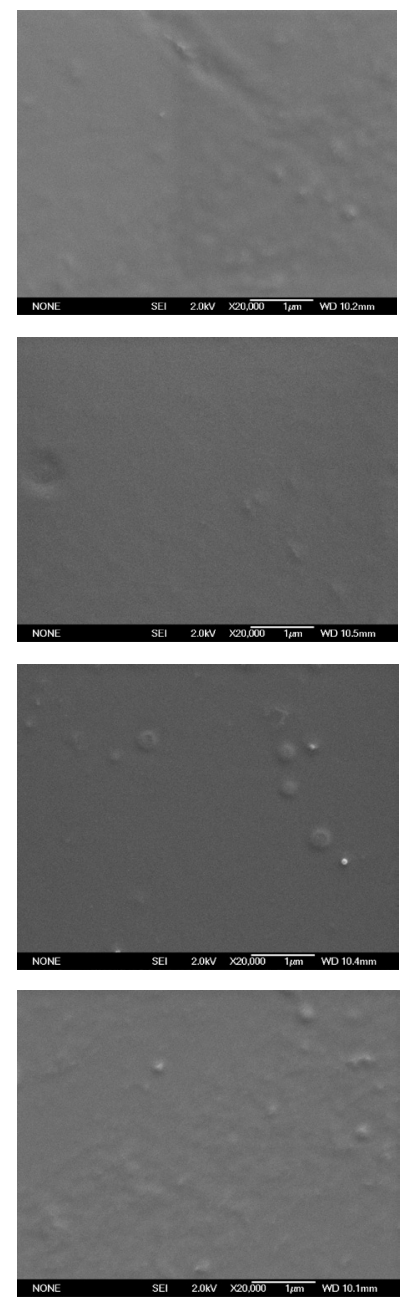

$x 100,000$
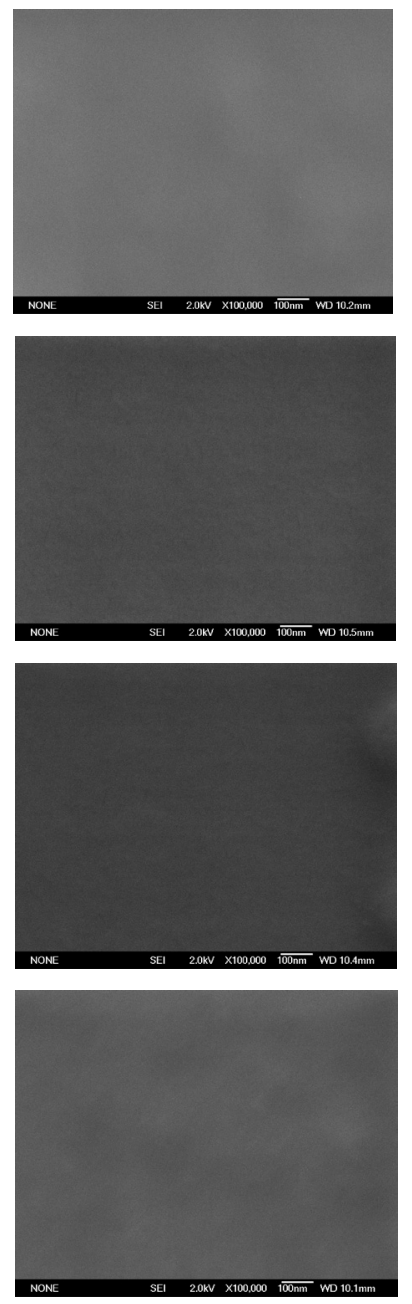

Image 3.22-3.37 (above group.) SEM result of the BP samples. 
$X 1000$

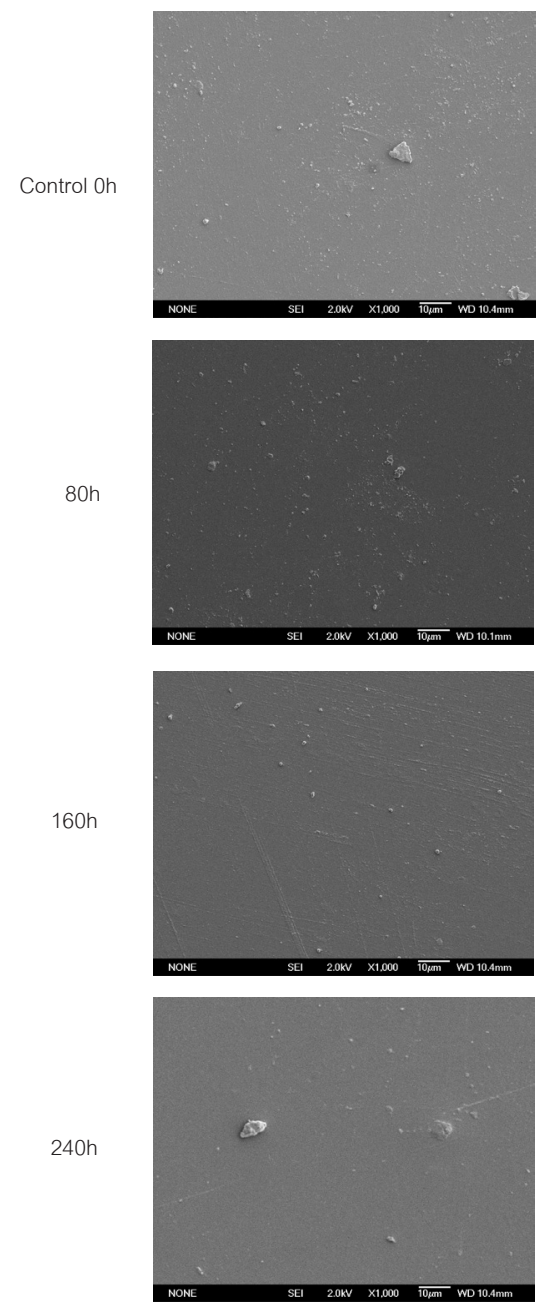

$\times 5000$
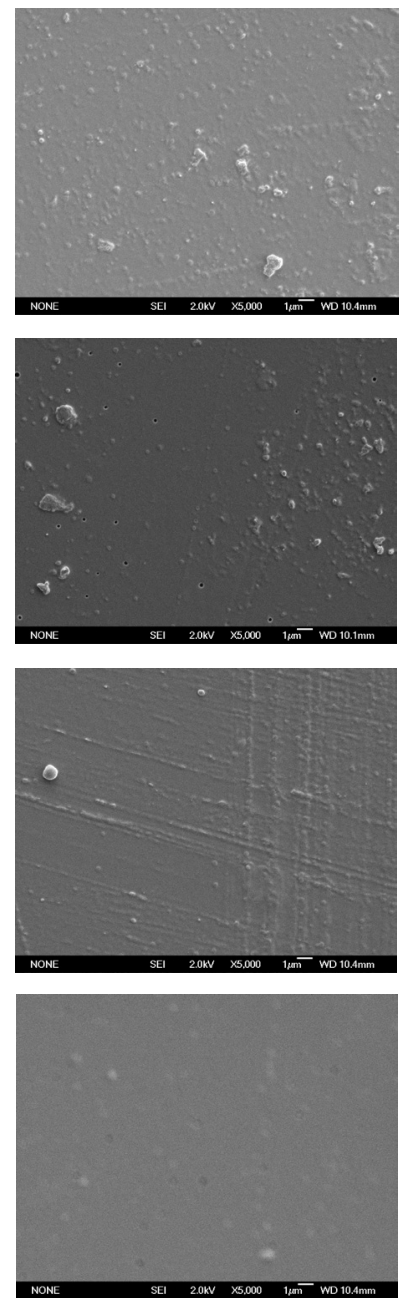

$\times 20,000$
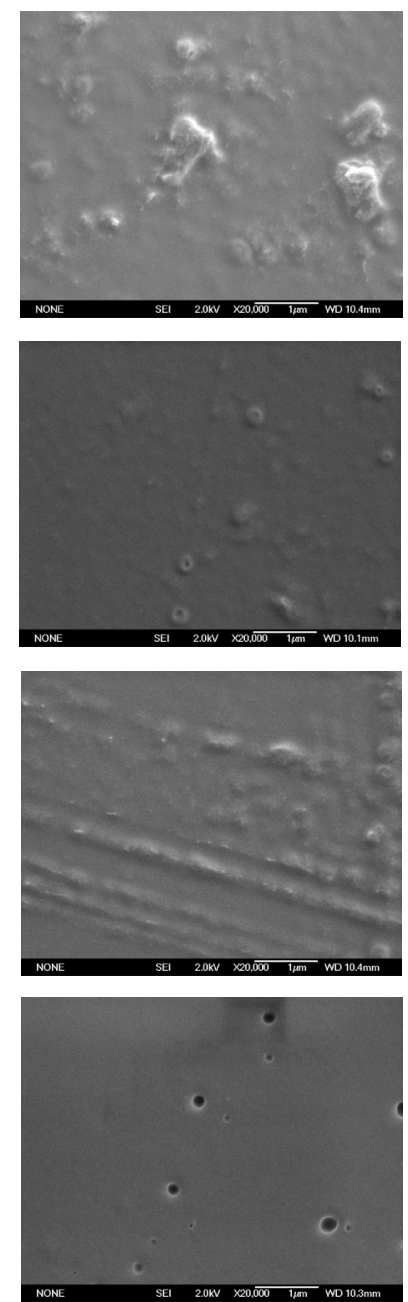

X 100,000
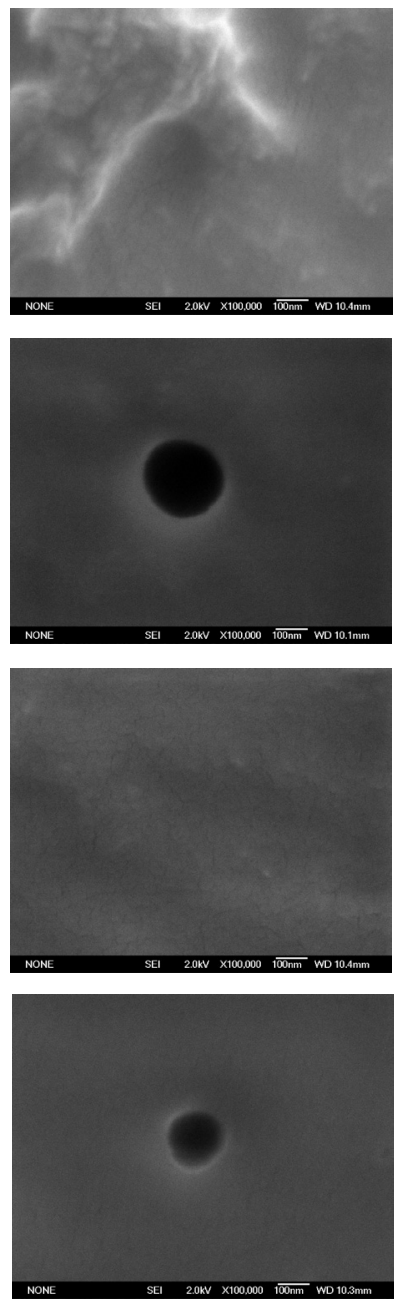

Image 3.38-3.53 (above group.) SEM result of the CA only samples. 
$\times 1000$

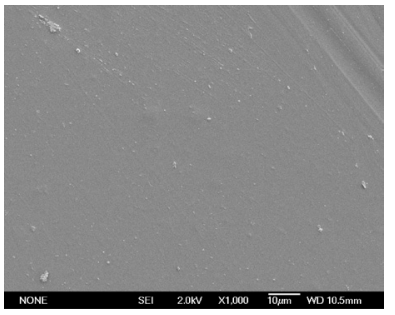

$80 \mathrm{~h}$

$160 \mathrm{~h}$

Set 2 $\times 5000$
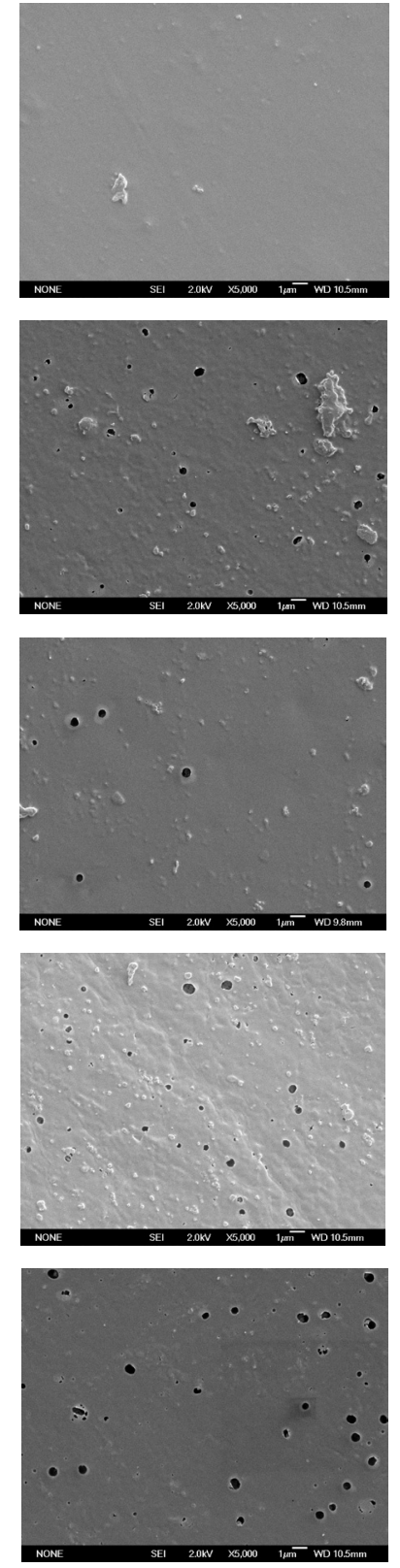

$\times 20,000$
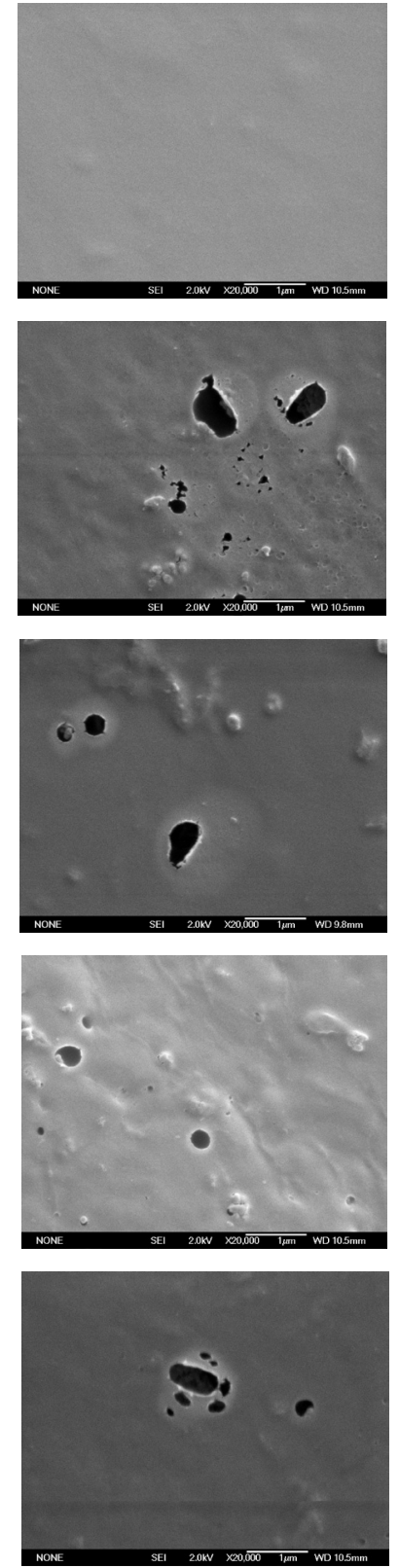

$\times 100,000$
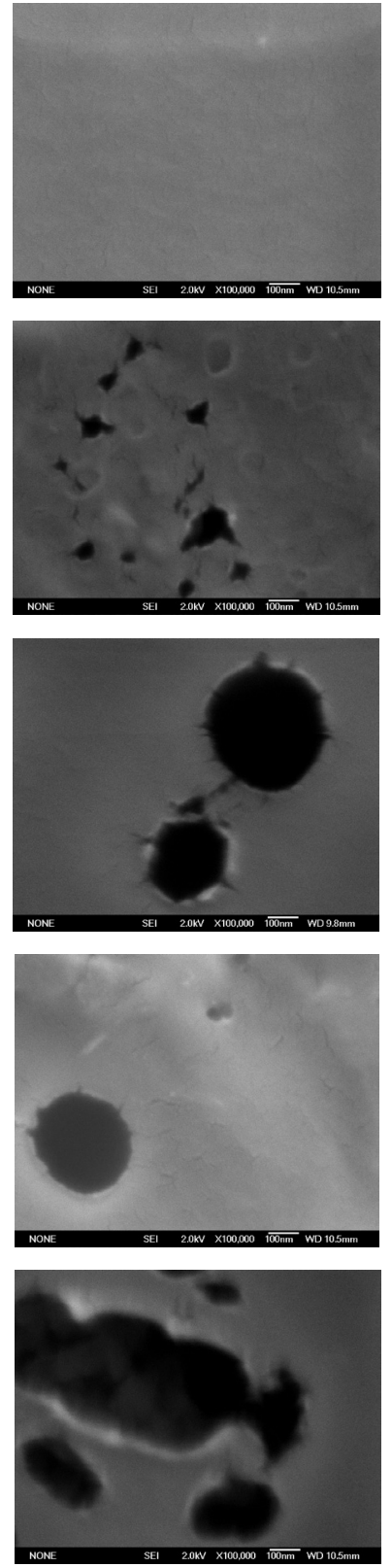

Image 3.54-3.69 (above group.)SEM result of the $\mathrm{TIO} 2$ samples. Image 3.70 (Bottom row) SEM result of the $\mathrm{TIO} 2$ samples recaptured images for confirmation. 
After 240h of UV exposure, on a visual level, all samples looked the same except for the Bp group, where the $160 \mathrm{~h}$ and $240 \mathrm{~h}$ samples turned slightly yellow. Four SEM image with the magnification of $\times 1000, x 5000, x 20 k$ and $\mathrm{x} 100 \mathrm{k}$ was taken for each sample.

SEM images showed no significant visual changes for the Bp group in any of the magnification.

The Control group surprisingly show a slight increase in holes at $240 \mathrm{~h}$. The 60h CA only have some holes, but it was not enough to conclude as a significant change.

The TiO2 group showed a significant change as hypothesised. There was an increase in holes throughout all samples from 80-240h. The control sample (Oh) of this group did not show any holes. This proved that the holes were developed over the exposure period. To confirm the findings, a second set of photos was taken in a random new area of the sample. The results reflected the same gradual increase in holes, meaning the increase in holes is a result of UV. However, some holes, when observed at $100 \mathrm{k}$ magnification, occasionally appear to be air bubbles that burst in the vacuum environment evident by its form.

The TiO2 samples were left in the SEM for 30 minutes to examine and eliminate the possibility of the SEM beam causing those holes. After 30 mins there was no visual change or increase in holes. This confirms the holes are the result of UV exposure.
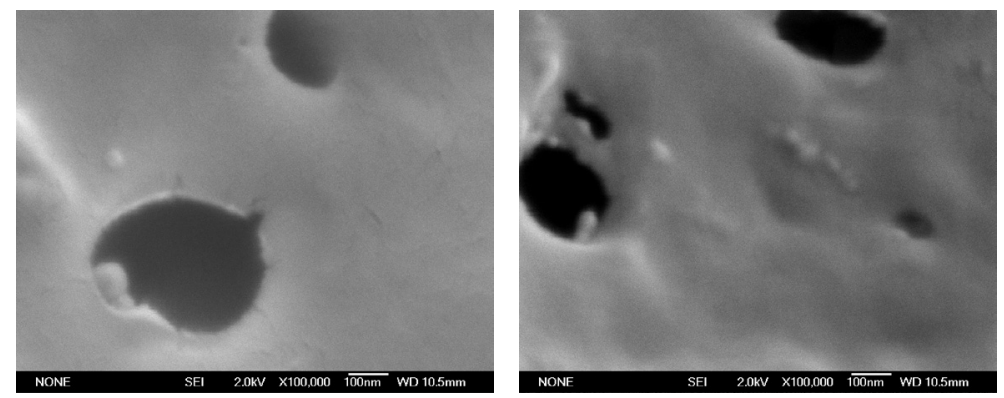

Image 3.71-3.72 (Above) SEM result of the TIO2 samples on SEM for 30 minute. 


\section{Discussion}

\section{PVA}

According to Haweel and Ammar (2008), PVA increases water solubility with its increased degree of hydrolysis, however only up to about $89 \%$. This corresponds to my findings, as PVA $205 \mathrm{mb}$ has a degree of hydrolysis of $86.5 \sim 89$. The hydrolysis level of the PVA filament is unknown as it is a commercial filament.

As PVA205mb and PVA filament were the only samples that readily dissolved in water. Therefore $205 \mathrm{mb}$ is used for further exploration.

\section{Starch}

All starch material will not carry on further as starch did not show any positive result in UV-test and tested not suitable for paste extrusion in material and process test.

\section{Cellulose}

CA are capable of UV degradation of different rate when different additives (TiO2 and TP) are added. CA without additives seems to slowly show some degradation. However, more experimentation is required to confirm findings.

In sum PVA filament, PVA205 and CA perform well in the degradation test. Therefore PVA205 and CA were chosen to continue the design exploration. PVA205 is chosen over PVA filament because the content and possible additive in the PVA filament is unknown. 


\section{Material Evaluation}

After exploration of the various type of PVA, Starch and Cellulose. Each material is rated against the material criteria. It is clear that the most suitable material is PVA205 and CA, PVA205mb was relaced with PVA205s (fine powder form) for prototype and iterations in the design stage.
PVA $117 \mathrm{k}$

Dry time Layers

Extrudability

Degradation

PVA 117s

Dry time

Layers

Extrudability

Degradation

PVA 205mb

Dry time

Layers

Extrudability

Degradation

PVA Filament

Dry time

Layers

Extrudability

Degradation
Potato starch

Dry time

Layers

Extrudability

Degradation

0000

1000

100

Wheat starch

Dry time

Layers

Extrudability

Degradation

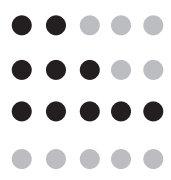

$\circ \bigcirc \bigcirc$
0000
0000

- ००

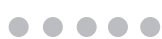

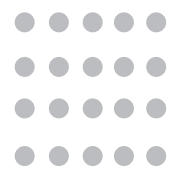

Hydroxypropyl cellulose with water

Dry time

Layers

$\bullet \bullet \bullet \bullet$

Extrudability

Degradation
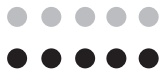

$\circ \circ \circ \circ \circ$

Hydroxypropyl cellulose with isopropyl
Dry time
$\bullet \bullet \bullet \bullet$
Layers
Extrudability
Degradation

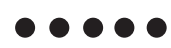

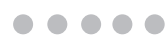

Methyl cellulose with water

Dry time

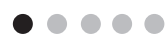

Layers

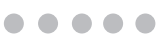

-

$\bullet \bullet \bullet \circ$

$\bullet \bullet \bullet \bullet \bullet$

Extrudability

Degradation

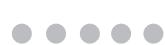

Carboxymethyl cellulose with water

Dry time

Layers

$\bullet \circ \odot \bigcirc \circ$

$\circ \circ \circ$

Extrudability

Degradation

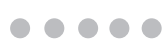

Cellulose acetate with acetone

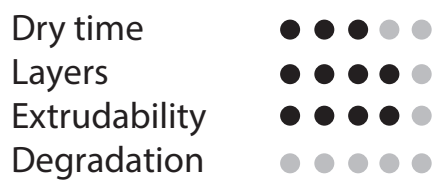


(2)

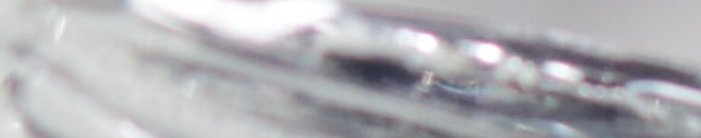

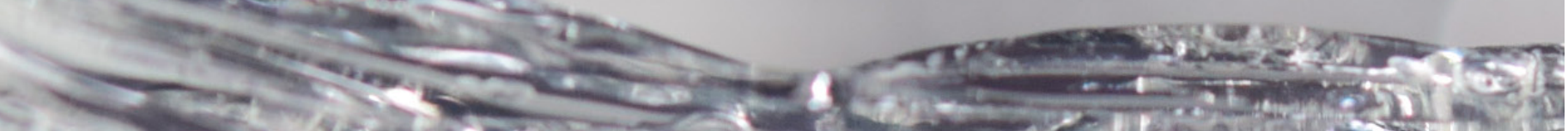

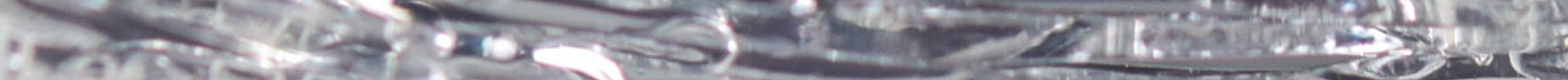

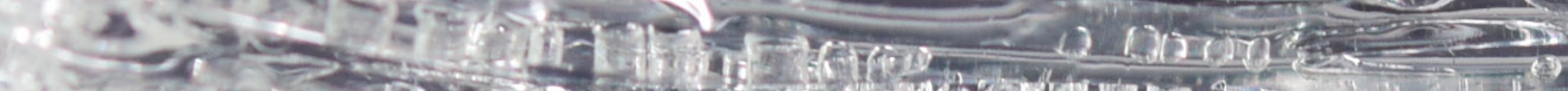

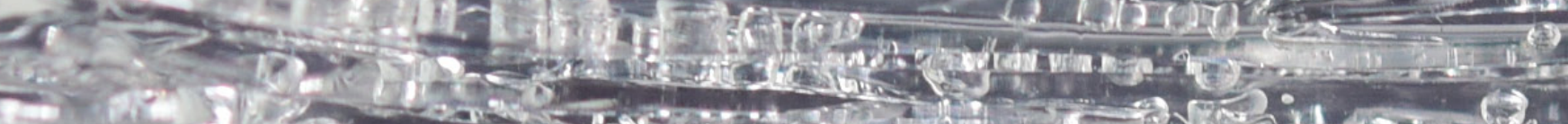

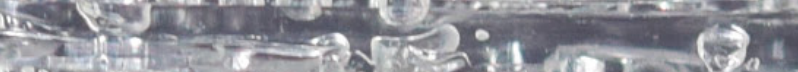

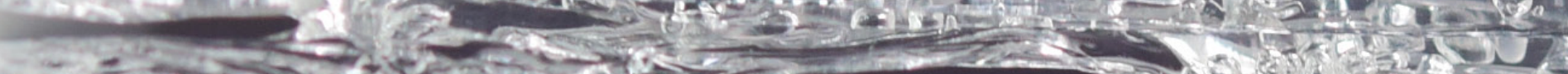

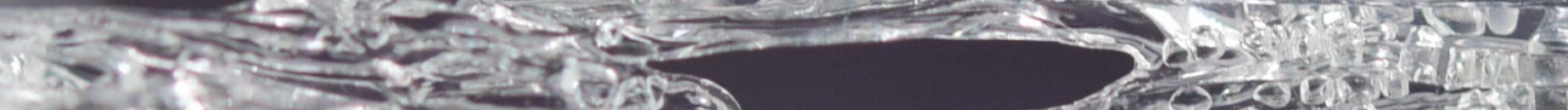

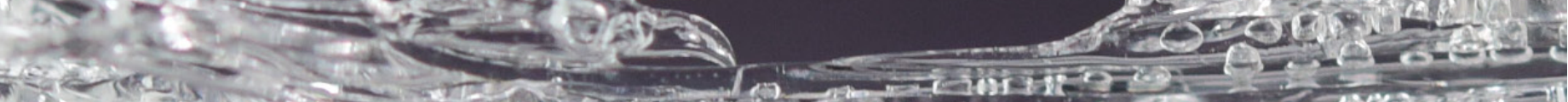

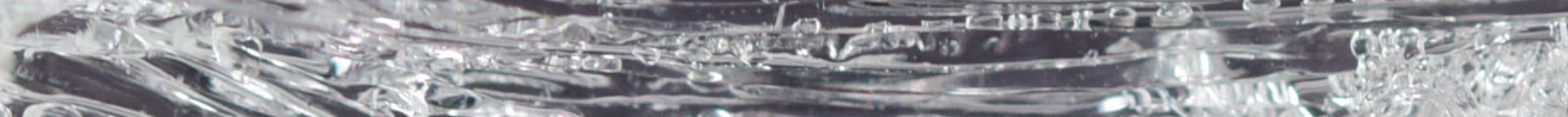

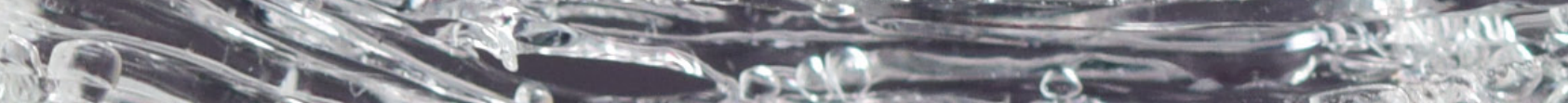

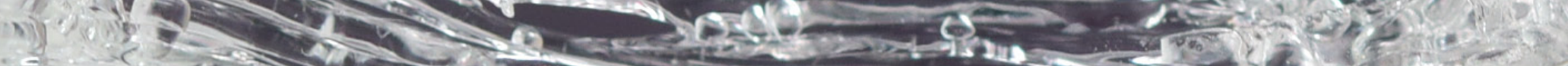
5. सu S

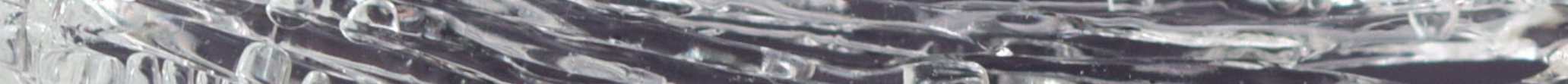

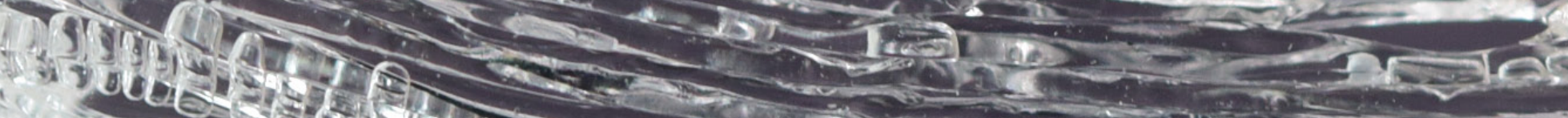

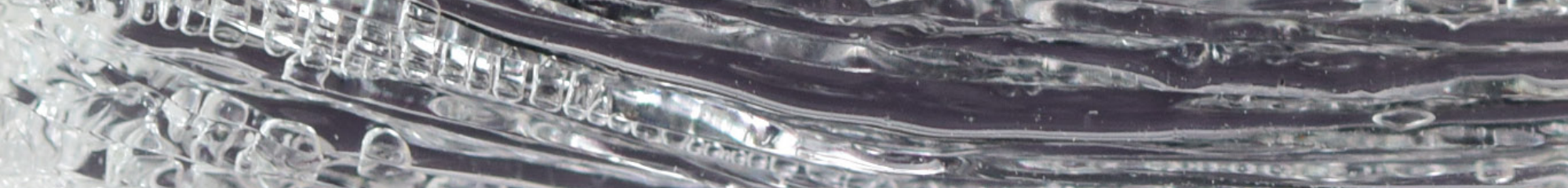

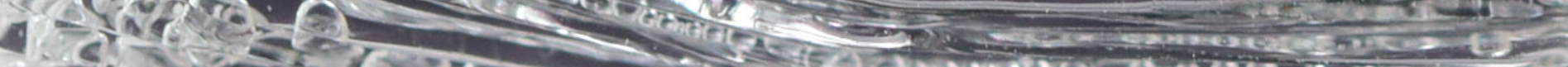

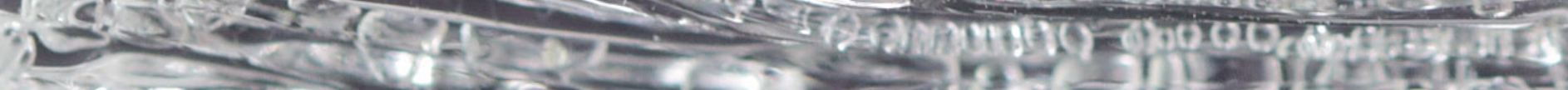

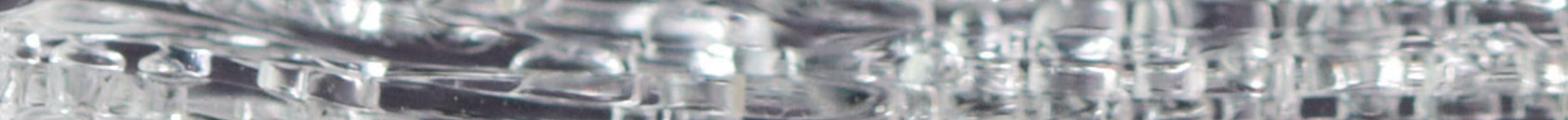

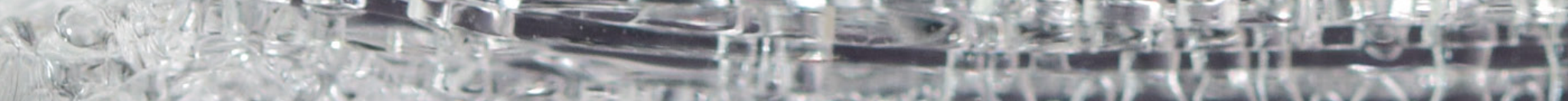

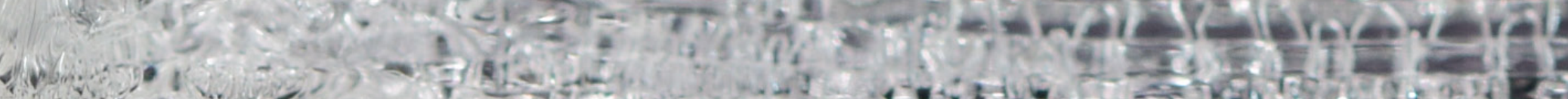

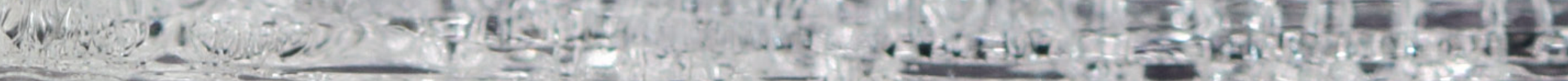




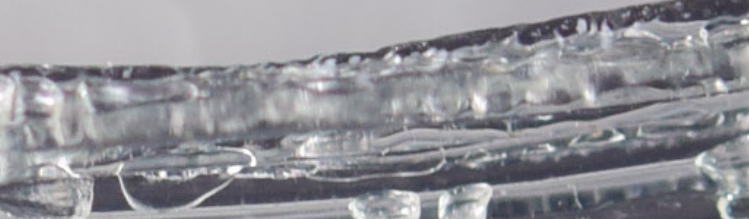

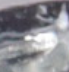

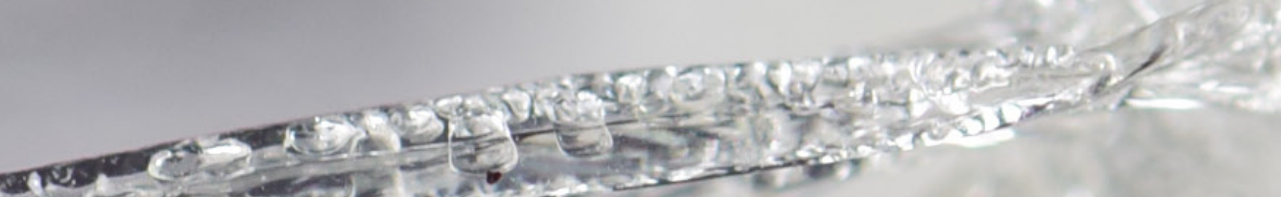

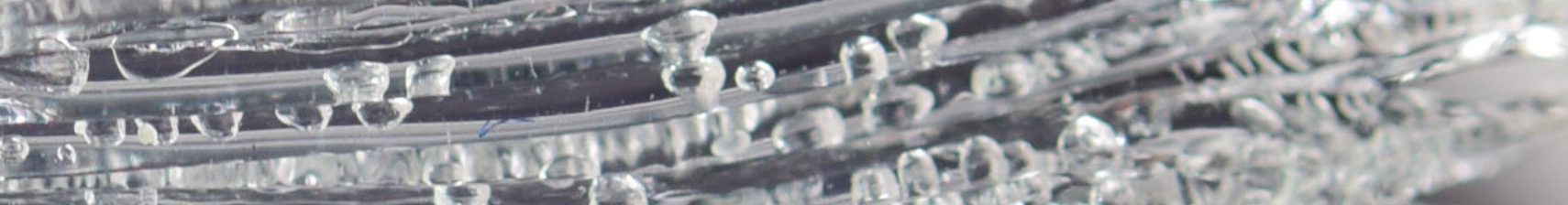

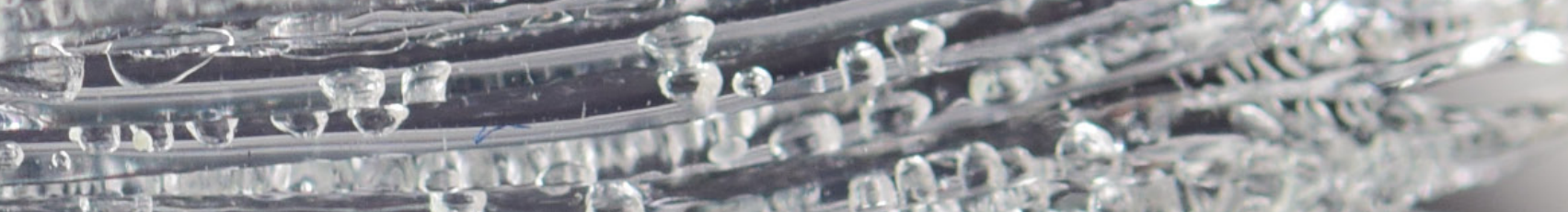

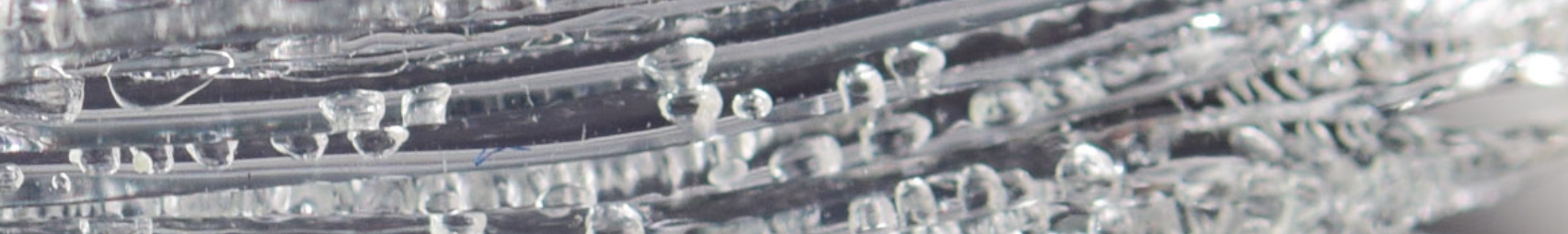

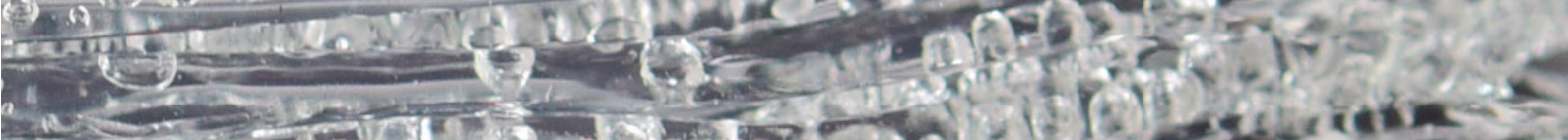

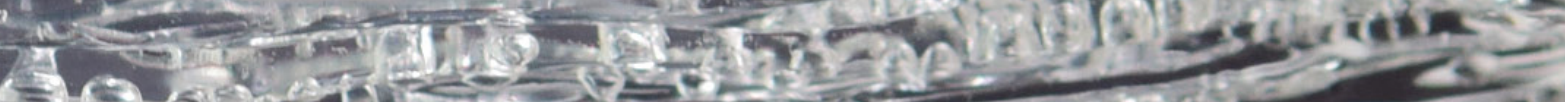

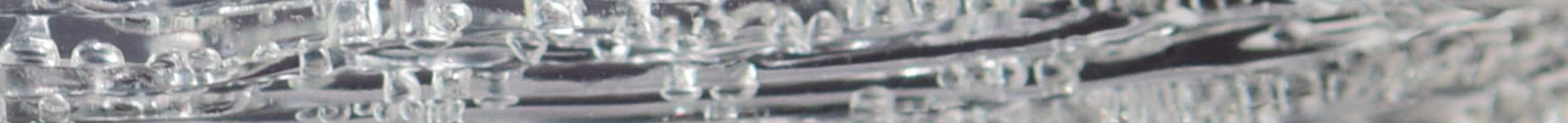

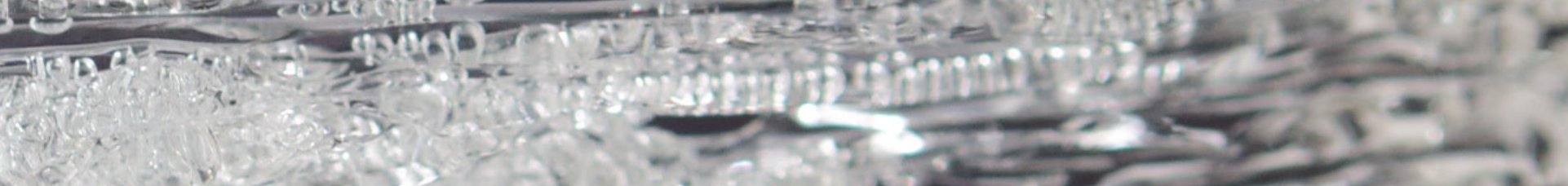

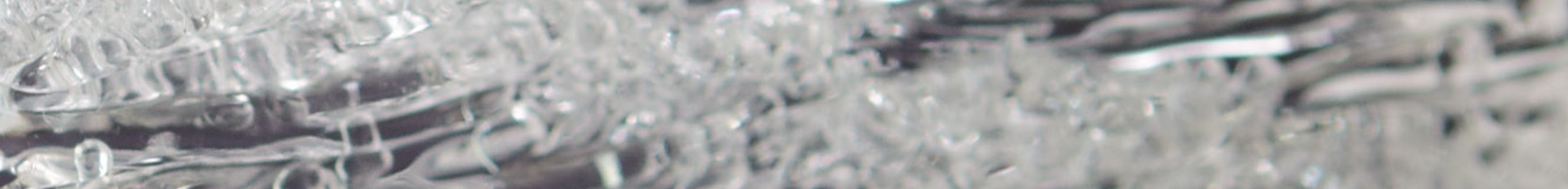

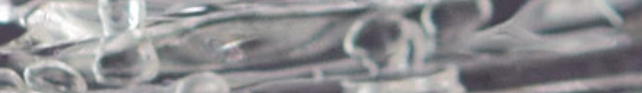

A.

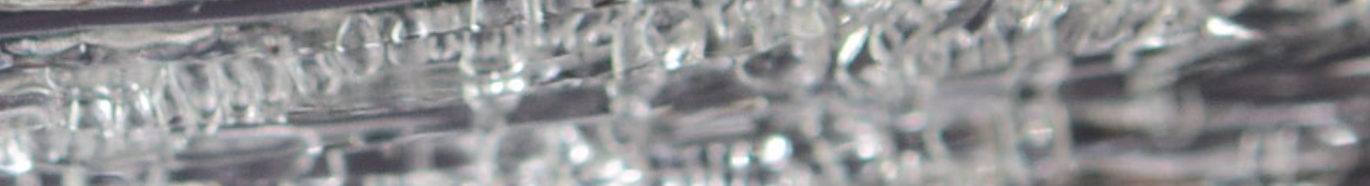

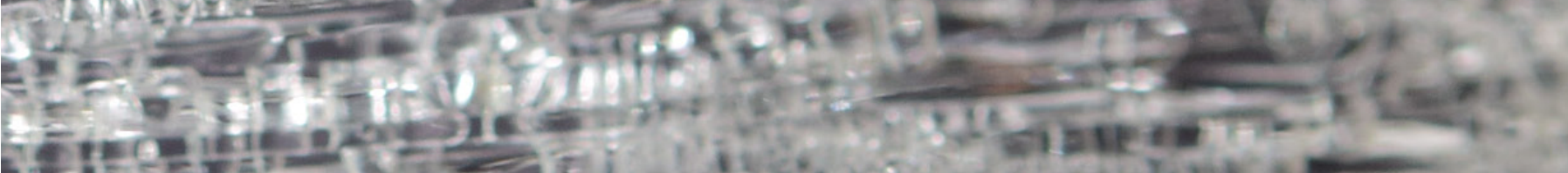

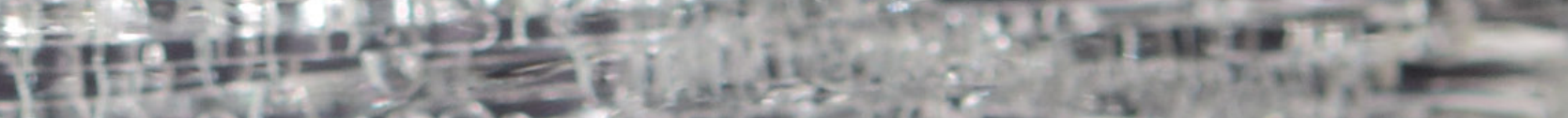

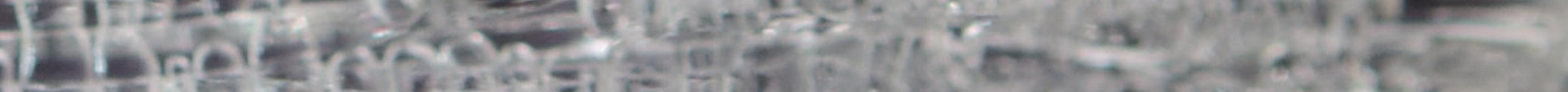

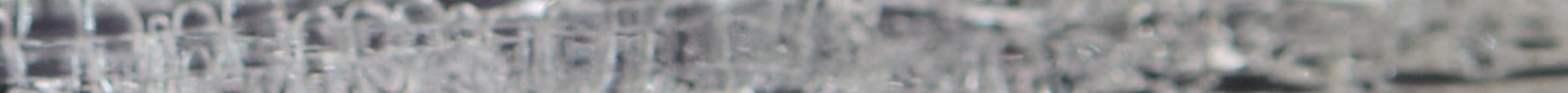

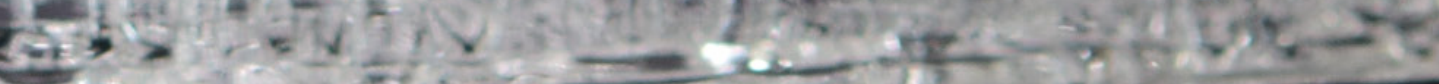


CHAPTER

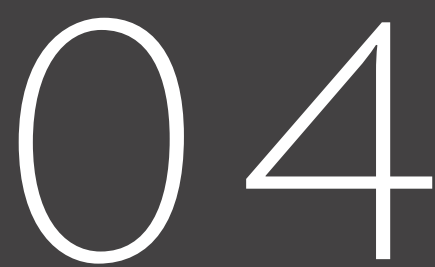

Design exploration 


\section{Idea Generation}

Observation

The following set of photos includes various decaying natural objects that we tend to disregard, avoid, or pay minimal attention. The purpose of this visual observation is to reveal stages of decay that we usually do not appreciate, which play an immense role in nature.
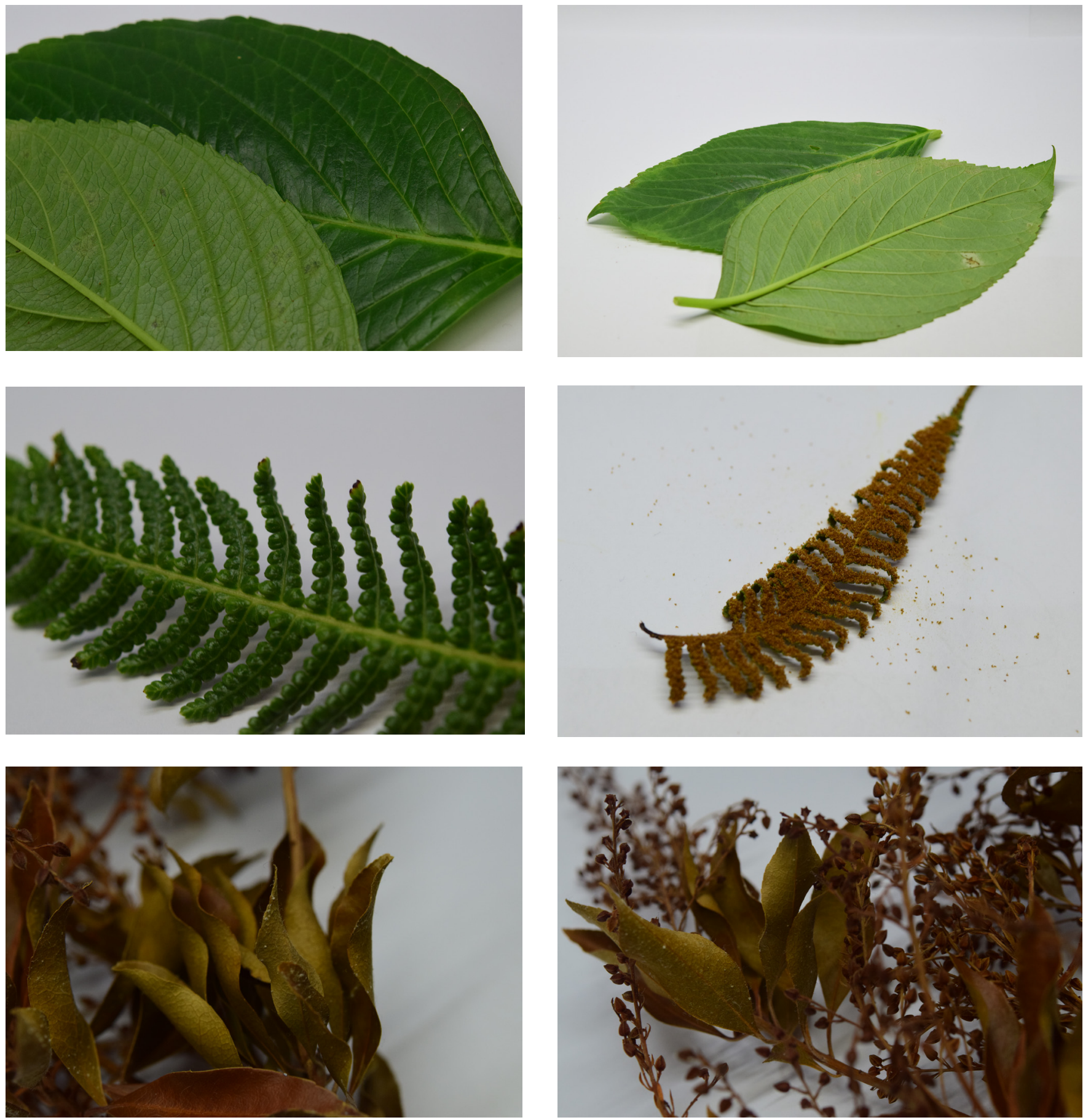
Image 4.1 - 4.12 (Group below ) Leave degradation photo observation
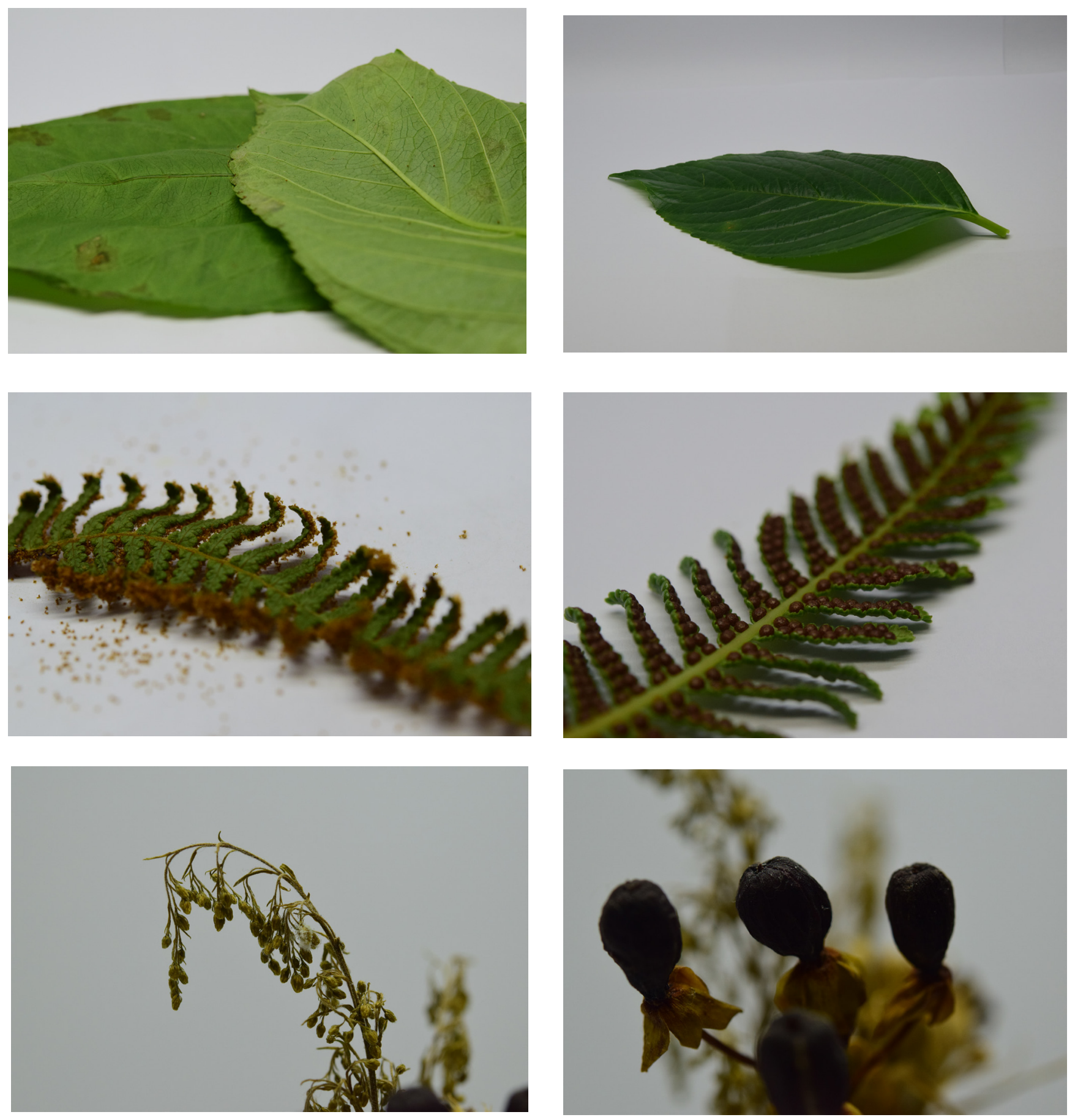

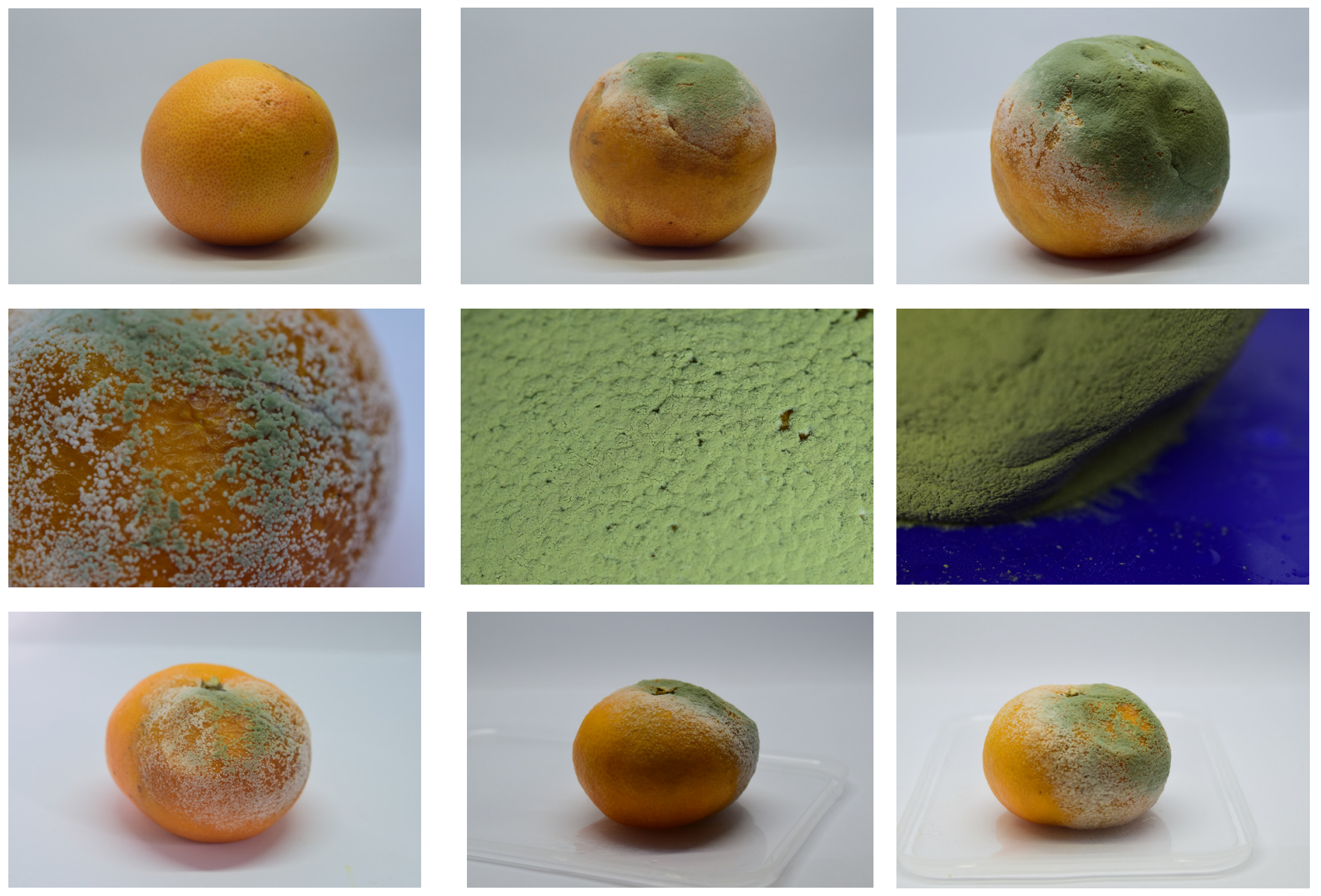
Design to Degrade
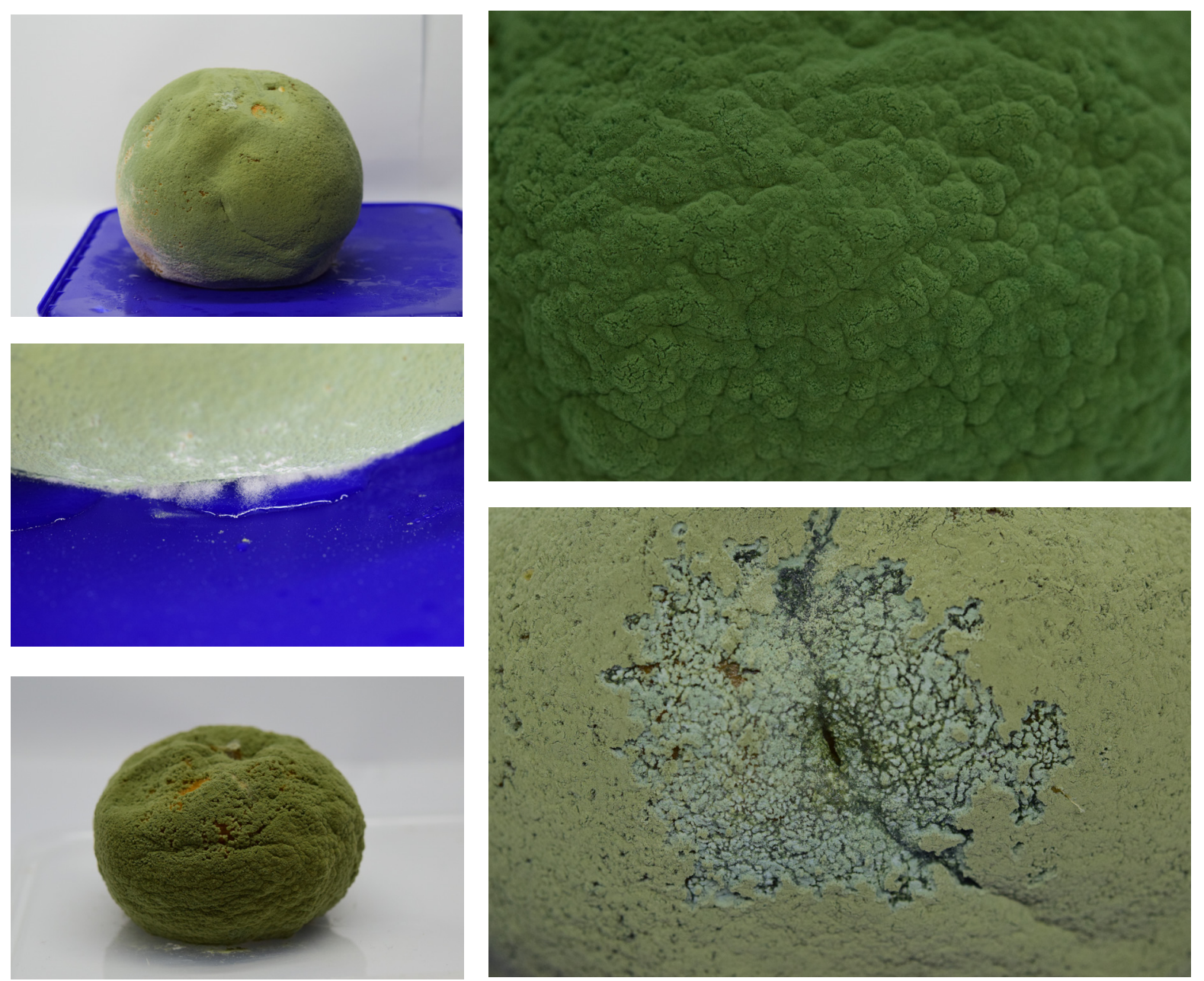

Image 4.13-3.26 (Group) Orange degradation photo observation. 
Analysis

\begin{tabular}{|c|c|}
\hline Objects & Qualities \\
\hline Orange & $\begin{array}{l}\text { - Wrinkles } \\
\text { - } \text { Darkens } \\
\text { - White mould starts then green mould } \\
\text { - Softens and flattens } \\
\text { transfly emerged green mould results in total } \\
\text { transfon texture and colour }\end{array}$ \\
\hline Leaves & $\begin{array}{l}\text { Brown spots } \\
\text { Fade in colour } \\
\text { Edge curl inwards }\end{array}$ \\
\hline Ferns & $\begin{array}{l}\text { Wither and wrinkles } \\
\text { Edge of fern starts to turn brown } \\
\text { Spore in casing is dispersed and forms a new fluffy } \\
\text { texture as well as falling off }\end{array}$ \\
\hline
\end{tabular}

Revealing

Table 4.1(Top) Analysis of photo observation

Through analysing the visual observations, two dominant themes emerge: change in form and texture. These elements continuously surface in a various different decaying object. Its seem to be a continuous surfacing element that visually indicates different stages. Therefore these core visual elements will be used within the design process to integrate degradation into an artificial artefact. At the same time, use of multi-material materials will assist the transformative quality of degradation 

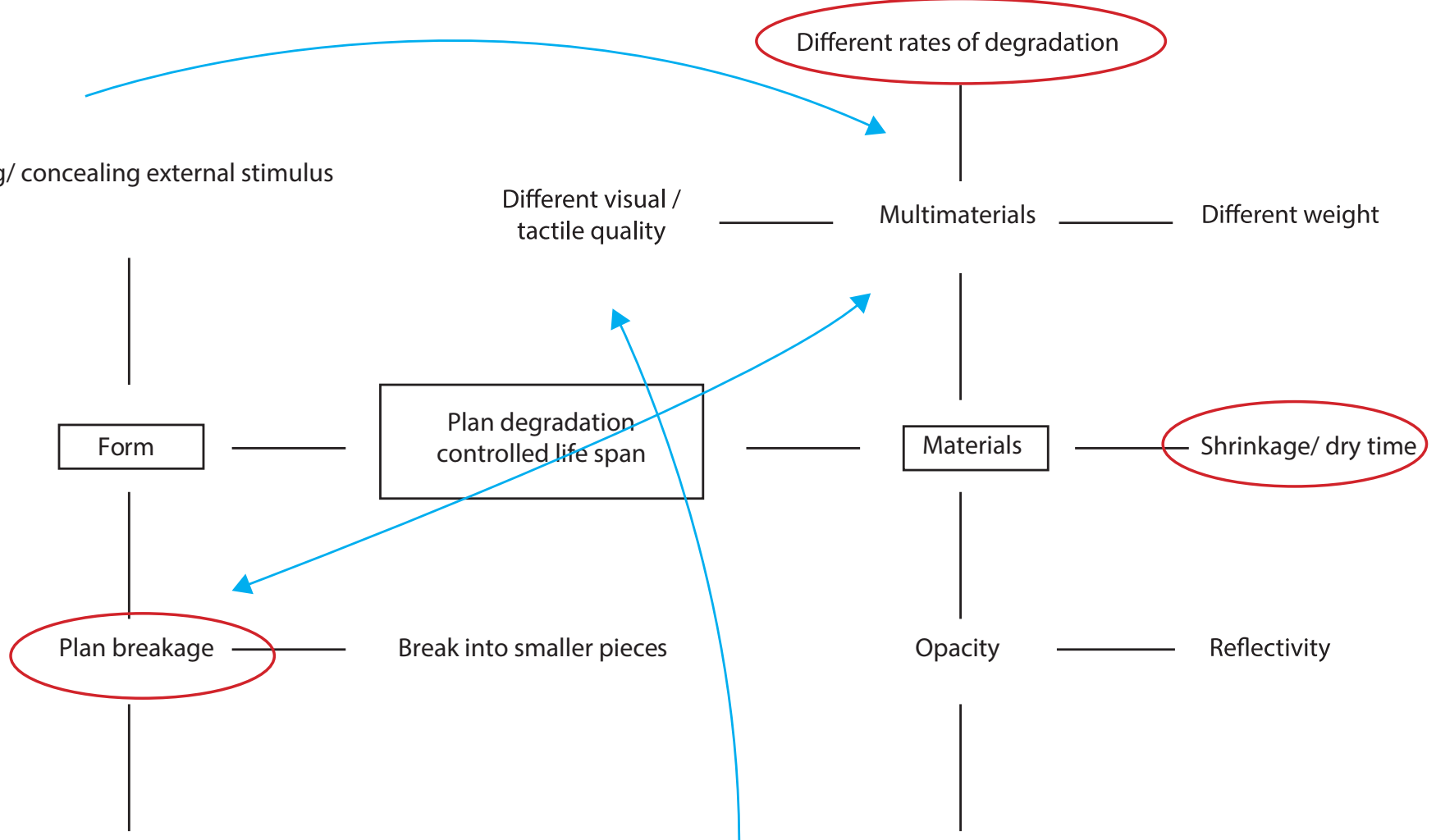

Different visual /

Multimaterials

Different weight

Weak spots

Transparency

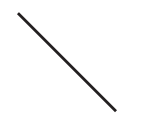

Surface area

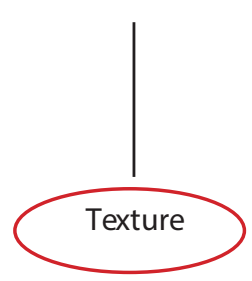

This mindmap aims to answer the question: How to design degradation with multi-material of different degradation rate? The mind map visually organises the ideas to generate more interesting method to answer the question. The ideas circle in red help formulated the different design degradation approach.

Image 4.27 (Top) Brainstorm 
PVA (fast degrading) and CA (slow degrading) degraded via different stimulus and at a different rate, by arranging varying thickness, size, form and position of each material in the desired way. It is possible to design the outcome and process of degradation and predetermine the appearance of a second entity once the object is degraded over time. Here are a few possible design approaches.

\section{Approach A}

This approach is inspired by textures that form during degradation. The holes of the texture will be filled with PVA to disguise as one full surface, as the PVA degrade the designed texture will appear. In between the process, the texture will keep changing until it reaches the design form, meaning the pattern will continuously change until it achieves the designed form. This changing texture will make the object more animated.
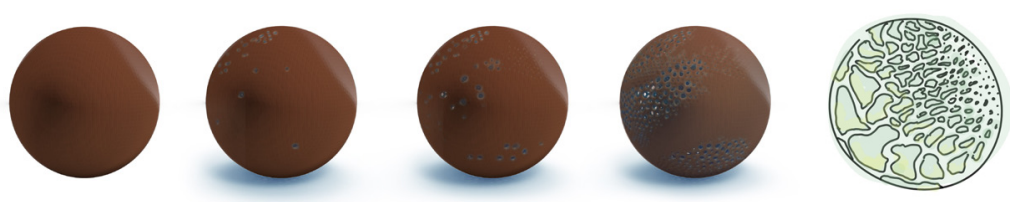

Image 4.28 (Top) Approach 1

\section{Approach B}

This approach focuses on changing shape. A degrading outer form reveals the second form with a different function. This is to draw attention to the necessity of degradation and remind the user that degradation can be a shift in function, not only a diminishing of function.
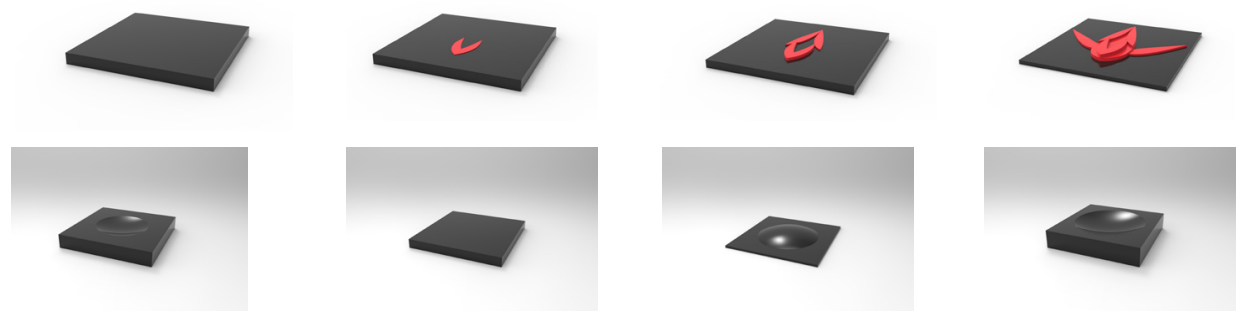

Image 4.29 (Top) Approach 2 


\section{Approach C}

This approach took the idea of a degrading material breaking into smaller parts. These smaller pieces are still functional. This concept aims to predetermine weak areas that will be the first site of separation.
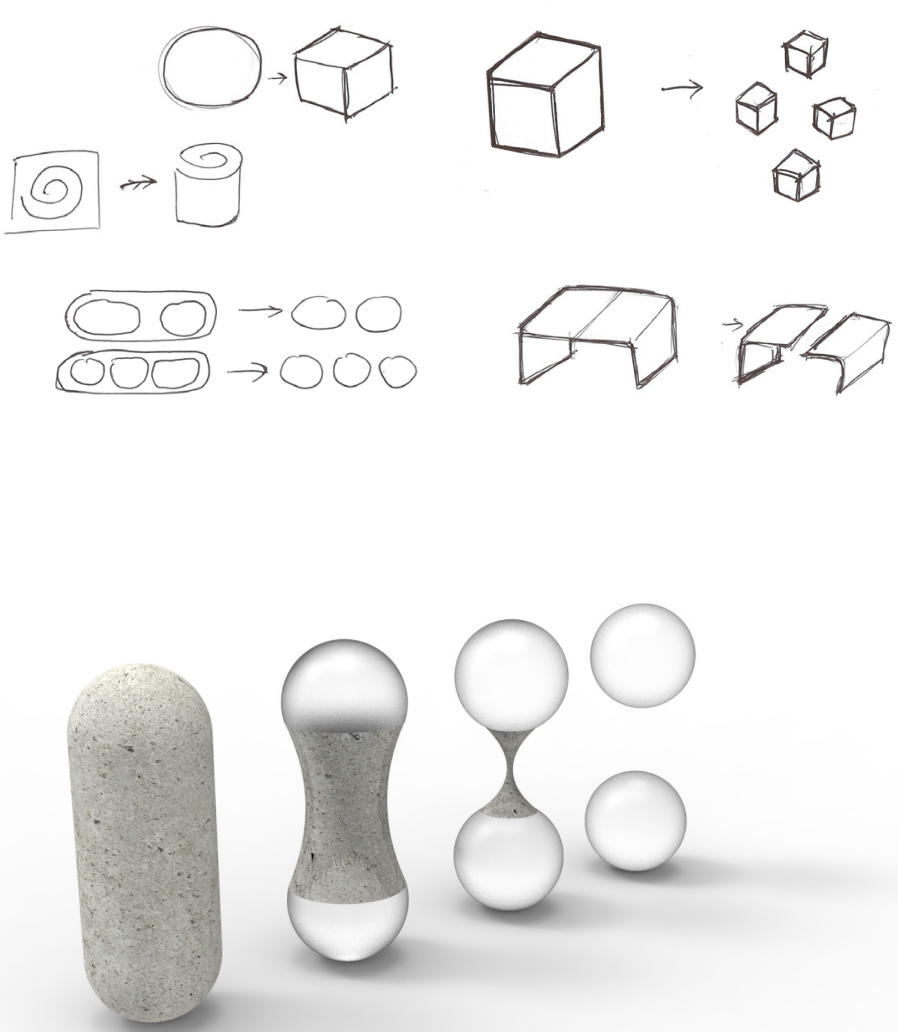
These case studies observed natural degradation and applied to the artificial making process. Firstly mimicking the natural object, subsequently apply the principle to an artificial object. Here we look at two example an orange and a leaf. They are both common objects that we do not normally examine their degradation stages in detail.

\section{Case Study}

Leaf - The degradation of leaf include the change in form, texture, colour and curling of the edge. This was mimicked through $3 \mathrm{D}$ printing thin layer of CA and allowing it to curl naturally. The leaf was coloured to show colour changes. And holes were printed as part of the design to show degradation.
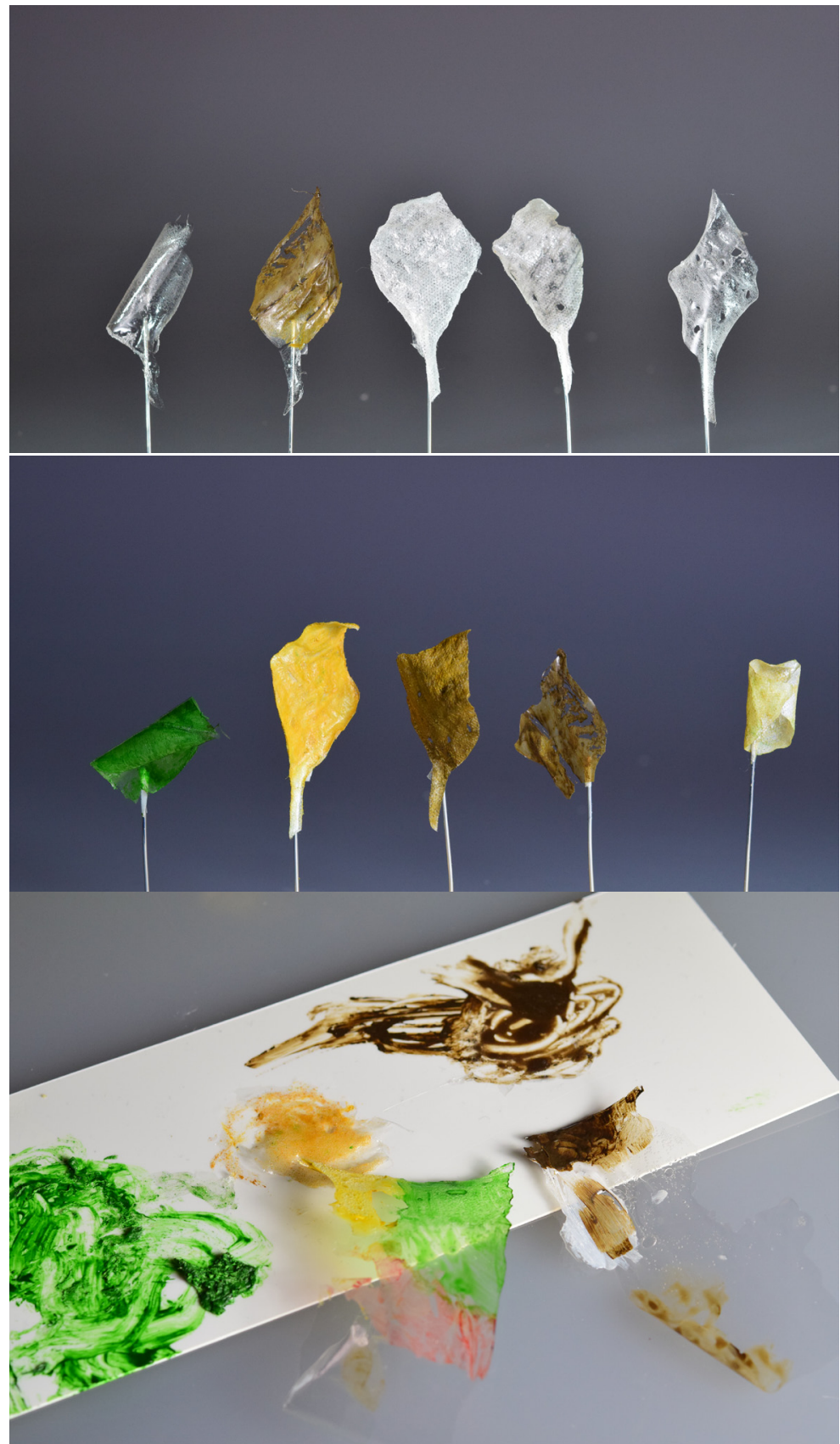

Image 4.31 (Top) Initial prototype with no colour was not very representative of nature's process of decay.

Image 4.32 (Middle) Soon I realised colour acted as a strong indicator of degradation stages.

Image 4.33 (Bottom) Exploration with mixing acrylic paint with aquious cellulose acetate and direct painting of acrylic paint. 
Nature

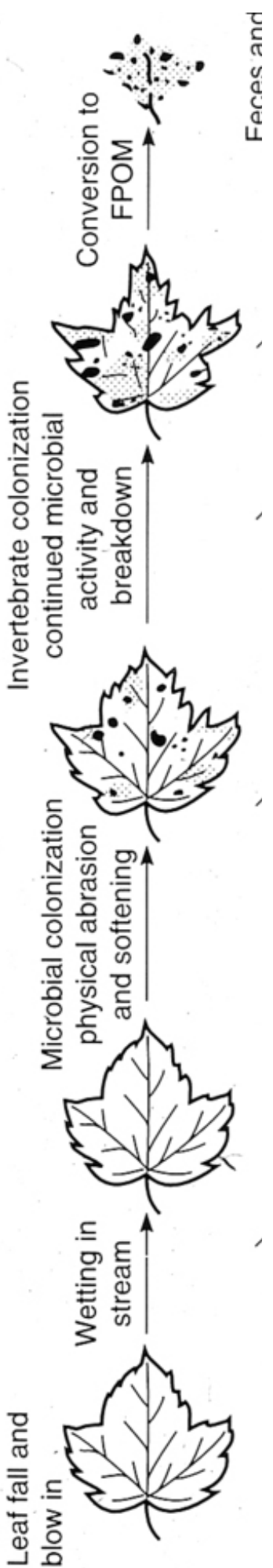

Image 4.34 (Top) Leaf

degradation in natrue
Mimicing nature
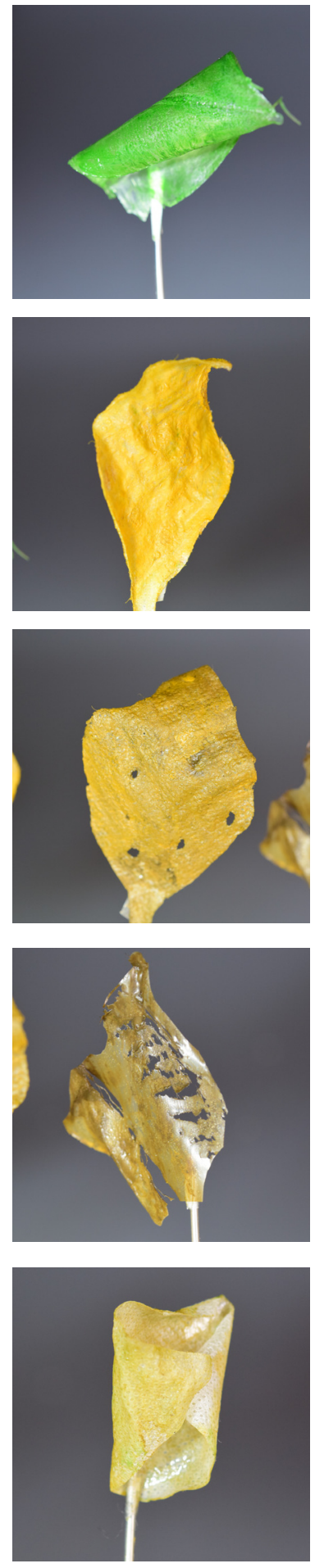

Image 4.35 (Top) Leaf made by CA to repreent degradtion
Application
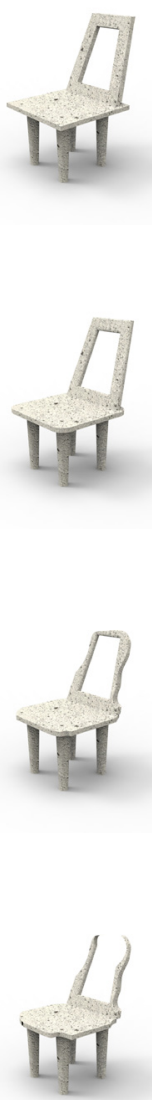

पII
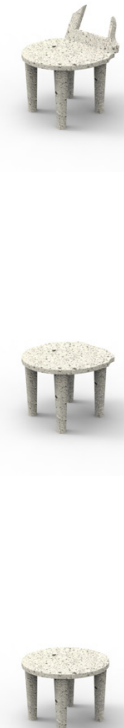

Image 4.36 (Top) Degradation learnt from leaf apply to a chiar that degrade to a stool. 
As observed earlier the degradation of an orange shows gradual change in texture due to growth of mould. This texture is photographed and used as an input to generate a 3D texture parametrically in Grasshopper. I was able to generate and visualise different stage of degradation. This can be applied to any surface or object.
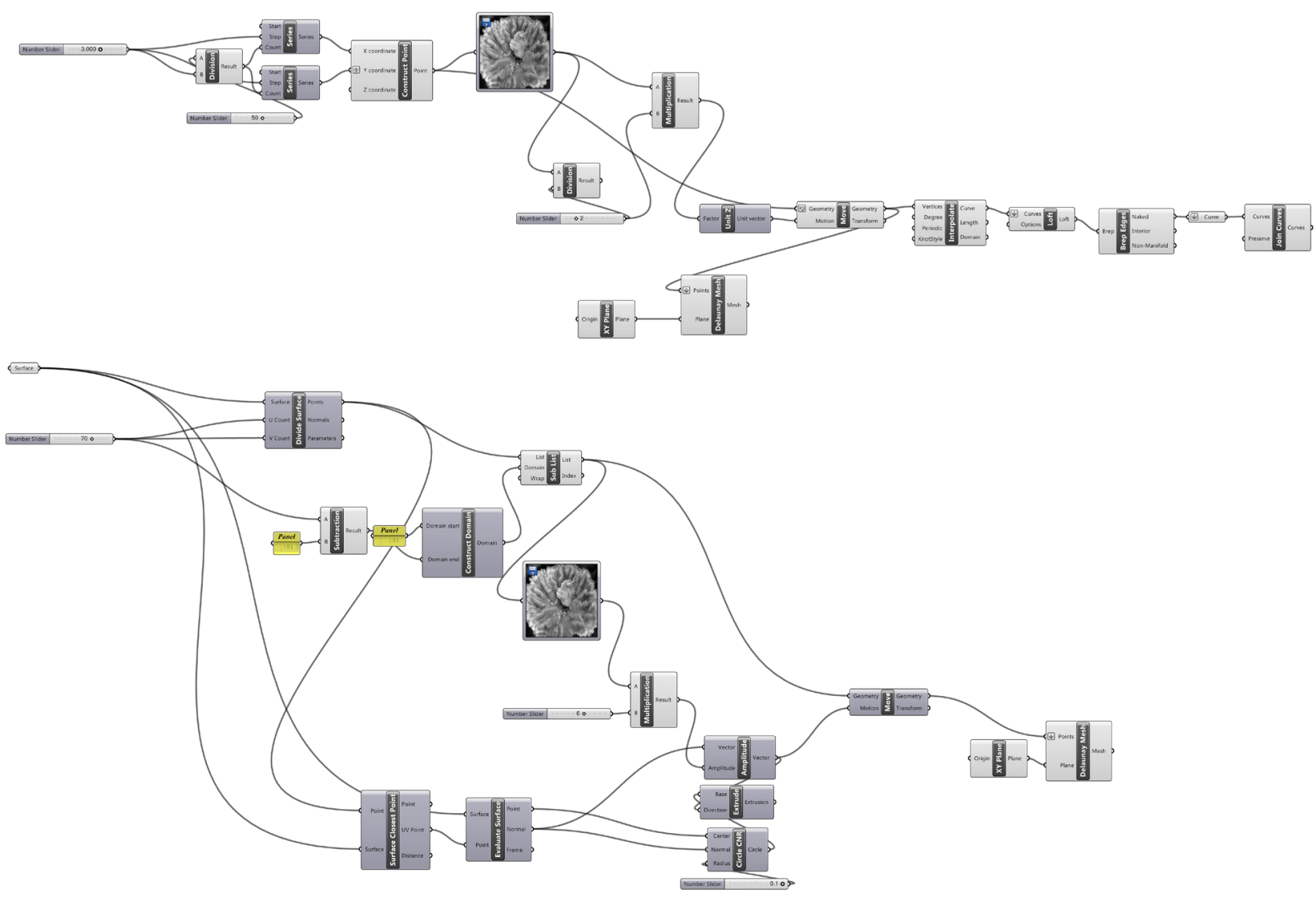

Image 4.37 (Top) Grasshopper definition to imput degradation image to transelate degradation to a 3D form ready for printing. 


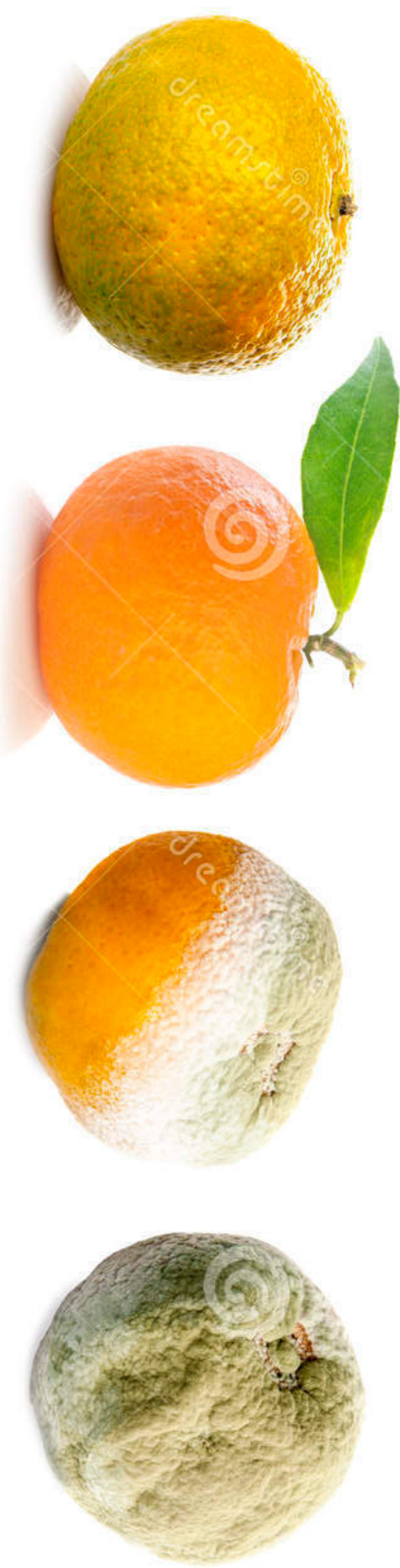

Image 4.38 (Top) Orange degradation in natrue

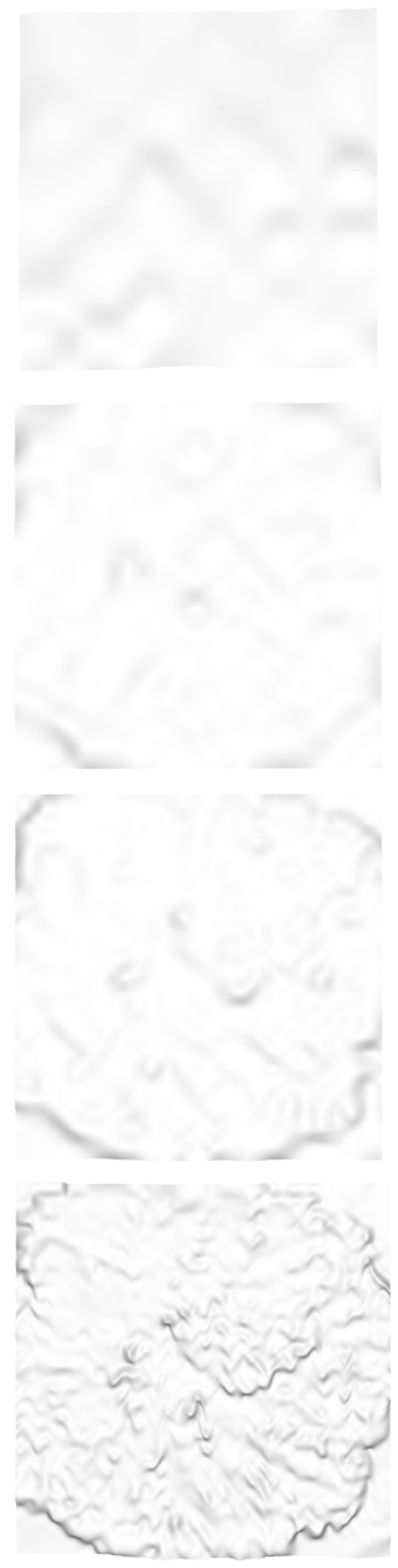

Image 4.39 (Top) Degradaing texture made by Grasshopper
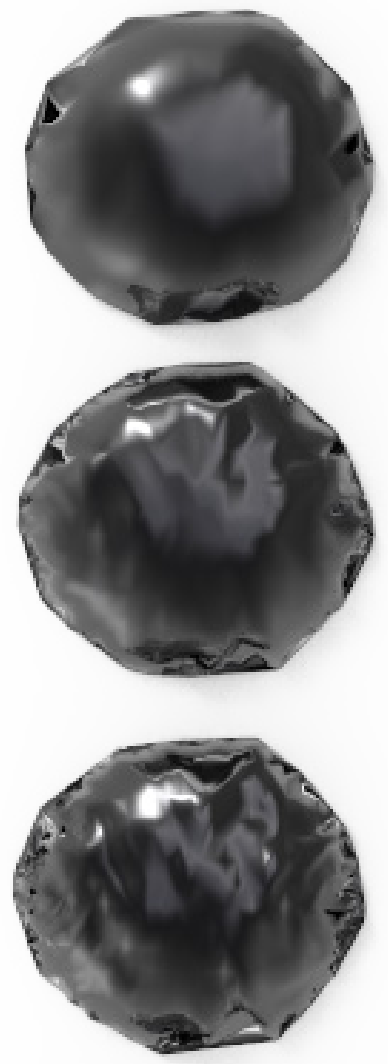

108

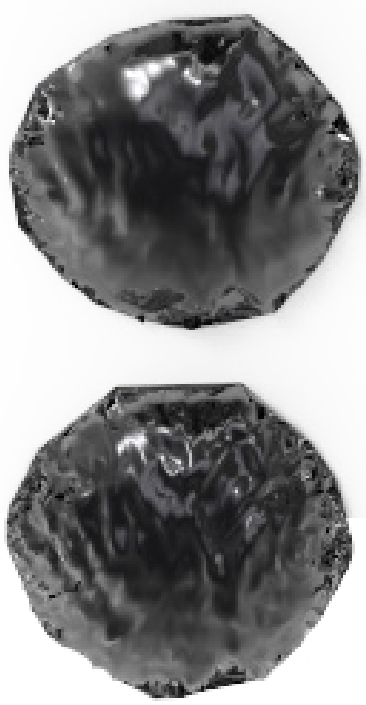

Image 4.40 (Top) Grasshopper definition apply on to 3D form. 

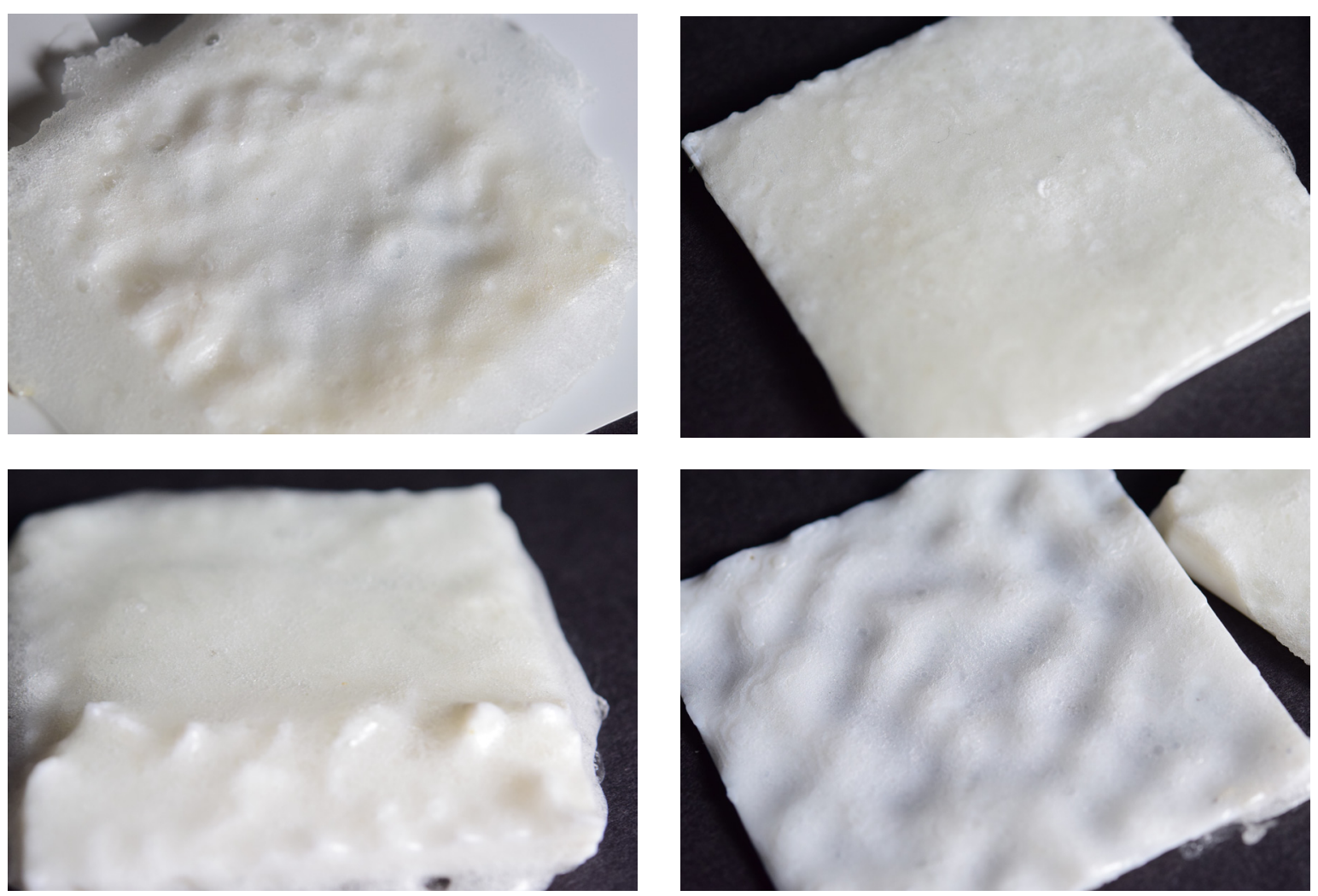

Image 4.41 -4.46 (Group) thermal abs print of degradation texture generated through grasshopper. The models are coated with PVA. It is hypothesising that the PVA will degrade and reveal the textures. 


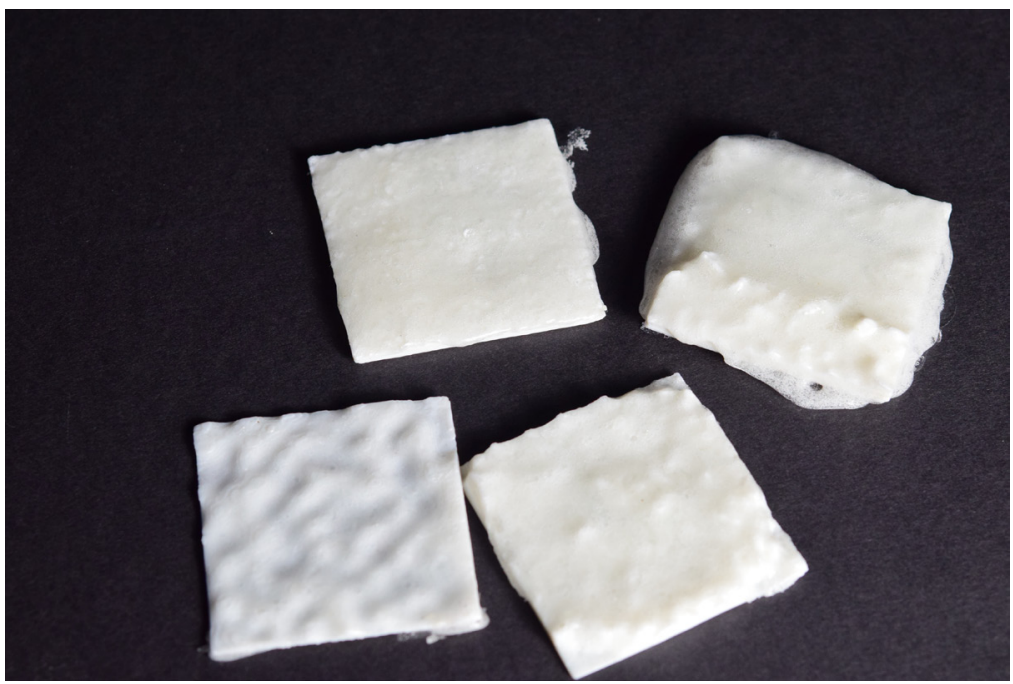

The degrading texture that was generated is 3D-printed and was covered in PVA. This is done to show the possibility of complex form being revealed by design degradation.

Moreover, the case study, suggest that potentially this design degradation can be paired with parametric design to customise death and lifespan of objects. 
Fake plants

Texture

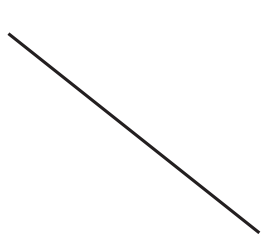

\section{Design Idea}

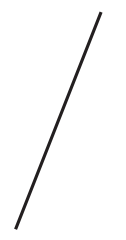

Modular unit

Manually mc<smiles>C1CC1</smiles>
around

Utilise shrinkage to create form<smiles>C=CC=C</smiles>

Join units together to form bigger structures.

Main feature of cellulose paste printing

- soft - can embed things

- still malluable - can sculpt/ mold/ adjust

- Differetn every time

- speed can cause stringing ( also depends on materials) 
When degradated the objects will become bigger than itself

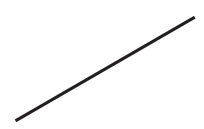

Apply pressure to tcreate tension

mould PVA ind CA

Embed other material

Colour

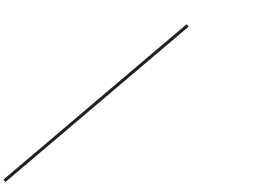

e.g. stone

nbed wire to control shrinkage

as well as function

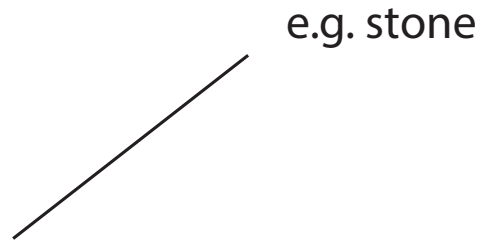

Light unit

Led strips

Light quality

Main disavantage of cellulose paste printing

- difficult to build layers, if one layer part of the layer missed,

influence the whole structure.

- can't print comp.licated forms or much overhang. 
Preliminary Design

Design criteria - from concept mapping

Celebrate beauty and the necessity of degradation

Transformative and dynamic.

Resemble natural degradation change in form and texture.

\section{Concept 1}

\section{Concept 2}

In concept one I wish to the reduce the use of materials, particularly support materials, that are usually involved in 3D printing. The main part of the design will be printed in a large area with a low $z$ height for quicker and more economical printing with CA. Then a secondary material will be inserted to form the structural part of the design. This design uses the shrinkage to create organic curves, as well as to reduce manufacture time and material. The surface will have designed texture that reveals itself over time.
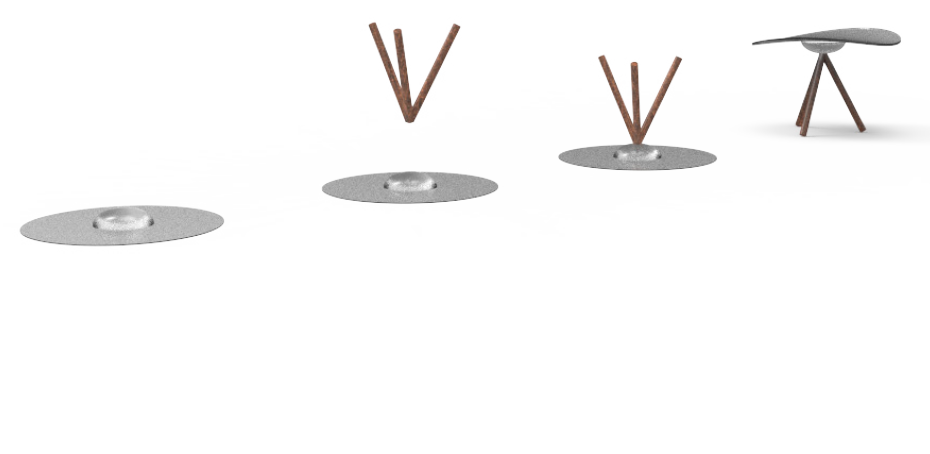

Image 4.48 (Top) Render of concept 1

Concept two uses shrinkage to create degradable therefore this concept will CA degradation as part of the design.
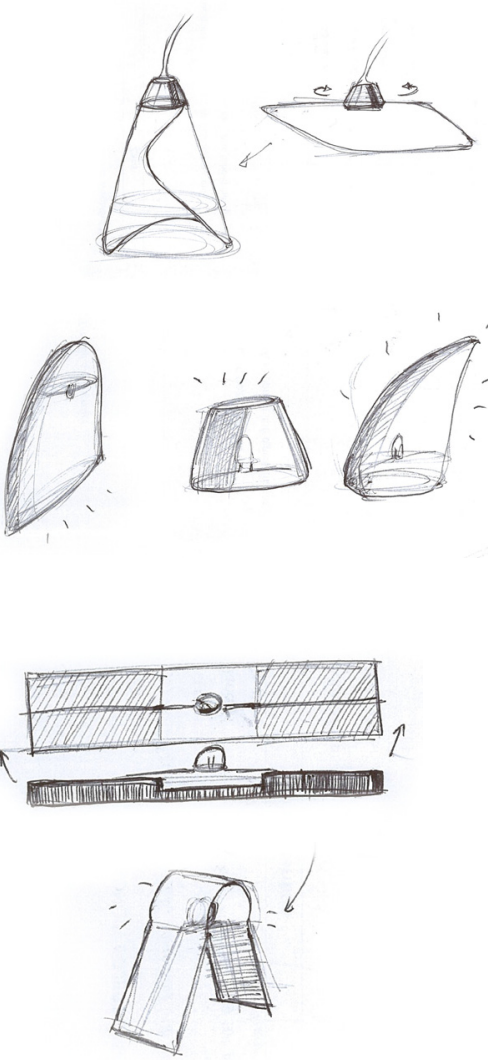
sate 3D forms for lighting. CA was proven UV : will use this relationship between lights and gn.

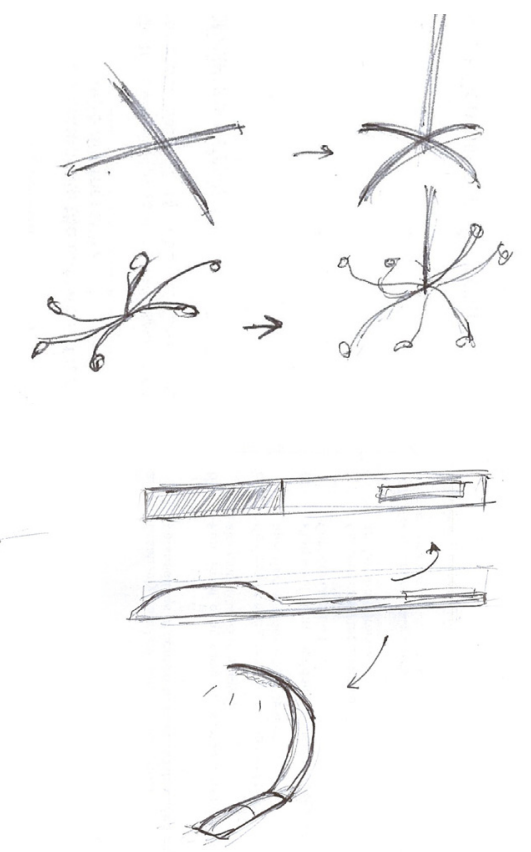

Image 4.49 (Top) sketches of concept 2

\section{Concept 3}

Concept three aims to create provocative digital plants or flowers with CA (naturally found in plants), in order to address the importance of degradation in artificial objects. This concept again uses the shrinkage of CA to create organic forms that cannot be done via common FDM printing or expensive high-end printers (e.g. SLS) without large amounts of support materials.
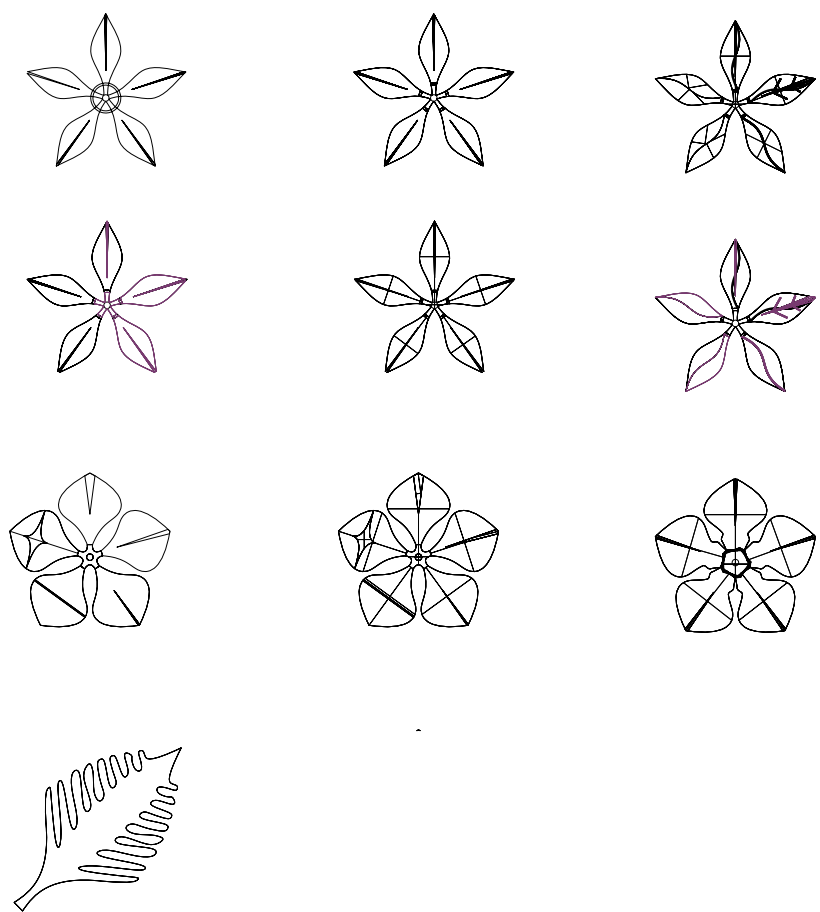

Image 4.50 (Top) drawings of concept 3 


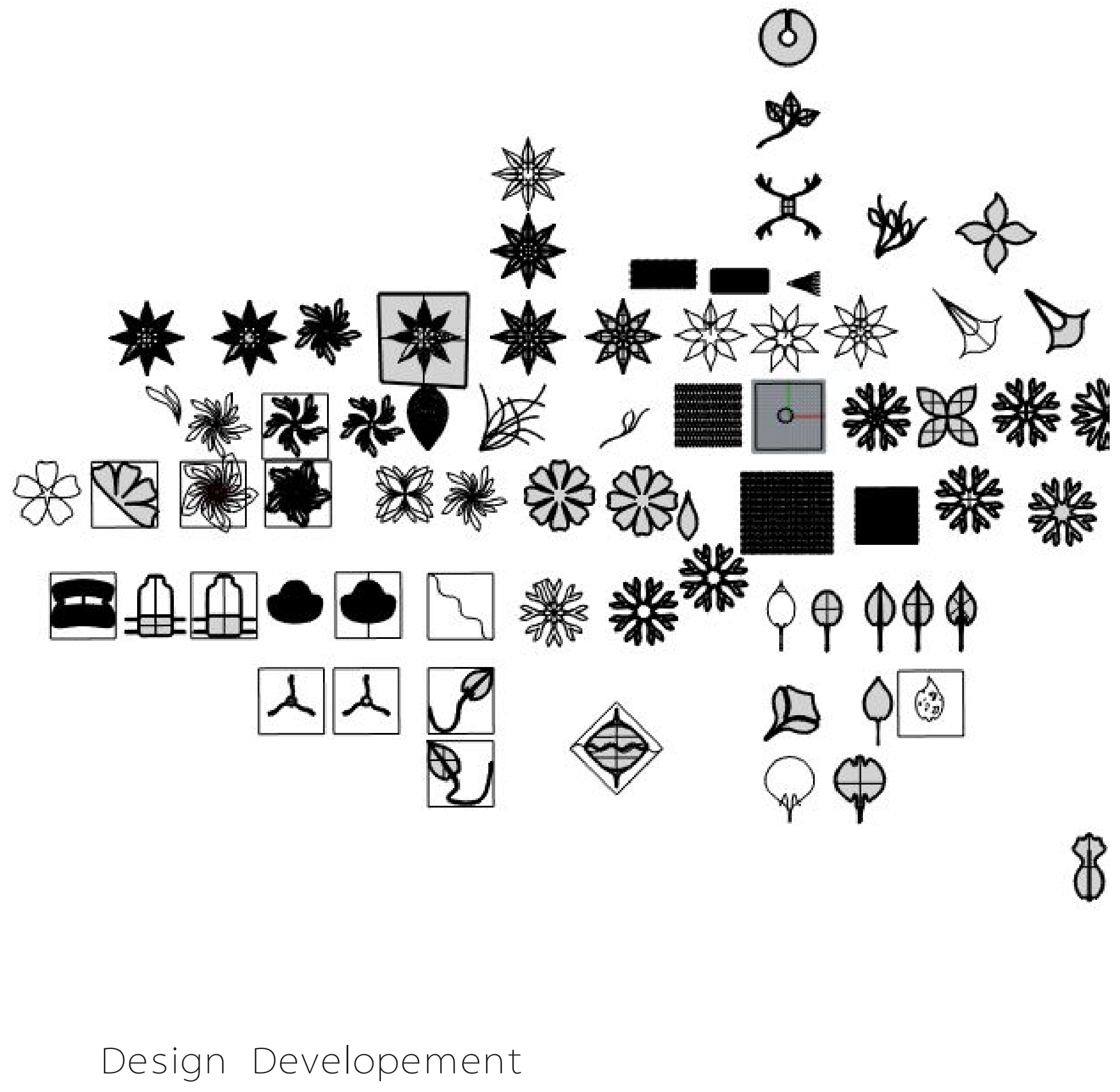

Concept 3 was explored further as it was the most neutral idea that did not provide any specific way to integrate designed degradation into a product. This idea was chosen in the hope of inspiring other designers to create other diverse approaches to designing the way that products degrade. 


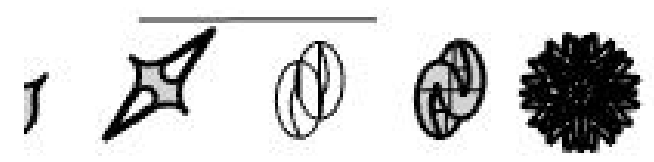

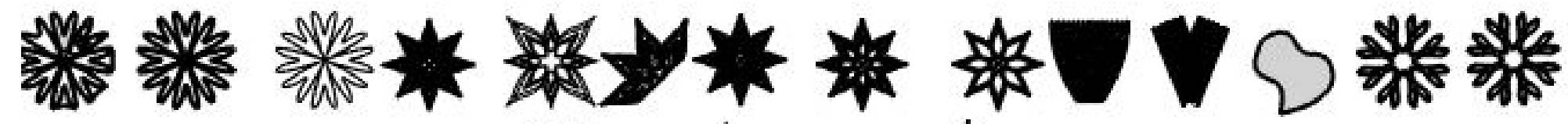

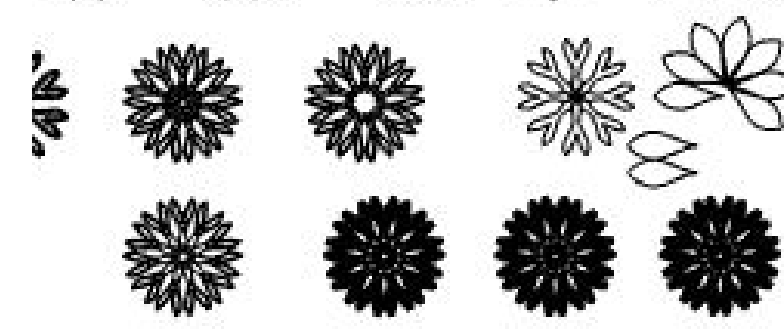

23
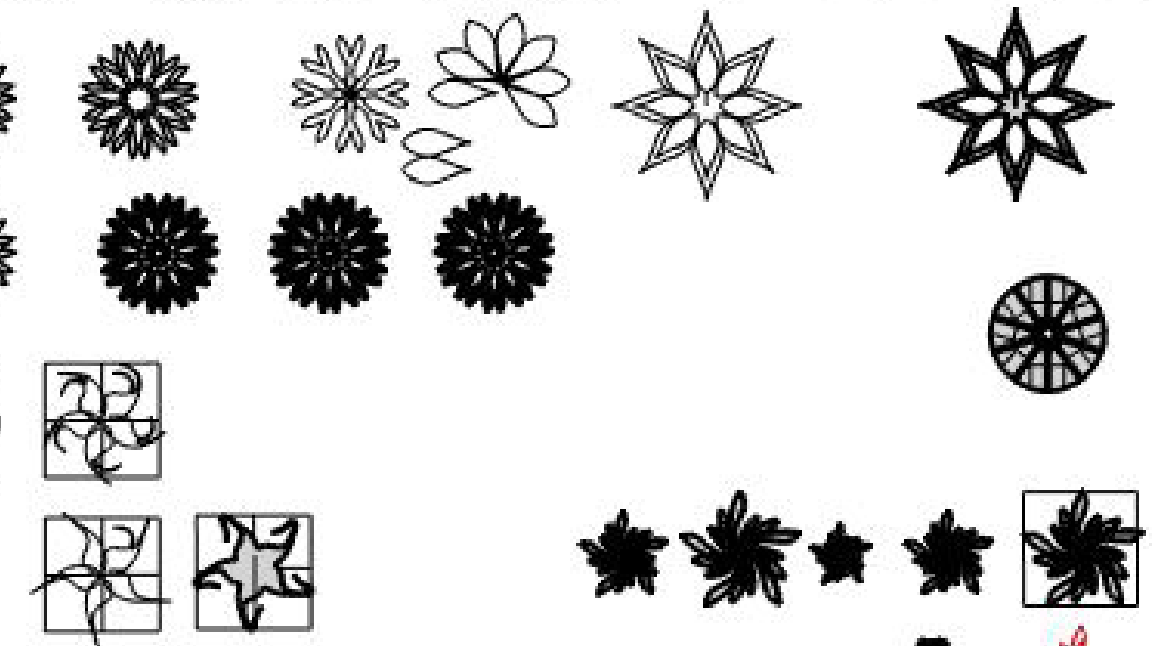

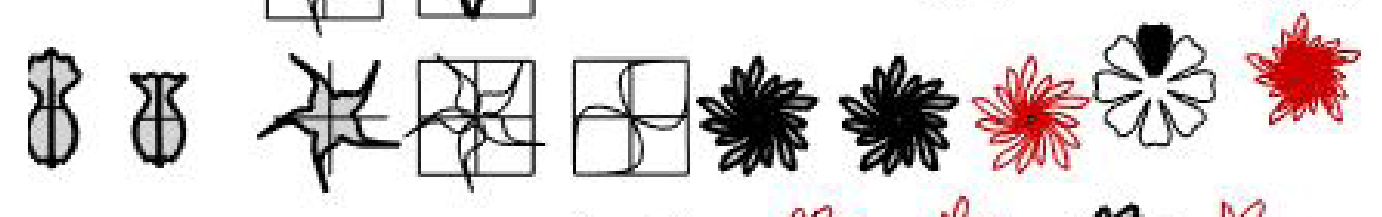

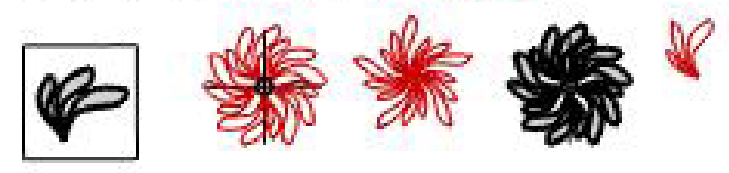

ก
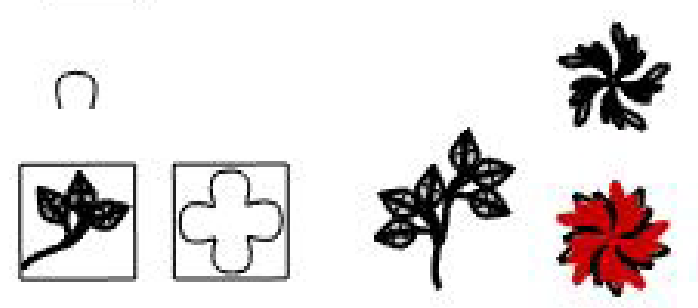


\section{Prototype and Iteration 1}

This first set of iteration and prototype draws inspiration from plants. I like the idea of using a derivative of a plant (cellulose) to make a digital plant. This can effectively address the concept of natural and man-made hybrid design. These prototypes will be 3D printed with CA focusing on using minimal material and allow the shrinkage of $\mathrm{CA}$ to naturally give form to the artefact. This set of iteration mainly explore forms that resemble plants, yet directs interesting curling.
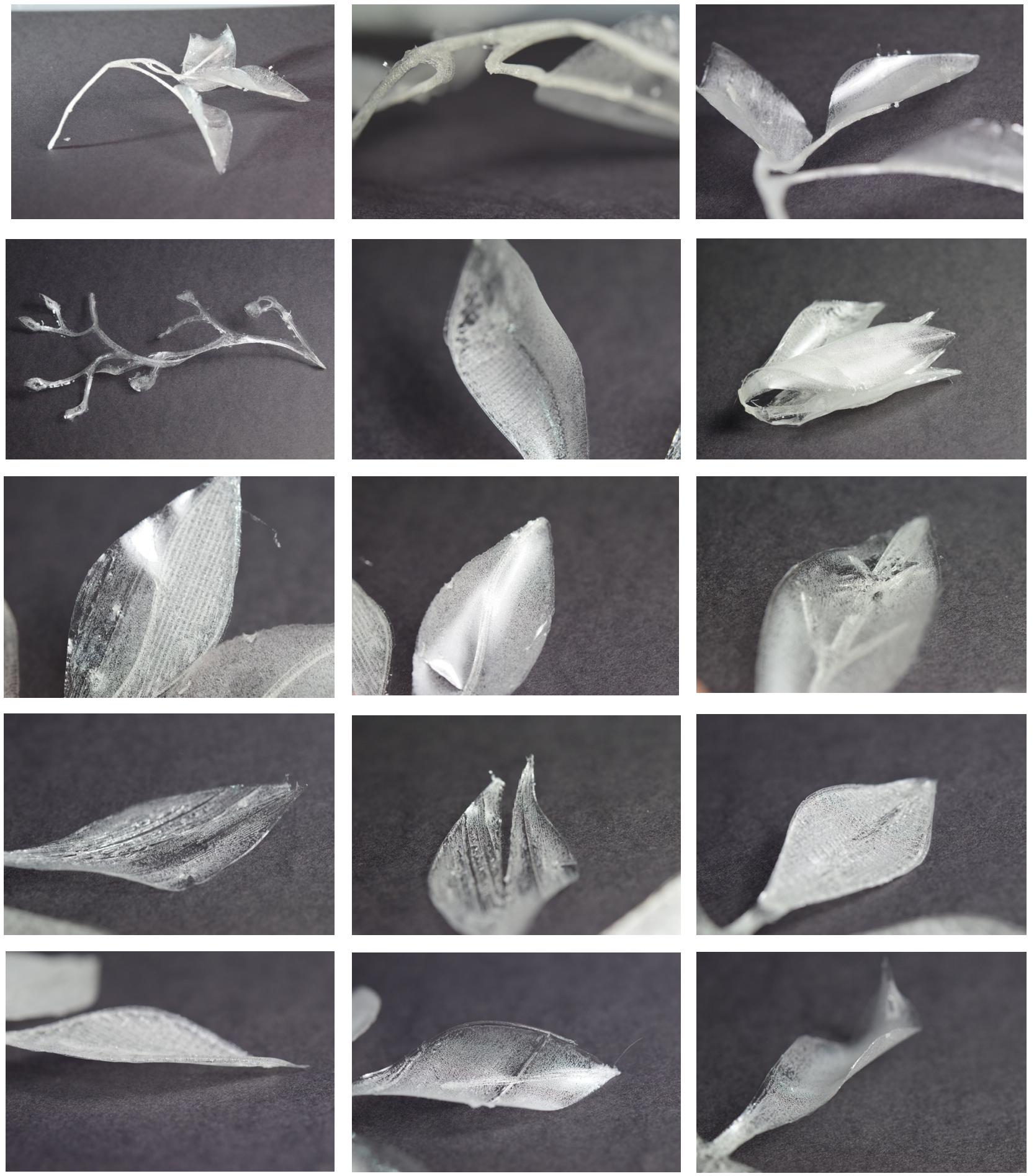
Image 4.52-4.81 (below) Iteration and prototype of concep 1
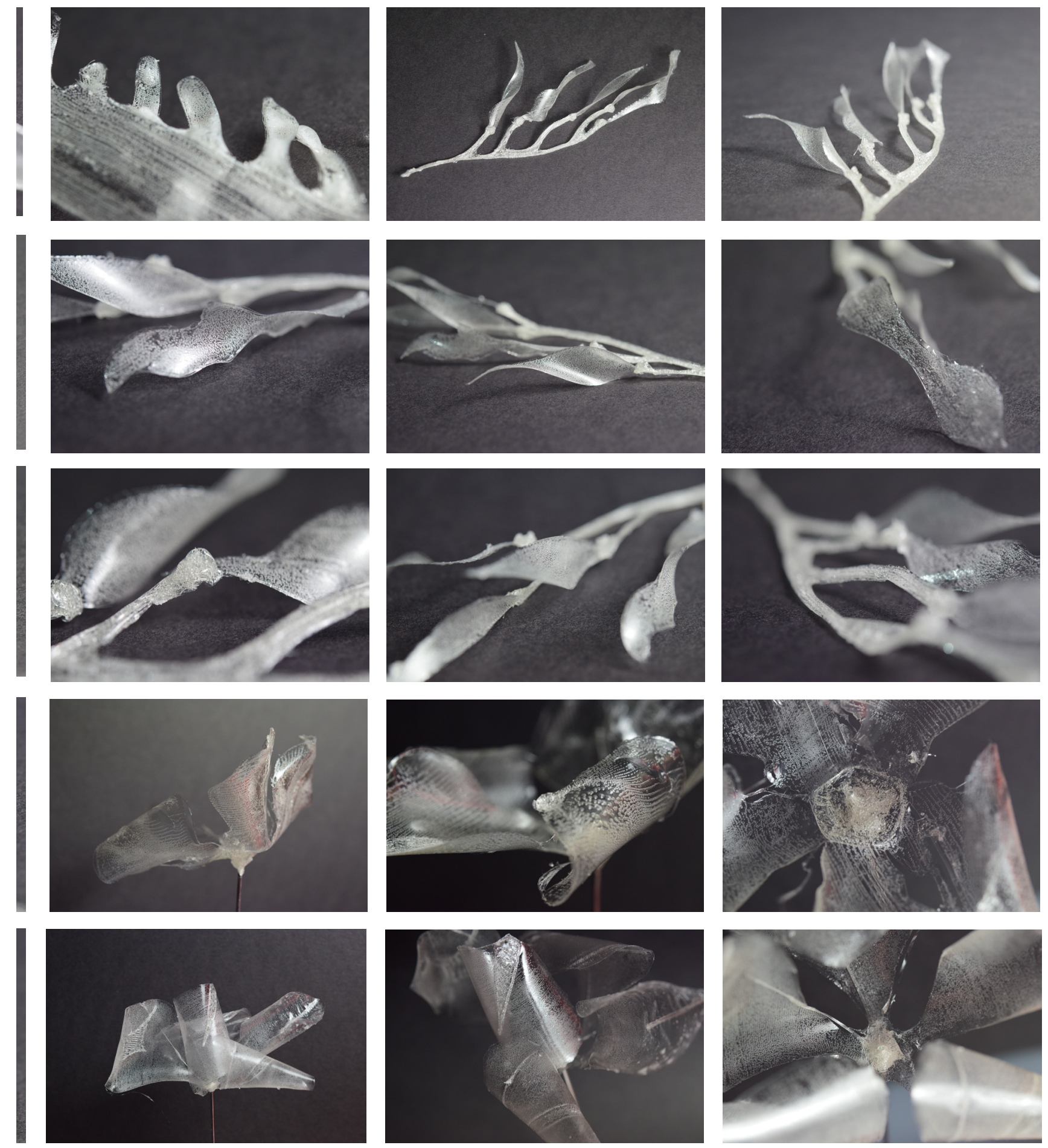

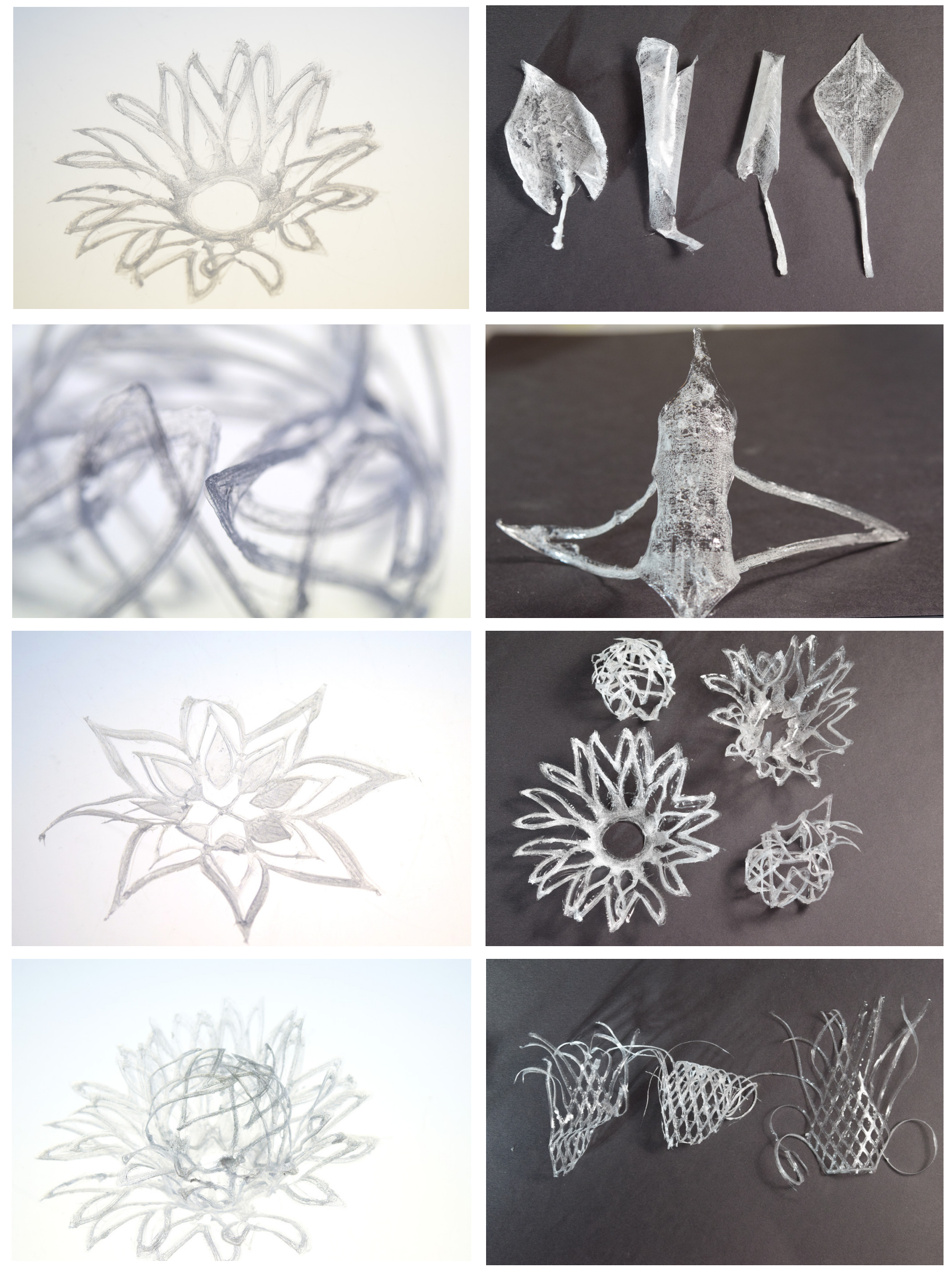

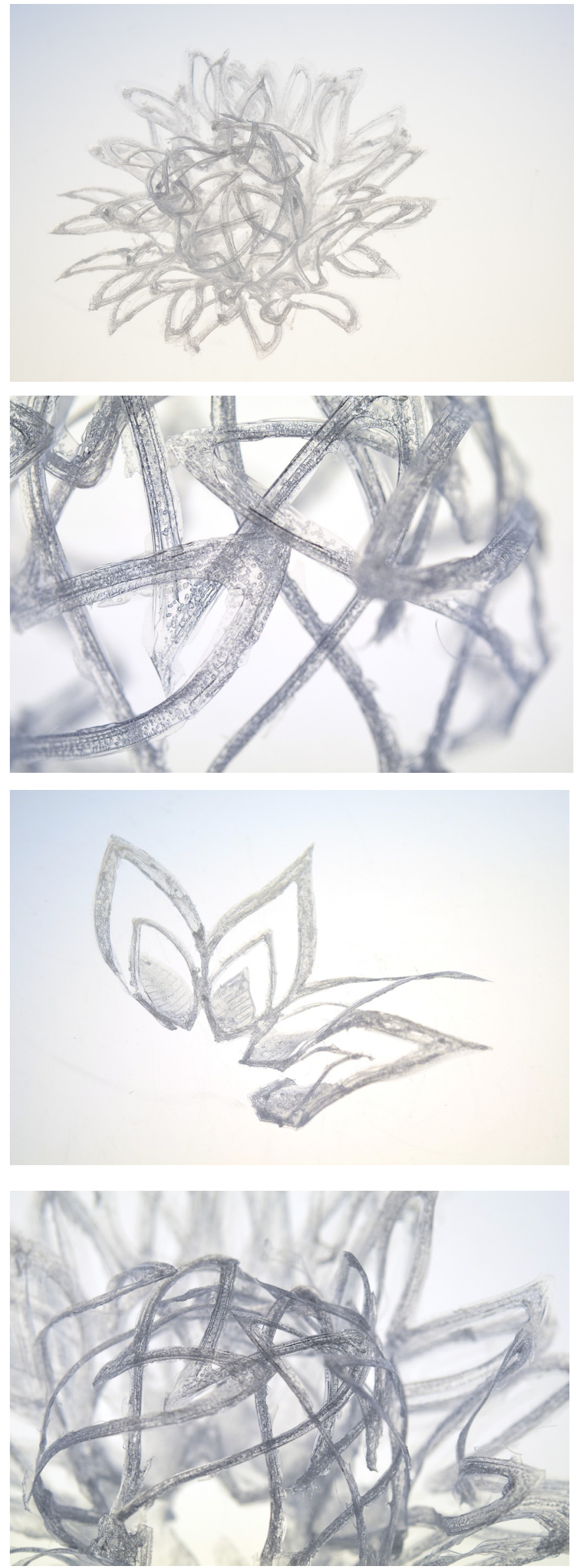

\section{Prototype and Iteration 2}

The second set of prototypes are further iteration of design in prototype one that accommodates both aesthetic (plant remblance form) and able to direct interesting curling. This set of prototypes intent to refine and narrow down the range of designs. Larger prints utlising the whole print bed was made hopping to apmplify the curling effect.

Image 4.82 - 4.93 (Left) Prototype and iteration 2 

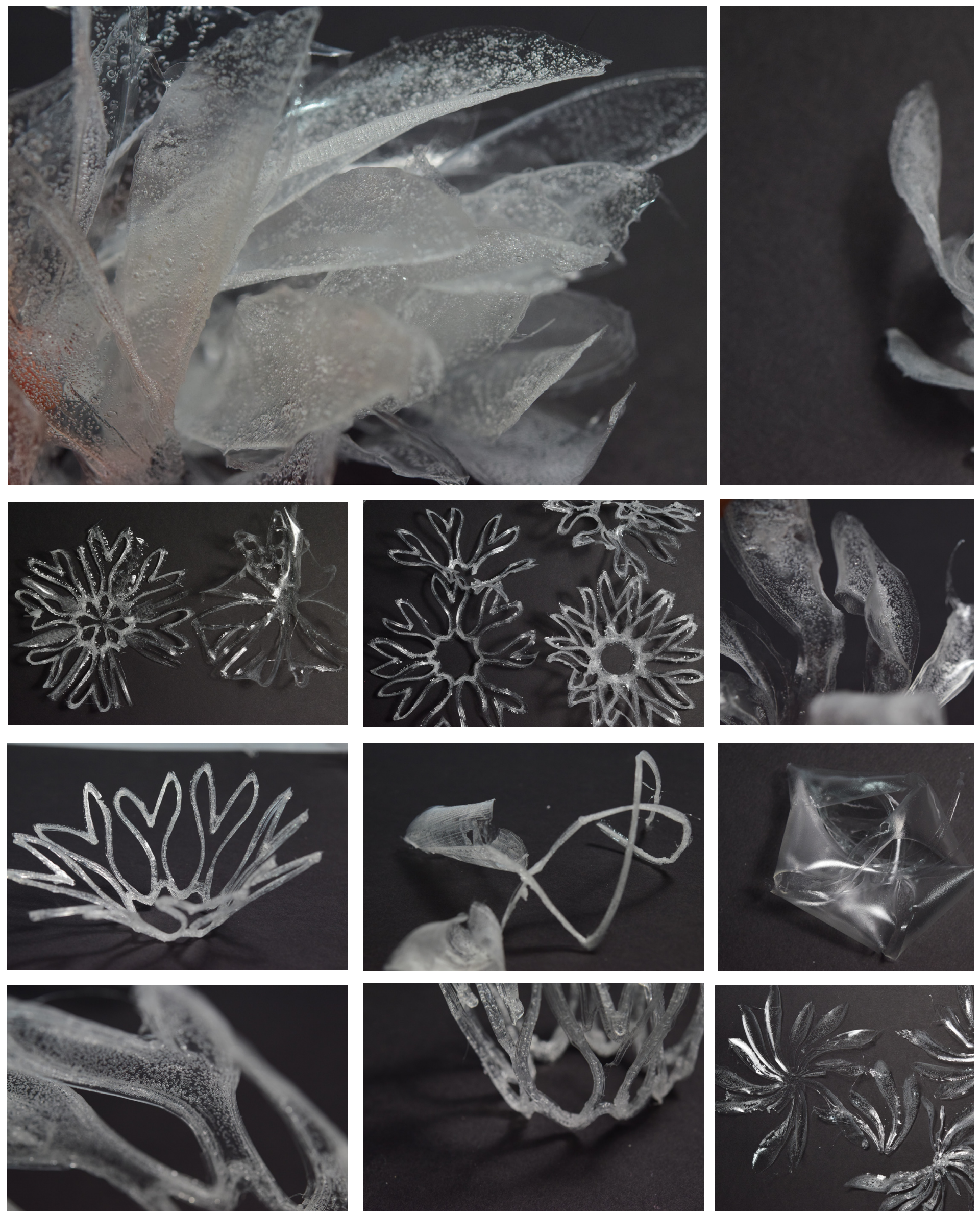


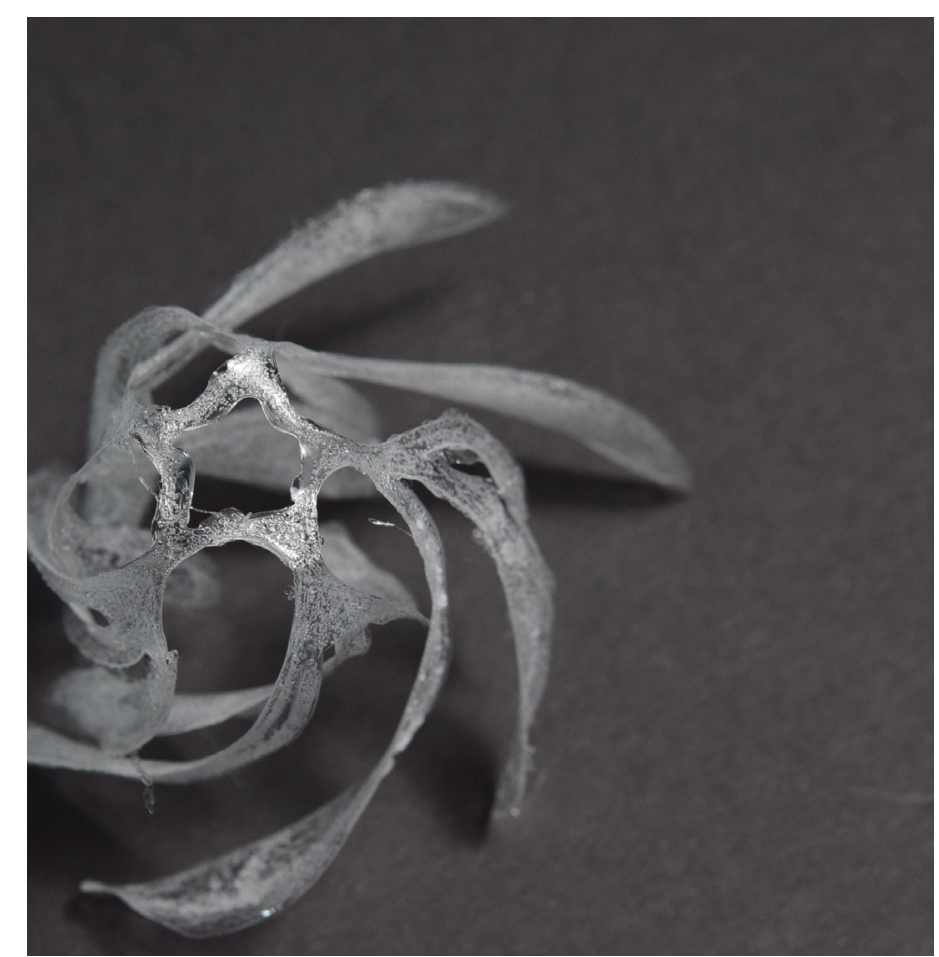

Final prototypes

The final prototypes consist of PVA and CA using the same process to disguise the difference between the two materials to maintain an element of surprise. PVA print itself curl slightly. However, it does not curl as much as CA. Therefore the CA part is designed to assist the PVA and hold it up. As PVA dry slower than CA, PVA is first printed to give it more time to dry then CA is applied.

Image 4.94 - 4.107 (Left) Final prototype
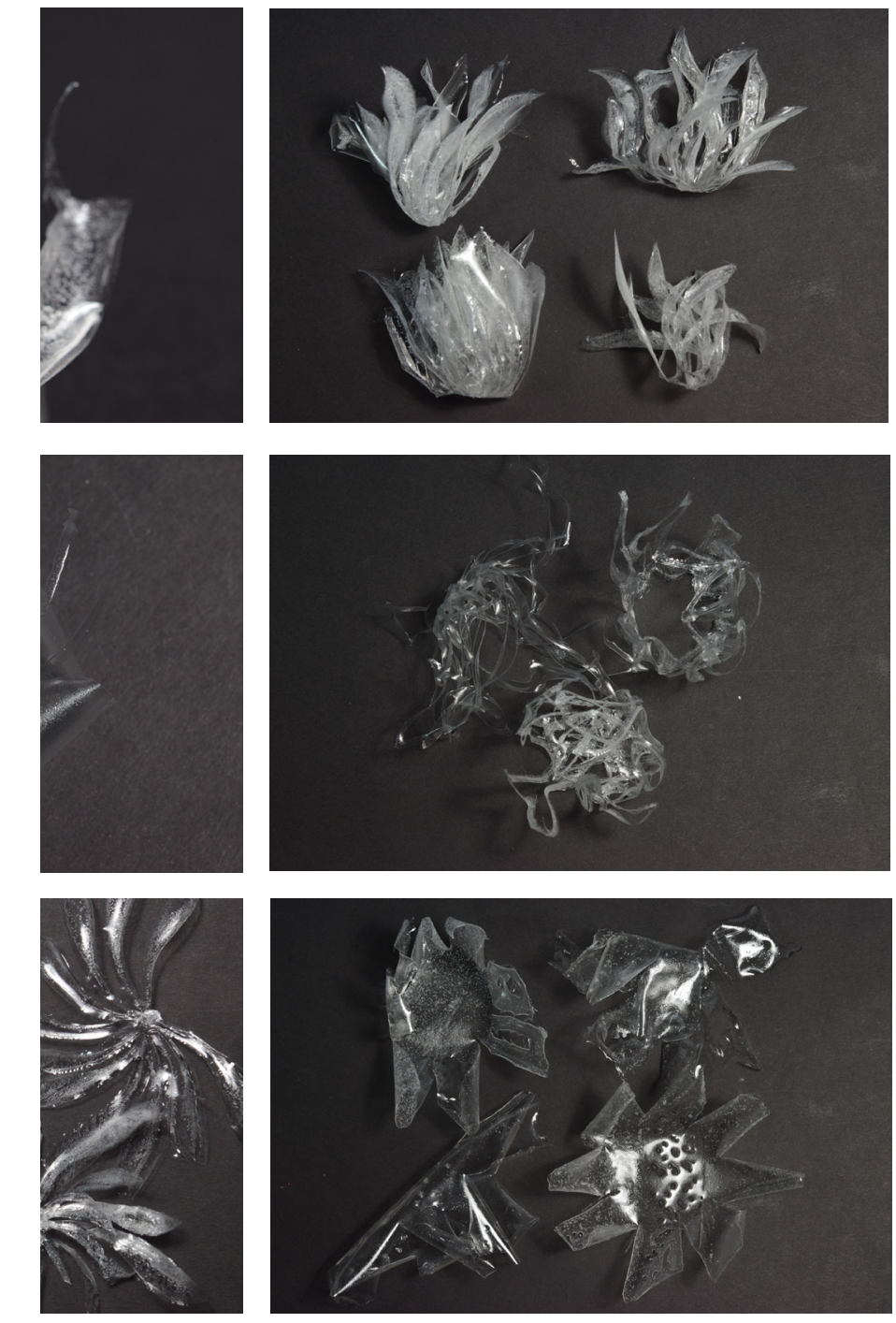


\section{Final ideas}

There was two final idea; both revolved around the concept of digital plants. The first idea is a light. And the second idea is the family of digital plants. I've decided to pursue the family of digital plants. This idea simpler and I can solely focus on designing degradation.

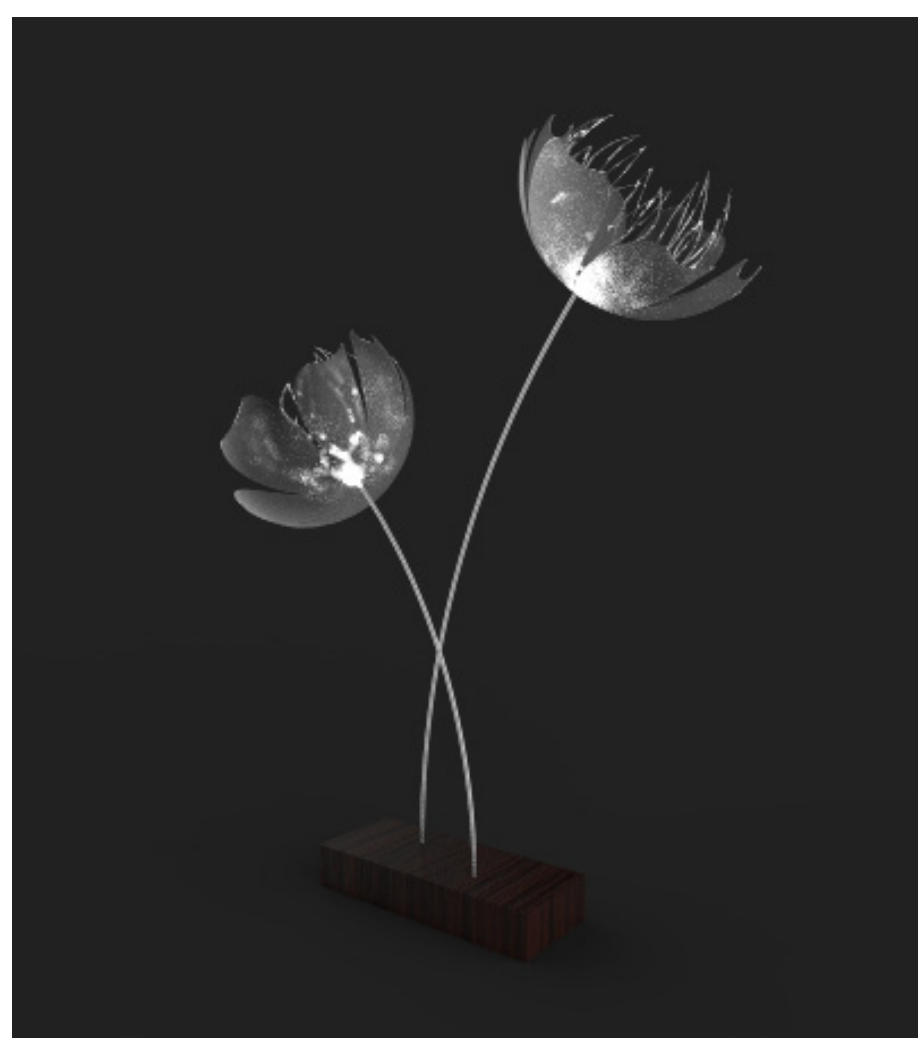

Image 4.108 (Top) second final set up of idea. place plants like a light. However this idea was dismised.

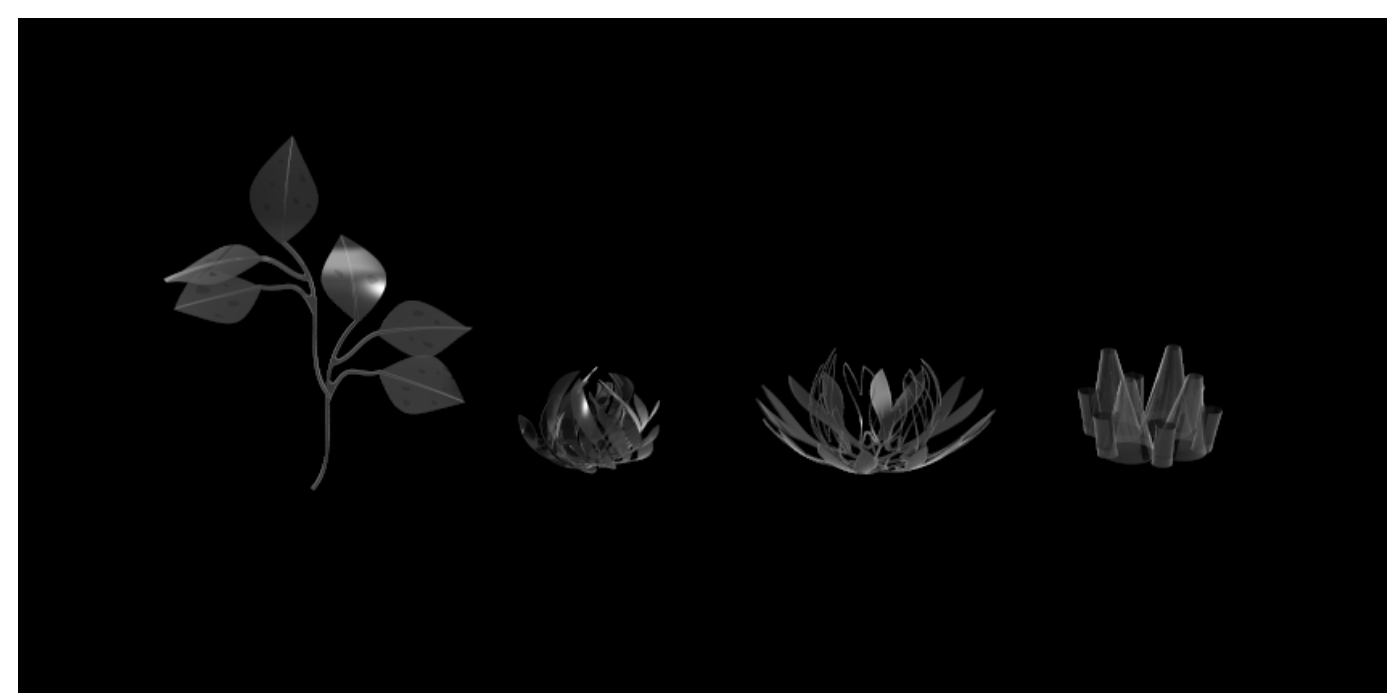

Image 4.109 (Top) Final design series 


\title{
Results \& Discussion
}

\author{
Idea generation
}

The observation method analysed the degradation process and helped me to gain a better understanding of degradation in simple objects. Most people will know what a rotten orange looks like, but through those series of photos, I was able to observe the order that the visual indicator appeared and also to closely examine all the details and form. And by capturing these changes, I was able to appreciate it's beauty, especially through macro photos. These results showed me that not only do an object morph when degrading but when look closely the texture changes too. These changes are a result of both internal material decaying and external mould and bacterial assisting and accelerating the degradation. The features observed in the series of photos are fascinating yet hard to mimic fully. However, the concepts learnt from the process is applied to the design output.

The findings of the observation informed the ideation of designed degradation approach. Three approaches were concluded: designed form, designed texture and reveal. These three ideas actively use the different degrade rate of the materials to design and prioritise forms area of degradation to control the degradation process and metamorphosis.

This knowledge was practised with two case study. The case study successfully proven that mimicking degradation features are feasible. In the orange case study, I was able to use parametric tools to determine the amount of degradation and material distribution. This is a proof of concept that parametric tools can be used to customise lifespan.

\section{Design development}

Prototype and iteration 1

Iteration one explored a variety of forms and using it to direct curve. There are some interesting forms surfaced, and some are comparable to natural plant forms. It is found that forms with a less complex curve, thin surface and thin lines prompt more curling.

\section{Prototype and Iteration 2}

The second set of prototypes are the further iteration of design in prototype one that accommodates both aesthetic (plant resemblance form) and able to direct interesting curling. This collection of prototypes intent to refine and narrow down the range of designs. It was found that prints that are longer or with have a larger area curls more, as more material is used and therefore dries slower. It was also found that designs with arrays of petal become quite interesting when it all curls slightly different. It also gives more volume to the prints. 
CHAPTER

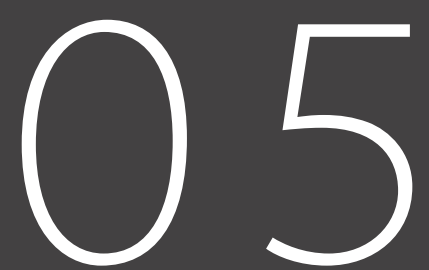

Final design 


\section{Design Results}

Each model is printed with 3D-paste printing of PVA (short-term degradation) and CA (long-term degradation). Hence this series is designed to degrade and transform over time, each with a slightly different approach. A final degradation was conducted and videoed, to observe the transformation in all four designs.

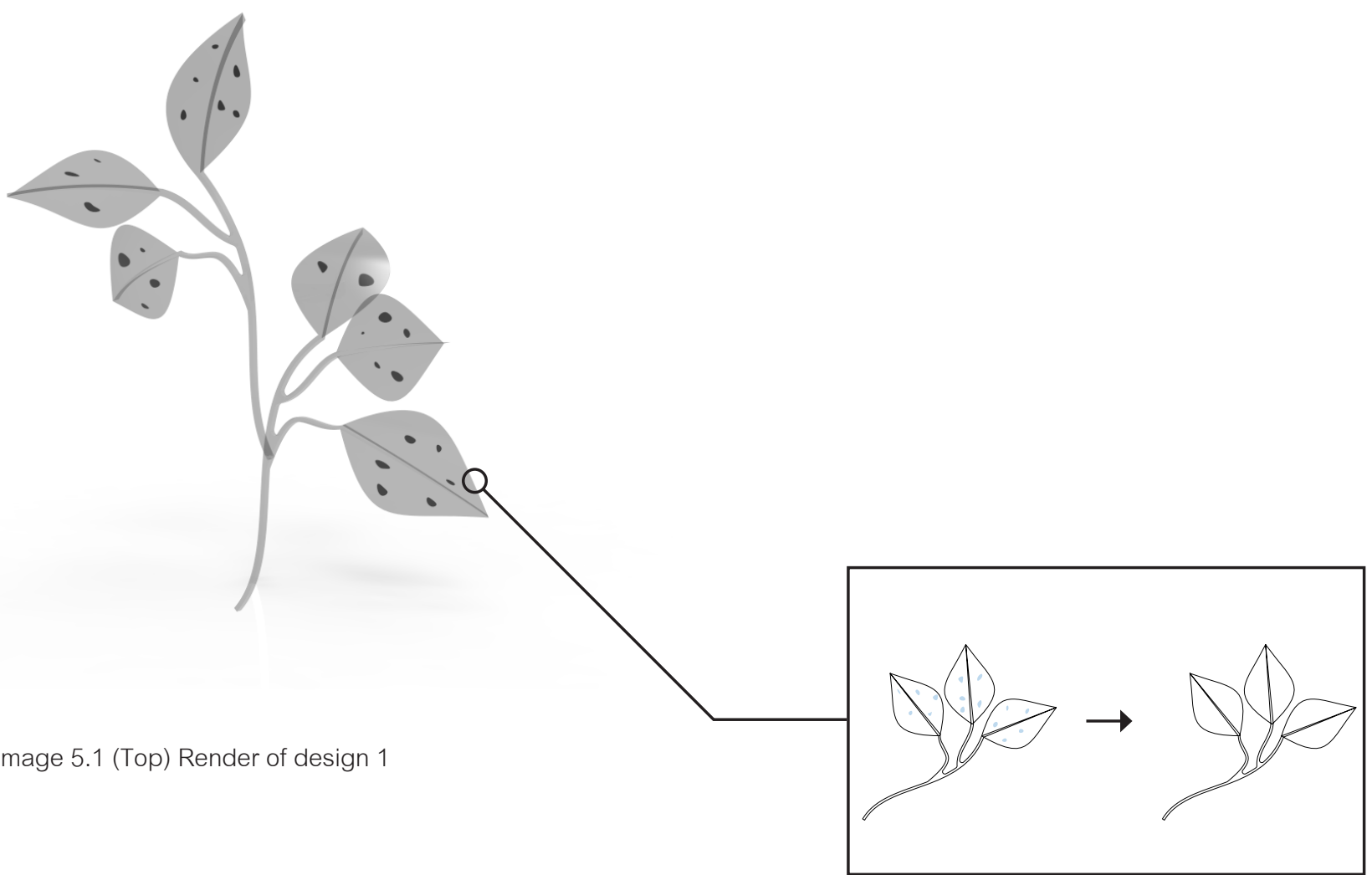




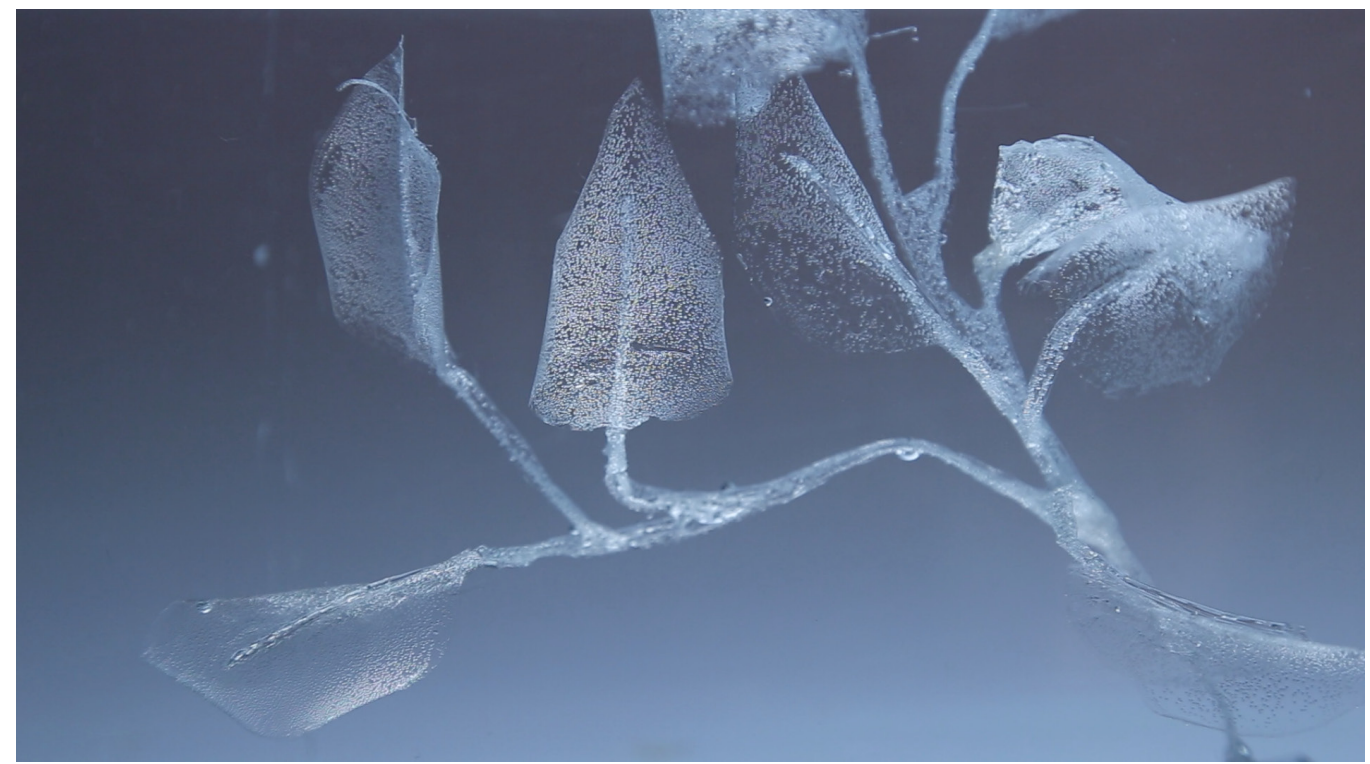

\section{Design 1 Liquetphyllus}

Image 5.2 (Top) Design 1 final image

Degradation Element - Change in texture (Holes on leaves), form (leaves falling).

Material and Forms - The overall form of Liquetphyllus is constructed with CA, and the predesigned degradative texture (holes) that is filled with PVA. This means that the PVA will degrade first, and remain with CA branch for secondary degradation. The leaves are printed with one single $0.3 \mathrm{~mm}$ layer, meaning, in theory, they will degrade faster than the branches.

The form of a leaf resembles natural plants forms. More importantly, it directs the curling of the material. Long thin branches were designed to allow the shrinkage of CA to form organic curves. At branch nodes, there is an accumulation of material, These areas are less dry, inducing higher shrinkage that influences the form. Some of the leaves are designed to fall off by depositing PVA at joints. 


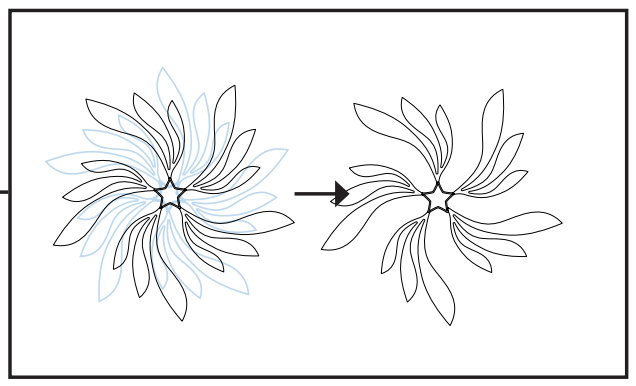

\section{Design 2 Liquet Crispus}

\section{Degradation criteria - Form, environmental interaction}

Material and Forms - Design two consists of equal amounts of PVA and CA. Every second petal lamina (the leaf-like structures of seaweed) is made with PVA. The lamina alternate in size from small, to medium, to large, and they repeat. Each lamina is designed to be long and converge at a point allows organic curves to occur once the material is dried and shrank. The base where the lamina connects to the centre is designed to be the narrowest part. This is so that during degradation, this would be the weakest part each lamina will fall off individually. The disappearance of these PVA laminae should make space for the CA ones to expand. Both PVA and CA lamina share the same form and thickness to disguise the difference in materials. 

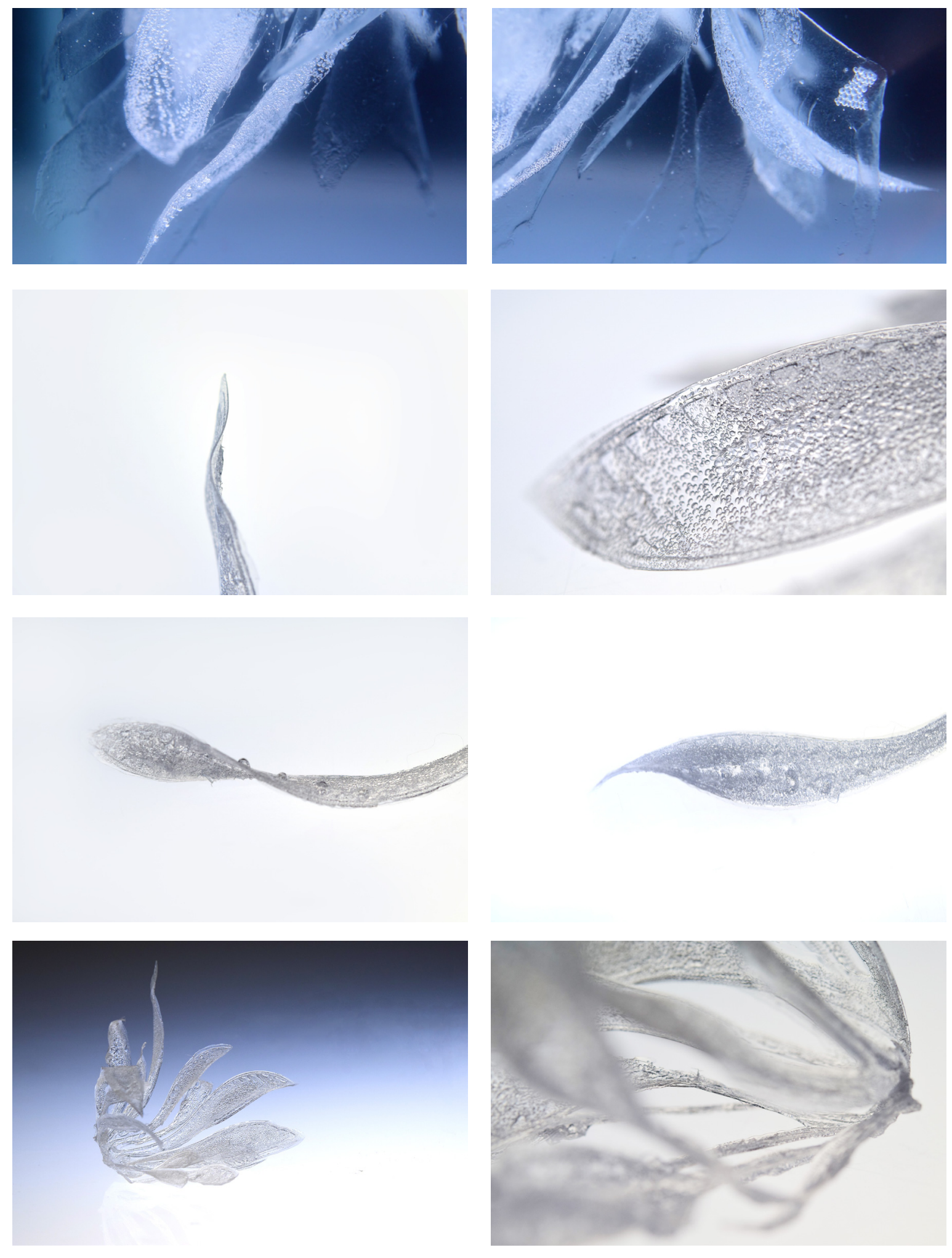

Image 5.4 - 5.11(Group) Design 2 Final images 


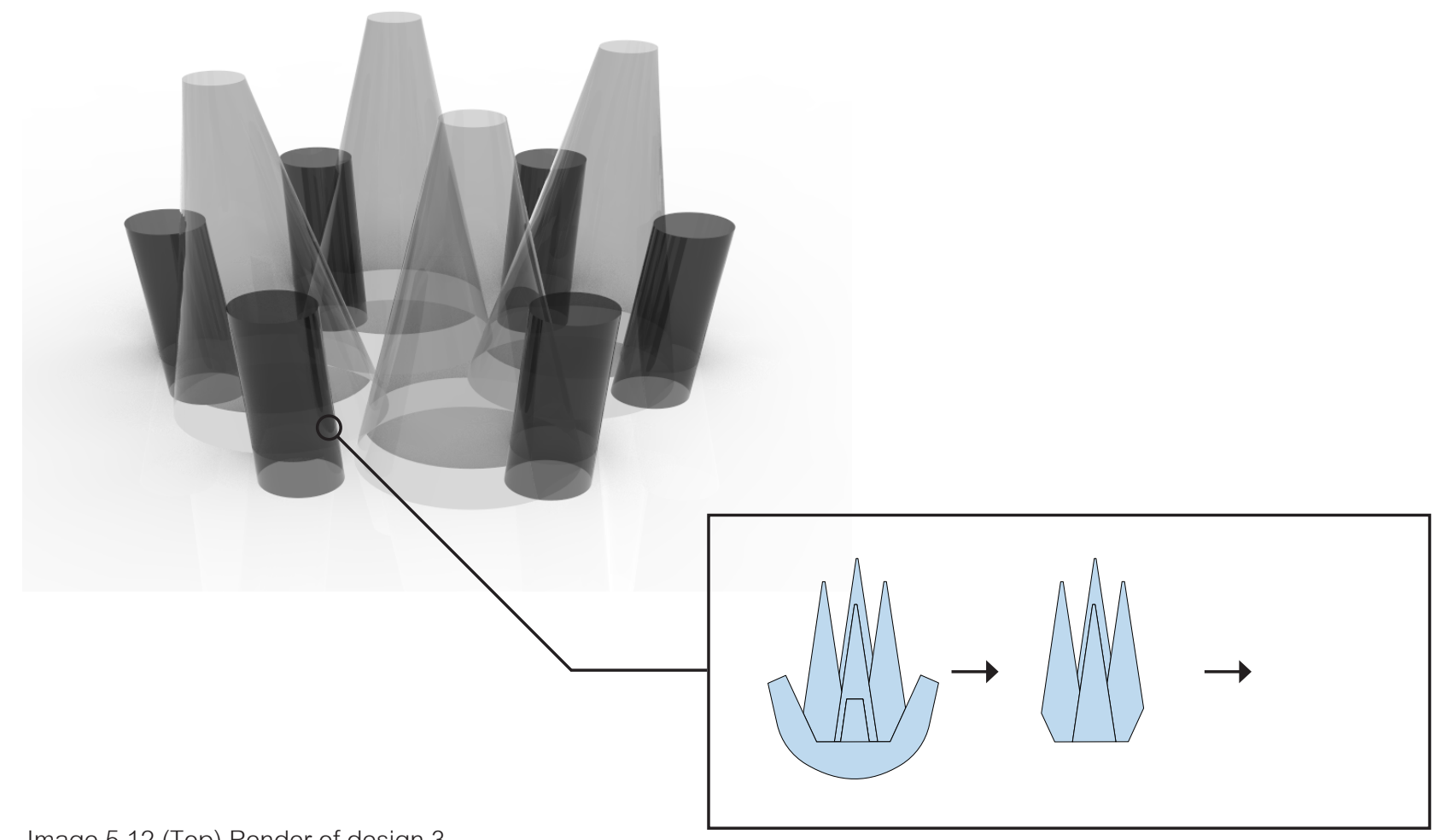

Image 5.12 (Top) Render of design 3

\section{Design 3 Liquet Procombens}

Degradation criteria - Form, colour, environmental interaction

Material \& Forms - The corals are made entirely out of a PVA tube structure.

The PVA structure is designed with a hollow centre the way the tube falls. 

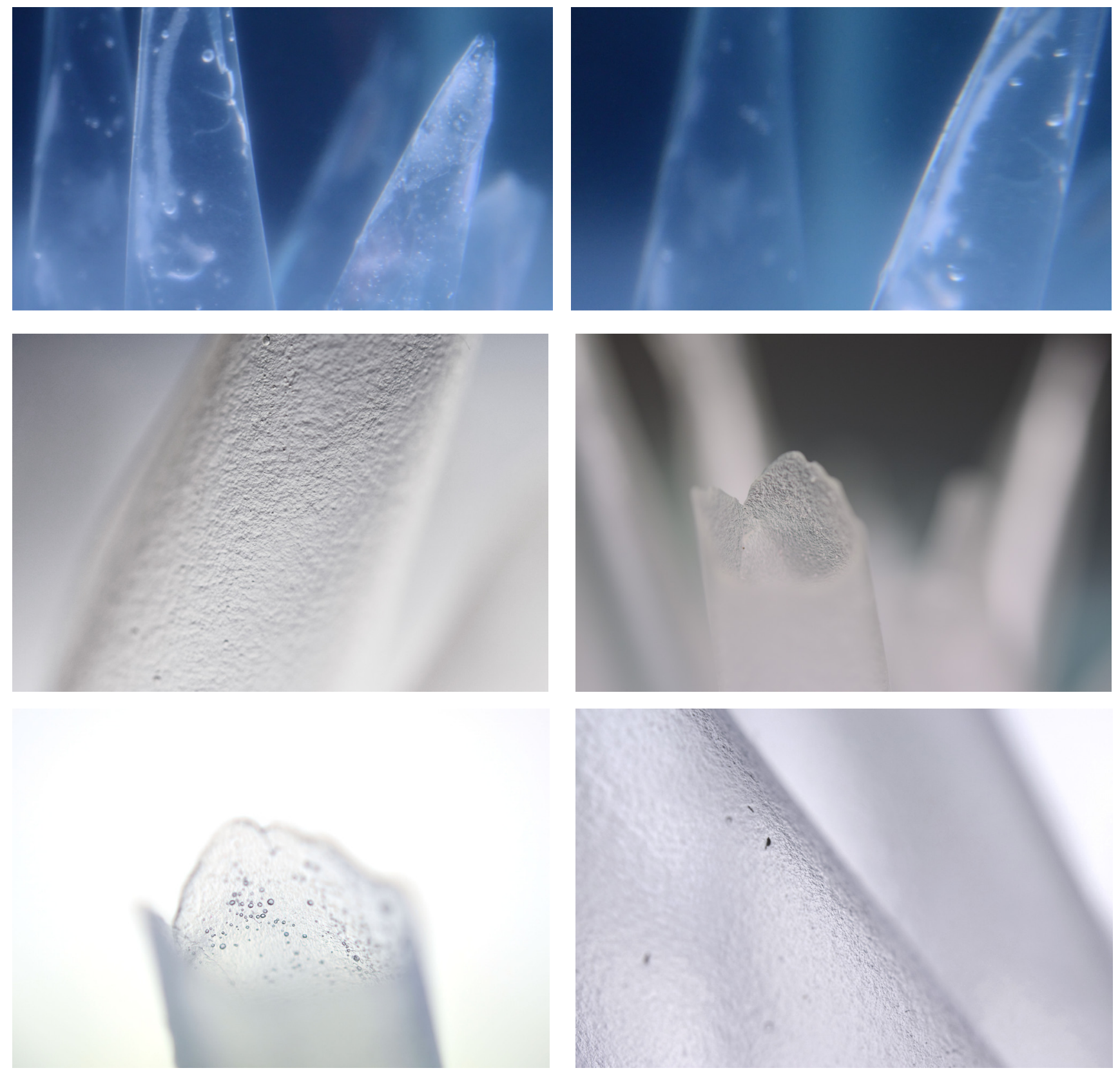

Image 5.13-5.18 (Group) Design 3 Final images 


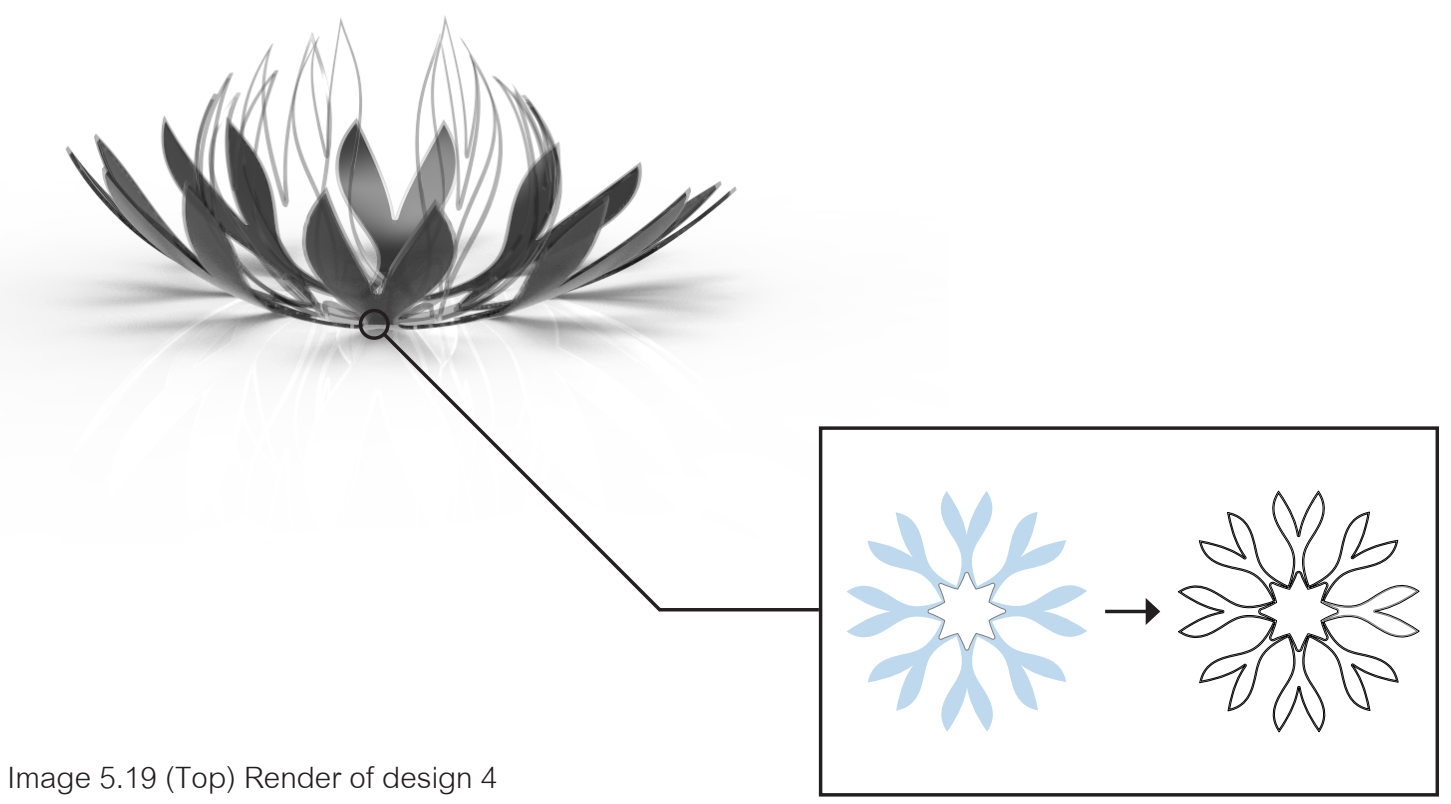

Design 4 - Liquetanthus

Degradation criteria - Texture, form, environmental interaction

Material and Forms - The CA wireframe form of the outer layer is concealed with PVA. This is to prioritise the PVA's degradation. The CA should not degrade until after the protective layer of PVA has. 

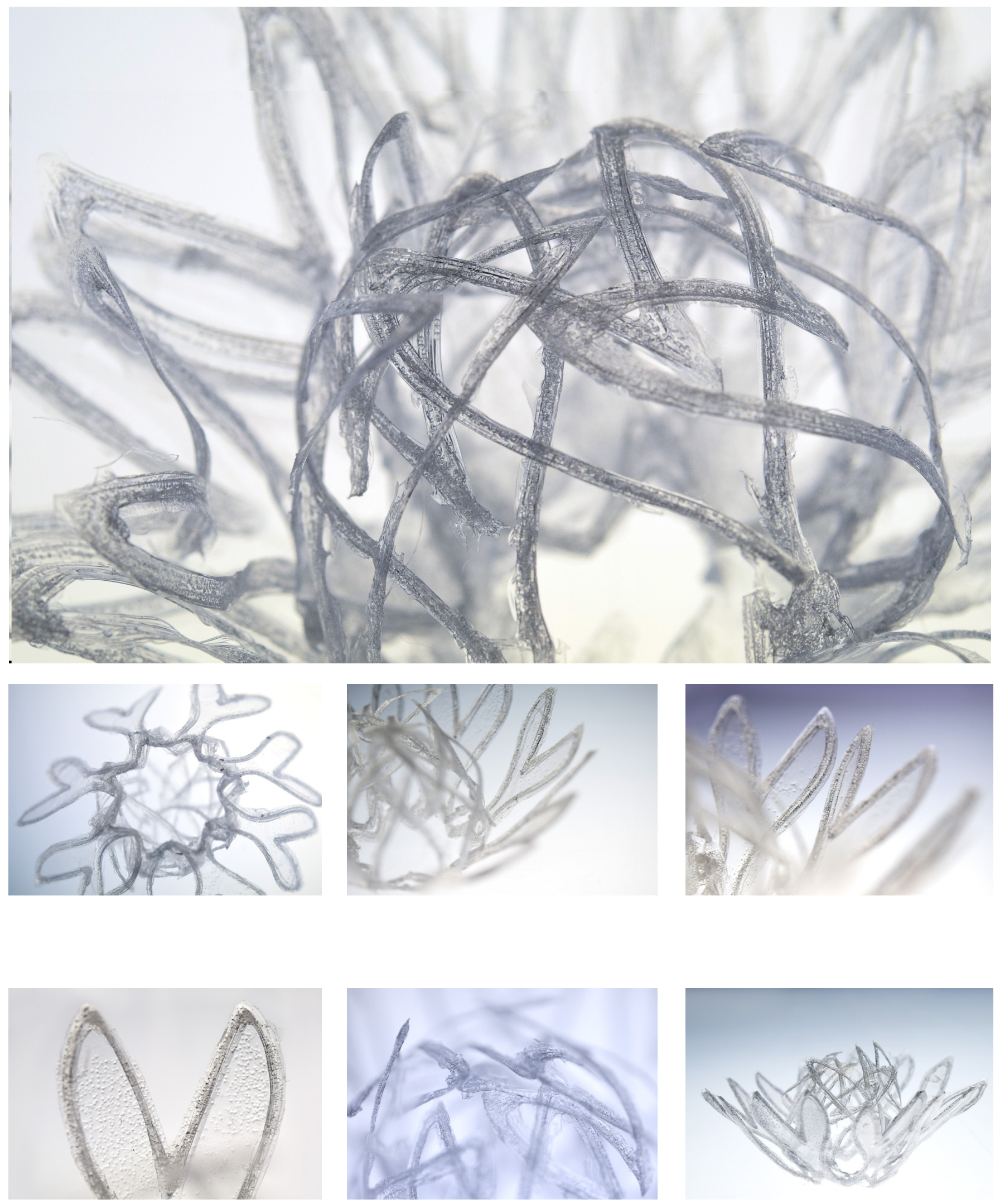

Image 5.20-5.26 (Top) Images of design 4 
Design 1 - The pre-designed texture of the leaves was revealed very quickly but not very clearly. Light actuated the division between the different material thus diminished the element of surprise.

Image 5.27- 5.31 (group) Close up for design 1

\section{Design 2}

The final degradation test result was particularly successful in this design. The PVA at the base of the lamina degrades first, allowing the lamina to fall off and eventually disappear. Once the PVA dissolved, it allowed the CA part of the print to expand and created a blooming effect.
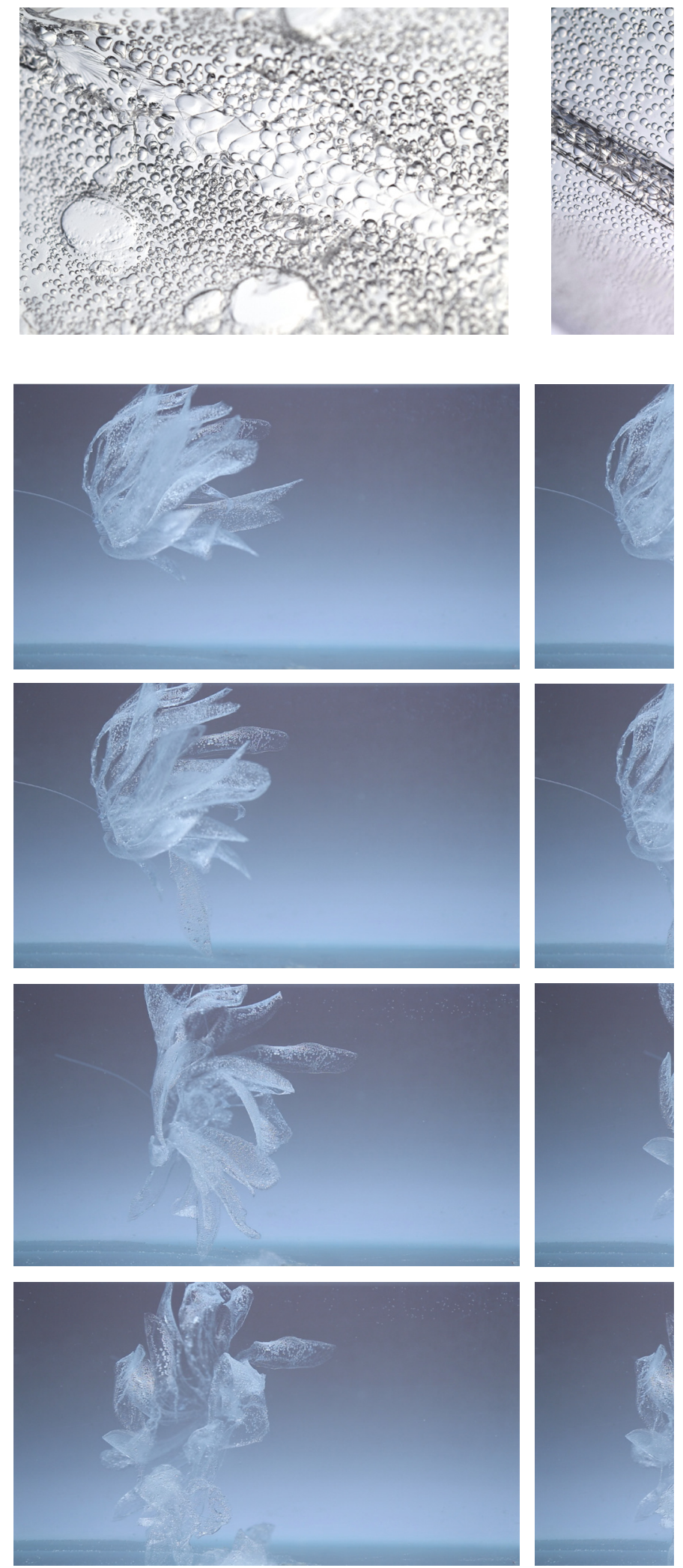

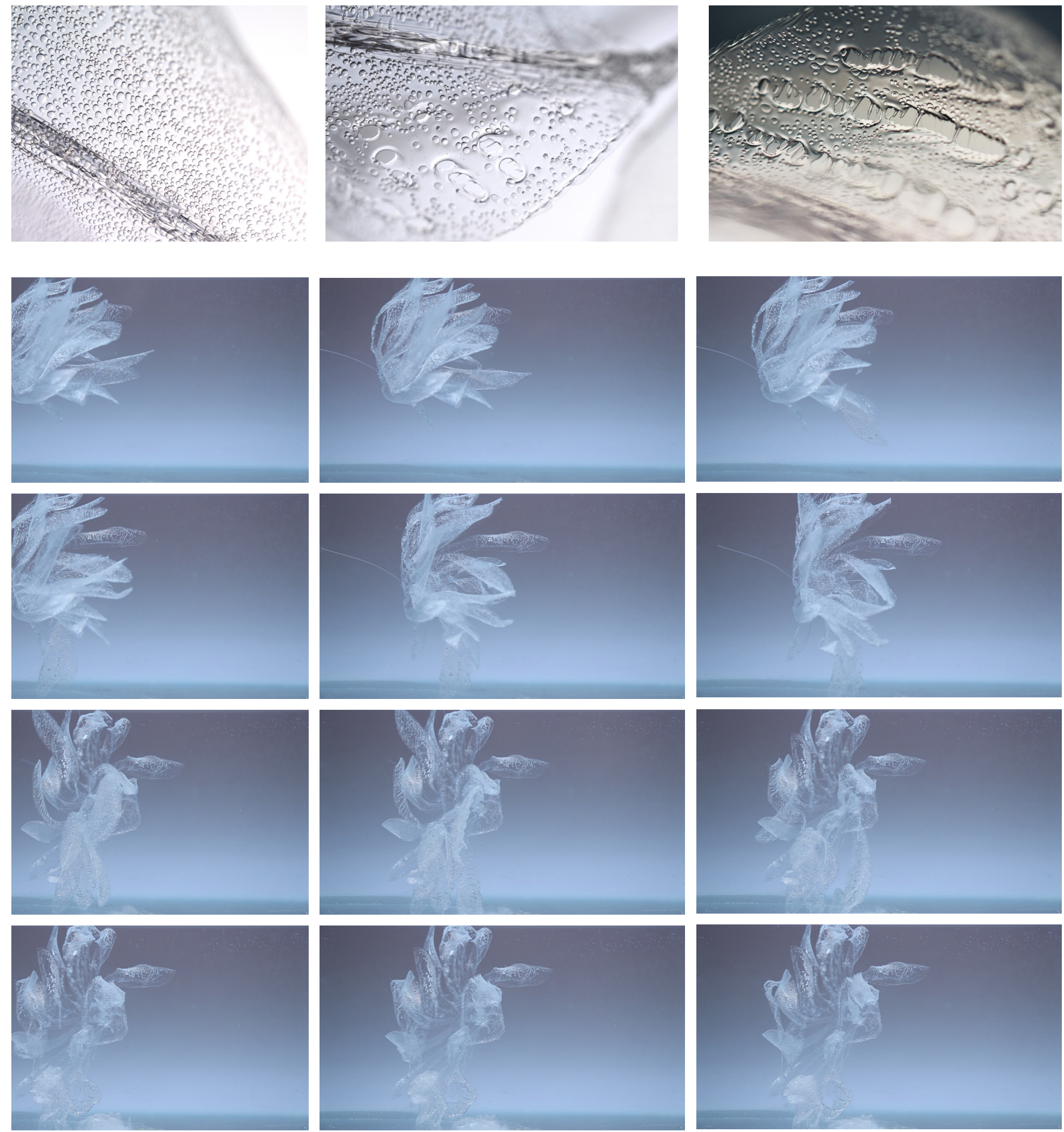

Image 5.32- 5.47 (group) transformation of design 2 


\section{Design 3}

The result was very satisfying to watch and has a high resemblance to the death and decay of natural objects. The tube structure almost simultaneously fell open and outwards.
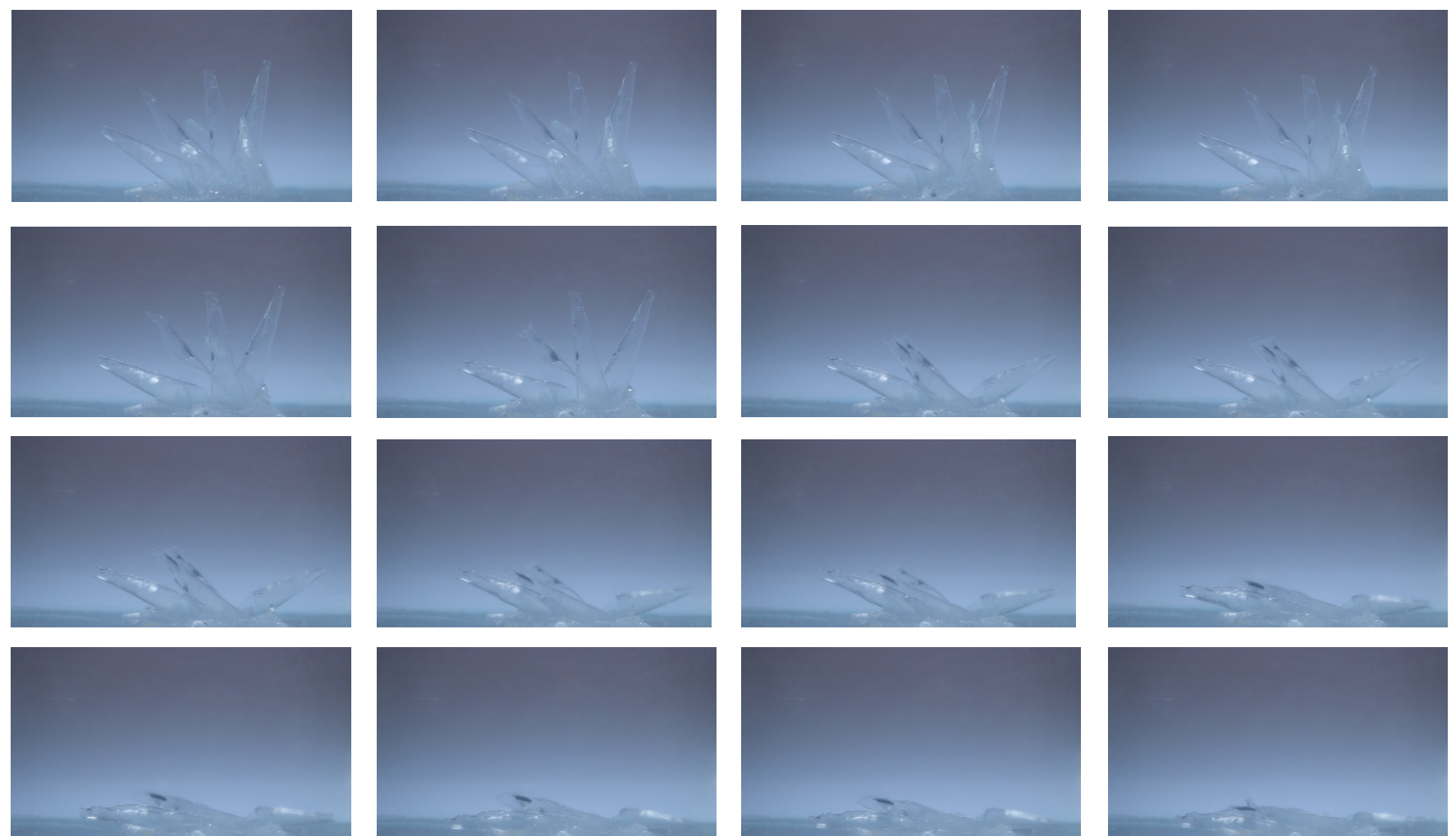

Image 5.48- 5.63 (group) transformation of design 3 
Design 4

The results were interesting as the PVA section did not only gradually dissolve, but the whole surface fell off from the CA frame.
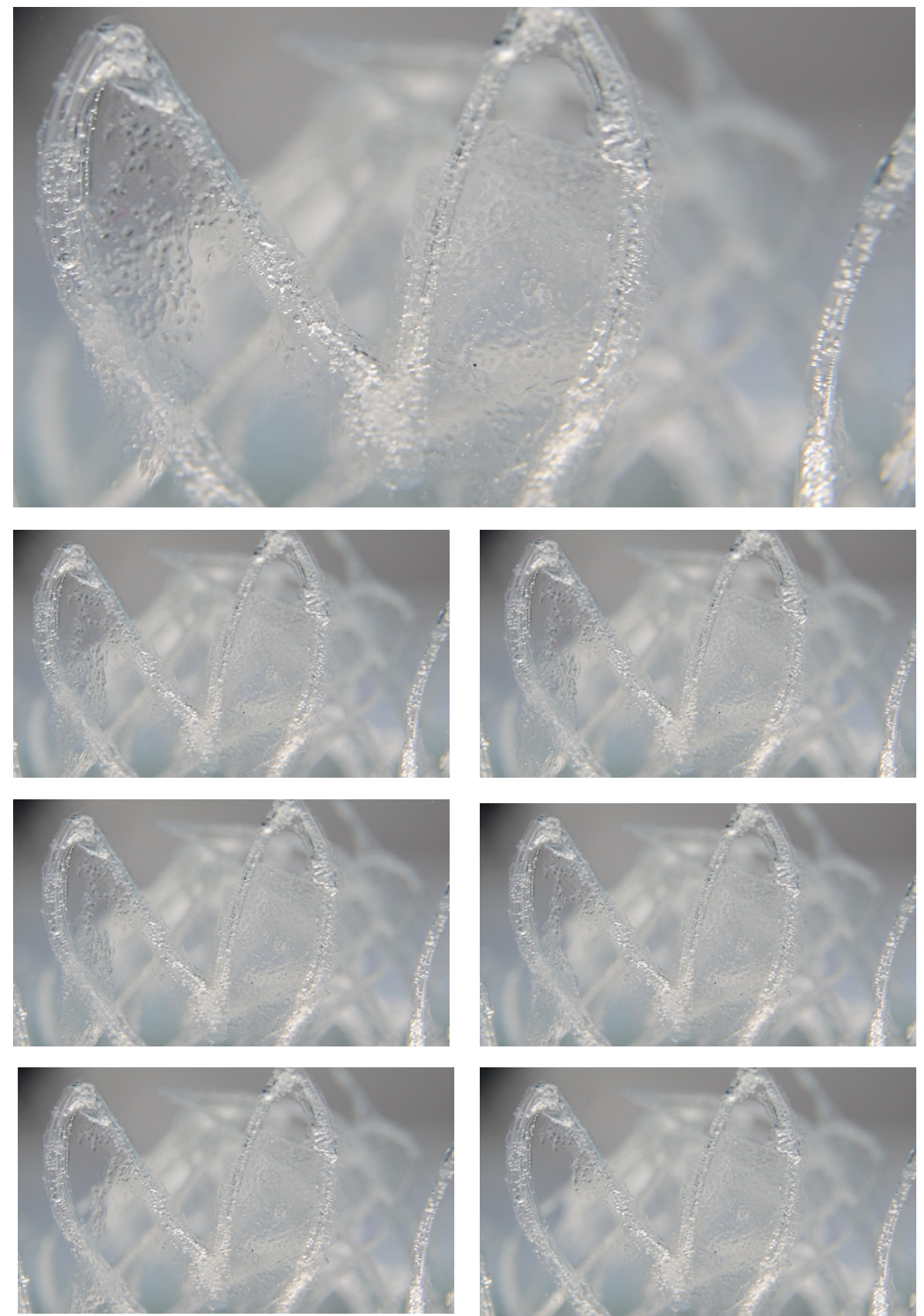

Image 5.48-5.54.(group) transformation of design 4 


\section{Discussion}

The final output successfully incorporates degradation traits into an artificially made object via multi-material (PVA and CA) 3D-paste printing. Designed degradation allowed man-made objects to be environmentally conscious in a fun and dynamic manner, offering an alternative approach to deal with the environmental crisis. The final outcome only represents a small fraction of the possible ways for design degradation to establish dynamic products that meet consumers' needs while acknowledging environmental issues.

All four design in the final series expressed degradation quality and transformed through external stimulus over time. Across all four design, there were changes in form and texture in response to the degradation element identified.

The metamorphic quality appeared in the degradation test distinguish the series of design from conventional man-made objects. The beautiful transformation is made possible because of degradation, therefore responded to the design criteria.

Design two is especially successful in both degradation and transformation. The expansion of the model is very provocative as we often think of degradation as a process to diminish, but in this case, degradation enhanced the design and altered the identity of the design.

Design three have the most significant transformation, where the entire form disappeared. Although the degradation did not remain in anything, the process in between the initial and end form is the most worth cherished moments.

Design one show a piece of the leaf falling of the dividing the model into two separate entity to continue to degrade. The form particularly reflects the results of the 3D printing test. The form utilized single layer material curling to create a curled up leaf and the branch uses the form to direct form.

Design four was least successful in transformation, but the transformation of 3D print was shown in the model. The model shows that different thickness can control the amount of curl. The inner and outer form is the same form with a slight difference in the centre, but one was $0.3 \mathrm{~mm}$, and the other is $0.9 \mathrm{~mm}$. This allowed the form to curve differently.

There was a minimal amount of research on paste 3D-printing, especially on CA printing. Because of this, my, Research required a lot of trial and error. There were also some technical difficulties.

The rapid degradation of PVA acts as a proof of the concept. Future studies can attempt larger prints with different $\mathrm{CA}$ and additive combinations that degrade at various rates. There could potentially be more than two distinct rates of degradation, allowing more precise control of the secondary form and transitional forms. Textural changes through degradation can be studied more. There is potential to use the change in tactility for blind people. Change in tactility could also be studied about its effect on emotion and perspective, perhaps for robotics.

This series depicted some very fascinating transformations that suit the focus of this research. Most of the transformations were no surprise. They transformed and degraded as they were designed to. However, there are some serendipitous qualities discovered through this research. 
CHAPTER

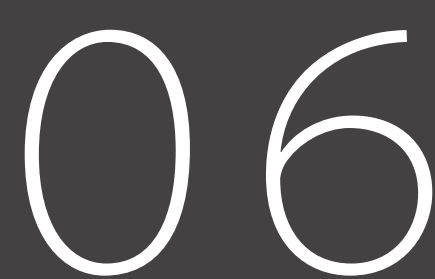

Conclusion 


\section{Conclusion}

Death and degradation are essential to the natural balance and to make space for new growth. Indeed this is an aspect that is often ignored, especially when designing and producing man-made objects. This lack of consideration since the industrial revolution has accumulated and led to many of today's environmental problems. Threatened by the growing environmental issues, humanity must produce more sustainable technology and materials.

Research on the merging of $\mathrm{AM}$ and degradable materials concluded with a series of multi-material 3D-printed plants made with CA and PVA. The final output critiques the mass production process and attempts to visually prompt awareness about the lack death and degradation in the artificial realm. This marriage of natural degradation with artificial objects via digital tools could be coined as designed degradation.

By using CA's high shrink rate, a minimal amount of material was used to create intricate 3D forms without support or heat. These objects successfully responded to the research question and fulfilled the degradation criteria observed from decaying natural objects. Not only was I able to inject natural degradation qualities into a 3D-printed object, but I was able to control its form, texture, and duration of degradation by instructing material disposition via CAD.

Even though this process of designed degradation is based on technology, it offers manmade objects a predetermined form of degradation and a limited lifespan. It empowers designers to create objects purposefully and responsibly. It exemplifies an innovative application of bio-based materials rather than trying to fit them into mass production. This process suggests a sustainable way to use digital technology and AM. Designed degradation indicated a revised way of making that acknowledges the importance of death and degrading as well as the throwaway culture.

To design degradation via digital tools ( $A M$ and $C A D$ ) can predetermine the timeline for death, and the degradation process of a man-made object. The relationship of the artefact and external environmental stimulus, allows a concealed entity, form, or texture to be revealed over time as material disappear orderly, subsequently entirely disappear.

I have presented a design solution that is continuously changing in form. It can apply to product design to influence style obsolescence and reduce waste through product disposal. This means it can fulfil the financial imperative of any business to sell more products and abate need of plan obsolescent, minimising the severity of the disposal problem without the challenge of changing consumers' attitudes, behaviours and sociocultural norms.

This is pioneering research about the printing of CA on a medium scale. This has not been done previously. The results demonstrate the potential of CA 3D printing with its intrinsic shrinkage. This shrinkage has been considered an obstacle to full-scale adoption, but here it is an essential element for creation. Parametric tools were used to control printing paths which influence the curling, shrinking, and drying behaviours of the material.

I believe the result of this research is applicable across various disciplines including design, science, and engineering. 

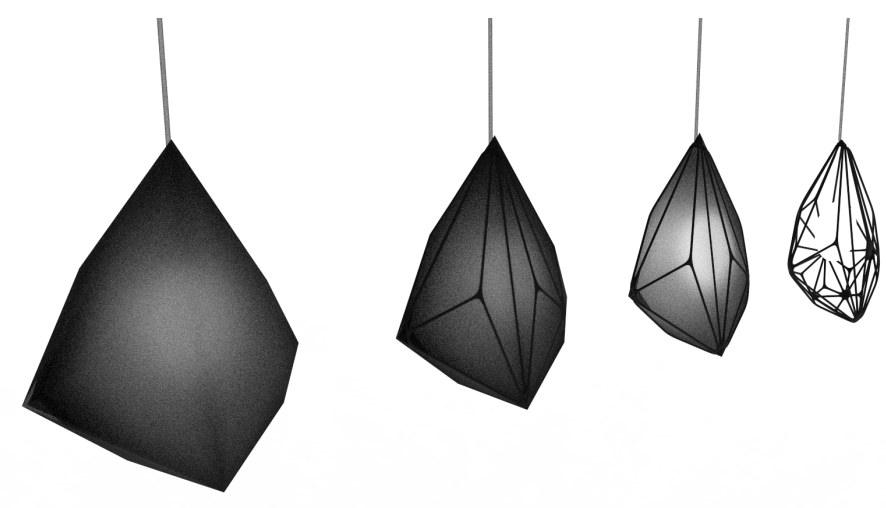

\section{Light}

This design applies the concept of design 3. The light will first be an ambient light concealed. Over time the outer layer will disappear changing the light quality and eventually remain with a wireframe. This is only one example of many possibilities to utilize designs degradation allows material quality to alter over time.

Table

This design applied the concept of the design 1 to create a dynamic table top that changes in texture and form over time. This allows the digitally made table to have a similar ageing and wearing process.
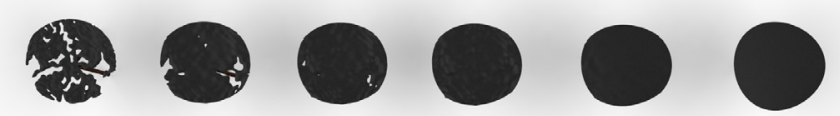
- 
CHAPTER

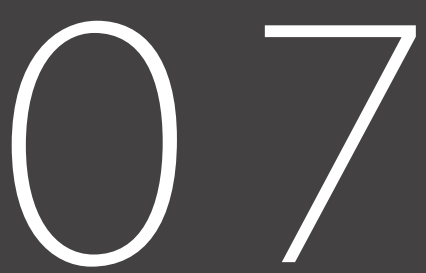

References 


\section{Reference}

3D printing from scratch (2017). Types of 3d printers or 3D printing technologies overview. Retrieved from http://3dprintingfromscratch.com/common/types-of-3d-printers-or-3d-printing-technologies-overview/\#fdm

Abd El-Rehim, H. A., Hegazy, E.-S. A., Ali, A. M., \& Rabie, A. M. (2004). Synergistic effect of combining UV-sunlight-soil burial treatment on the biodegradation rate of LDPE/starch blends. Journal of Photochemistry and Photobiology A: Chemistry, 163(3), 547-556. https://doi.org/10.1016/j.jphotochem.2004.02.003

Addington, D. M., \& Schodek, D. L. (2005). Smart Materials and New Technologies: For the Architecture and Design Professions. Routledge.

Aiello, C. (2014). Digital \& parametric architecture / [editor-in-chief/creative director, Carlo Aiello]. (Evolo ; issue 06). Los Angeles, CA ; New York, NY: EVolo.

Akhras, G. (2000). Smart materials and smart systems for the future. Canadian Military Journal, 1(3), 25-31.

Algix. (2015). Retrieved from http://algix.com/seaweed-as-biobased-material-for-3d-printing-biopen/

Ashby, M. F., \& Johnson, K. (2013). Materials and Design: The Art and Science of Material Selection in Product Design. Butterworth-Heinemann.

Baley,.S. (2013). Ugly: the aesthetic of everything. United states: Peter Mayer

Bastioli, C. (Ed.). (2005). Handbook of biodegradable polymers. iSmithers Rapra Publishing.

BBC. (2014). Smart materials. Retrieved from http://www.bbc.co.uk/schools/gcsebitesize/design/electronics/ materialsrev5.shtml

Berman, B. (2012). 3-D printing: The new industrial revolution. Business Horizons, 55(2), 155-162. http://doi.org/10.1016/j. bushor.2011.11.003

Bernabei, R. \& Power, J.(2016). Living Design. N.F. Lepora et al.(Eds), Biomimetic and Biohybrid Systems (pp. 40-47). Switzerland: Springer International Publishing.

Billiet, T., Vandenhaute, M., Schelfhout, J., Van Vlierberghe, S., \& Dubruel, P. (2012). A review of trends and limitations in hydrogel-rapid prototyping for tissue engineering. Biomaterials, 33(26), 6020-6041. https://doi.org/10.1016/j. biomaterials.2012.04.050

Buechley, L. \& Zoran, A. (2013). Hybrid Reassemblage: An Exploration of Craft, Digital fabrication and artifact uniqueness. Leonardo 46(1), p6.

Chen, A. (2015). This is the product Death Cycle. Why it happens, and how to break out. Retrieved from https://www. linkedin.com/pulse/product-death-cycle-why-happens-how-break-out-andrew-chen

Cooper, T. (2004). Inadequate life? Evidence of Consumer Attitudes to Product Obsolescence. Kluwer Academic Publishers, 27(4), 421-449.

Cooper, T. (2010). Longer Lasting Products: Alternatives To The Throwaway Society. CRC Press.

Copinet, A., Bertrand, C., Longieras, A., Coma, V., \& Couturier, Y. (2003). Photodegradation and Biodegradation Study of a Starch and Poly(Lactic Acid) Coextruded Material. Journal of Polymers and the Environment, 11(4), 169-179. https://doi.org/10.1023/A:1026056415604

Corpuscoli (2010). Continuous Bodies - The Ephemeral Icon. Retrieved from http://www.corpuscoli.com/projects/theephemeral-icon/

Creswell, J. W. (2013). Research design: Qualitative, quantitative, and mixed methods

D. R. Lu, C.M. Xiao \& S. J. Xu (2009). Starch-based completely biodegrabale polymer materials. eXPRESS polymer letters , Vol.3 (6), 366-275. Doi: 10.3144/expresspolymlett.2009.46

De Graaf, R. A., \& Janssen, L. P. B. M. (2000). The production of a new partially biodegradable starch plastic by reactive extrusion. Polymer Engineering \& Science, 40(9), 2086-2094. https://doi.org/10.1002/pen.11340

Dutch Filaments. (2016). PVA Filament. Retreived from http://www.dutchfilaments.com/pva-filament/

Gero, J. S. (2000). Research methods for design science research: computational and cognitive approaches. Unpublished manuscript, University of Sydney.

Gibson, I., Rosen, D., \& Stucker, B. (2015). Introduction and Basic Principles. In Additive Manufacturing Technologies (pp. 1-18). Springer New York. Retrieved from http://link.springer.com/chapter/10.1007/978-1-4939-2113-3_1

Gironi, F., \& Piemonte, V. (2011). Bioplastics and Petroleum-based Plastics: Strengths and Weaknesses. Energy Sources, Part A: Recovery, Utilization, and Environmental Effects, 33(21), 1949-1959. http://doi. org/10.1080/15567030903436830

Goff, M. L. (2009). Early Postmortem Changes and Stages of Decomposition. In J. Amendt, M. L. Goff, C. P. Campobasso, \& M. Grassberger (Eds.), Current Concepts in Forensic Entomology (pp. 1-24). Dordrecht: Springer Netherlands. https://doi.org/10.1007/978-1-4020-9684-6_1 
Granek, J. A., \& Magwene, P. M. (2010). Environmental and Genetic Determinants of Colony Morphology in Yeast. PLOS Genet, 6(1), e1000823. https://doi.org/10.1371/journal.pgen.1000823

Hanington, B., \& Martin, B. (2012). Universal methods of design: 100 ways to research complex problems, develop innovative ideas, and design effective solutions. Rockport Publishers.

Harmsen, P. F. H., Hackmann, M. M., \& Bos, H. L. (2014). Green building blocks for bio-based plastics. Biofuels, Bioproducts and Biorefining, 8(3), 306-324. https://doi.org/10.1002/bbb.1468

Haweel, C., \& Ammar, S. H. (2008). Preparation of polyvinyl alcohol from local raw material. Iraqi J. Chem. Petrol. Eng, 9, 1521.

Hosono, K., Kanazawa, A., Mori, H., \& Endo, T. (2007). Photodegradation of cellulose acetate film in the presence of benzophenone as a photosensitizer. Journal of Applied Polymer Science, 105(6), 3235-3239. https://doi.org/10.1002/ app.26386

Hottle, T. A., Bilec, M. M., \& Landis, A. E. (2013). Sustainability assessments of bio-based polymers. Polymer Degradation and Stability, 98(9), 1898-1907. http://doi.org/10.1016/j.polymdegradstab.2013.06.016

https://en.oxforddictionaries.com/definition/degradation

Inhabitate. (2015). Could bacteria-grown material be the future of building. Retrieved from http://inhabitat.com/could-bacteriagrown-materials-be-the-future-of-building/

Ishii, K., Eubanks, C., \& Marco, P. D., . (1994). Design for product retirement and material life-cycle. Material and design, 15(4), 225-223.

Karana, E., Hekkert, P., \& Kandachar, P. (2008). Material considerations in product design: A survey on crucial material aspects used by product designers. Materials \& Design, 29(6), 1081-1089. https://doi.org/10.1016/j.matdes.2007.06.002

Khoo, Z. X., Teoh, J. E. M., Liu, Y., Chua, C. K., Yang, S., An, J., ... Yeong, W. Y. (2015). 3D printing of smart materials: A review on recent progresses in 4D printing. Virtual and Physical Prototyping, 10(3), 103-122. https://doi.org/10.1080 /17452759.2015.1097054

Klarenbeek, E. (2013) Mycelium chair., retrieved from http://www.ericklarenbeek.com/

Kolybaba, M., Tabil, L. G., Panigrahi, S., Crerar, W. J., Powell, T., \& Wang, B. (2003, October). Biodegradable polymers: past, present, and future. In An ASAE Meeting Presentation.

Lam, C. X. F., Mo, X. M., Teoh, S. H., \& Hutmacher, D. W. (2002). Scaffold development using 3D printing with a starch-based polymer. Materials Science and Engineering: C, 20(1-2), 49-56. http://doi.org/10.1016/S0928-4931(02)00012-7

Lee, S. G., Lye, S. W., \& Khoo, M. K. (2001). A Multi-Objective Methodology for Evaluating Product End-of-Life Options and Disassembly. The International Journal of Advanced Manufacturing Technology, 18(2), 148-156. https://doi. org/10.1007/s001700170086

Leja, K., \& Lewandowicz, G. (2009, november ). Polymer biodegradation and biodegradable polymers-a review. Polish Journal of Environmental Studies, 19(2), 255-266

Mayer, J. M., \& Elion, G. R. (1994). U.S. Patent No. 5,288,318. Washington, DC: U.S. Patent and Trademark Office.

Medical dictionary, (2017). Death. Retrieved February 8. 2017, from http://medical-dictionary.thefreedictionary.com/death

Medical dictionary, (2017). Degradation. Retrieved February 8. 2017, from http://medical-dictionary.thefreedictionary.com/ degradation

MIT. (NA). Self-assembly laboratory. Retrieved from http://www.selfassemblylab.net/index.php

MOGAS-SOLDEVILA, L., Jorge, D. R., LIZARDO, D., KAYSER, M., PATRICK, W., SHARMA, S., ... \& OXMAN, N. (2015). DESIGNING THE OCEAN PAVILION: Biomaterial Templating of Structural, Manufacturing, and Environmental Performance. In Proceedings of the International Association for Shell and Spatial Structures (IASS) Symposium, Amsterdam.

Mohanty, A. K., Misra, M., \& Drzal, L. T. (2002). Sustainable Bio-Composites from Renewable Resources: Opportunities and Challenges in the Green Materials World. Journal of Polymers and the Environment, 10(1), 19-26. http://doi. org/10.1023/A:1021013921916

Motherboard. (2012). Phil Ross Grows Furniture with Mushroom. Retrieved from https://docs.google.com/document/d/1UbviR mKkXPVyGIImFLxyoXBJRFTcWzPOkG2oKz8A0vY/edit\#

Myers, W. (2012). Bio Design. New York: The Museum of Modern Art.

National geographic. (2014). Visualizing Waste: Klaus Pichler's Gorgeous, Rotting Food. Retrieved from http://proof. nationalgeographic.com/2014/07/16/visualizing-waste-klaus-pichlers-gorgeous-rotting-food/

Oxford Dictionary, (2017). Death. Retrieved Febuary 8, 2017, from https://en.oxforddictionaries.com/definition/death

Oxford Dictionary, (2017). Degradation. Retrieved Febuary 8, 2017, from

Pattinson, S. W., \& Hart, A. J. (2017). Additive Manufacturing of Cellulosic Materials with Robust Mechanics and Antimicrobial 
Functionality. Advanced Materials Technologies, n/a-n/a. https://doi.org/10.1002/admt.201600084

Pramauro, E., Bianco Prevot, A., Vincenti, M., \& Brizzolesi, G. (1997). Photocatalytic Degradation of Carbaryl in Aqueous Solutions Containing TiO2 Suspensions. Environmental Science \& Technology, 31(11), 3126-3131. https://doi.org/10.1021/ es970072z

Puls, J., Wilson, S. A., \& Hölter, D. (2011). Degradation of Cellulose Acetate-Based Materials: A Review. Journal of Polymers and the Environment, 19(1), 152-165. https://doi.org/10.1007/s10924-010-0258-0

Puls, J., Wilson, S. A., \& Hölter, D. (2011). Degradation of Cellulose Acetate-Based Materials: A Review. Journal of Polymers and the Environment, 19(1), 152-165. https://doi.org/10.1007/s10924-010-0258-0

Qiu, X. \& Hu, S. (2013). "Smart"materials based on cellulose: A review of the preparations, properties and application. Materials, 6, 738-781.

Quintana, R., Persenaire, O., Lemmouchi, Y., Sampson, J., Martin, S., Bonnaud, L., \& Dubois, P. (2013). Enhancement of cellulose acetate degradation under accelerated weathering by plasticization with eco-friendly plasticizers. Polymer degradation and stability, 98(9), 1556-1562.

Shah, A. A., Hasan, F., Hameed, A., \& Ahmed, S. (2008). Biological degradation of plastics: A comprehensive review. Biotechnology Advances, 26(3), 246-265. https://doi.org/10.1016/j.biotechadv.2007.12.005

Shimao. M (2001). Biodegradation of plastic. Curr Opinion Biotechnol, 12 (2001), pp. 242-247

Stepto, R. F. T. (2003, October). The processing of starch as a thermoplastic. In Macromolecular Symposia (Vol. 201, No. 1, pp. 203-212). WILEY $\square$ VCH Verlag.

sustainable management. (2016). Bio-based material. Retrieved from http://www.sustainabilitydictionary.com/bio-basedmaterial/

Tedeschi, A. (2014). ADD_Algorithms-Aided Design. Italy: Le Penseur. https://www.wired.com/2013/12/mushroom-chair/

Tharanathan, R. N. (2003). Biodegradable films and composite coatings: past, present and future. Trends in Food Science \& Technology, 14(3), 71-78. https://doi.org/10.1016/S0924-2244(02)00280-7

Thilmany, J. (2009). a new kind of design. Mechanical Engineering, 131(1), 36-40.

Tibbits, S. (2013, February). The emergence of "4D printing" [Video file]. Retrieved from https://www.ted.com/talks/skylar_ tibbits_the_emergence_of_4d_printing

Tomka, I. (1994, November 8). Thermoplastically processable starch and a method of making it. Retrieved from http://www. google.com/patents/US5362777

Travaglini.,S, Ross,. P., Dharan C.K.H., (2013). Mycology Matrix Composites. Proceedings of the American Society for Composites-Twenty-Eighth Technical Conference.

Wijk, A. \& Wijk I. (2015). 3D PRINTING WITH BIOMATERIALS TOWARDS A SUSTAINABLE AND CIRCULAR ECONOMY. DOI: 10.3233/978-1-61499-486-2-i

Woodbury, R. (2010) Elements of Parametric Design. Taylor and Francis.

Zeng, J., Liu, S., Cai, J., \& Zhang, L. (2010). TiO2 Immobilized in Cellulose Matrix for Photocatalytic Degradation of Phenol under Weak UV Light Irradiation. The Journal of Physical Chemistry C, 114(17), 7806-7811. https://doi.org/10.1021/jp1005617 


\section{Images List}

All unlisted Images belong to author

Image 1.1 (right)

Surrogate, 2005

silicone, fibreglass, leather,

plywood, human hair

$180 \times 306 \times 103 \mathrm{~cm}$ high

Courtesy of the artist, Tolarno and Roslyn Oxley9 Galleries

Image $1.2 \& 1.3$ (left)

The Alessi tea and coffee tower

Greg Lynn FORM, 2003

Photographed by Carlo Lavatori

Image 1.6 (Right) MushLume Trumpet Pendant ,

Danielle Trofe (2016)

Image 1.7 (Left) Water Reaction

Chao Chen (2005)

Image 1.8 (Right) MushLume Trumpet Pendant,

Danielle Trofe (2016)

Image 1.9 (Left) The Ephemeral Icon,

Maurizio Montalti (2010).

Image 1.10 \& 1.11 (Right) One Third. Klaus Pichler (2014).

Image 1.12 (right last) Mestic Manure-Derived Bioplastic.

Image 1.13 (Left) Mycelium Project.

Studio Eric Klarenbeek, Designers of the unusual (2013).

Image 1.14 (Right) Water-based digital fabrication platform. MOGAS-SOLDEVILA, et al. (2015).

Image 1.15 (Left) Xylinum Cones.

Jannis Huelsen, (2015). 